Aus dem Institut für Klinische Chemie

(ehemaliger Direktor: Prof. Dr. med. Dr. h.c. M. Oellerich)

im Zentrum Innere Medizin

der Medizinischen Fakultät der Universität Göttingen

\title{
Zirkulierende Nukleinsäuren im zellfreien Plasma von LTx-Patienten als Frühmarker einer Schädigung des Spenderorgans
}

\author{
INAUGURAL-DISSERTATION \\ zur Erlangung des Doktorgrades \\ für Zahnheilkunde \\ der Medizinischen Fakultät der \\ Georg-August-Universität zu Göttingen
}

vorgelegt von

Philipp Clemens Kanzow

aus Göttingen

Göttingen 2014 
Dekan:

I. Berichterstatter:

II. Berichterstatter:
Prof. Dr. rer. nat. H. K. Kroemer

Prof. Dr. med. Dr. h.c. M. Oellerich FACB, FFPath(RCPI), FRCPath

Prof. Dr. med. O. Kollmar

Tag der mündlichen Prüfung: 29. September 2014 


\section{Inhaltsverzeichnis}

1 Einleitung $\quad 1$

1.1 Organtransplantation und Steuerung der immunsuppressiven Therapie . . . . 1

1.2 Möglichkeiten und Grenzen der Medikamentenspiegelbestimmung von Im-

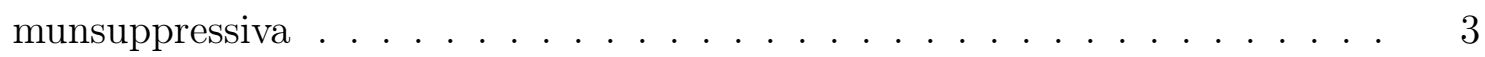

1.3 Wirkungsweise von Immunsuppressiva . . . . . . . . . . . . . . . . . 4

1.4 Notwendigkeit neuer Biomarker . . . . . . . . . . . . . . . . 6

1.5 Potentielle Biomarker für das Immunmonitoring . . . . . . . . . . . . . . . . 7

1.6 Potentielle Prädiktoren für Toleranz . . . . . . . . . . . . . . . . . . . 9

1.7 Potentielle Marker für eine Schädigung des Spenderorgans . . . . . . . . . . 13

1.7.1 Zellfreie Nukleinsäuren als potentieller Biomarker . . . . . . . . . 13

1.8 Personalisierte Immunsuppression mit neuen Biomarkern . . . . . . . . . . . 15

2 Fragestellung $\quad 16$

3 Patienten, Material und Methodik $\quad 17$

3.1 Patienten . . . . . . . . . . . . . . . . . . . . . . 17

3.1.1 Studiendesign . . . . . . . . . . . . . . . . . . 17

3.1.2 Ein- und Ausschlusskriterien . . . . . . . . . . . . . . . . . . 17

3.1.3 Therapie der transplantierten Patienten . . . . . . . . . . . . . 18

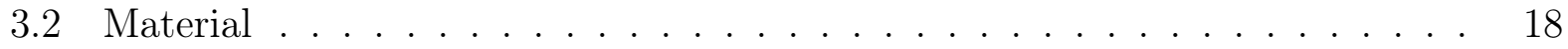

3.2.1 Vacutainer ${ }^{\circledR}$ für Blutabnahmen . . . . . . . . . . . . . . . . 18

3.2.2 Monovetten ${ }^{\circledR}$ für Blutabnahmen . . . . . . . . . . . . . . . . . 19

3.3 Methodik . . . . . . . . . . . . . . . . . . . . . . . . 19

3.3.1 Entnahme der Proben . . . . . . . . . . . . . . . . . . . 19

3.3.2 Bestimmung der zellfreien Nukleinsäuren . . . . . . . . . . . . 20

3.3.2.1 Auswahl der informativen Single-Nukleotid-Polymorphismen 20

3.3.2.2 Isolation der zellfreien DNA . . . . . . . . . . . . . . . 21 
3.3.2.3 Amplifikation der zellfreien DNA . . . . . . . . . . . . 22

3.3.2.4 Digital droplet PCR . . . . . . . . . . . . . . 23

3.3.2.5 Auswertung der digital droplet PCR . . . . . . . . . . 23

3.3.3 Referenzwerte für stabile Organfunktion . . . . . . . . . . . . . . 26

3.3.4 Bestimmung der Immunsuppressiva im Vollblut . . . . . . . . . . . 26

3.3.5 Bestimmung der Aspartat-Aminotransferase, $\gamma$-Glutamyl-Transferase und Bilirubin-Konzentration . . . . . . . . . . . . . . . 27

3.3 .6 Statistik . . . . . . . . . . . . . . . . . 29

4 Ergebnisse $\quad 30$

4.1 Demographische Daten . . . . . . . . . . . . . . . . . 30

4.2 Kinetik der zirkulierenden zellfreien Spender-DNA im Plasma . . . . . . . . 32

4.3 Reperfusions- und Ischämieschädigung der Spenderorgane . . . . . . . . . . . 35

4.4 Einfluss der Immunsuppression auf die Freisetzung der zirkulierenden zellfreien Spender-DNA . . . . . . . . . . . . . . . . . 37

4.5 Vorschläge für eine Reduzierung der Tacrolimus-Dosierungen auf Basis der zirkulierenden zellfreien Spender-DNA . . . . . . . . . . . . . . . . 41

4.6 Vergleich der zirkulierenden zellfreien Spender-DNA mit herkömmlichen Markern und Leberenzymen . . . . . . . . . . . . . . . . . . . . . . . 43

4.7 Vorstellung der Einzelverläufe . . . . . . . . . . . . . . . . . . . . . . . . 49

4.7.1 Verläufe ohne erkennbare Schädigung des Transplantates . . . . . . . 49

4.7.2 Patienten mit Cholestasen . . . . . . . . . . . . . . . 57

4.7.3 Patienten mit Transplantatabstoßungen . . . . . . . . . . . . . . 60

4.7.4 Patienten mit Infektionen . . . . . . . . . . . . . . . . 71

4.7.4.1 Patienten mit Hepatitis-C-Infektionen . . . . . . . . . . 77

4.7.5 Patienten mit Umstellung der Immunsuppression . . . . . . . . . . . 82

5 Diskussion $\quad 86$

5.1 Notwendigkeit für Biomarker . . . . . . . . . . . . . . . . . . . . . 86

5.2 Nutzen der zirkulierenden zellfreien Spender-DNA als potentieller Biomarker 87

5.3 Diagnostischer Aussagewert der zirkulierenden zellfreien Spender-DNA im Vergleich zu konventionellen Leberfunktionswerten . . . . . . . . . . . . . 88 
5.4 Diagnostische Aussagekraft der zirkulierenden zellfreien Spender-DNA bei den Verlaufsuntersuchungen . . . . . . . . . . . . . . . . . . . 89

5.5 Offene Fragen . . . . . . . . . . . . . . . . . . . . . . . . . . . . . 92

6 Zusammenfassung $\quad 96$

$\begin{array}{lll}7 & \text { Abkürzungsverzeichnis } & 98\end{array}$

8 Abbildungsverzeichnis $\quad 100$

9 Tabellenverzeichnis $\quad 105$

$\begin{array}{ll}10 \text { Literaturverzeichnis } & 106\end{array}$

11 Bildnachweise $\quad 123$

12 Anhang $\quad 125$

12.1 Studienaufklärung und Einwilligungserklärung . . . . . . . . . . . 126

12.2 Protokoll der Standard-Immunsuppression nach Lebertransplantation . . . . 132

12.3 Liste der bei der Bestimmung der zellfreien Spender-DNA betrachteten 41 Assays . . . . . . . . . . . . . . . . . . . . . 133 


\section{Einleitung}

\subsection{Organtransplantation und Steuerung der immunsuppressiven Therapie}

Die Transplantationschirurgie ist heute ein wichtiger Bereich der modernen Medizin. Organtransplantationen stellen oft den einzigen Ausweg bei einer Vielzahl von irreversibel lebensbedrohlichen Erkrankungen und angeborenen genetischen Defekten dar (Lauchart 1992).

In den Vereinigten Staaten von Amerika werden jährlich ca. 30.000 Organtransplantationen durchgeführt (siehe Tabelle 1.1). Die Zahl der Patienten auf der Warteliste ist mit 100.000 jedoch deutlich größer (Rollins 2012). Die entsprechenden Zahlen für Deutschland lauten für das Jahr 2012: 3.522 Transplantationen gegenüber 11.233 Patienten auf der Warteliste (Rahmel 2012). Dieses zahlenmäßige Missverhältnis dokumentiert den Mangel an transplantierbaren Organen.

\begin{tabular}{c|c|c|c|c|c} 
Niere & Leber & Herz & Lunge & Pankreas & Darm \\
\hline \hline 16.526 & 5.731 & 2.035 & 1.771 & 1.014 & 106
\end{tabular}

Tabelle 1.1: Transplantationszahlen im Jahr 2012 in den Vereinigten Staaten von Amerika aus dem SRTR (The Scientific Registry of Transplant Recipients) 2012 Annual Data Report (Matas et al. 2014; Kim et al. 2014; Colvin-Adams et al. 2014; Valapour et al. 2014; Israni et al. 2014; Smith et al. 2014)

Besonders problematisch gestaltet sich die Steuerung der immunsuppressiven Therapie im Anschluss an eine Transplantation, wodurch zum Teil nur unbefriedigende Langzeitergebnisse erreicht werden (Sagoo et al. 2010). Die Tabelle 1.2 zeigt, dass es innerhalb von 3 Jahren bei der Niere in 14 bis 16\%, bei der Leber in $22 \%$, beim Herzen in $45 \%$ und beim Pankreas in 50\% aller Fälle zu akuten Abstoßungsreaktionen der transplantierten Organe kommt (Rollins 2012). 


\begin{tabular}{c|c|c|c|c|c|c}
\multicolumn{2}{c|}{ Niere } & Leber & Herz & Lunge & Pankreas & Darm \\
\hline \hline $\begin{array}{c}16,6 \% \\
\text { postmortale } \\
\text { Spenden }\end{array}$ & $14,2 \%$ & $21,9 \%$ & $45,3 \%$ & $49,8 \%$ & $27,2 \%$ & $53,5 \%$ \\
Lebendspenden & & & & &
\end{tabular}

Tabelle 1.2: Häufigkeit des Auftretens akuter Abstoßungsreaktionen in den ersten 3 Jahren nach Transplantation (Rollins 2012)

Die Medikation bewegt sich dabei stets zwischen einer Unter-Immunsuppression auf der einen und einer Über-Immunsuppression auf der anderen Seite. Folgen einer unzureichenden Suppression des Immunsystems sind Abstoßungen des Transplantates mit daraus resultierender - zum Teil irreversibler - Organschädigung und -dysfunktion. Bei einer Überdosierung kommt es hingegen vermehrt zu begleitenden Infektionen, Nierenschädigungen, HerzKreislauf-Erkrankungen und einer Erhöhung des Risikos von Tumorerkrankungen (Wieland et al. 2010). Viele Immunsuppressiva verfügen zudem auch über neurologische und gastrointestinale Nebenwirkungen (Piedras et al. 2013). Die Notwendigkeit zur Suche nach einer verbesserten Therapiesteuerung ergibt sich aus der Tatsache, dass es beispielsweise bei postmortalen Spenden in mehr als 50\% der Nierentransplantationen zu einem Transplantatverlust innerhalb der ersten 10 Jahre kommt (Schröppel und Heeger 2010). Erschwert wird die optimale Dosierung der Medikamente durch die Variabilität der Halbwertszeiten der meisten Immunsuppressiva: Tacrolimus (FK 506) $34 \pm 5$ Stunden, Everolimus $28 \pm 8$ Stunden (Kovarik et al. 2010; van Damme-Lombaerts et al. 2002). Interaktionen mit anderen Medikamenten und intra- sowie interindividuell unterschiedliche Verstoffwechselung kommen hinzu (Staatz und Tett 2004; American Society of Nephrology 2005; Piedras et al. 2013). Daraus folgt, dass dieselben Medikamente bei verschiedenen Patienten trotz gleicher Dosierung unterschiedlich starke Wirkungen haben und es keine definierte Dosis gibt, die bei allen Patienten anwendbar ist.

Es ist daher das Ziel, eine für den Patienten individuell angepasste, personalisierte immunsuppressive Therapie zu erreichen. Auf diesem Gebiet werden aktuell zahlreiche Anstrengungen unternommen. Diese umfassen sowohl die Entwicklung neuer Medikamente als auch die Suche und Evaluierung neuer Biomarker. Die Bestrebungen, neue Biomarker in der Transplantationsmedizin zu finden, ergeben sich aus der Tatsache, dass es mit herkömmlichen Methoden nicht möglich ist, Abstoßungen und Organschädigungen rechtzeitig und zuverlässig zu erkennen (Henley et al. 1992; Rodríguez-Perálvarez et al. 2012). Außerdem 
fehlen prädiktive Marker, die vor oder nach Transplantation das Abstoßungsrisiko beurteilen lassen können.

\subsection{Möglichkeiten und Grenzen der Medikamentenspiegelbestimmung von Immunsuppressiva}

Bei den gebräuchlichsten Immunsuppressiva, wie z. B. den Calcineurin-Inhibitoren (CNIs) Tacrolimus und Cyclosporin A (CsA) sowie dem mTOR-(mammalian Target of Rapamycin)Inhibitor Everolimus, hat sich die Medikamentenspiegelbestimmung (TDM, engl. Therapeutic Drug Monitoring) im klinischen Alltag durchgesetzt (siehe Tabelle 1.3). Hierbei werden die Konzentrationen der Medikamente im Vollblut bestimmt. Dadurch lässt sich zwar vielfach eine Überdosierung mit toxischen Nebenwirkungen verhindern, eine sichere Aussage über die Wirksamkeit ist aber nicht möglich. Grundlage des TDM ist die Annahme, dass die Blutspiegel des Wirkstoffes den therapeutischen Effekt besser widerspiegeln als die eingenommene Menge des Medikamentes (Koch-Weser 1972). Dabei wird jedoch nicht berücksichtigt, dass die Immunzellen den eigentlichen Wirkungsort darstellen. Aus den Konzentrationen im Vollblut kann nur bedingt auf die intrazellulären Konzentrationen geschlossen werden (Lemaitre et al. 2013).

\begin{tabular}{c|c} 
Pharmakon & TDM \\
\hline \hline Tacrolimus (FK 506) & ja \\
\hline Sirolimus & ja \\
\hline Everolimus & ja \\
\hline Cyclosporin A (CsA) & ja \\
\hline Voclosporin (ISA247) & ja \\
\hline Mycophenolsäure (MPA) & $($ ja $)$ \\
\hline Anti-Human-T-Lymphozyten-Immunglobulin (ATG) & nein \\
\hline Basiliximab & nein \\
\hline Belatacept & nein
\end{tabular}

Tabelle 1.3: Anwendung der Medikamentenspiegelbestimmung (TDM, engl. Therapeutic Drug Monitoring) gängiger Immunsuppressiva (Klupp et al. 2002; Streit et al. 2002; Su et al. 2012; Ling et al. 2013) 
Die Entwicklung des TDM zeigt sich am Beispiel der Mycophenolsäure (MPA): Ursprünglich wurde MPA unter dem Handelsnamen CellCept ${ }^{\circledR}$ in Europa im Jahr 1996 ohne TDM zugelassen (Shaw et al. 1998; Land 2006), obwohl MPA eine pharmakokinetische Variabilität von $44 \%$ aufweist (van Hest et al. 2005). Daraus lässt sich bereits ableiten, dass nicht für alle Patienten eine identische Dosis sinnvoll ist. Studien zeigen hier, dass es einen direkten und positiven Zusammenhang zwischen der Vermeidbarkeit akuter Abstoßungsereignisse und der Anwendung des TDM gibt (Starling et al. 2004; Schiff et al. 2007; Lemaitre et al. 2013).

Auf der anderen Seite gibt es aber auch Studien, die keinen signifikanten Zusammenhang zwischen Organabstoßungen und den Talspiegeln des traditionellen TDM finden (Falck et al. 2008). Stattdessen werden hier direkt die intralymphozytären Konzentrationen von CsA als potentiellem Biomarker für Organabstoßungen diskutiert und als dem TDM überlegen dargestellt. Begründen lässt sich dies z. B. durch eine unterschiedlich starke Expression bzw. Aktivität des P-Glykoprotein 1 (Multidrug Resistance Protein 1, MDR1), eines ABCTransporters und Produktes des ABCB1-Gens (Soranzo et al. 2004). Dieses Glykoprotein fungiert in der Zelle als Efflux-Transporter. Es zeigt sich, dass die intralymphozytäre CsAKonzentration vom 3435 Genotyp abhängt. Diese ist bei den Genotypen CT und TT 1,7 Mal höher als bei Patienten mit Genotyp CC (Crettola et al. 2008). Diese Patienten haben eine geringe Aktivität des P-Glykoprotein 1 in ihren Lymphozyten, folglich eine geringere Ausscheidungsrate und somit höhere intrazelluläre Wirkstoffspiegel. Im Gegensatz dazu haben Träger des 1199A-Allels eine um das 1,8 fache erniedrigte intrazelluläre CsA-Konzentration. Diese Beobachtung stellt ein Beispiel für die interindividuell unterschiedliche Konzentration der Immunsuppressiva an ihrem Wirkort aufgrund genetischer Polymorphismen dar. Auch bei Everolimus wird nur eine schwache Korrelation zwischen den Konzentrationen in den Immunzellen und denen im Vollblut gefunden (Roullet-Renoleaua et al. 2012). Hier ist ebenfalls anzunehmen, dass die intrazellulären Konzentrationen besser mit den klinischen Beobachtungen korrelieren.

\subsection{Wirkungsweise von Immunsuppressiva}

Um die Wirkungsweise und Ansatzpunkte der verschiedenen Immunsuppressiva zu verstehen, ist es zunächst notwendig, die einzelnen Schritte der T-Zell-Aktivierung genauer zu betrachten. Dabei werden drei Signale voneinander unterschieden (Cooper und Wiseman 2010): Signal 1 ist die Präsentation eines Antigens am T-Zell-Rezeptor durch eine Antigen- 
präsentierende Zelle. Infolgedessen werden weitere Signaltransduktionswege aktiviert und schließlich über Transkriptionsfaktoren die Proteinbiosynthese positiv beeinflusst. Wichtiges Zwischenglied in dieser Kette ist Calcineurin. Signal 2 ist die Co-Stimulation durch CD80 und CD86 auf den Antigen-präsentierenden Zellen an den CD28-Rezeptoren der T-Zelle. Durch die Aktivierung der Proteinkinase C (PKC) wird Signal 1 verstärkt. Zell-Proliferation wird durch Signal 3, die Bindung von Interleukin-2 (IL-2) an T-Zell-Rezeptoren und den nachfolgenden JAK-(Januskinase)-STAT-(Signal Transducers and Activators of Transcription)-Signalweg sowie durch mTOR-Aktivität ausgelöst (siehe Abbildung 1.1).

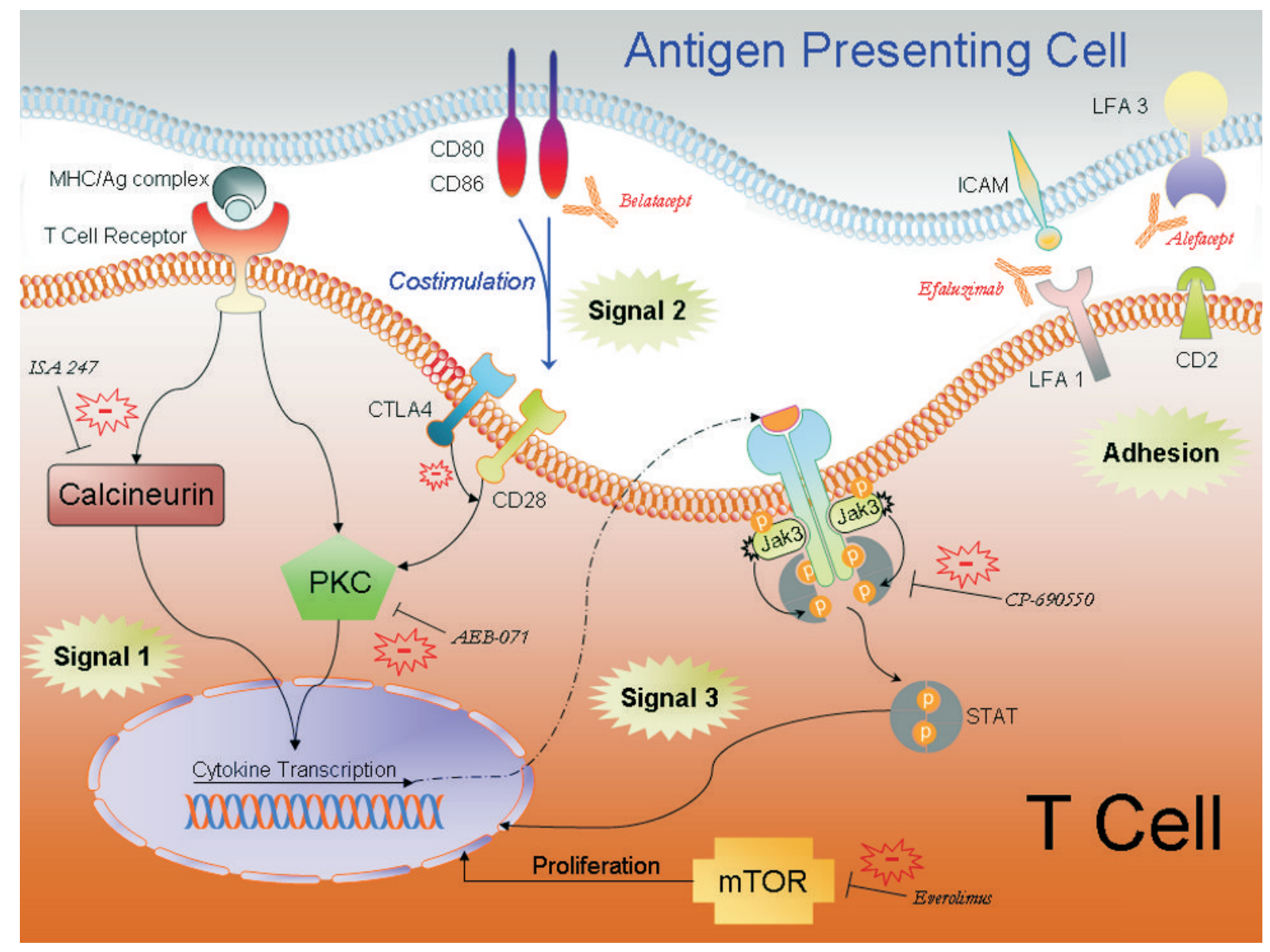

Abbildung 1.1: Modell der T-Zell-Aktivierung (Cooper und Wiseman 2010 - Abdruck mit Genehmigung, Bildnachweis auf Seite 123)

Genau an diesen Signalwegen greifen die immunsuppressiven Medikamente an. Folglich eignen sich die Zielenzyme wie Calcineurinphosphatase, Zytokine wie IL-2, der IL-2-Rezeptor CD28, STAT-Phosphorylierung und weitere Marker der T-Zell-Proliferation als potentielle Biomarker. Calcineurinphosphatase wird dabei durch CNIs wie CsA, Voclosporin (ISA247) sowie Tacrolimus gehemmt, PKC durch Sotrastaurin (AEB071) und Inosinmonophosphatase- 
dehydrogenase (IMPDH) durch MPA (Kovarik und Slade 2010). Die Expression der durch Nuclear factor of activated T-cell (N-FAT) regulierten Gene wie IL-2, Interferon- $\gamma$ (INF$\gamma)$ und Granulozyten-Kolonie stimulierender Faktor (G-CSF) ist ebenfalls ein spezifischer Marker für das Monitoring von CsA, Tacrolimus und Sotrastaurin. Patienten mit akuten Abstoßungen haben signifikant höhere Konzentrationen der durch N-FAT regulierten Gene (Sommerer et al. 2011). Der Anteil der IL-2-produzierenden CD8 ${ }^{+}$-T-Zellen ist bei Patienten mit Organabstoßungen deutlich höher als bei stabilen Patienten (Millán et al. 2010). In einer weiteren Studie wurde gezeigt, dass Patienten mit akuten Abstoßungen schon vor der Transplantation eine höhere Produktion von IL-2 durch die CD8 ${ }^{+}$-T-Zellen aufweisen (Boleslawski et al. 2004). IL-2 wirkt dabei über einen JAK/STAT-Signalweg in der Immunzelle. Genau hier greift Tofacitinib (CP-690550), ein neues Immunsuppressivum, durch Hemmung der JAK3 ein (Vafadari et al. 2012). Basiliximab führt ebenfalls zur kurzfristigen Hemmung durch Blockade des IL-2R $\alpha$-Rezeptors. Dadurch kommt es zur Inhibierung der IL-2-induzierten Aktivierung von STAT5. Folglich eignet sich der Phosphorylierungsgrad von STAT5 ebenfalls als Biomarker für diese neuen Immunsuppressiva. Phosphorylierung der P70S6-Kinase ist hingegen ein Marker für die Hemmung des mTOR-Signalweges und wird durch Sirolimus sowie Everolimus beeinflusst (Wieland et al. 2010; Hartmann 2012).

\subsection{Notwendigkeit neuer Biomarker}

Herkömmliche Biomarker und Leitenzyme haben nur eingeschränkten Nutzen bei der Steuerung der immunsuppressiven Therapie. So steigt z. B. nach Nierentransplantation (NTx) die Kreatinin-Konzentration im Plasma erst an, wenn bereits ein erheblicher Anteil der Niere zerstört ist (American Society of Nephrology 2005). Auch nach Lebertransplantationen haben Leberenzym- und Bilirubin-Konzentrationen alleine keinen diagnostischen Nutzen zum zuverlässigen und frühen Erkennen akuter Abstoßungen (Rodríguez-Perálvarez et al. 2013). Hieraus folgt, dass klinische Interventionen erst spät - oftmals zu spät - möglich sind. Wünschenswert wäre also schon die Diagnose subklinischer Abstoßungen, um bereits frühzeitig intervenieren zu können, da eine unbehandelte Schädigung des Transplantates zu einer chronischen Organdysfunktion führen kann (American Society of Nephrology 2005). Für den klinischen Einsatz müssen potentielle Biomarker vor allem von praktischem Nutzen sein: Ergebnisse sollten kurzfristig - möglichst noch am selben Tag - verfügbar und die Kosten hierfür möglichst niedrig sein. Außerdem sollten sie mit der Fläche unter der Konzentrations- 
Zeitkurve der Immunsuppressiva im Blut (AUC, engl. area under the curve) korrelieren, welche die Exposition reflektiert. Alle Anstrengungen auf diesem Gebiet dienen letztendlich dem Ziel, eine Verbesserung der Langzeitergebnisse nach Organtransplantationen zu erreichen und die immunsuppressive Therapie sicherer und zuverlässiger zu gestalten.

Viele neue Biomarker betrachten - im Gegensatz zum herkömmlichen TDM - nicht direkt die Konzentration der Immunsuppressiva, sondern vielmehr einzelne Faktoren innerhalb ihrer Wirkungskette. Durch die Kombination geeigneter Biomarker mit traditionellem TDM sollten sich dann die tatsächlichen pharmakodynamischen Effekte bei einem individuellen Patienten besser bestimmen lassen (Wieland et al. 2012). Grundsätzlich sind dabei drei Arten von Biomarkern zu unterscheiden: Erstens Biomarker für das Immunmonitoring, zweitens Prädiktoren für Toleranz und drittens Biomarker der Organschädigung.

\subsection{Potentielle Biomarker für das Immunmonitoring}

Diese Biomarker dienen dazu, den Status des Immunsystems im Transplantatempfänger zu beschreiben. Daraufhin kann die immunsuppressive Therapie angepasst werden, um den schmalen Grad zwischen Unter- und Über-Immunsuppression einzuhalten. Beispielsweise wird das Hilfsprotein Proliferating-Cell-Nuclear-Antigen (PCNA) der DNA-Polymerase, das an der DNA-Replikation beteiligt ist, als Marker der Lymphozytenproliferation genutzt (Shipkova und Wieland 2012). Durch die Bestimmung der Lymphozytenaktivierung mit Hilfe von Markern wie CD25 (IL-2-Rezeptor), CD71 (Transferrin-Rezeptor) und CD26 sowie des für die Co-Stimulation relevanten CD28-Rezeptors und aktivierungsassoziierter Zelloberflächenrezeptoren der TNF-TNF-(tumor necrosis factor-tumor necrosis factor receptor)Rezeptorfamilie wie z. B. CD134 lässt sich der gemeinsame Effekt von CNIs und mTORInhibitoren abschätzen (Shipkova und Wieland 2012). Der Vorteil dieser Biomarker liegt also darin, dass nicht die Wirkung eines einzelnen Immunsuppressivums, sondern vielmehr der Effekt der gesamten immunsuppressiven Therapie ermittelt wird, da sie die gemeinsamen Endprodukte der intrazellulären Signalkaskaden innerhalb der Lymphozyten darstellen. Diese sind das Ergebnis verschiedenster Medikamente, die jeweils unterschiedliche Zwischenschritte beeinflussen. Neuere Forschungen haben gezeigt, dass die Expression des Oberflächenrezeptors CD28 auch als Marker für das Risiko maligner Erkrankungen in Folge einer Über-Immunsuppression nutzbar ist, da ihr Anteil bei Tumorpatienten signifikant niedriger ist (Boleslawski et al. 2011). Auch ein kommerzieller T-Zell-Test zur Ermitt- 
lung der Phytohämagglutinin-(PHA)-stimulierten intrazellulären ATP-Produktion (iATPProduktion) der CD4-Zellen ist unter dem Namen ImmuKnow ${ }^{\circledR}$ von Cylex ${ }^{\top M}$ verfügbar und scheint die kumulierten Effekte unterschiedlicher Immunsuppressiva wiederzugeben (Gupta et al. 2008). Dabei ist die iATP-Konzentration ein Marker für den allgemeinen Status des Immunsystems und - im Gegensatz zu Biomarkern wie IMPDH oder Calcineurinphosphatase - unabhängig von kurzzeitiger Beeinflussung durch aktuelle Anpassungen der Medikation. Es zeigen sich keine Unterschiede zwischen den Messwerten vor und 2 Stunden nach der Gabe von Tacrolimus, MPA und Prednisolon (Akhlaghi und Gohh 2010). Folglich lässt sich keine Korrelation zwischen Tacrolimus bzw. CsA und den iATP-Konzentrationen finden (Schulz-Juergensen et al. 2012). Patienten mit Infektionen haben signifikant niedrigere und Patienten mit Abstoßungsreaktionen höhere iATP-Werte als stabile Patienten in einer Vergleichsgruppe (Israeli et al. 2010). Der Nutzen des Tests von Cylex ${ }^{\top M}$ liegt also darin, Überund Unter-Immunsuppressionen mit gravierenden Folgen wie Infektionen oder Abstoßungen zu vermeiden. Es werden dabei drei verschiedene Zustände der Immunantwort unterschieden: „,niedrig“, „mittel“ und „hoch“. Bei der Diagnostik akuter Abstoßungen wurde eine Korrelation mit den Ergebnissen konservativer Biopsien gezeigt (Hashimotoa et al. 2010). Fraglich bleibt jedoch, inwieweit dieselben Referenzwerte für die iATP-Konzentration auf alle Patienten gleichermaßen anwendbar sind. Das illustriert der publizierte Fall einer 55-jährigen Frau vier Jahre nach Herztransplantation: Hier ging schon ein Anstieg der iATP-Werte in den „mittleren“ Bereich mit einer Abstoßungsreaktion einher (Israeli et al. 2012). Anscheinend lag bereits bei mittelstarker Immunantwort eine individuelle Unter-Immunsuppression vor und niedrigere iATP-Werte waren für eine stabile Organfunktion nötig. Dies zeigt, dass isoliert betrachtete Messwerte der iATP-Konzentration nur bedingte Aussagekraft besitzen und bei jedem Patienten langfristige Verlaufsbeobachtungen nötig sind. In einer anderen Studie zeigte sich bei Patienten nach Absetzung der immunsuppressiven Therapie nur ein geringfügiger bzw. gar kein Anstieg der iATP-Werte (Millán et al. 2009). Die meisten Werte bewegten sich dabei in der mittleren Zone. Daraus folgt, dass die Definition von UnterImmunsuppression durch die Messung der iATP-Konzentration problematisch ist. Der Zusammenhang der iATP-Werte mit dem Auftreten akuter Abstoßungsreaktionen wird in der Literatur widersprüchlich beschrieben (Kowalskia et al. 2003; Kowalski et al. 2006; Gupta et al. 2008; Cabrera et al. 2009; Hashimotoa et al. 2010; Israeli et al. 2010; Huskey et al. 2011; Schulz-Juergensen et al. 2012). Auf der anderen Seite wird oft von einem signifikan- 
ten Zusammenhang mit dem Auftreten von Infektionen berichtet (Cadillo-Chávez et al. 2006; Kowalski et al. 2006; Lee et al. 2006; Bhorade et al. 2008; Gupta et al. 2008; Cabrera et al. 2009; Serban et al. 2009; Hashimotoa et al. 2010; Husain et al. 2009; Israeli et al. 2010; Kobashigawa et al. 2010; Xue et al. 2010; Huskey et al. 2011; Schulz-Juergensen et al. 2012). Der ImmuKnow ${ }^{\circledR}$-Test scheint also sehr hilfreich für die Diagnostik einer ÜberImmunsuppression zu sein. Ein Beispiel für den praktischen Nutzen des ImmuKnow ${ }^{\circledR}$-Test beschreibt der publizierte Fall eines 2-jährigen lebertransplantierten Patienten: Hier kam es aufgrund hoher Tacrolimus-Konzentrationen zur Entwicklung einer Epstein-Barr-Virus(EBV)-Infektion. Die ImmuKnow ${ }^{\circledR}$-Werte waren erwartungsgemäß niedrig und zeigten eine Über-Immunsuppression an. Infolge der Therapie mit Aciclovir und gleichzeitiger Absetzung von Tacrolimus erholte sich der Patient von der Infektion und die ImmuKnow ${ }^{\circledR}$-Werte erreichten die untere Grenze des mittleren Bereichs. Nach Wiederaufnahme der immunsuppressiven Therapie mit CsA fielen die ImmuKnow ${ }^{\circledR}$-Werte wieder in den niedrigen Bereich ab und es kam zur Reinfektion, obwohl die CsA-Spiegel im Rahmen des therapeutischen Bereiches lagen. Nach Anpassung der Dosierung und erneutem Einsatz von Aciclovir konnte die Infektion erfolgreich bekämpft werden (Schulz-Juergensen et al. 2012).

\subsection{Potentielle Prädiktoren für Toleranz}

Ziel des Einsatzes potentieller Prädiktoren für Toleranz ist die Ermittlung des individuellen immunologischen Risikos schon im Vorfeld der Transplantation als Ergänzung zum HLAAntikörper-Status. Durch die Definition von immunologischen Risikopatienten könnten so schon vor der Transplantation Patienten ermittelt werden, die eine niedrigere oder höhere Dosierung der immunsuppressiven Medikamente benötigen. Dabei ist die Definition spontaner operativer Toleranz vage: Sie ist definiert als stabile Organfunktion im Langzeitverlauf ohne klinisch signifikante Reaktion oder Immundefizit nach Absetzung der immunsuppressiven Therapie (Roussey-Kesler et al. 2006). Im Bereich der Nierentransplantation spricht man von Toleranz, wenn es innerhalb eines Jahres nicht zu einem Anstieg der Serum-Kreatininwerte über $10 \%$ gekommen ist (Sagoo et al. 2010). Derartige klinische Toleranz muss von der „Beinahe-Toleranz“, bei der für die stabile Organfunktion immer noch - wenn auch sehr niedrig dosiert - Immunsuppressiva notwendig sind, unterschieden werden (Roussey-Kesler et al. 2006). Die Häufigkeit der operativen Toleranz beträgt im Bereich der Lebertransplantation bis zu 20\%, bei der Nierentransplantation ist sie jedoch deutlich niedriger (Newell et al. 
2010). Genau bei dieser Patientengruppe kommt es auf eine perfekt angepasste immunsuppressive Therapie unter Nutzung neuer Biomarker an. Als Anzeichen für derartige Toleranz werden zur Zeit unter anderem die Messungen folgender Parameter untersucht: Anzahl der natürlichen regulatorischen T-Zellen (Tregs) $\left(\mathrm{CD} 4^{+} \mathrm{CD} 25^{++} \mathrm{CD} 127^{-} \mathrm{FOXP} 3^{+}\right)$(Litjens et al. 2012), B-Zell-Differenzierungsgene wie IGKV4-1, IGLLA, IGKV1D-13 (Newell et al. 2010) für NTx-Patienten und spezifische Gensets in natürlichen Killerzellen (NK-Zellen) wie ERBB2, SENP6 und FEM1C (Li et al. 2012) nach Lebertransplantation (LTx).

So wird beispielsweise beschrieben, dass man sich bei der Quantifizierung von natürlichen Tregs die FOXP3-Demethylierung zu Nutze machen kann (Baron et al. 2007). Im Gegensatz zu anderen Zellen weisen sie eine spezifische DNA-Demethylierung innerhalb des FOXP3Lokus auf. Andere Subtypen der Tregs wie die induzierten Tregs sind demgegenüber im Bereich der Treg-spezifischen Demethylierungsregion (TSDR) des FOXP3-Gens hochgradig methyliert (Shalev et al. 2012). Die oben beschriebenen B-Zell-Differenzierungsgene und die Gesamtzahl bzw. die Zahl an nativen B-Zellen erweisen sich nach NTx als diagnostisch relevant beim Erkennen toleranter Patienten (Newell et al. 2010). In der Lebertransplantation zeigen sich einige Genprodukte natürlicher Killerzellen als zuverlässige Marker für Toleranz (Li et al. 2012). Bezüglich der Wirkung einzelner Immunsuppressiva auf die Entwicklung der Tregs lässt sich sagen, dass CNIs (Tacrolimus, CsA) durch Hemmung der FOXP3Transkription sowie auch Basiliximab einen negativen Effekt haben. Belatacept weist neueren Untersuchungen zufolge ebenfalls einen hemmenden Effekt auf. MPA, ein humanisierter Antikörper, zeigt hingegen keinen Effekt (De Serres et al. 2009; Wojciechowski und Vincenti 2011; Levitsky et al. 2013). Folglich dürfte sich der exzessive Einsatz von CNIs negativ auf die Entwicklung von Toleranz auswirken. Genau diese Ergebnisse spiegeln sich auch in der Statistik der transplantierten Patienten aus den letzten Jahren wider: Während die immunsuppressive Therapie durch die Entdeckung der CNIs einen gewaltigen Aufschwung zu verzeichnen hatte und das Auftreten akuter Infektionen in der Frühphase nach Transplantationen zuverlässig verringert werden konnte, verbesserten sich die Langzeitergebnisse nicht (Meier-Kriesche et al. 2004). Tregs wurden auf ihre Eignung als Indikatoren für die Entwicklung von Toleranz untersucht. Die Ergebnisse sind hier allerdings widersprüchlich (Franzese et al. 2013): Die Gesamthäufigkeit der FOXP3 ${ }^{+}$-Tregs im peripheren Blut korreliert nicht zwingend mit Toleranz. Die antigenspezifischen Tregs können sich aber z. B. im transplantierten Organ konzentrieren und somit im Einzelfall nur schlecht mit der Häufigkeit der 
zirkulierenden Zellen korrelieren (Cobbold und Waldmann 2013). Erfolgversprechende Tests basieren auf der Betrachtung komplexer Genexpressionsmuster und zeigen Unterschiede zwischen nieren- und lebertransplantierten Patienten (Londoño et al. 2012). Ein derartiger Test zum Erkennen von Toleranz nach NTx beinhaltet die Betrachtung einer Kombination von 10 verschiedenen Genen, der Anzahl der peripheren B- und NK-Zellen, der Zahl der kürzlich aktivierten $\mathrm{CD}^{+}{ }^{+}$-T-Zellen, eine donorspezifisch abgeschwächte Antwort der CD4 ${ }^{+}$-T-Zellen sowie eine stark ausgeprägte FOXP3/ $\alpha$-1,2-mannosidase-Genexpression im peripheren Blut (Sagoo et al. 2010).

Besonders im Langzeitverlauf sind Prädiktoren für die Entwicklung einer Toleranz gegenüber dem transplantierten Organ von großem Interesse. Dies ist beispielsweise durch den Nachweis spenderspezifischer Antikörper (DSA, engl. donor-specific antibodies) möglich, die zu einer antikörpervermittelten Abstoßung des Organs führen. Studien haben hier gezeigt, dass die Organfunktion transplantierter Nieren bei DSA-positiven Patienten schlechter als bei DSA-negativen Patienten ist (Sagoo et al. 2010). Halloran et al. entwickelten ein Microarray für die Diagnose antikörpervermittelter Abstoßungen nach NTx (Halloran et al. 2013). Konventionelle diagnostische Kriterien fußen hier alleine auf der Beurteilung von Biopsien, die nach wie vor als Goldstandard für die Diagnose akuter Abstoßungen gelten (Chandraker und Strom 2013; Thiene et al. 2013; Verhelst et al. 2013). Allerdings treten derartige Abstoßungen oftmals erst viele Jahre nach Transplantation auf und führen durch eine Glomerulopathie zum späten Versagen des Transplantates (Sellarés et al. 2013). Der neuartige Microarray-basierte Test diagnostiziert antikörpervermittelte Abstoßungen anhand eines Scores, der verschiedene Transkriptionsprodukte, die überwiegend in Endotheloder NK-Zellen exprimiert und Interferon- $\gamma$-induziert sind, betrachtet. Dieser Score zeigt in ersten Untersuchungen bereits einen frühen Zusammenhang mit dem Auftreten von Abstoßungen (Halloran et al. 2013). Auch Moleküle wie lösliches CD30 (sCD30, engl. soluble CD30), ein T-Zell-Aktivierungsmarker, wurden auf ihre Eignung als Biomarker hin untersucht (Süsal und Opelz 2012): Die Fünf-Jahres-Überlebensrate nach NTx ist bei hohen Werten $(\geq 100 \mathrm{U} / \mathrm{ml})$ signifikant geringer als bei Patienten mit geringen sCD30-Konzentrationen $(<100 \mathrm{U} / \mathrm{ml})$ vor Transplantation (Süsal et al. 2002). Des Weiteren wird ein Zusammenhang der IMPDH-Aktivität vor Transplantation mit dem Auftreten akuter Abstoßungsreaktionen bei NTx-Patienten beschrieben (Glander et al. 2004). Bei Patienten mit hoher IMPDH-Aktivität vor Transplantation und einer späteren Dosisreduktion der MPA besteht 
ein deutlich höheres Risiko für das Auftreten akuter Abstoßungen als in anderen Patientengruppen. Auf der anderen Seite zeigt IMPDH aber auch einen Zusammenhang mit der Plasmakonzentration von MPA und eignet sich daher als pharmakodynamischer Biomarker nach Transplantationen (Fukuda et al. 2011). Die Auswirkungen der IMPDH-Hemmung auf die Ergebnisse von Nierentransplantationen wird in einer anderen Studie beschrieben (Raggi et al. 2010). Hier ist eine niedrige Hemmung mit signifikant häufiger auftretenden Abstoßungen assoziiert.

Weitere prädiktive Marker stellen verschiedene Genexpressionstests dar. Grundlage dieser Genexpressionstests ist die Annahme, dass es eine Prädisposition für das Auftreten akuter Abstoßungen gibt und diese Patienten über ein aggressiveres Immunsystem verfügen. Einer dieser Tests misst z. B. die Genexpression von 25 verschiedenen Genen (u. a. NRAS, PLA2G4A, EPS15L1, F2RL1, FBN1, ANXA4, EMP1, RAB38 und STK32C) in einer Biopsie des Spenderorgans vor Transplantation und von 18 Genen (u. a. BSG, CHMP 4B, HEBP1, TBL1XR1, WNK1, TMEM158, MMP25) in den Immunzellen des Blutes, die auf eine Hochregulation mehrerer bekannter immunologischer Reaktionswege hindeuten VEGF-(VascularEndothelial-Growth-Factor)-Signalweg, EGFR-(Epidermal-Growth-Factor-Receptor)-Signalweg, MAP-(mitogen-activated protein)-Kinase-Weg). Studien haben gezeigt, dass dieser Test eine Alternative zur Biopsie des Spenderorgans darstellt (Hollander et al. 2013). Zum jetzigen Zeitpunkt gibt es in der klinischen Routine noch keinen Biomarker, der das Risiko für akute zelluläre Abstoßungen zum Zeitpunkt der Transplantation vorhersagen kann. Einzig der AlloMap ${ }^{\circledR}$-Test erlaubt gegenwärtig eine Aussage über dieses Risiko. In der Herztransplantation ist AlloMap ${ }^{\circledR}$ (XDx Expression Diagnostics Inc.) als Genexpressionstest bei Patienten mit geringem Abstoßungsrisiko und mehr als 2 Monaten nach Transplantation zur Bestimmung der Wahrscheinlichkeit von Abstoßungsepisoden zugelassen. Dieser Test misst die Genexpression 20 verschiedener Gene in den Immunzellen des Blutes und ermittelt daraus einen Wert zwischen 0 und 40. Studien haben gezeigt, dass der Test bei dieser begrenzten Patientengruppe eine Alternative zu Biopsien darstellt (Starling et al. 2006; Pham et al. 2010). Nachteil ist jedoch, dass gerade in der Anfangszeit nach Herztransplantation (HTx) eine engmaschige Beobachtung notwendig ist und das Risiko einer akuten Abstoßung hier besonders hoch ist (Mehra und Parameshwar 2010). 


\subsection{Potentielle Marker für eine Schädigung des Spenderorgans}

Zu den potentiellen Markern einer Organschädigung zählt die Analyse des Profils der BotenRNA (mRNA, engl. messenger RNA), Expressionsmuster bestimmter microRNAs (miRNA), sowie zellfreie DNA (cfDNA, engl. cell-free DNA) - im Bereich der Transplantationsmedizin als cfDNA des Spenderorgans (GcfDNA, engl. graft-derived cell-free DNA) verwendet. In einer Studie zur Bestimmung des Transplantatschadens bei Nieren wurde ein nicht-invasiver Test auf Basis der mRNA im Urin entwickelt und bei 485 Empfängern ein Zusammenhang mit dem Auftreten von Abstoßungen nachgewiesen. Das kombinierte Expressionsmuster von 3 verschiedenen Genen (CD3ع mRNA, IP-10 mRNA und 18S rRNA (ribosomale RNA)) erwies sich hier als diagnostisch relevant für die Diagnose akuter zellulärer Abstoßungen (Suthanthiran et al. 2013). Auch miRNAs werden als potentielle Biomarker untersucht. Dies ist eine Gruppe von Posttranskriptionsregulatoren, die die mRNA beeinflussen. Sie werden im Rahmen der Zellerneuerung freigesetzt und lassen sich somit in zahlreichen Körperflüssigkeiten wie Speichel, Blut und Urin wiederfinden. Bestimmte Expressionsmuster sind mit dem Auftreten pathologischer Veränderungen assoziiert. Folglich ist durch ihre Bestimmung ein Rückschluss auf die Organfunktion denkbar (Mas et al. 2013). Eine weitere Methode beruhte auf der Bestimmung spenderspezifischer HLA-Allele bei Nieren- und Pankreastransplantierten Patienten (Gadi et al. 2006).

\subsubsection{Zellfreie Nukleinsäuren als potentieller Biomarker}

Zellfreie Nukleinsäuren aus dem Spenderorgan werden schon länger als potentieller Biomarker diskutiert. Erstmals beschrieben wurde cfDNA in menschlichem Plasma bereits 1948 (Mandel und Métais 1948). Im Zusammenhang mit pathologischen Veränderungen wurden sie erstmals in den 1960er-Jahren bei Patienten mit systemischem Lupus erythematodes (SLE) untersucht (Tan et al. 1966). Doch cfDNA bedarf keinerlei pathologischer Veränderungen und ist auch im Plasma von Gesunden zu finden (Kamm und Smith 1972; Beck et al. 2009). Die Hauptquelle stellen hier apoptotische Zellen dar (Suzuki et al. 2008; Jung et al. 2010). Im Falle von malignen Erkrankungen ist ihre Konzentration erhöht (Stroun et al. 1987). Bei virusassoziierten Tumorerkrankungen wie Nasopharynxkarzinomen (verursacht durch EBV) sowie Zervixkarzinomen (durch humane Papillomaviren (HPV) verursacht), ist freie Virus-DNA im Plasma nachweisbar (Lo et al. 1999a; Dong et al. 2002). Ein weiteres Anwendungsgebiet der cfDNA liegt in der Pränataldiagnostik: Über die im maternalen Blut 
vorhandene fetale DNA (Lo et al. 1997) lässt sich z. B. auf nichtinvasive Weise der fetale Rhesus-D-Status bestimmen (Zhong et al. 2000). Auch die Diagnostik genetischer Erkrankungen wie myotoner Dystrophie (Amicucci et al. 2000), Achondroplasie (Saito et al. 2000) oder Trisomie 21 (Fan et al. 2008) ist möglich. Bei Schwangerschafts-assoziierten Erkrankungen wie der Präeklampsie stellt cfDNA ein potentielles Nachweismittel zur Einschätzung von Risikopatientinnen dar (Lo et al. 1999b).

In der Transplantationsmedizin wurde GcfDNA erstmalig 1998 in Transplantatempfängern nachgewiesen und der potentielle Nutzen von cfDNA als Biomarker für die Organfunktion diskutiert (Lo et al. 1998; Lo 2011). Dabei wird angenommen, dass cfDNA im Falle von Abstoßungsreaktionen infolge von Apoptose und Nekrose aus dem Spenderorgan freigesetzt wird. Bereits 2003 wurde erstmals eine quantitative Bestimmung bei herz-, leber- und nierentransplantierten Patienten durchgeführt (Lui et al. 2003). Hier erfolgte die Messung durch Bestimmung der prozentualen Konzentration des Y-Chromosoms. Dies beschränkt die Anwendung auf weibliche Patienten, die Organe eines männlichen Spenders erhalten haben. In einer weiteren Studie wurde der Nutzen von GcfDNA zum Erkennen von Organabstoßungen speziell nach NTx untersucht. Dabei erfolgte die Bestimmung der Konzentration des Y-Chromosoms im Urin und erstmals mittels digitaler Polymerase-Kettenreaktion (PCR, engl. Polymerase Chain Reaction). Es wurde gezeigt, dass Patientinnen mit akuten Abstoßungen signifikant höhere Werte als Patientinnen mit stabiler Organfunktion oder chronischer Organschädigung haben (Sigdel et al. 2013). Auch bei Patienten speziell nach HTx wurde der Nutzen von GcfDNA untersucht (Snyder et al. 2011). Im Verlauf von Abstoßungsreaktionen steigen die gemessenen DNA-Werte des Spenderorgans von Grundwerten unter 1\% auf bis zu 5\% an. Die Untersuchung zeigt, dass die Werte der GcfDNA bereits drei Monate vor einer durch Biopsie gesicherten Abstoßung ansteigen. Hier erfolgten die Messungen zunächst ebenfalls über das Y-Chromosom. In einem zweiten Schritt wurde die Bestimmung der GcfDNA erstmals geschlechtsunabhängig durch Massive Parallel Sequencing der DNA von Spender und Empfänger durchgeführt.

Trotz aller Verbesserungen liegen die Hauptnachteile der bisher veröffentlichten Methoden in den vergleichsweise hohen Kosten, langen Analysezeiten, geschlechtsspezifischen Einschränkungen oder in der Notwendigkeit einer DNA-Probe auch des Spenders. Der Vorteil aller Verfahren auf Basis von cfDNA ist jedoch in der Tatsache zu sehen, dass Aussagen auf nichtinvasive, einfache und risikofreie Weise gemacht werden können. Aufwändige Verfahren 
wie Punktionen und Biopsien entfallen. Daher wird im Zusammenhang mit diesen Methoden auch der Begriff „flüssige Biopsie“ (Beck et al. 2013b) verwendet.

\subsection{Personalisierte Immunsuppression mit neuen Biomarkern}

Das Ziel einer modernen immunsuppressiven Therapie auf der Basis neuer Biomarker ist es also, den Fokus von der alleinigen Reaktion auf klinische Events (z. B. akute Abstoßungen) in den Bereich der Prävention zu verlagern. Zentraler Bestandteil ist dabei die Früherkennung von beginnenden Organschädigungen auf der einen Seite und möglicherweise immuntoleranten Patienten auf der anderen Seite. Invasive Verfahren wie Organbiopsien könnten dann auf ein Minimum reduziert werden. Dies ermöglicht jedem Patienten eine individualisierte Immunsuppressionstherapie auf der Basis der individuell optimalen Medikamentendosierungen. Auch immuntolerante Patienten könnten sich auf diese Art finden lassen. Nebenwirkungen aufgrund von Überdosierungen ließen sich vermeiden. Insgesamt würde sich die Medikation organtransplantierter Patienten also sicherer, berechenbarer, effektiver und kostengünstiger gestalten. 


\section{Fragestellung}

Mit dieser Arbeit sollte die klinische Evaluation eines neuen Biomarkers basierend auf der Bestimmung von GcfDNA im Plasma der Transplantatempfänger im Rahmen einer klinischprospektiven Studie erfolgen. Dabei wurde bei 22 Patienten postoperativ nach Lebertransplantation kontinuierlich der neue Biomarker bestimmt und die gewonnenen Werte im Verlauf dokumentiert und hinsichtlich ihrer Signifikanz für den klinischen Einsatz mit etablierten Markern verglichen.

Besonderer Schwerpunkt dieser Arbeit liegt auf der Frühphase nach Transplantation. Im Einzelnen sollten Antworten auf die folgenden Fragen gefunden werden:

1. Wie sieht die Kinetik und Halbwertszeit der GcfDNA im Empfängerorganismus aus?

2. Besteht ein Zusammenhang zwischen Reperfusions- und Ischämieschädigung der Spenderorgane und initialer GcfDNA-Freisetzung?

3. Korreliert die GcfDNA-Freisetzung mit der Tacrolimus-Dosierung und den Blutspiegeln? Kann im Umkehrschluss mit Hilfe der GcfDNA ein neuer Vorschlag für den Zielspiegel gemacht und eine minimal notwendige Konzentration definiert werden?

4. Wie verhält sich die GcfDNA-Konzentration im Vergleich zu den etablierten Leberfunktionstests wie der Aspartat-Aminotransferase-(AST)- und $\gamma$-Glutamyl-Transferase-(GGT)-Aktivität sowie Bilirubin-Konzentration im Plasma in der frühen Phase nach Transplantation, bei klinischen Events (wie z. B. Cholestasen und Abstoßungen) und entsprechenden Interventionen? 


\section{Patienten, Material und Methodik}

\subsection{Patienten}

\subsubsection{Studiendesign}

Die Daten dieser Arbeit sind Teil einer prospektiven nicht-interventionellen Beobachtungsstudie über zirkulierende zellfreie Nukleinsäuren in der Lebertransplantation. Eingeschlossen wurden ausschließlich volljährige Patienten und Patientinnen innerhalb der ersten 9 Monate nach Lebertransplantation, die ihr ausdrückliches schriftliches Einverständnis gegeben hatten. Die Studie wurde durch die Ethikkommission der Georg-August-Universität geprüft und genehmigt (Studienaufklärung siehe Anhang). Sie erfolgte in Anlehnung einer vonseiten des Bundesministeriums für Bildung und Forschung (BMBF) unter dem Förderkennzeichen 01ES1102 geförderter Studie mit dem Titel „Personalisierte Immunsuppression nach Organtransplantation: Eine Beobachtungsstudie zum Nutzen und zu therapeutischen Bereichen innovativer Biomarker". Sämtliche klinische Therapien blieben durch diese Studie unbeeinflusst. Blutuntersuchungen erfolgten nur zu den Zeitpunkten, an denen aus klinischem Kontext heraus ohnehin Visiten und Blutabnahmen durchgeführt wurden.

\subsubsection{Ein- und Ausschlusskriterien}

In meiner Arbeit habe ich den Schwerpunkt auf die postoperative Frühphase, die ersten 30 Tage nach Transplantation, gelegt und meine Untersuchungen auf die im Göttinger Transplantationszentrum lebertransplantierten Patienten sowie die GcfDNA als potentiellem neuen Biomarker einer Transplantatschädigung beschränkt. Eingeschlossen wurden de novolebertransplantierte, volljährige Patienten, deren schriftliches Einverständnis vorlag. Für den einzelnen Patienten betrug die Beobachtungsdauer im Rahmen des BMBF-Projekts maximal 1 Jahr. Mögliche Gründe für ein vorzeitiges Ausscheiden aus der Studie waren die Notwendigkeit einer Re-Transplantation, das Versterben des Patienten oder der Erhalt einer überdurchschnittlichen Menge an Blutprodukten, deren Einfluss auf die Bestimmung der GcfDNA bisher noch nicht geklärt ist. 


\subsubsection{Therapie der transplantierten Patienten}

Bei den lebertransplantierten Patienten erfolgte die Immunsuppression gemäß dem in Göttingen etablierten Schema für eine immunsuppressive Therapie (siehe Anhang). Bereits intraoperativ wurde die Induktionstherapie durch Gabe von Methylprednisolon (Urbason ${ }^{\circledR}$ ) und Basiliximab (Simulect ${ }^{\circledR}$ ), einem rekombinanten, murin-/human-chimären monoklonalen Antikörper, der gegen die IL-2-Rezeptor- $\alpha$-Kette (CD25-Antigen) gerichtet ist, begonnen. Die Gabe von Basiliximab erfolgte zu zwei Zeitpunkten: Einmal während der anhepatischen Phase und am 4. postoperativen Tag. Nach der Transplantation kam MycophenolatMofetil (MMF) (Cellcept $\left.{ }^{\circledR}\right)$, ein Ester der MPA, als weiteres Medikament hinzu. Die Dosierung des Methylprednisolons wurde langsam reduziert und das Medikament bei unproblematischem postoperativen Verlauf nach 13 Tagen schließlich ganz abgesetzt. Ergänzend erfolgte ab dem 2. postoperativen Tag die Gabe von Tacrolimus (Prograf $\left.{ }^{\circledR}\right)$. Gegebenenfalls wurde hier zu einem späteren Zeitpunkt eine Umstellung auf Advagraf ${ }^{\circledR}$, eine andere Formulierung von Tacrolimus, oder Everolimus (Certican ${ }^{\circledR}$ ) vorgenommen. Die Dosierung des Tacrolimus erfolgte auf Basis der im Vollblut bestimmten Talspiegel. In letzter Zeit wurde gezeigt, dass auch niedrigere Tacrolimus-Spiegel zu einer suffizienten Immunsuppression führen und ein Langzeitüberleben des Transplantates fördern (Wallemacq et al. 2009). Daher wurden hier 8 bis $12 \mu \mathrm{g} / \mathrm{l}$ während der ersten 6 Wochen, 4 bis $8 \mu \mathrm{g} / \mathrm{l}$ für die folgenden 6 Wochen nach Transplantation und im weiteren Verlauf etwa $4 \mathrm{\mu g} / \mathrm{l}$ angestrebt. Die Dosierung der MMF orientierte sich an den Zellzahlen der Leukozyten. Im Falle einer Leukopenie erfolgte eine Dosisreduktion (Halbierung bei einer Leukozytenzahl/ $\mathrm{\mu l}<3000$ ) oder ggf. Pausierung (Leukozytenzahl/ $\mathrm{ll}<1000)$. Von diesem Schema wurde nur in wenigen Ausnahmefällen (z. B. Entfallen der Induktionstherapie mit Basiliximab bei Re-Transplantationen oder verlängerter Gabe von Methylprednisolon) abgewichen. Die Langzeitimmunsuppression bestand dann aus einer Zweifachkombination von MMF und Tacrolimus bzw. Everolimus.

\subsection{Material}

\subsubsection{Vacutainer ${ }^{\circledR}$ für Blutabnahmen}

Die Blutabnahmen für die Bestimmung der GcfDNA erfolgten überwiegend in speziellen Vacutainern ${ }^{\circledR}$ (Cell-Free DNA ${ }^{\mathrm{TM}}$ BCT, Streck Inc.). Diese Röhrchen stabilisieren die weißen Blutkörperchen und verhindern somit eine Freisetzung der genomischen DNA (gDNA). Da- 
durch käme es sonst bei längerer Liegezeit zu einer Beeinflussung des prozentualen Anteils der GcfDNA.

\subsubsection{Monovetten ${ }^{\circledR}$ für Blutabnahmen}

Alternativ erfolgte die Bestimmung der GcfDNA aus Blutproben in S-Monovetten ${ }^{\circledR}$ (Sarstedt) mit Kalium-EDTA, wie sie routinemäßig in der Universitätsmedizin Göttingen verwendet werden. Da hierbei keine Stabilisierung der weißen Blutkörperchen erfolgt, ist die Aufbewahrungszeit vor Abtrennung des Plasmas begrenzt. Daher erfolgte die Abzentrifugation des Plasmas bei diesen Proben innerhalb von 5 Stunden nach Blutentnahme.

\subsection{Methodik}

\subsubsection{Entnahme der Proben}

Die Probenentnahmen orientierten sich an dem durch die Ethikkommission genehmigten Studienprotokoll. Die erste Blutabnahme erfolgte bei den transplantierten Patienten noch während der Operation, 15 Minuten nach Reperfusion der Leber. Die nächste Blutabnahme fand dann 6 Stunden nach Reperfusion auf der Intensivstation statt. Während der ersten 14 Tage nach LTx waren weitere tägliche Blutabnahmen auf den jeweiligen Stationen vorgesehen und anschließend - für den Rest des ersten Monats - in dreitägigem Intervall. Ein genaues Schema der durchgeführten Visiten ist in Abbildung 3.1 dargestellt. Die Abnahmen zu späteren Zeitpunkten erfolgten dann im Rahmen der BMBF-Studie (siehe Kapitel 3.1.1). Bei den Blutabnahmen wurden überwiegend spezielle Blutentnahmeröhrchen (Cell-Free DNA ${ }^{\mathrm{TM}}$ BCT, Streck Inc.) verwendet und dabei etwa 10ml Blut entnommen. Alternativ wurden etwa $2 \mathrm{ml}$ Blut aus den routinemäßig für das TDM eingelieferten Sarstedt-Monovetten ${ }^{\circledR}$ genutzt. Die Abnahmen zur Bestimmung der GcfDNA waren dabei nicht an bestimmte Zeitpunkte (z. B. Talspiegel der Immunsuppressiva) gekoppelt.

Zusätzlich erfolgte die Erfassung von klinischen Daten zu Abstoßungen (Biopsieergebnisse) sowie Infektionen und Routinelaboruntersuchungen (AST-Aktivität, GGT-Aktivität und Bilirubin-Konzentration im Plasma), die zwar im Rahmen dieser Arbeit ausgewertet, aber nicht studienbedingt durchgeführt wurden. 


\begin{tabular}{|c|c|c|c|c|c|c|c|c|c|c|c|c|c|c|c|c|c|c|c|c|c|}
\hline Visiten & $\begin{array}{l}15 \mathrm{~min} \text { nach } \\
\text { Reperfusion }\end{array}$ & $\begin{array}{c}\text { 6h nach } \\
\text { Reperfusion }\end{array}$ & $\begin{array}{c}\text { Tag } \\
1\end{array}$ & $\begin{array}{c}\text { Tag } \\
2\end{array}$ & $\begin{array}{c}\text { Tag } \\
3\end{array}$ & $\begin{array}{c}\text { Tag } \\
4\end{array}$ & $\begin{array}{c}\text { Tag } \\
5\end{array}$ & $\begin{array}{c}\text { Tag } \\
6\end{array}$ & $\begin{array}{c}\text { Tag } \\
7\end{array}$ & $\begin{array}{c}\text { Tag } \\
8\end{array}$ & $\begin{array}{c}\text { Tag } \\
9\end{array}$ & $\begin{array}{c}\mathrm{Tag} \\
10\end{array}$ & $\begin{array}{c}\text { Tag } \\
11\end{array}$ & $\begin{array}{c}\mathrm{Tag} \\
12\end{array}$ & $\begin{array}{c}\text { Tag } \\
13\end{array}$ & $\begin{array}{c}\mathrm{Tag} \\
14\end{array}$ & $\begin{array}{c}\text { Tag } \\
17\end{array}$ & $\begin{array}{c}\text { Tag } \\
20\end{array}$ & $\begin{array}{c}\text { Tag } \\
23\end{array}$ & $\begin{array}{c}\text { Tag } \\
26\end{array}$ & $\begin{array}{r}\text { Tag } \\
29\end{array}$ \\
\hline CNA & $x$ & $x$ & $x$ & $x$ & $x$ & $x$ & $x$ & $x$ & $x$ & $x$ & $x$ & $x$ & $x$ & $x$ & $x$ & $x$ & $x$ & $x$ & $x$ & $x$ & $x$ \\
\hline \multicolumn{22}{|c|}{$\begin{array}{l}\text { Blutentnahmen täglich über die ersten } 14 \text { Tage und im Anschluss bis zum Ende des ersten Monats in dreitägigem Intervall } \\
\text { (bzw. bis zur Entlassung, wenn Verweildauer <30 Tage). } \\
\text { Zusätzlich erfolgte die Erfassung von klinischen Daten und Routinelaboruntersuchungen (AST, GGT und Bilirubin), die zwar ausgewertet aber } \\
\text { nicht studienbedingt durchgeführt wurden. }\end{array}$} \\
\hline
\end{tabular}

Abbildung 3.1: Schema mit den Abnahmezeitpunkten für die im Rahmen dieser Arbeit durchgeführten Untersuchungen der GcfDNA

\subsubsection{Bestimmung der zellfreien Nukleinsäuren}

Die Messungen der GcfDNA erfolgten durch Chronix Biomedical, Göttingen, nach einem dort entwickelten Verfahren (Beck et al. 2013b). Aufgrund der Neuartigkeit der angewandten Methodik gebe ich im Folgenden einen kurzen Überblick.

\subsubsection{Auswahl der informativen Single-Nukleotid-Polymorphismen}

Ein Single-Nukleotid-Polymorphismus (SNP) ist definiert als Variation eines Abschnitts der DNA, bei der sich eine Nukleotidbase unterscheidet. Derartige SNPs stellen etwa 90\% der genetischen Variationen im menschlichen Genom dar (Montenarh und Löffler 2007). Für die Ermittlung der GcfDNA ist es zunächst einmal möglich, beliebige SNPs zu betrachten, bei denen Spender und Empfänger homozygot, aber unterschiedlich sind. Hierfür wäre allerdings DNA-Material des Spenders nötig. Im klinischen Alltag stellt dies eine erhebliche Einschränkung dar, insbesondere wenn die Transplantation schon lange zurückliegt. Zur Umgehung dieser Problematik wurden für die Analysen solche SNPs ausgewählt, die eine Minor Allelic Frequency (MAF) zwischen 0,4 und 0,5 aufweisen. Gemäß dem Hardy-Weinberg-Gesetz erscheinen diese SNPs mit einer Wahrscheinlichkeit von 23 bis 25\% homozygot in Spender und Empfänger. Die Wahrscheinlichkeit, dass diese unterschiedlich in Spender und Empfänger sind, beträgt dann 11,5 bis 12,5\% (Jamieson und Taylor 1997). Um mindestens drei derartige SNPs zu finden, müssen folglich 30 bis 35 unterschiedliche SNPs mit entsprechender MAF analysiert werden. Bei der Betrachtung unselektierter SNPs wären über 3000 Assays für ein vergleichbares Ergebnis notwendig. Die besten Ergebnisse liefern dabei SNPs, die jeweils homozygot, aber in Spender und Empfänger unterschiedlich sind. Limitierender Faktor bei den genetischen Analysen ist die Menge an DNA bzw. das Volumen der eingesetzten Blutprobe: Wenn man davon ausgeht, dass in einem Milliliter Blut ca. 1000 DNA-Moleküle vorhanden sind und die Konzentration der GcfDNA $5 \%$ beträgt, wären darin nur etwa 50 Moleküle der Spender-DNA vorhanden (Chiu et al. 2001; Jung et al. 2003). 
Die Bestimmung informativer SNPs erfolgte durch einen Lauf im LightCycler ${ }^{\circledR} 480$ (Roche Applied Sciences) mit gDNA aus dem Buffy-Coat. Hierdurch konnten die im Empfänger heterozygoten SNPs von den weiteren Analysen ausgeschlossen werden. Die eigentlichen Messungen erfolgten im Anschluss durch digital droplet PCR (ddPCR) mit dem QX100 ${ }^{\top \mathrm{TM}}$ Droplet Digital ${ }^{\text {Th }}$ PCR System (Bio-Rad Laboratories Inc.). Der gesamte Prozess der GcfDNABestimmung ist in Abbildung 3.2 dargestellt.

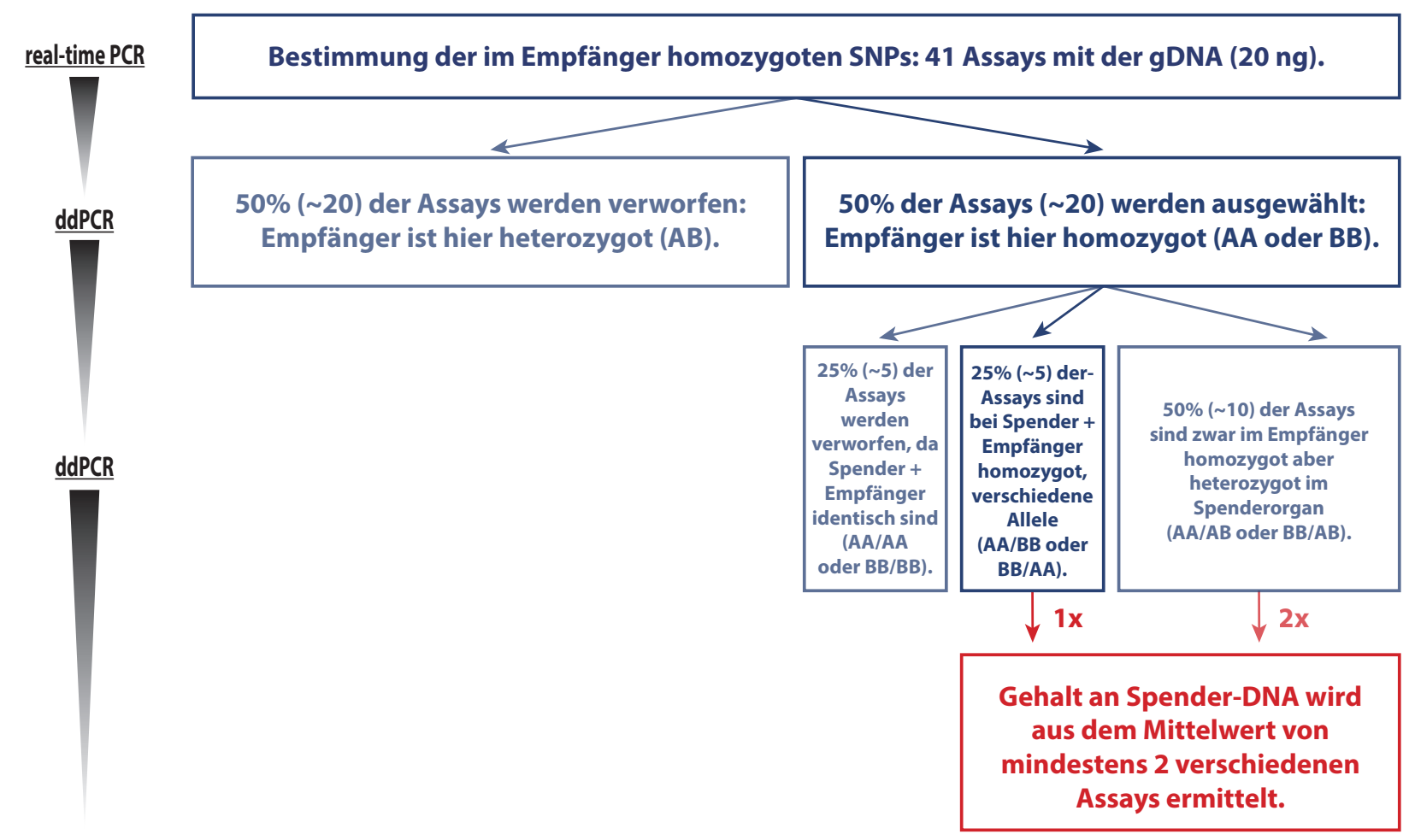

Abbildung 3.2: Prinzip der GcfDNA-Messungen (verändert nach Beck et al. 2013b - Abdruck mit Genehmigung, Bildnachweis auf Seite 123)

\subsubsection{Isolation der zellfreien DNA}

Die in speziellen Streck-Röhrchen (Cell-Free DNA ${ }^{T M}$ BCT, Streck Inc.) bzw. S-Monovetten ${ }^{\circledR}$ (Sarstedt) abgenommenen Blutproben wurden zunächst zentrifugiert (Relative Zentripetalbeschleunigung (RCF, engl. Relative Centrifugal Force): $1.200^{*} \mathrm{~g}$ für 10 Minuten bei $22^{\circ} \mathrm{C}$ ), um die Zellen vom Plasma zu separieren. Das Plasma und der Buffy-Coat wurde anschließend bis zur Weiterverarbeitung bei $-20^{\circ} \mathrm{C}$ eingefroren. Anschließend wurde nach erneuter Zentrifugation (RCF: 4000*g für 20 Minuten bei $4^{\circ} \mathrm{C}$ ) die cfDNA mit dem High Pure Viral Nucleic Acid Extraktionskit (Roche Applied Science) isoliert. Zum Teil wurden auch Blutproben aus den EDTA-antikoagulierten Sarstedt-Monovetten ${ }^{\circledR}$ für die Bestimmung der GcfDNA verwendet. Hierbei erfolgte die erste Zentrifugation (RCF: 2.500*g für 10 Minuten 
bei $4^{\circ} \mathrm{C}$ ) innerhalb von 5 Stunden nach Blutentnahme, um eine Lyse der Zellen und folglich eine Erhöhung der gDNA auszuschließen.

\subsubsection{Amplifikation der zellfreien DNA}

In einem ersten Schritt erfolgte zunächst die unselektierte Amplifikation der extrahierten cfDNA durch maximal 12 PCR-Zyklen bzw. bis zum Erreichen der Plateauphase mit dem NEBNext ${ }^{\circledR}$ Ultra $^{\text {TM }}$ DNA Library Prep Kit (New England Biolabs Inc.) in einem LightCycler ${ }^{\circledR}$ 480 (Roche Applied Sciences). Hierdurch wurden die eingesetzten Mengen der cfDNA, die zum Teil nur 5ng betrugen, auf durchschnittlich etwa 1100ng erhöht.

Um zu kontrollieren, ob dieser Präamplifikationsschritt die Messungen der cfDNA beeinflusst, wurde zu Vergleichszwecken von Beck et al. für die gDNA des Empfängers und der cfDNA das Verhältnis zwischen präamplifizierten und direkt gemessenen Proben (ohne vorhergehende Präamplifikation) ermittelt.

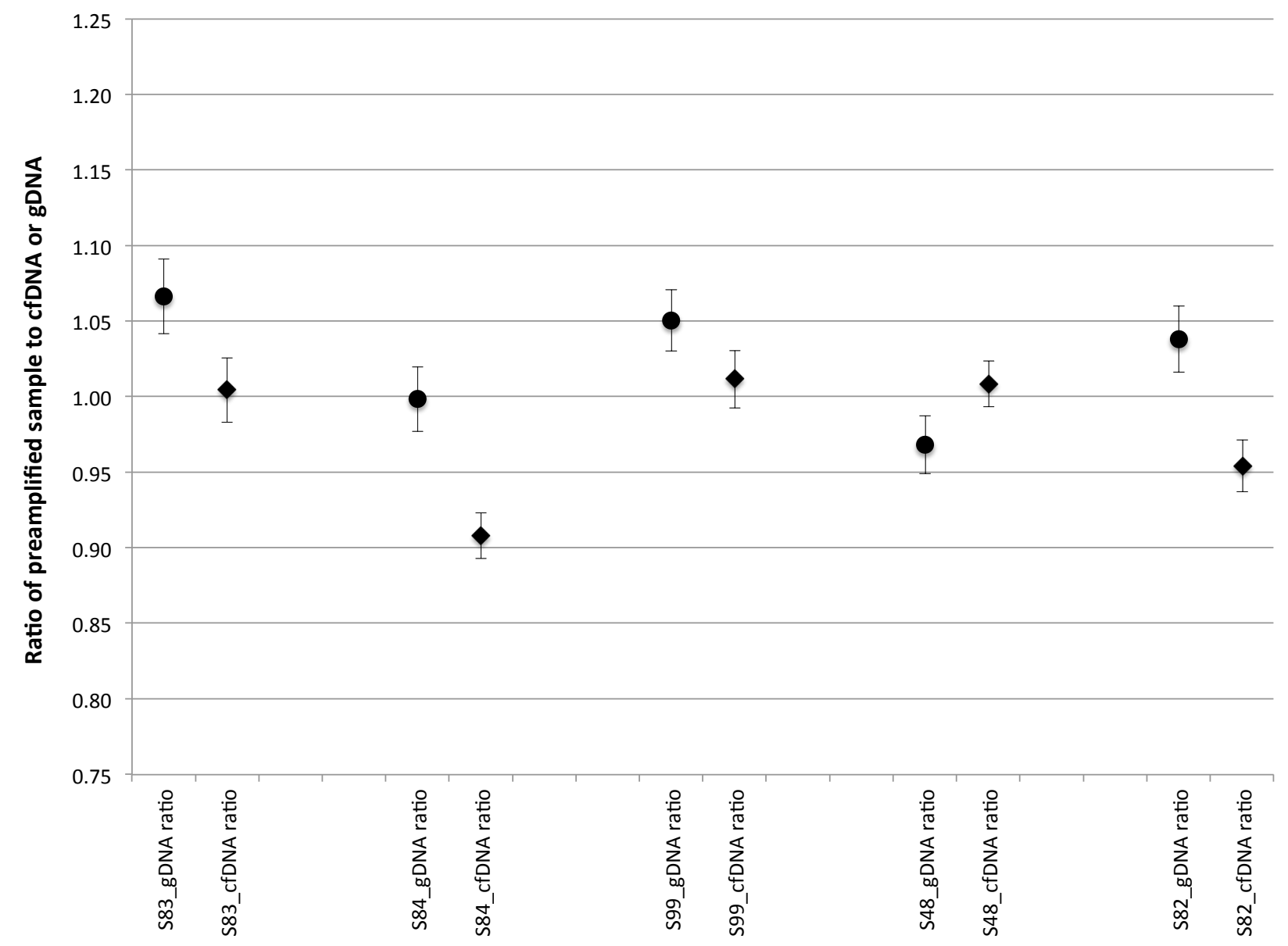

Abbildung 3.3: Verhältnisse der Kopienanzahl ohne und mit vorhergehender Präamplifikation mit Standardabweichungen (Beck et al. 2013b - Abdruck mit Genehmigung, Bildnachweis auf Seite 123) 
Abbildung 3.3 zeigt, dass durch die Präamplifikation keine Beeinflussung der prozentualen Häufigkeit der beiden untersuchten Allele entsteht (gDNA: $102 \pm 4 \%$, cfDNA: $98 \pm 5 \%$ ) und die Verhältnisse der beiden Methoden daher um 1 liegen. Dies ist auf den geringfügigen Unterschied von nur einem Nukleotid zwischen den beiden Amplikons pro Assay zurückzuführen.

\subsubsection{Digital droplet PCR}

Bei der ddPCR wird die Probe auf etwa 20.000 Öltröpfchen (droplets) verteilt, die jeweils als eigenständige Einzelansätze dienen (Hindson et al. 2011; Pinheiro et al. 2012). Die Detektion erfolgte über TaqMan ${ }^{T M}$-Sonden mit den Fluoreszenzfarbstoffen FAM und HEX sowie BHQ1 (MWG-Biotech) als Quencher. Nach erfolgter Reaktion sendet jedes Tröpfchen ein positives oder negatives Fluoreszenz-Signal aus. Durch Auszählung der Farbsignale lässt sich der Anteil der Spender-DNA an den gesamten zirkulierenden Nukleinsäuren bestimmen.

\subsubsection{Auswertung der digital droplet PCR}

Im Folgenden ist beispielhaft die Berechnung der GcfDNA-Konzentration für LTx4 am Tag 99 nach Transplantation gezeigt: Die Voranalysen haben gezeigt, dass die Organempfängerin für die Assays S38, S48, S50, S70, S77 und S82 (PCR bei $61^{\circ}$ C) sowie S57, S78, S86 und S97 (PCR bei 59 ${ }^{\circ} \mathrm{C}$ ) homozygot ist. Die Auswertung der ddPCR erfolgte mit der Software QuantaSoft $^{\text {TM }}$ (Version 1.3.2.0, Bio-Rad Laboratories Inc.). Für die Quantifizierung der GcfDNA wurde die in der Software integrierte „Rare Event Detection“ auf Basis der PoissonVerteilung (Gesetz der kleinen Zahlen) verwendet. Die Software liefert dabei zunächst, wie in Abbildung 3.4 gezeigt, ein Streudiagramm (2D-Plot) mit den Signalen der empfängerspezifischen SNPs (Allel A, Ch1+Ch2-, blau dargestellt) und der spenderspezifischen SNPs (Allel B, Ch1-Ch2+, grün dargestellt). Die braunen Punkte repräsentieren Droplets mit beiden Allelen $(\mathrm{Ch} 1+\mathrm{Ch} 2+)$ und die grauen Punkte unten links Droplets ohne Fluoreszenzsignal (Ch1-Ch2-). 


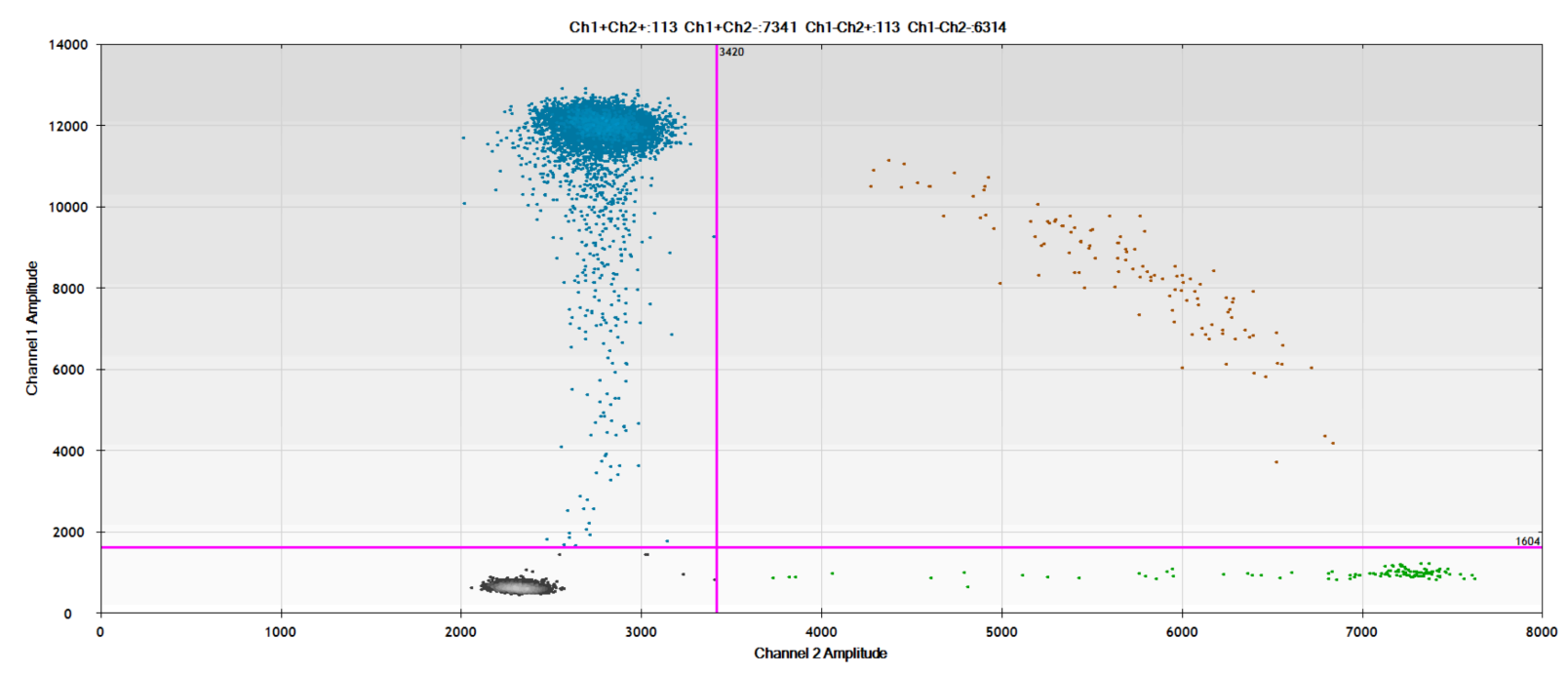

Abbildung 3.4: Streudiagramm mit Signalen der einzelnen Droplets (Beck et al. 2013b Abdruck mit Genehmigung, Bildnachweis auf Seite 123)

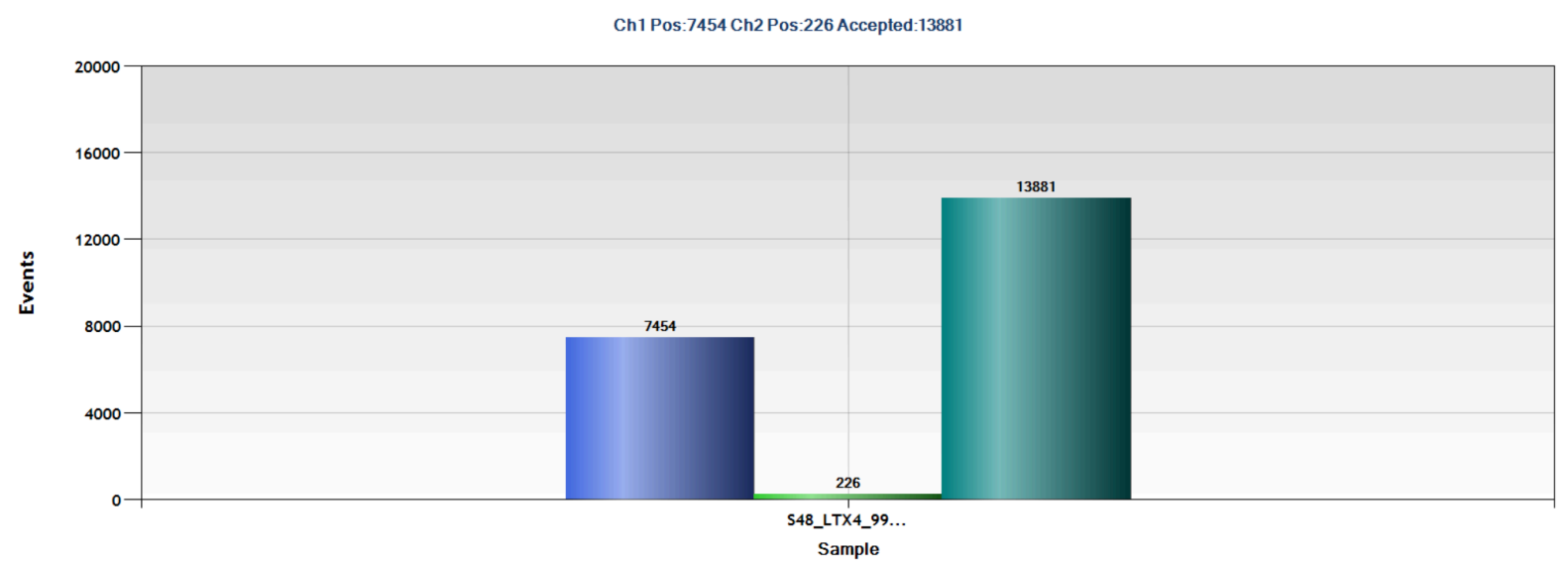

Abbildung 3.5: Anzahl der Droplets für beide Kanäle und Gesamtzahl aller gemessenen Droplets (Beck et al. 2013b - Abdruck mit Genehmigung, Bildnachweis auf Seite 123)

Die Anzahl der Droplets wird für beide Farbkanäle (Ch1 und Ch2) jeweils getrennt addiert (siehe Abbildung 3.5). Die Gesamtzahl aller gemessenen Droplets, also inklusive der negativen und doppelt positiven (Allel A und B), wird ebenfalls angegeben. Der prozentuale Anteil der GcfDNA lässt sich über die Poisson-Verteilung wie folgt berechnen:

Kopien der Spender-DNA je Droplet $=-\ln (1-p)$

Kopien der Empfänger-DNA je Droplet $=-\ln \left(1-p^{\prime}\right)$

Anteil der Spender-DNA [\%] $=\frac{-\ln (1-p)}{-\ln (1-p)-\ln \left(1-p^{\prime}\right)}$ 
Dabei entspricht $p$ dem Anteil der positiven Droplets mit Spender-DNA und $p^{\prime}$ dem Anteil der positiven Droplets mit Empfänger-DNA. Mit den Messwerten für Assay S48 ergibt sich aus der Formel 3.3 nun:

$$
\operatorname{GcfDNA}[\%]=\frac{-\ln \left(\frac{13881-226}{13881}\right)}{-\ln \left(\frac{13881-226}{13881}\right)-\ln \left(\frac{138811-7454}{13881}\right)}=0,020875=2,1 \%
$$

Der finale GcfDNA-Messwert stellt den Mittelwert der einzelnen Assays dar, wobei Ausreißer verworfen werden und die Ergebnisse von im Spender heterozygoten SNPs (AA/AB oder $\mathrm{BB} / \mathrm{AB}$ ) verdoppelt werden. In diesem Beispiel betrifft das die Assays S38, S50, S82 und S97. Assays, die bei Spender und Empfänger homozygot gleich sind (AA/AA oder BB/BB), werden verworfen (S70, S77 und S86). Die Ergebnisse der einzelnen Assays sind in der Tabelle 3.1 dargestellt.

\begin{tabular}{c|c|c|c|c} 
Assay & $\begin{array}{c}\text { Prozentualer } \\
\text { Anteil der } \\
\text { Spenderallele }\end{array}$ & $\begin{array}{c}\text { Prozentualer } \\
\text { Anteil der } \\
\text { GcfDNA }\end{array}$ & $\begin{array}{c}\text { Genotyp } \\
\text { Empfänger }\end{array}$ & $\begin{array}{c}\text { Genotyp } \\
\text { Spender }\end{array}$ \\
\hline \hline S38* & 0,2 & 0,4 & AA & AB \\
\hline S48 & 2,1 & 2,1 & AA & BB \\
\hline S50 & 1,7 & 3,4 & AA & AB \\
\hline S70 & - & - & AA & AA \\
\hline S77 & - & - & AA & AA \\
\hline S82* & 3,27 & 6,54 & BB & AB \\
\hline S57 & 3,33 & 3,33 & BB & AA \\
\hline S78 & 2,12 & 2,12 & BB & AA \\
\hline S86 & - & - & AA & AA \\
\hline S97 & 0,793 & 1,586 & BB & AB
\end{tabular}

Tabelle 3.1: Messwerte der einzelnen Assays für LTx4 am Tag 99 nach Transplantation $(*=$ Ausreißer $)$

Der prozentuale Anteil der GcfDNA an der gesamten cfDNA ergibt sich durch die folgende Rechnung (die Standardabweichung der verwendeten Assays beträgt 0,812\%):

$$
\operatorname{GcfDNA}[\%]=(2,1+1,7 * 2+3,33+2,12+0,793 * 2): 5=2,5 \%
$$




\subsubsection{Referenzwerte für stabile Organfunktion}

Bei der Ermittlung eines Referenzwertes dienten Beck et al. stabile Transplantatempfänger, d. h. klinisch unauffällige Patienten ohne Anzeichen einer Rejektion, als Anhaltspunkt. Insgesamt wurden bei diesen Referenzpatienten 16 verschiedene ddPCR SNP-Assays untersucht. Der prozentuale Anteil der GcfDNA lag bei stabilen LTx-Patienten $(\mathrm{n}=10)$, wie in Abbildung 3.6 gezeigt, unter 10\%. Die einzelnen Patienten schwankten zwischen 1\% und 8,5\%. Der Mittelwert betrug 3,5\%. Die Mittelwerte der NTx- (in Abbildung 3.6 abweichend als KTx-Patienten bezeichnet) und HTx-Patienten lagen mit 1,2\% bzw. 0,9\% deutlich niedriger.

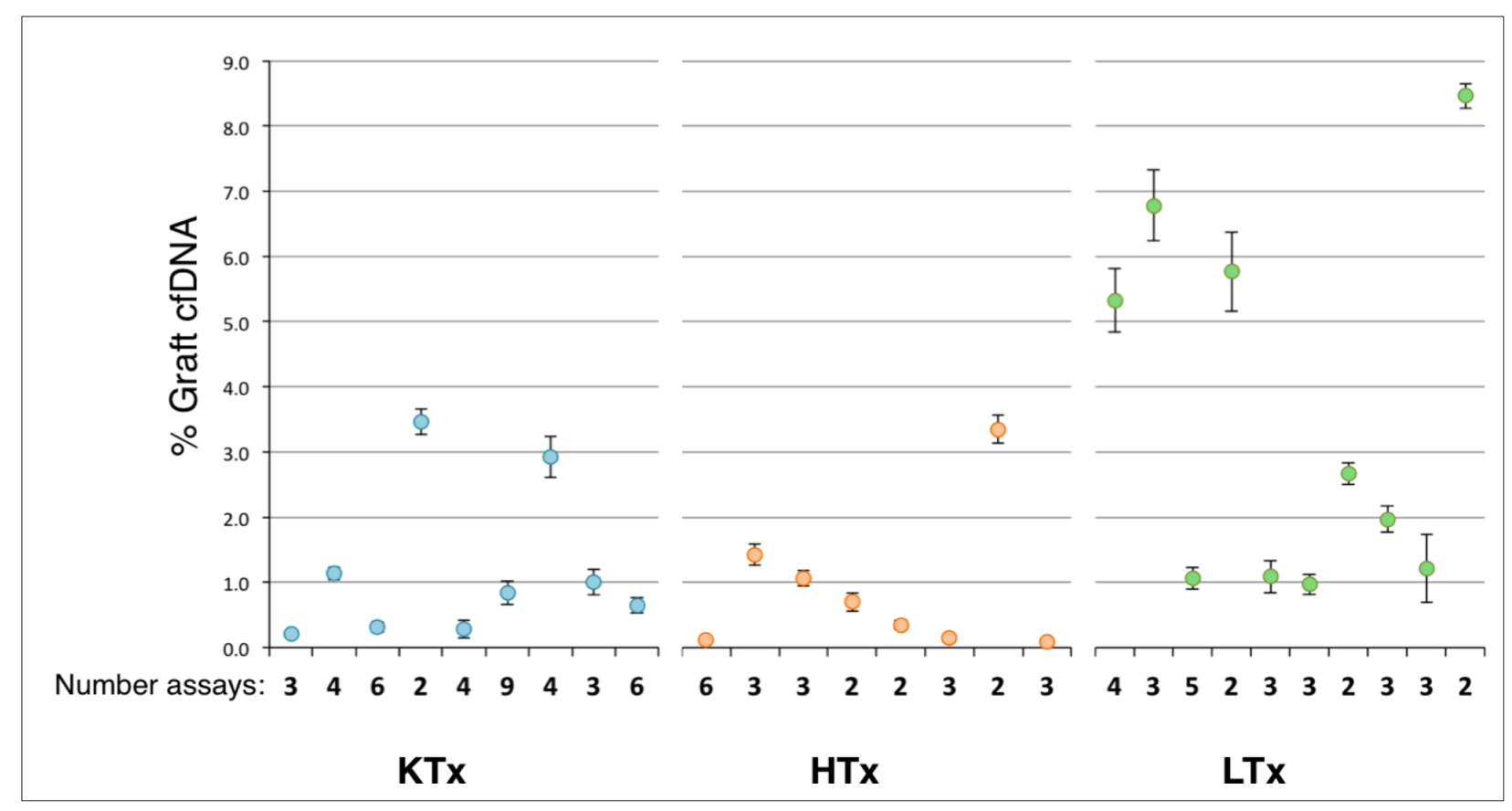

Abbildung 3.6: GcfDNA-Messwerte bei stabilen nieren-, herz- und lebertransplantierten Patienten. Angegeben sind jeweils Mittelwert, Standardabweichung und die Anzahl der verwendeten SNP-Assays (Beck et al. 2013b - Abdruck mit Genehmigung, Bildnachweis auf Seite 123)

\subsubsection{Bestimmung der Immunsuppressiva im Vollblut}

Die Bestimmung der Immunsuppressiva im Vollblut erfolgte im Rahmen der angeforderten Routine-Laboruntersuchungen aus EDTA-Vollblut (Tacrolimus, Everolimus) bzw. EDTAPlasma (MPA). Die Talspiegel wurden in den morgendlichen Blutabnahmen vor Einnahme der Medikamente gemessen. Die Analysen erfolgten durch das UMG-Labor der Universitätsmedizin Göttingen unter Verwendung der Flüssigchromatographie in Kombination mit 
zwei hintereinander geschalteten Massenspektrometer-Einheiten (Liquid-ChromatographieMassenspektrometrie/Massenspektrometrie, LC-MS/MS) mit einem Quattro Premier ${ }^{T M}$ XE Massenspektrometer der Firma Waters ${ }^{\circledR}$ nach publizierten Methoden (Streit et al. 2002, 2004; Brandhorst et al. 2006) und internen Arbeitsanweisungen (SOPs, engl. Standard Operating Procedures) des UMG-Labors. Dabei wurden die Patientenproben zunächst mit einem internen Standard versetzt (Ascomycin / FK520, deuteriertes Everolimus bzw. CarboxyButoxy-Ether-Mycophenolsäure / MPAC) und einer Proteinfällung durch Zinksulfatlösung $\left(\mathrm{ZnSO}_{4}\right)$ mit anschließender Zentrifugation (relative Zentripetalbeschleunigung, engl. Relative Centrifugal Force (RCF): 18.620*g für mindestens 5 Minuten) unterzogen. Die im Überstand enthaltenen Analyten wurden durch eine Oasis ${ }^{\circledR}$ HLB-(Hydrophilic Lipophilic Balance)-Kartusche durch Spül- und Elutionsschritte angereichert. Im Anschluss erfolgte die chromatographische Auftrennung auf einer MZ-Aqua-Perfect ${ }^{\text {TM }}$-Säule C18 (5um, 125*2,1mm bei Tacrolimus und Everolimus bzw. 5um, 150*4,4mm bei MPA). Die selektive Detektion der charakteristischen Fragmente erfolgte im Anschluss massenspektrometrisch nach Ionisierung durch eine Ionenquelle und Fragmentierung. Als Trennkriterium wurde die Retentionszeit sowie die charakteristischen MRM-(Multiple Reaction Monitoring)-Übergänge genutzt. Die Quantifizierung erfolgte über den Quotienten der Signalflächen der Analyten und der internen Standards.

\subsubsection{Bestimmung der Aspartat-Aminotransferase, $\boldsymbol{\gamma}$-Glutamyl-Transferase und Bilirubin-Konzentration}

Die Bestimmung der Leberenzyme AST und GGT sowie der Konzentration des Bilirubin erfolgte ebenfalls durch das UMG-Labor im Rahmen der Routine-Laboruntersuchungen mit dem ARCHITECT c16000 (Abbott Diagnostics), einem vollautomatischen Analysesystem zur Probenbearbeitung mit potentiometrischen und photometrischen Verfahren.

Der Nachweis der AST erfolgte auf Grundlage der NADH-Oxidation mit Pyridoxal-5'phosphat (Bergmeyer et al. 1986; Schumann et al. 2002). Die AST katalysiert in Anwesenheit von P-5'-P (Reagenz 1) die Übertragung der Aminogruppe von $L$-Aspartat auf 2-Oxoglutarat (Reagenz 2) unter Bildung von Oxalacetat und $L$-Glutamat. Oxalacetat wird in einem weiteren Schritt in Anwesenheit von NADH und Malatdehydrogenase (MDH) zu L-Malat reduziert. Durch die Oxidation von NADH zu NAD ${ }^{+}$wird eine Extinktionsabnahme bei 340nm 
verursacht (Abbott 2010a). Die genauen Bestandteile des Reagenzienkits sind in Tabelle 3.2 aufgeführt. Dabei laufen die folgenden Reaktionen ab:

$$
\begin{gathered}
L \text {-Aspartat }+2 \text {-Oxoglutarat } \stackrel{A S T, P-5^{\prime}-P}{\longrightarrow} \text { Oxalacetat }+ \text {-Glutamat } \\
\text { Oxalacetat }+\mathrm{NADH} \stackrel{M D H}{\longrightarrow} L \text {-Malat }+\mathrm{NAD}^{+}
\end{gathered}
$$

\begin{tabular}{c|c|c} 
Reagenz & Reaktive Bestandteile & Konzentration \\
\hline \hline $\mathbf{R 1}$ & $L$-Asparaginsäure & $278 \mathrm{mmol} / \mathrm{l}$ \\
\hline & $\beta$-NADH & $0,231 \mathrm{mmol} / \mathrm{l}$ \\
\hline & $\mathrm{LDH}$ & $770 \mathrm{U} / \mathrm{l}$ \\
\hline & $\mathrm{MDH}$ & $539 \mathrm{U} / \mathrm{l}$ \\
\hline \hline $\mathbf{R 2}$ & Pyridoxalphosphat-Monohydrat & $0,128 \mathrm{mmol} / \mathrm{l}$ \\
\hline & TRIS & $30 \mathrm{mmol} / \mathrm{l}$ \\
\hline & L-Asparaginsäure & $120 \mathrm{mmol} / \mathrm{l}$ \\
\hline & 2-Oxoglutarsäure & $61,6 \mathrm{mmol} / \mathrm{l}$ \\
\hline & TRIS & $291 \mathrm{mmol} / \mathrm{l}$
\end{tabular}

Tabelle 3.2: Reaktive Bestandteile des Reagenzienkits für die Bestimmung der AspartatAminotransferase-(AST)-Aktivität (Abbott 2010a)

Die Bestimmung der GGT erfolgte durch die Modifikation einer in der Literatur beschriebenen Methode (Theodorsen und Strømme 1976). Die GGT katalysiert während des Analyseverfahrens die Übertragung der Gammaglutamylgruppe von L-Gammaglutamyl-3-carboxy4-nitroanilid (Reagenz 2) auf Glyzylglyzin (Reagenz 1), wobei 3-Carboxy-4-nitroanilin entsteht. Die Extinktionszunahme wird dabei bei 416nm ermittelt und ist direkt proportional zur Aktivität der GGT in der Probe (Abbott 2012). Die genauen Bestandteile des Reagenzienkits sind in Tabelle 3.3 aufgeführt.

\begin{tabular}{c|c|c} 
Reagenz & Reaktive Bestandteile & Konzentration \\
\hline \hline R1 & Glyzylglyzin & $191 \mathrm{mmol} / \mathrm{l}$ \\
\hline \hline $\mathbf{R 2}$ & L-Gammaglutamyl-3-carboxy-4-nitroanilid & $30,6 \mathrm{mmol} / \mathrm{l}$
\end{tabular}

Tabelle 3.3: Reaktive Bestandteile des Reagenzienkits für die Bestimmung der $\gamma$-GlutamylTransferase-(GGT)-Aktivität (Abbott 2012) 
Auch die Bestimmung des Gesamtbilirubins (Summe aus konjugiertem und unkonjugiertem Bilirubin) erfolgte photometrisch (Malloy und Evelyn 1937; Winsten und Cehelyk 1969; Walters und Gerade 1970). Dabei wird das Bilirubin mit einem Diazo-Reagenz (2, 4-Dichloranilin, Reagenz 2) in Anwesenheit einer oberflächenaktiven Substanz (in Reagenz 1 und 2 enthalten) zu Azobilirubin gekoppelt. Dadurch kommt es bei 548nm zu einer Extinktionszunahme, die direkt proportional zur Gesamtbilirubin-Konzentration ist (Abbott 2010b). Die genauen Bestandteile des Reagenzienkits sind in Tabelle 3.4 aufgeführt.

\begin{tabular}{c|c|c} 
Reagenz & Reaktive Bestandteile & Konzentration \\
\hline \hline $\mathbf{R} 1$ & oberflächenaktive Substanz & $4,51 \%$ \\
\hline \hline $\mathbf{R 2}$ & $\mathrm{HCl}$ & $8,204 \mathrm{~g} / 1$ \\
\hline & $2,4-D i c h l o r a n i l i n$ & $0,81 \mathrm{~g} / 1$ \\
\hline & $\mathrm{HCl}$ & $5,563 \mathrm{~g} / 1$ \\
\hline & Natriumnitrit & $0,345 \mathrm{~g} / 1$ \\
\hline & oberflächenaktive Substanz & $1,96 \%$
\end{tabular}

Tabelle 3.4: Reaktive Bestandteile des Reagenzienkits für die Bestimmung der BilirubinKonzentration (Abbott 2010b)

\subsubsection{Statistik}

Die statistische Auswertung erfolgte mit Microsoft ${ }^{\circledR}$ Excel ${ }^{\circledR}$ für Mac 2011 (Version 14.3.9). Kalkulationen des Student's t-Tests, des Youden-Index und lineare sowie exponentielle Regressionen wurden mit den eingebauten Funktionen durchgeführt. Der Wilcoxon-VorzeichenRang-Test (Wilcoxon 1945) und eine Parzen-Rosenblatt-Glättung (Parzen 1962; Rosenblatt 1956) wurden mit individuellen Makros realisiert. Die Berechnungen des linksseitigen p-Wertes für den Exakten Test nach Fisher (Fisher's p) wurde mit dem im Internet frei verfügbaren Add-In „fisherexactmac.xla“ (http://www.obertfamily.com/software/fisherexact.html) durchgeführt. Bei den statistischen Auswertungen wurden Konfidenzniveaus von 95\% bzw. Signifikanzniveaus von $\alpha=0,05$ angenommen. Bei den dargestellten Boxplots sind Median, Interquartilsabstand (Boxen) und die Whisker des 5. und 95. Perzentils gezeigt. Die Berechnung der relativen Konzentrationen der cfDNA erfolgte mit der Software QuantaSoft ${ }^{\text {TM }}$ (Version 1.3.2.0, Bio-Rad Laboratories Inc.) auf Basis der Poisson-Verteilung (Hindson et al. 2011; Pinheiro et al. 2012). 


\section{Ergebnisse}

\subsection{Demographische Daten}

Im Rahmen der vorliegenden Arbeit wurden 22 de novo-lebertransplantierte Patienten untersucht. Eine Übersicht der untersuchten Patienten gibt die Tabelle 4.1. Der Anteil der weiblichen Patientinnen beträgt 31,8\%. Das Empfängeralter beträgt 53,1 \pm 13,2 Jahre und das Spenderalter 58,0 \pm 13,2 Jahre (Mittelwerte \pm Standardabweichung). Der Anteil der Re-Transplantationen beträgt 18,2\%.

Insgesamt kam es bei drei Patienten zu einem Studienausschluss. Von diesen Patienten erhielt LTx5 im Rahmen der postoperativen Therapie zahlreiche Blutprodukte, deren Einfluss auf die Bestimmung der GcfDNA bisher noch nicht geklärt ist. Zwei Patienten verstarben wenige Stunden nach Transplantation (LTx9 und LTx11).

Bei einem Studienteilnehmer wurde zeitweise ein Molecular Adsorbent Recirculation System (MARS-Therapie) angewandt (LTx13). Die GcfDNA-Werte aus diesem Zeitraum wurden bei den statistischen Auswertungen der vorliegenden Arbeit nicht berücksichtigt. Ebenfalls nicht berücksichtigt wurden die GcfDNA-Werte der Tage mit Steroid-Stoßtherapien und die der drei darauf folgenden Tage. LTx2 wurde während des Beobachtungszeitraumes der BMBF-Studie (siehe Kapitel 3.1.2) re-transplantiert. 


\begin{tabular}{|c|c|c|c|c|}
\hline & Alter & Geschlecht & Indikation zur Transplantation & sonstiges \\
\hline LTx1 & 49 & männlich & Leberzirrhose & Hepatitis $\mathrm{C}$ \\
\hline LTx2 & 41 & männlich & $\begin{array}{l}\text { Re-Transplantation } \\
\text { (sklerosierende Cholangitis) }\end{array}$ & \\
\hline LTx3 & 68 & männlich & Leberzirrhose und HCC & \\
\hline LTx4 & 52 & weiblich & PCLD & \\
\hline LTx5 & 22 & weiblich & $\begin{array}{l}\text { Re-Transplantation } \\
\text { (Morbus Wilson) }\end{array}$ & Drop-out \\
\hline LTx6 & 64 & weiblich & Leberzirrhose und HCC & \\
\hline LTx7 & 44 & männlich & Leberzirrhose & Hepatitis $\mathrm{C}$ \\
\hline LTx8 & 60 & männlich & Leberzirrhose & \\
\hline LTx9 & 47 & männlich & $\begin{array}{l}\text { Leberzirrhose, } \\
\text { akutes Leberversagen }\end{array}$ & Drop-out \\
\hline LTx10 & 64 & männlich & Leberzirrhose & Hepatitis C \\
\hline LTx11 & 57 & männlich & Leberzirrhose & Drop-out \\
\hline LTx12 & 64 & männlich & Leberzirrhose und HCC & \\
\hline LTx13 & 62 & männlich & $\begin{array}{l}\text { Re-Transplantation } \\
\text { (chron. Transplantatversagen) }\end{array}$ & Hepatitis B \\
\hline LTx14 & 58 & männlich & Leberzirrhose & \\
\hline LTx15 & 42 & männlich & $\begin{array}{l}\text { Re-Transplantation } \\
\text { (chron. Transplantatversagen) }\end{array}$ & $\begin{array}{l}\text { Re-Tx } \\
\text { von LTx2 }\end{array}$ \\
\hline LTx16 & 69 & männlich & Leberzirrhose und HCC & Hepatitis B \\
\hline LTx17 & 58 & männlich & Leberzirrhose und HCC & Hepatitis B \\
\hline LTx18 & 20 & weiblich & Sklerosierende Cholangitis & \\
\hline LTx19 & 56 & weiblich & Akutes Leberversagen & Hepatitis B \\
\hline LTx20 & 51 & männlich & Leberzirrhose und HCC & Hepatitis C \\
\hline LTx21 & 54 & weiblich & Leberzirrhose & \\
\hline LTx22 & 66 & weiblich & Leberzirrhose & Split-LTx \\
\hline
\end{tabular}

Tabelle 4.1: Demographische Daten und Indikationen zur Transplantation (HCC: Leberzellkarzinom, engl. hepatocellular carcinoma) 


\subsection{Kinetik der zirkulierenden zellfreien Spender-DNA im Plasma}

Unmittelbar nach Transplantation (15min-Probe) sind sehr hohe Werte der GcfDNA - zum Teil über 90\% - messbar. Wie in der Abbildung $4.1 \mathrm{zu}$ sehen ist, fällt die GcfDNA nach wenigen Tagen deutlich ab und erreicht bei komplikationslosen Patienten bereits nach weniger als 14 Tagen Werte um 10\%. Dieser Wert wird bei einer Reihe lebertransplantierter Patienten $(\mathrm{n}=10)$ mit stabiler Transplantatfunktion als oberer Grenzwert für die GcfDNA beschrieben (Beck et al. 2013b). Bei Werten unter 10\% ist folglich von einer stabilen Funktion des Lebertransplantates und einer ausreichenden Immunsuppression auszugehen.

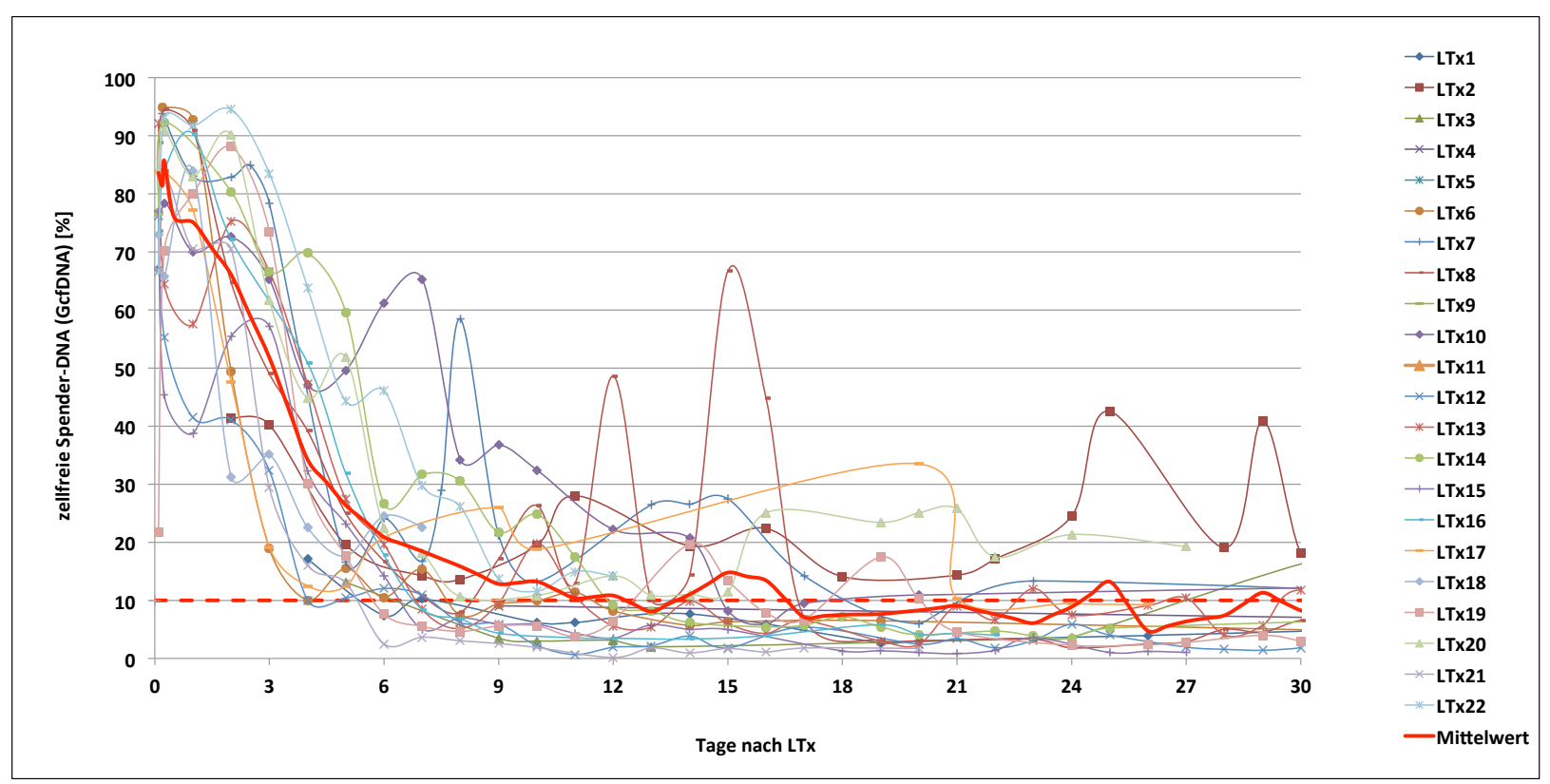

Abbildung 4.1: Einzelverläufe der GcfDNA über die ersten 30 Tage nach Transplantation

Nach durchschnittlich 0,25 Tagen hat die gemittelte GcfDNA ihr Maximum von 85,68\% erreicht. Von hier fällt diese bis zum Tag 9 auf 12,82\% ab, wo ein kurzzeitiges Plateau und Angleichung an die 10\%-Grenze (siehe Kapitel 3.3.3) zu beobachten ist. Nach 12,5 Tagen kommt es im Mittel erstmals zu Werten unterhalb von 10\%. Die Berechnung der initialen Halbwertszeit erfolgt näherungsweise mit Hilfe des Eliminationsgesetzes für Reaktionen 1. Ordnung (Freissmuth 2012):

$$
C(t)=C_{0} * e^{(-k * t)}
$$


Durch Logarithmieren erhält man aus der Formel 4.1:

$$
k=\frac{1}{t_{2}-t_{1}} * \ln \frac{c_{1}}{c_{2}}
$$

Aus der Eliminationskonstante $k$ lässt sich die Halbwertszeit dann wie folgt berechnen:

$$
t_{1 / 2}=\frac{\ln 2}{k}
$$

Hier stellen $t_{1}$ und $c_{1}$ den Zeitpunkt des Maximums und die maximale Konzentration der GcfDNA dar. Die entsprechenden Werte nach Abfall der GcfDNA werden durch $t_{2}$ und $c_{2}$ beschrieben. Dadurch ergibt sich aus den Formeln 4.2 und 4.3:

$$
\begin{gathered}
k=\frac{1}{9,5-0,25} * \ln \frac{0,8568}{0,1282}=0,2171 \\
t_{1 / 2}=\frac{\ln 2}{0,2171}=3,1934
\end{gathered}
$$

Somit ergibt sich für die initiale GcfDNA-Freisetzung unmittelbar nach Transplantation eine mittlere Halbwertszeit von 3,2 Tagen. Für die Berechnung der initialen Halbwertszeit der GcfDNA, unabhängig vom Ischämie- / Reperfusionsschaden und dem chirurgischen Eingriff während der Transplantation, wurde der Abfall der GcfDNA nach dem Auftreten von Peaks außerhalb der ersten Woche nach Transplantation untersucht. Die Beobachtungen zeigen, dass die GcfDNA aufgrund ihrer kurzen Halbwertszeit unmittelbar auf Therapieänderungen reagiert. Dies zeigt sich z. B. beim Einsatz von hoch dosierten Corticosteroiden in Form von Steroid-Stoßtherapien (Abbildung 4.2). Unmittelbar nach deren Gabe ist ein deutlicher Abfall der GcfDNA erkennbar. Im folgenden Patientenverlauf ist ein starker Anstieg der GcfDNA ab Tag 31 mit einem Maximum von etwa 60\% am Tag 38 zu beobachten. Während dieser Zeit zeigt der konventionelle Marker AST variablere Verläufe. 


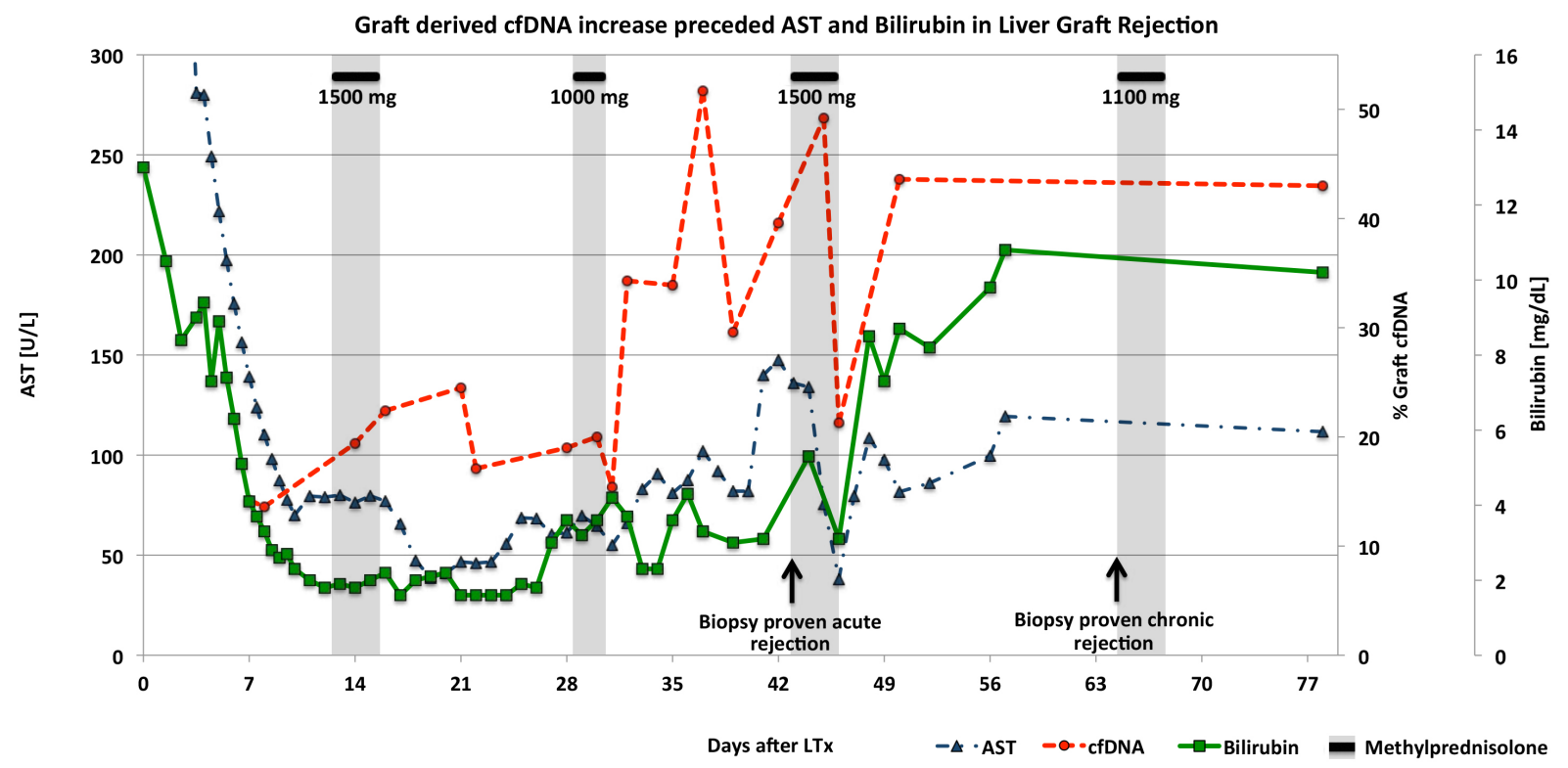

Abbildung 4.2: GcfDNA und traditionelle Lebermarker bei chronischer Abstoßung und Steroid-Stoßtherapien (Beck et al. 2013a - Abdruck mit Genehmigung, Bildnachweis auf Seite 123)

Insgesamt sind in die Berechnung der Halbwertszeit sieben derartige Abfälle der GcfDNA nach Steroid-Stoßtherapien zwischen den Tagen 8 und 338 mit eingeflossen. Für diese Verläufe wurde jeweils durch exponentielle Regression das Eliminationsgesetz nach der Formel 4.1 bestimmt. Aus der Eliminationskonstante $k$ und der Formel 4.3 ergibt sich dann jeweils die Halbwertszeit. 


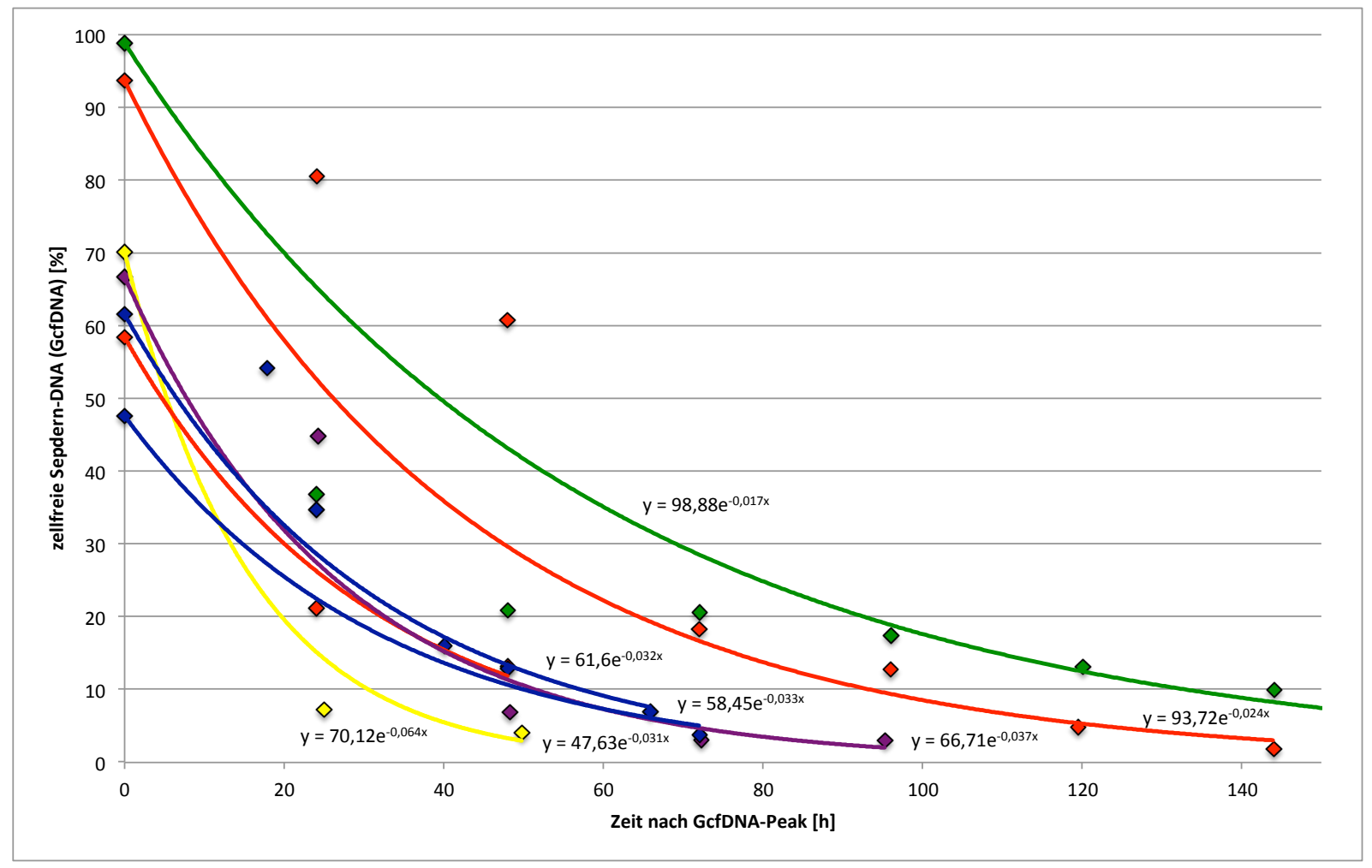

Abbildung 4.3: Abfälle der GcfDNA nach Steroid-Stoßtherapien und näherungsweise Beschreibung der Verläufe durch exponentielle Regression

Aus den in der Abbildung 4.3 dargestellten Verläufen nach Steroid-Stoßtherapien lässt sich eine durchschnittliche Halbwertszeit von 23,5 Stunden mit einer Standardabweichung von 9,3 Stunden berechnen.

\subsection{Reperfusions- und Ischämieschädigung der Spenderorgane}

Bei den Studienpatienten der vorliegenden Arbeit beträgt die kalte Ischämiezeit (KIZ) 9,9 \pm 1,9 Stunden und die warme Ischämiezeit (WIZ) 35,1 \pm 6,8 Minuten (Mittelwert \pm Standardabweichung). Die Ischämiezeiten der einzelnen Patienten sind der Tabelle 4.2 zu entnehmen. Die Untersuchungen zeigen, dass zwischen den Logits der AUCs der GcfDNA über die ersten 8 Tage nach Transplantation und der KIZ keine signifikante Korrelation $(\mathrm{p}=0,0742)$ besteht. Die Korrelation ist in der Abbildung 4.4 dargestellt. Der Punkt der Split-LTx (LTx22) ist in der Abbildung blau dargestellt und geht nicht in die Berechnung der Korrelation mit ein. Zwischen der WIZ und dem Spenderalter besteht ebenfalls kein signifikanter Zusammenhang. 


\begin{tabular}{l|l|l|l} 
& KIZ $[\mathbf{h}]$ & WIZ $[$ min] & Spenderalter \\
\hline \hline LTx1 & $14: 10$ & 30 & 61 \\
\hline LTx2 & $12: 30$ & 30 & 57 \\
\hline LTx3 & $11: 02$ & 40 & 71 \\
\hline LTx4 & $9: 31$ & 30 & 22 \\
\hline LTx5* & $9: 28$ & 30 & 52 \\
\hline LTx6 & $8: 25$ & 40 & 41 \\
\hline LTx7 & $8: 30$ & 48 & 59 \\
\hline LTx8 & $8: 07$ & 34 & 49 \\
\hline LTx9* & $7: 51$ & 30 & 53 \\
\hline LTx10 & $10: 17$ & 30 & 83 \\
\hline LTx11* & $11: 33$ & 35 & 75 \\
\hline LTx12 & $7: 04$ & 45 & 58 \\
\hline LTx13 & $9: 11$ & 26 & 77 \\
\hline LTx14 & $12: 10$ & 24 & 54 \\
\hline LTx15 & $6: 48$ & 37 & 58 \\
\hline LTx16 & $7: 59$ & 45 & 60 \\
\hline LTx17 & $10: 17$ & 35 & 74 \\
\hline LTx18 & $11: 20$ & 35 & 52 \\
\hline LTx19 & $11: 22$ & 30 & 53 \\
\hline LTx20 & $8: 24$ & 32 & 65 \\
\hline LTx21 & $9: 37$ & 45 & 49 \\
\hline LTx22 & $11: 53$ & 42 & 53 \\
\hline L & & & \\
\hline
\end{tabular}

Tabelle 4.2: Kalte (KIZ) und warme (WIZ) Ischämiezeiten der untersuchten Spenderorgane $(*=$ Drop-outs $)$ 


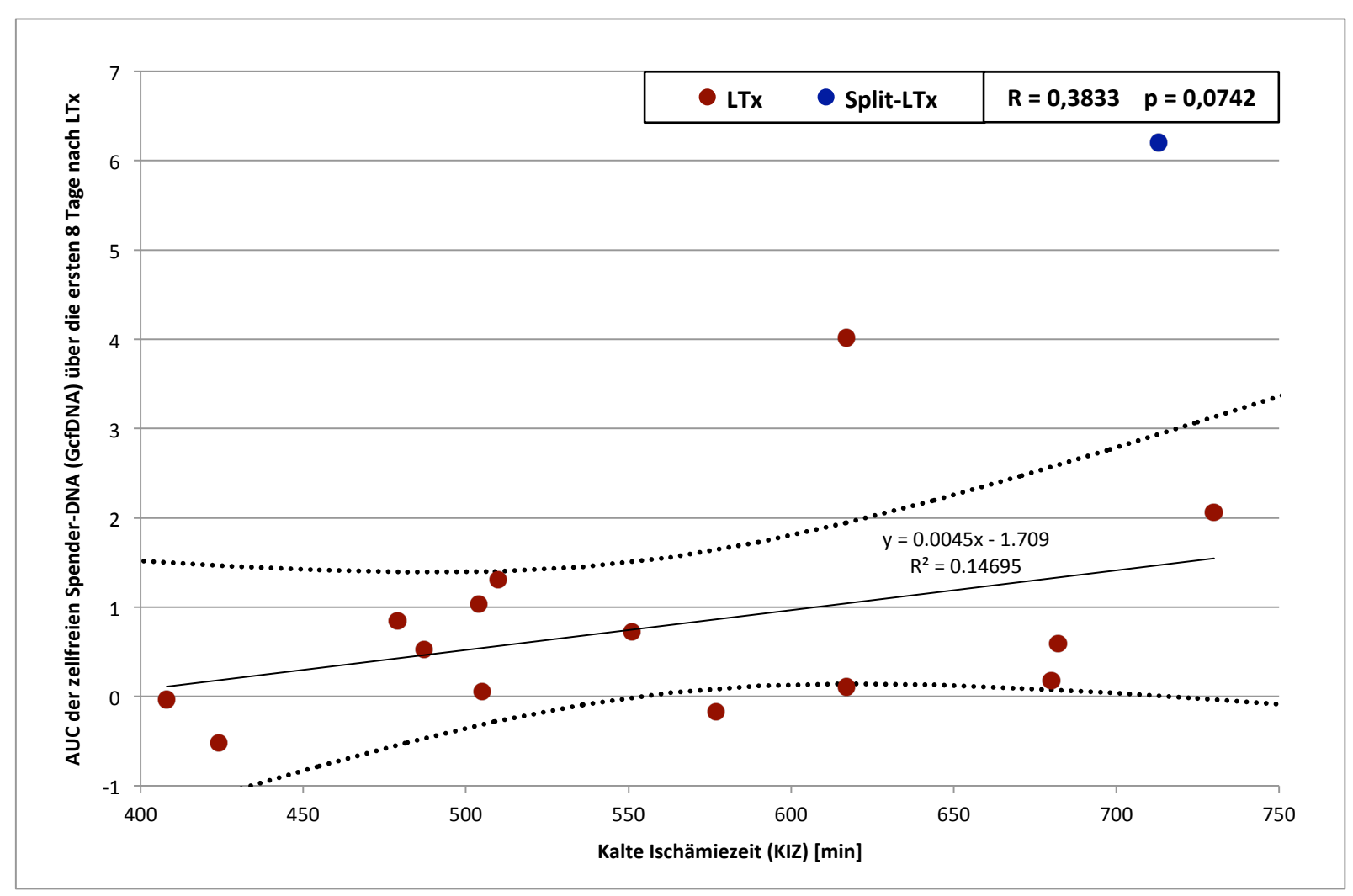

Abbildung 4.4: Korrelation der kalten Ischämiezeit (KIZ) mit den Logits der AUCs der GcfDNA über die ersten 8 Tage, 95\%-Konfidenzintervall gepunktet dargestellt

\subsection{Einfluss der Immunsuppression auf die Freisetzung der zirkulierenden zellfreien Spender-DNA}

Einen direkten Einfluss auf die Freisetzung der GcfDNA hat die Immunsuppression. Im Falle einer Schädigung des transplantierten Organs in Folge einer Unter-Immunsuppression kommt es zum Zelluntergang und somit zu erhöhten Messwerten. Folglich eignet sich dieser Marker, um eine Minimierung der Immunsuppression zu erreichen. Am Göttinger Transplantationszentrum wird bei Tacrolimus ein Zielspiegel von 8 bis $12 \mu \mathrm{g} / \mathrm{l}$ für die ersten 6 Wochen nach Transplantation angestrebt. Die notwendigen Dosierungen zeigen bei den untersuchten Patienten, wie in Abbildung 4.5 für die Tage 5 bis 30 dargestellt, hohe intra- sowie interindividuelle Unterschiede. 


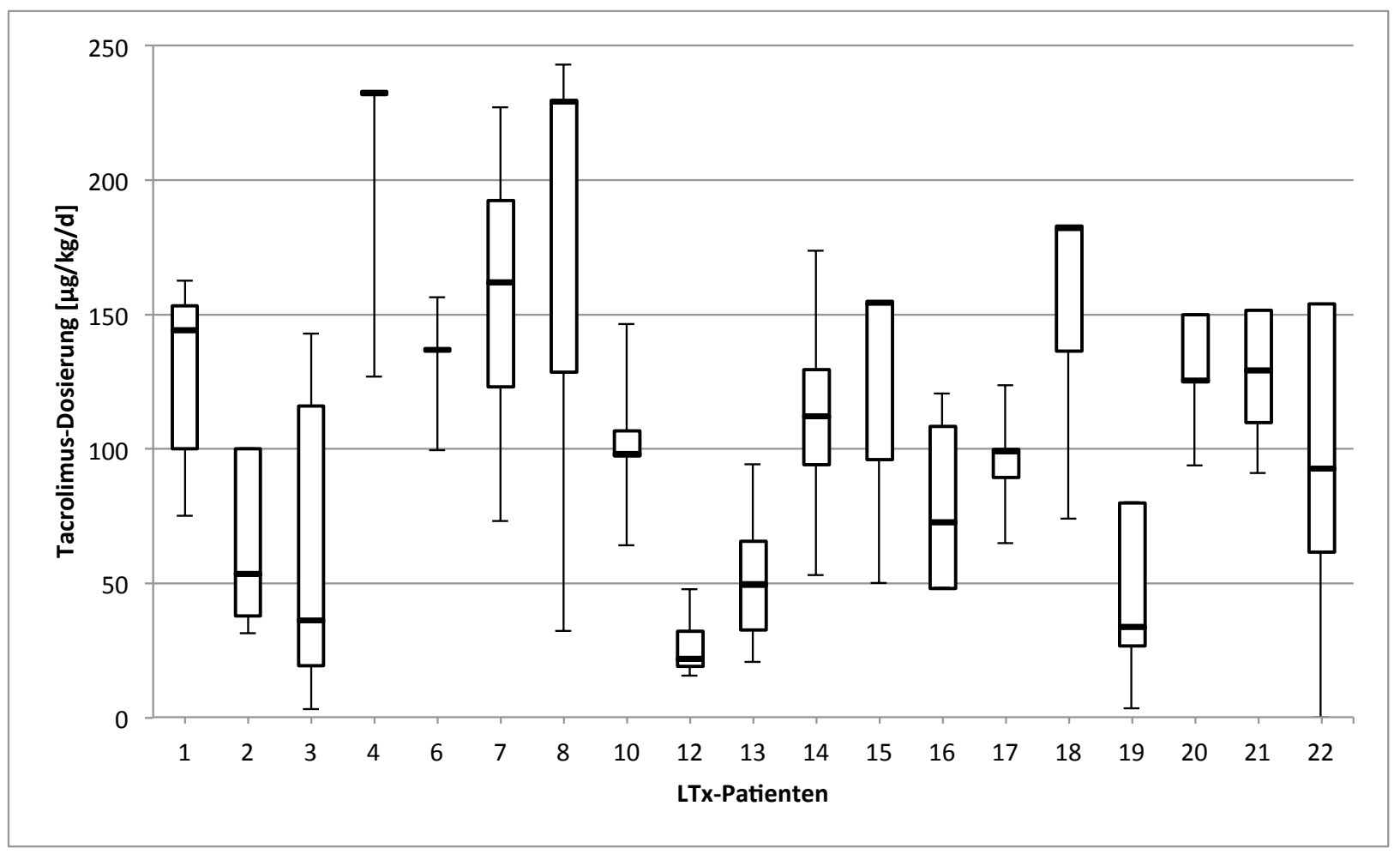

Abbildung 4.5: Boxplots mit den täglichen Tacrolimus-Dosierungen zwischen den Tagen 5 und 30 (verändert nach Oellerich et al. 2014b - Abdruck mit Genehmigung, Bildnachweis auf Seite 123)

Beim Vergleich der GcfDNA mit den zugehörigen Tacrolimus-Talspiegeln fällt auf, dass oberhalb der Grenze von 8 pg/l, abgesehen von den Patienten mit einer Hepatitis-C-Infektion $(\mathrm{HCV}+)$, fast alle GcfDNA-Werte unterhalb von 10\% liegen. Dies bedeutet eine suffiziente Immunsuppression, da es zu keiner erhöhten DNA-Freisetzung aus dem transplantierten Organ kommt. Der in Abbildung 4.6 gezeigte Zusammenhang von Tacrolimus-Spiegeln $\geq 8 \mu \mathrm{g} / \mathrm{l}$ und GcfDNA-Werten von $\leq 10 \%$ ist bei den untersuchten 211 Wertepaaren hoch signifikant (Fisher's $\mathrm{p}=0$,000008). In einem größeren Kollektiv haben sich hiermit die Ergebnisse unserer früheren Publikation (Oellerich et al. 2014b) bestätigt. Dabei zeigen die Patienten mit Hepatitis-C-Infektion (in der Abbildung rot dargestellt) einen variableren Verlauf der GcfDNA-Werte. Hier ist eine zusätzliche Zellschädigung durch die Hepatitis-Viren zu vermuten. Die vorgenommene Betrachtung ist auf einen Zeitraum von 5 bis 30 Tagen nach Transplantation beschränkt, um auf der einen Seite einen möglichen Einfluss durch Ischämie- / Reperfusionsschädigung zu minimieren und auf der anderen Seite weitere Einflüsse im Langzeitverlauf wie z.B. Infektionen oder einen Wechsel des Haupt-Immunsuppressivums zu verhindern. 


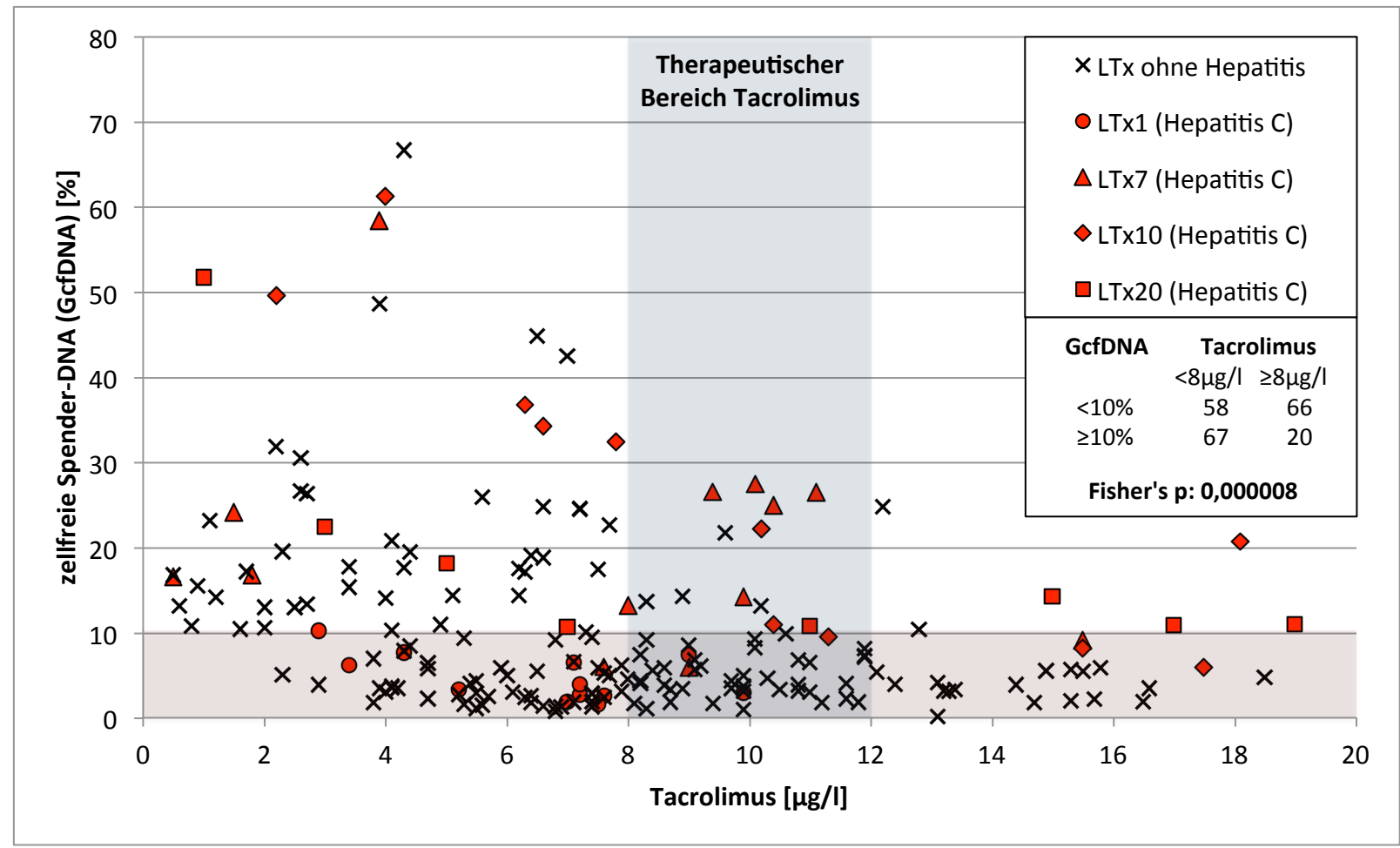

Abbildung 4.6: Vergleich der Tacrolimus-Talspiegel im Vollblut mit der GcfDNA-Freisetzung während der Tage 5 bis 30, $\mathrm{n}=211$ Wertepaare, $\mathrm{N}=18$ Patienten (verändert nach Oellerich et al. 2014b - Abdruck mit Genehmigung, Bildnachweis auf Seite 123)

Außerdem wurde untersucht, ob auch ein Zusammenhang zwischen konventionellen Markern wie der AST und der GGT mit den Tacrolimus-Spiegeln besteht. Die AST ist außer in der Muskulatur besonders in den Leberzellen in hoher Konzentration vorhanden. Daher hat sich die AST in der Labormedizin als Marker für eine Leberzellschädigung etabliert. Auch die GGT ist ein Enzym, das in Verbindung mit anderen Laborparametern ebenfalls als Marker für Lebererkrankungen Verwendung findet (Röhm 2007).

Daher wurde für den gleichen Zeitraum (Tag 5 bis 30) dieselbe Kalkulation mit den GcfDNA-Werten durchgeführt, für die an den jeweiligen Tagen ebenfalls auch die Aktivitäten der AST und GGT im Plasma bestimmt worden waren. Insgesamt sind in diese in der Abbildung 4.7 gezeigte Berechnung 183 Tacrolimus-GcfDNA- bzw. Tacrolimus-AST-Wertepaare mit eingeflossen. Die Ergebnisse zeigen, dass zwischen den AST-Werten und den Tacrolimus-

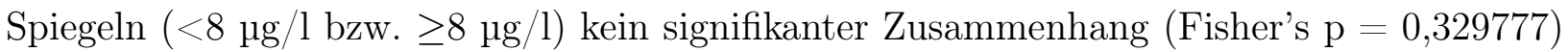
besteht. Allerdings gelten die für AST und GGT verwendeten Referenzbereiche für gesunde Normalpersonen (Abbott 2010a, 2012). Für die in diesem Fall untersuchten transplantierten Patienten gelten diese Angaben natürlich nur eingeschränkt. Für diese Personengruppe 
existieren in der Literatur keine dezidierten Entscheidungsgrenzen.
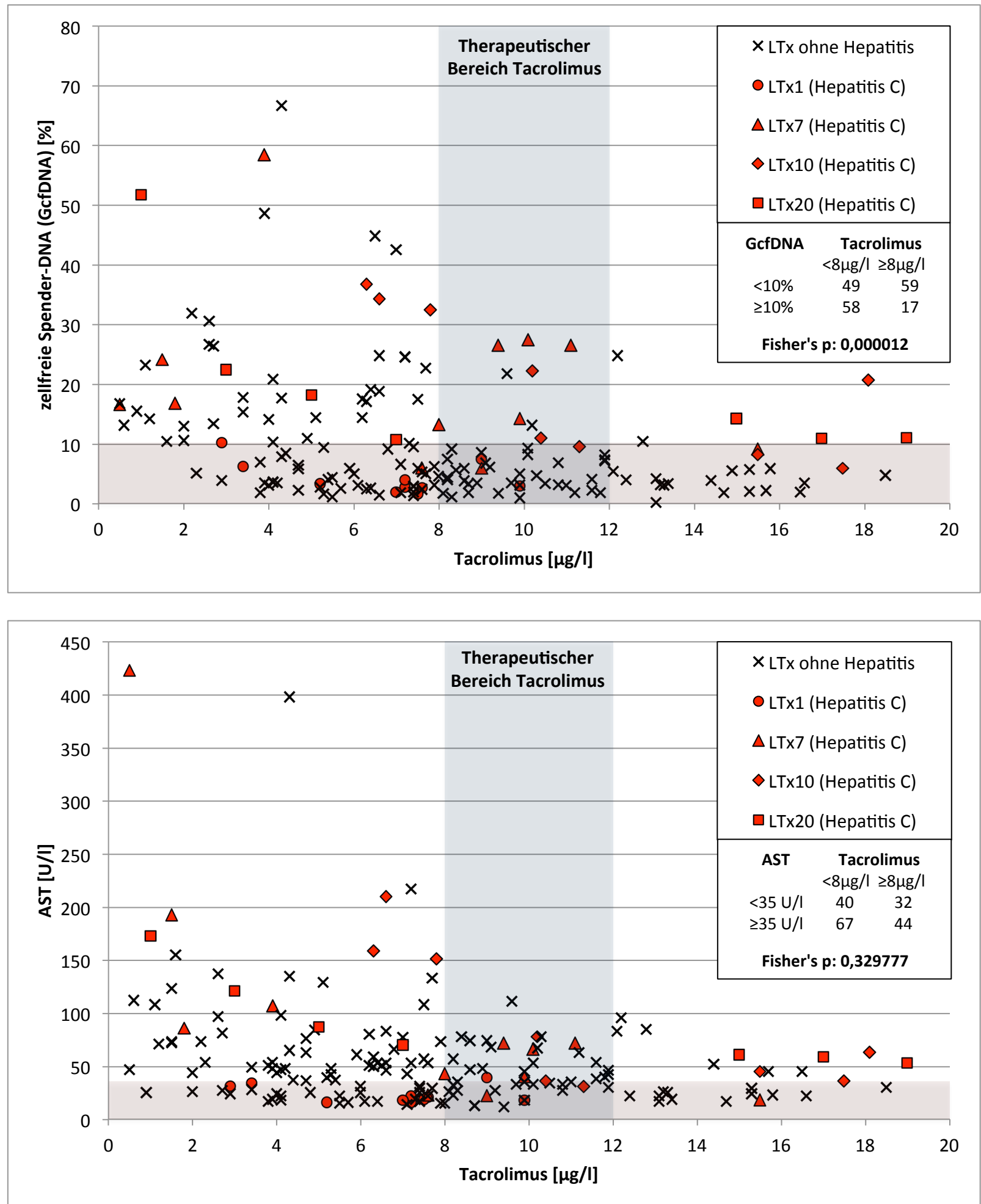

Abbildung 4.7: Vergleich der Tacrolimus-Talspiegel im Vollblut mit der Aspartat-Aminotransferase-(AST)-Aktivität im Plasma während der Tage 5 bis 30, n = 183 Wertepaare, $\mathrm{N}=18$ Patienten 
In einem zweiten Schritt wurde die Abhängigkeit der GGT-Aktivität im Plasma von den im Vollblut gemessenen Tacrolimus-Talspiegeln berechnet. Die GGT-Werte standen für dieselben Blutproben zur Verfügung wie auch die AST-Werte. Folglich gingen hier wieder 183 Tacrolimus-GcfDNA-GGT-Wertepaare von den identischen Tagen wie in Abbildung 4.7 mit ein. Es lässt sich kein signifikanter Zusammenhang (Fisher's p =0,112148) zwischen den beiden Größen belegen (Abbildung 4.8).

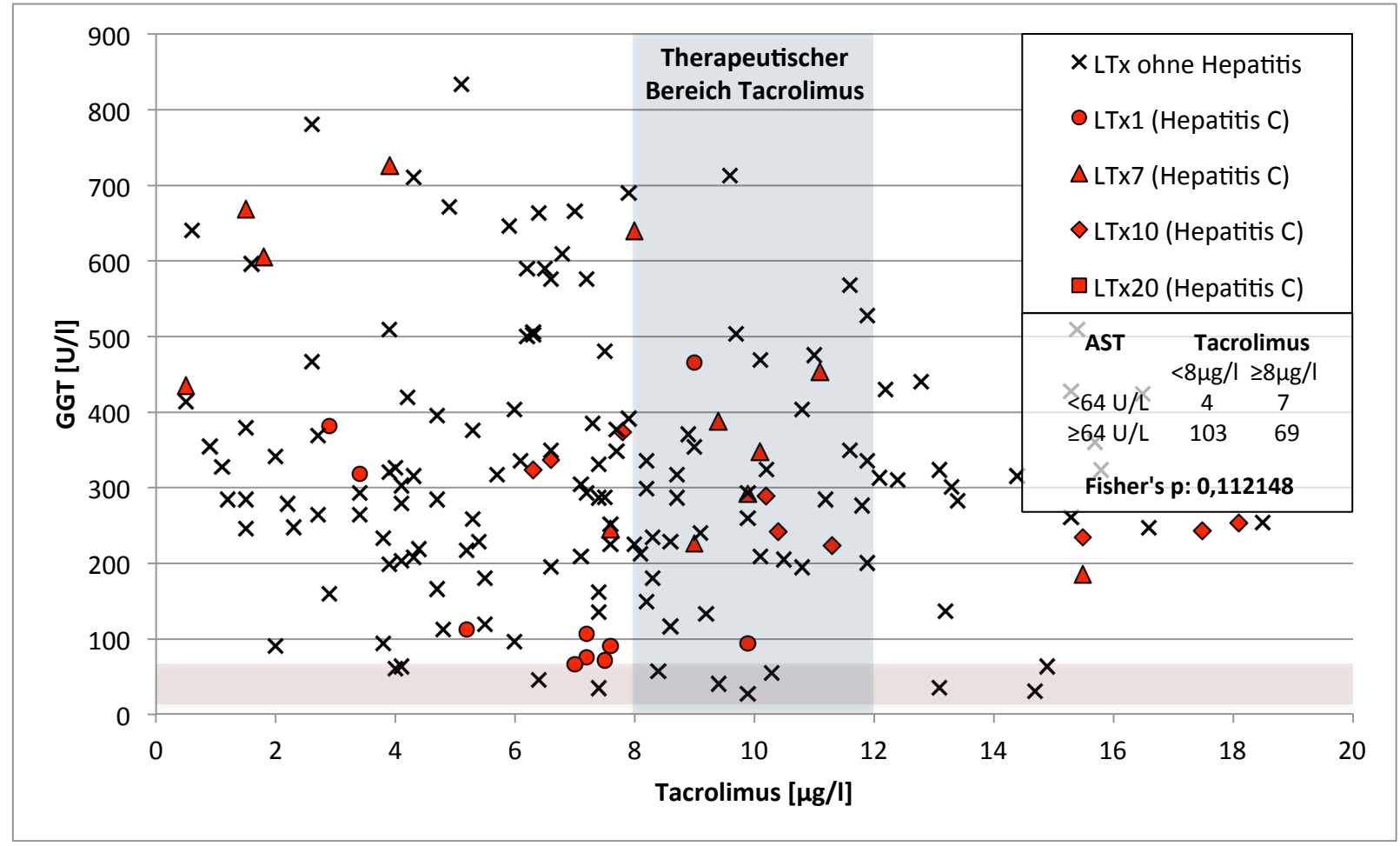

Abbildung 4.8: Vergleich der Tacrolimus-Talspiegel im Vollblut mit der $\gamma$-Glutamyl-Transferase-(GGT)-Aktivität im Plasma während der Tage 5 bis 30, $\mathrm{n}=183$ Wertepaare, $\mathrm{N}=18$ Patienten

\subsection{Vorschläge für eine Reduzierung der Tacrolimus-Dosierungen auf Basis der zirkulierenden zellfreien Spender-DNA}

In der Abbildung 4.6 zeigt sich, dass eine Immunsuppression mit Tacrolimus-Spiegeln über $8 \mu \mathrm{g} / \mathrm{l}$ allgemein als ausreichend erscheint, da die korrespondierenden GcfDNA-Werte größtenteils unterhalb 10\% liegen. Folglich sollten sich die Konzentrationen der Immunsuppressiva und gleichzeitig ihre Nebenwirkungen verringern lassen. Doch wie weit ist eine Reduktion der Dosis im Sinne einer Minimalisierung möglich, ohne eine Gefährdung für das transplantierte Organ zu verursachen? Zur Beantwortung dieser Frage diente Oellerich et al. die Analyse 
der Grenzwertoptimierungskurve (ROC-Kurve, engl. Receiver Operator Characteristic Cur$v e$ ) in Abbildung 4.9 mit der vermeintlichen Untergrenze des therapeutischen Bereichs des Tacrolimus als Trennwert (Hilgers 1991). Der Tacrolimus-Grenzwert wird in Schritten von $0,1 \mathrm{\mu g} / 1$ verschoben. Zunächst werden die Messwerte in eine Gruppe mit GcfDNA-Werten $\geq 10 \%$ und eine mit $<10 \%$ aufgeteilt. Der Anteil mit Tacrolimus-Spiegeln unterhalb dieses flexiblen Grenzwertes wird in beiden Gruppen zur Erstellung der Kurve berechnet (Oellerich et al. 2014b). Die mit der Trapezregel berechnete AUC der ROC-Kurve hat ihr Maximum von 0,75 (95\%-Konfidenzintervall: 0,62-0,84) bei einem Grenzwert von 10\% für die GcfDNA.
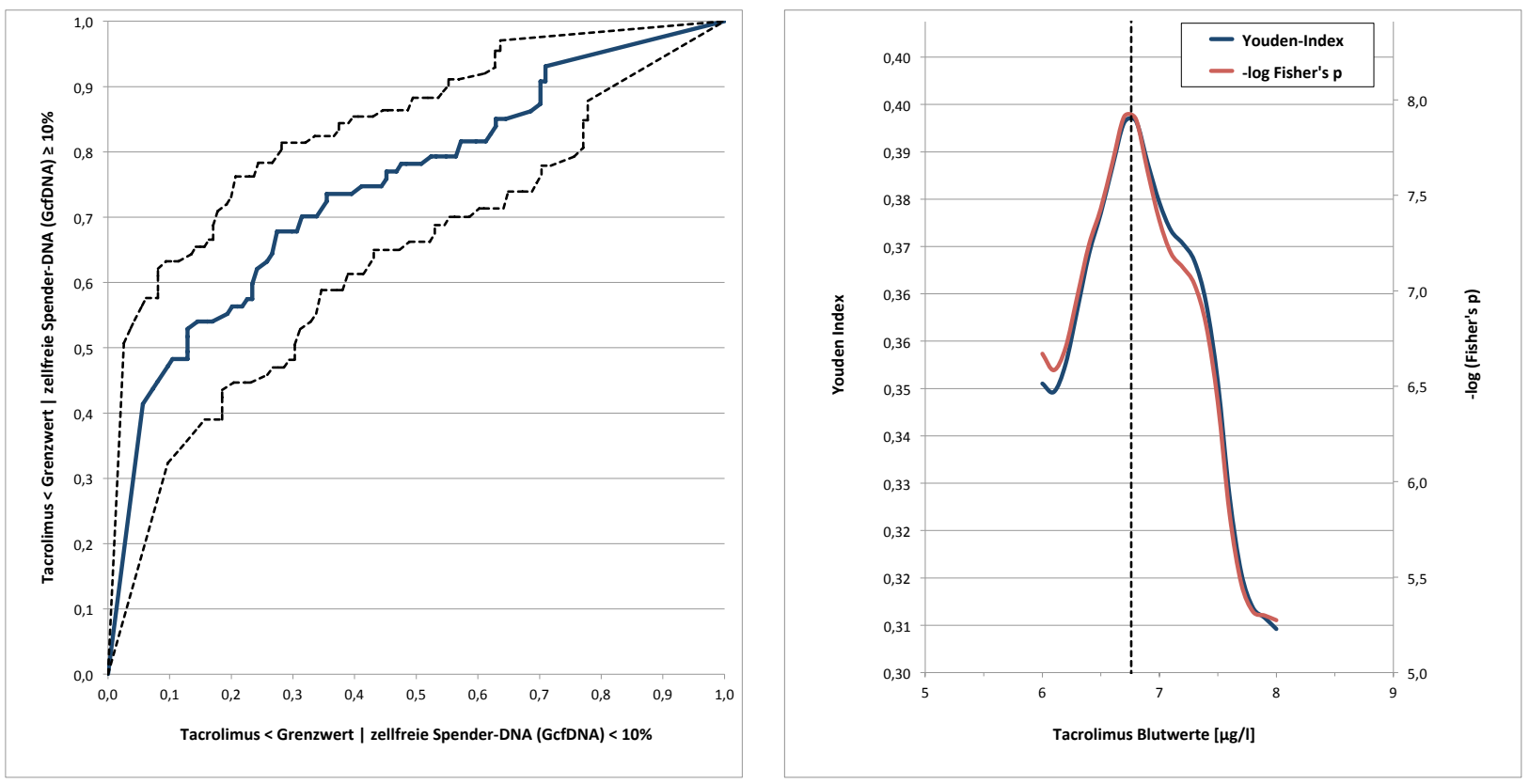

Abbildung 4.9: Grenzwertoptimierungskurve (ROC-Kurve), N = 18 Patienten, 95\%-Konfidenzintervall gestrichelt dargestellt (verändert nach Oellerich et al. 2014b Abdruck mit Genehmigung, Bildnachweis auf Seite 123)

Sowohl der höchste Youden-Index als auch der höchste negative dekadische Logarithmus des Fisher's p werden bei einem Grenzwert von 6,76 $\mathrm{gg} / \mathrm{l}$ beobachtet, nachdem der Youden-Index und der Wert des Fisher's p einer Parzen-Rosenblatt-Glättung unterzogen wurde $\left(\sigma^{2}=0,5 ; \mathrm{i}=3\right)$. Beide Kurven im rechten Teil der Abbildung 4.9 haben hier ihr Maximum (Youden-Index $=0,4 ;-\log$ Fisher's $\mathrm{p}=7,9$ ). Die Berechnung des Youden-Index erfolgt nach der folgenden Formel:

$$
\theta[\text { Tacro } \geq \text { Grenzwert } \mid \text { GcfDNA }<10]+\theta[\text { Tacro } \geq \text { Grenzwert } \mid \text { GcfDNA } \geq 10]-1
$$


Es zeigt sich also, dass ein Tacrolimus-Talspiegel von mindestens $6,8 \mu \mathrm{g} / \mathrm{l}$ bei den Patienten dieser Studie eine suffiziente Immunsuppression sicherstellt.

\subsection{Vergleich der zirkulierenden zellfreien Spender-DNA mit herkömmlichen Markern und Leberenzymen}

In den Abbildungen 4.6 und 4.9 zeigt sich bereits der Einfluss der Immunsuppression und Hepatitis $\mathrm{C}$ auf die Freisetzung der GcfDNA. In den folgenden Abbildungen stellen diese auch wieder die ersten vier Kategorien dar. Bei den Messungen der Frühphase, also innerhalb der Tage 8 (nach Erreichen stabiler und suffizienter Tacrolimus-Spiegel) bis 30, zeigt sich in Abbildung 4.10 ein Anstieg der GcfDNA bei unter-immunsupprimierten stabilen Patienten (Kategorie 2). Dieser Anstieg der GcfDNA ist bei der verwendeten Grenze von 8 $\mathrm{g} / \mathrm{l}$ für die Tacrolimus-Spiegel nicht signifikant. Es besteht allerdings eine wesentlich größere Streuung der Messwerte, wobei das 95. Perzentil bei 27,4\% im Vergleich zu 10,2\% bei stabilen Patienten mit Tacrolimus-Spiegeln von $\geq 8 \mu \mathrm{g} / 1$ liegt. Fünf (LTx8, LTx14, LTx17, LTx19 und LTx22) der elf Patienten dieser Gruppe hatten wiederholt GcfDNA-Werte über 10\%. Bei der Mehrzahl dieser Fälle traten, wie im Kapitel 4.7 beschrieben, Komplikationen im postoperativen Verlauf auf. Bei Patienten mit Tacrolimus-Spiegeln im therapeutischen Bereich, also oberhalb von $8 \mathrm{\mu g} / \mathrm{l}$, und Hepatitis-C-Infektion ist die GcfDNA signifikant erhöht (Kategorie 3). Auch hier führt eine Unter-Immunsuppression zu höheren GcfDNA-Werten (Kategorien 3 und 4). Patienten mit akuten Abstoßungen zeigen im Vergleich zu stabilen Patienten signifikant höhere GcfDNA-Messwerte (Kategorie 6) und das auch schon mehrere Tage vor der klinischen Diagnose (Kategorie 5) unter Berücksichtigung konventioneller Marker (wie der AST, GGT und Bilirubin) bzw. Biopsie. Bei Patienten mit Cholestasen ist dagegen kein Anstieg der GcfDNA zu beobachten.

In dieser und den folgenden Abbildungen basieren die angegebenen p-Werte auf dem Wilcoxon-Vorzeichen-Rang-Test. Zu beachten ist, dass ein und derselbe Patient in Abhängigkeit von Tacrolimus-Spiegeln und klinischem Verlauf in einer oder mehreren Kategorien auftauchen kann. Die Kategorien eins bis vier beziehen sich auf die ersten 30 Tage nach Transplantation. Die Gruppen der Abstoßungen und Cholestasen beeinhalten zusätzlich auch Proben von späteren Zeitpunkten. 


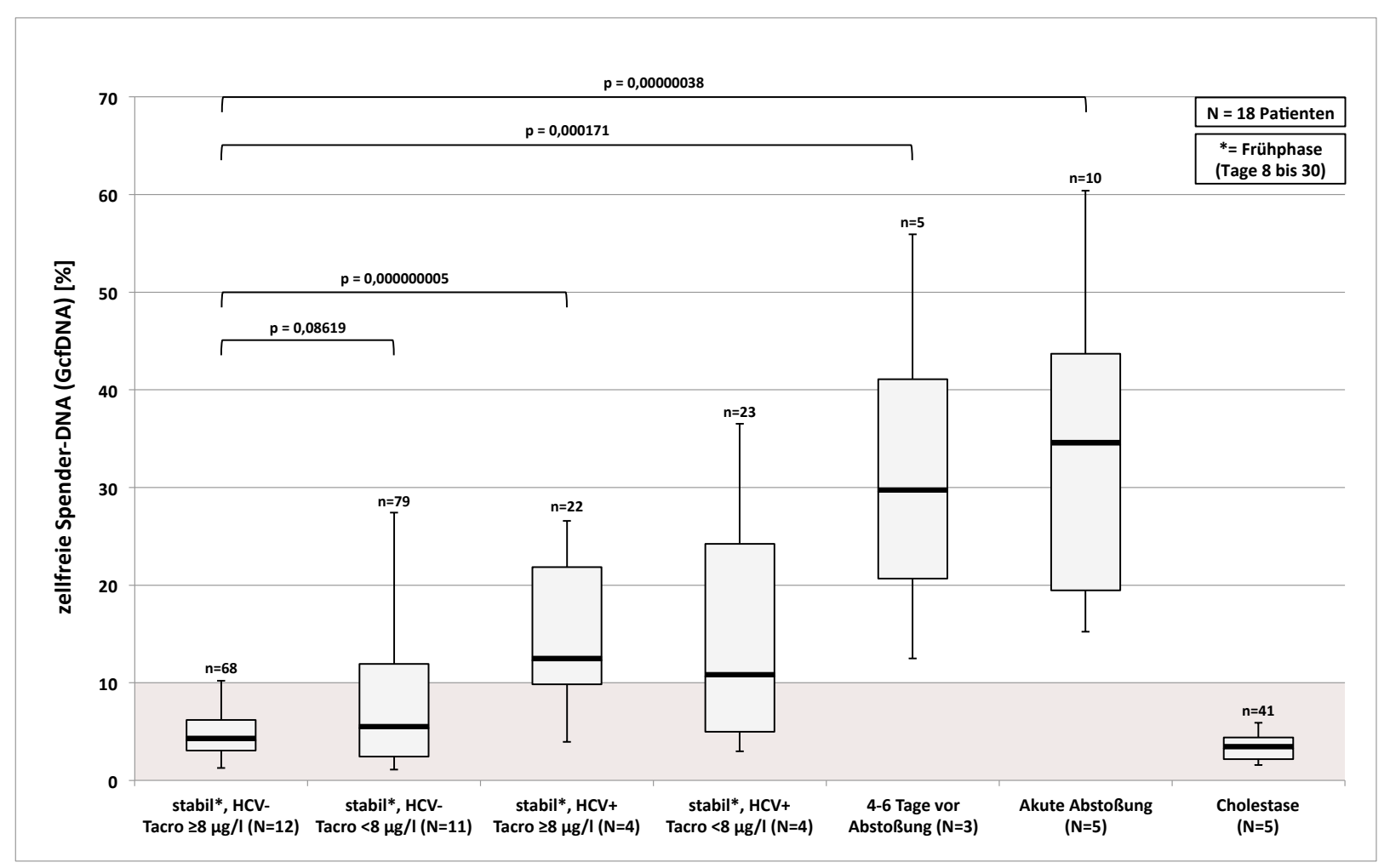

Abbildung 4.10: GcfDNA in Abhängigkeit von Tacrolimus-Spiegeln und Hepatitis-C-Status sowie bei Events (Abstoßungen und Cholestasen), $\mathrm{N}=18$ Patienten, $\mathrm{n}=248$ (verändert nach Oellerich et al. 2014a - Abdruck mit Genehmigung, Bildnachweis auf Seite 123)

Auch hier wurde wieder ein Vergleich mit etablierten Markern wie der AST-, GGT- und Bilirubin-Konzentration durchgeführt. Damit diese Betrachtung vergleichbar ist, ist die vorherige Auswertung der GcfDNA aus Abbildung 4.10 zunächst für eine Subgruppe wiederholt worden, bei der an den selben Tagen auch AST-, GGT- und Billirubin-Messwerte existieren. Dies ist in der Abbildung 4.11 dargestellt. Die Ergebnisse sind hier trotz der minimal geringeren Probenzahlen $(\mathrm{n}=207)$ anstelle von $\mathrm{n}=248)$ statistisch vergleichbar. Eine UnterImmunsuppression stabiler Patienten (Kategorie 2) führt zu einem signifikanten Anstieg der GcfDNA. Bei Tacrolimus-Spiegeln von $\geq 8 \mu \mathrm{g} / \mathrm{l}$ liegen hier 94,6\% der GcfDNA-Messwerte von Patienten ohne Hepatitis-C-Infektion (HCV-) unterhalb der 10\%-Grenze. Bei unzureichender Immunsuppression (Tacrolimus-Spiegel $<8 \mu \mathrm{g} / \mathrm{l}$ ) sind es nur noch 71,2\%. 


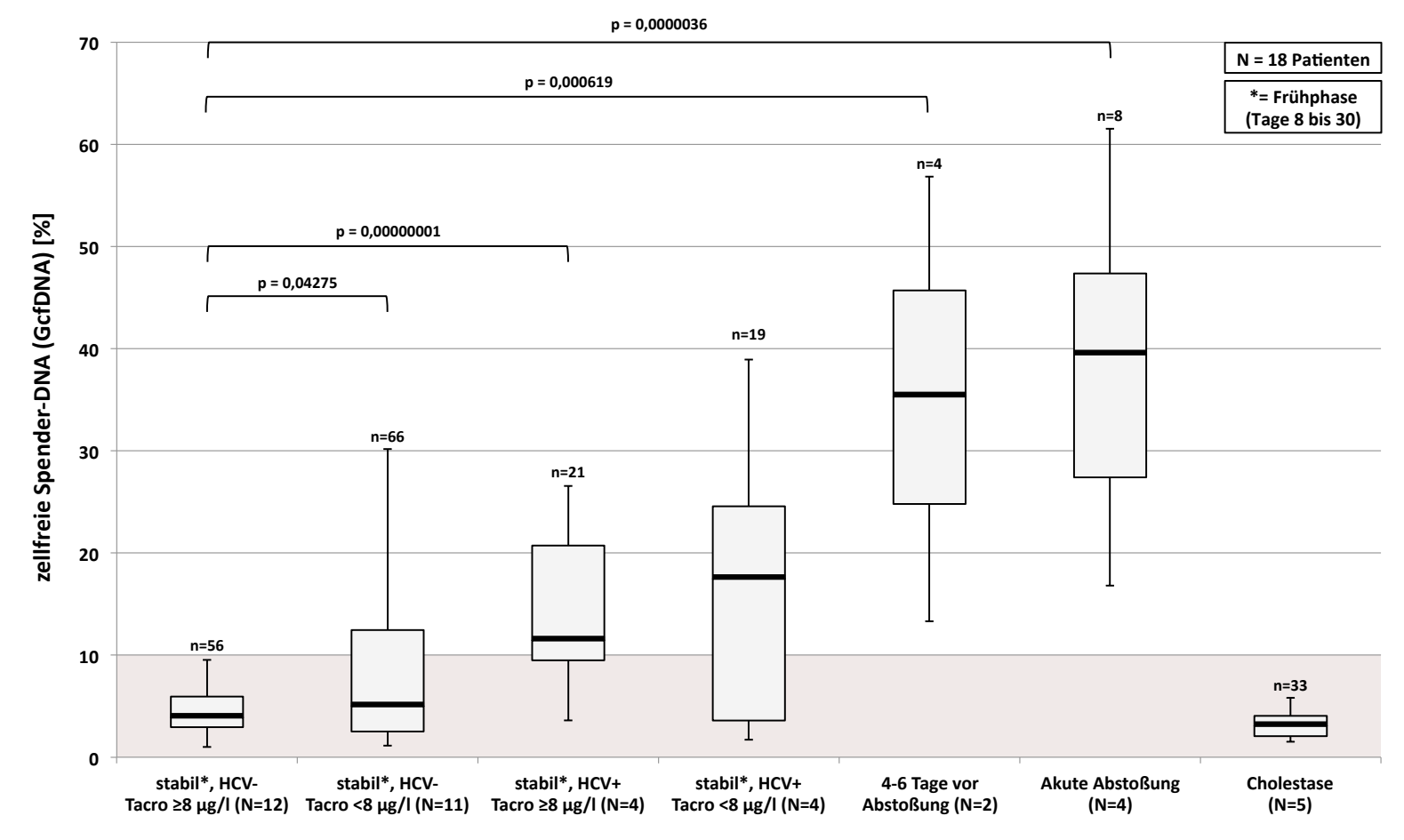

Abbildung 4.11: GcfDNA in Abhängigkeit von Tacrolimus-Spiegeln und Hepatitis-C-Status sowie bei Events (Abstoßungen und Cholestasen), N = 18 Patienten, Subgruppe von Abbildung $4.10(\mathrm{n}=207)$

Beim Vergleich mit der AST fällt auf, dass eine Unter-Immunsuppression hier zwar mit einem Anstieg der AST einhergeht, der aber nicht signifikant ist $(p=0,285)$. Die Werte von Patienten mit Hepatitis $\mathrm{C}$ sind jedoch signifikant $(\mathrm{p}=0,036)$ erhöht (Abbildung 4.12). Die obere Grenze des Referenzbereichs der AST liegt für gesunde Frauen bei $31 \mathrm{U} / 1$ und bei 35 U/l für gesunde Männer (Abbott 2010a). Bei Tacrolimus-Spiegeln von $\geq 8$ pg/1 und Patienten ohne Hepatitis-C-Infektion liegen nur 57,1\% der gemessenen AST-Werte innerhalb des Referenzbereichs. Im Falle einer unzureichender Immunsuppression (Tacrolimus-Spiegel $<8 \mathrm{\mu g} / \mathrm{l}$ ) sind es nur noch 45,5\%. Bei akuten Abstoßungen ist hingegen auch die AST signifikant angestiegen. Dafür steigt die AST auch bei Cholestasen signifikant an. 


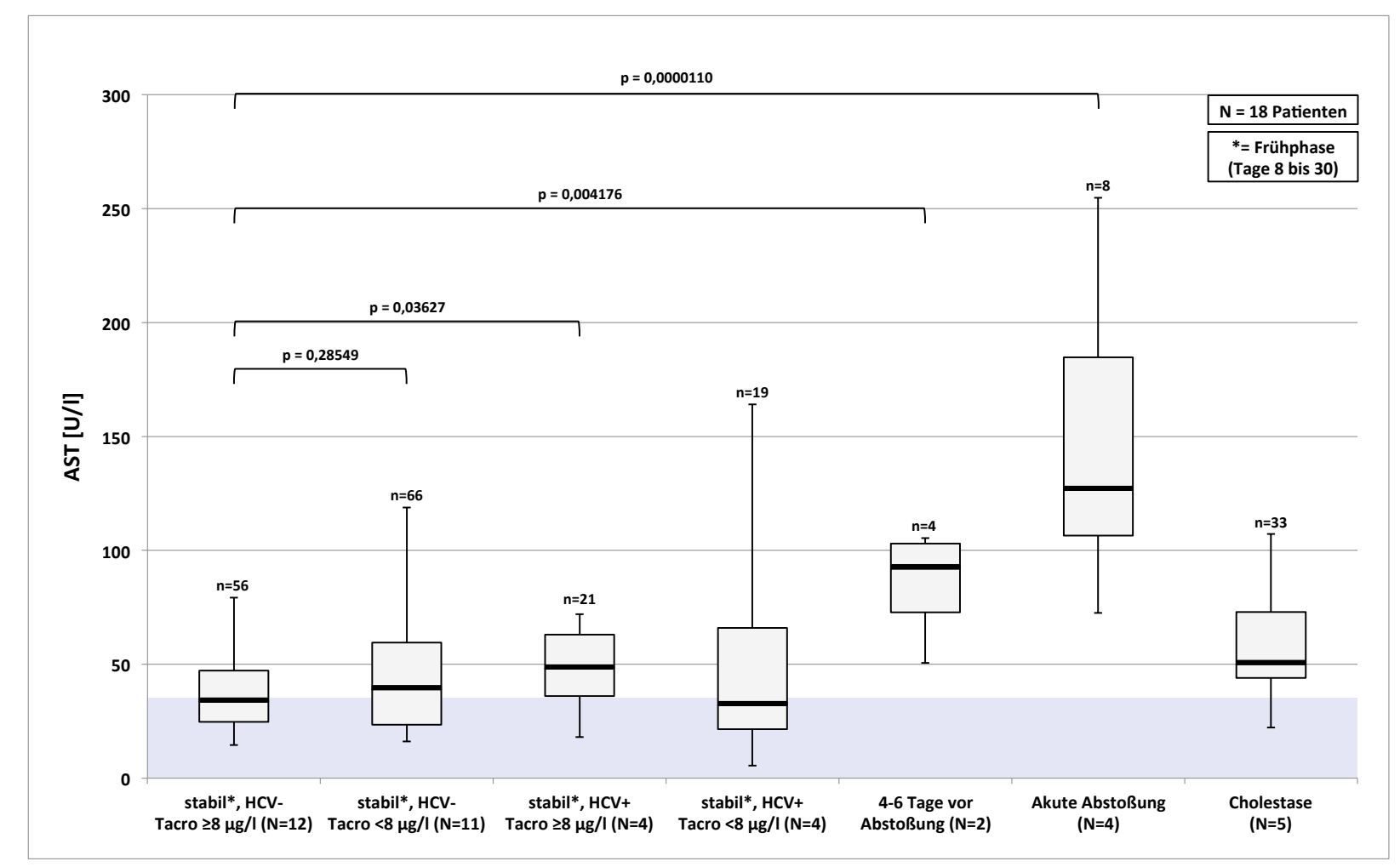

Abbildung 4.12: Aspartat-Aminotransferase-(AST)-Aktivität im Plasma in Abhängigkeit von Tacrolimus-Spiegeln und Hepatitis-C-Status sowie bei Events (Abstoßungen und Cholestasen), $\mathrm{N}=18$ Patienten, Subgruppe $(\mathrm{n}=207)$

Ein direkter Vergleich der 207 GcfDNA-AST-Wertepaare zwischen den Tagen 8 und 30 zeigt eine signifikante Korrelation $(\mathrm{p}<0,01)$ dieser beiden Parameter. Folglich gehen hohe AST-Werte, wie in Abbildung 4.13 dargestellt, mit erhöhten GcfDNA-Werten einher und umgekehrt. 


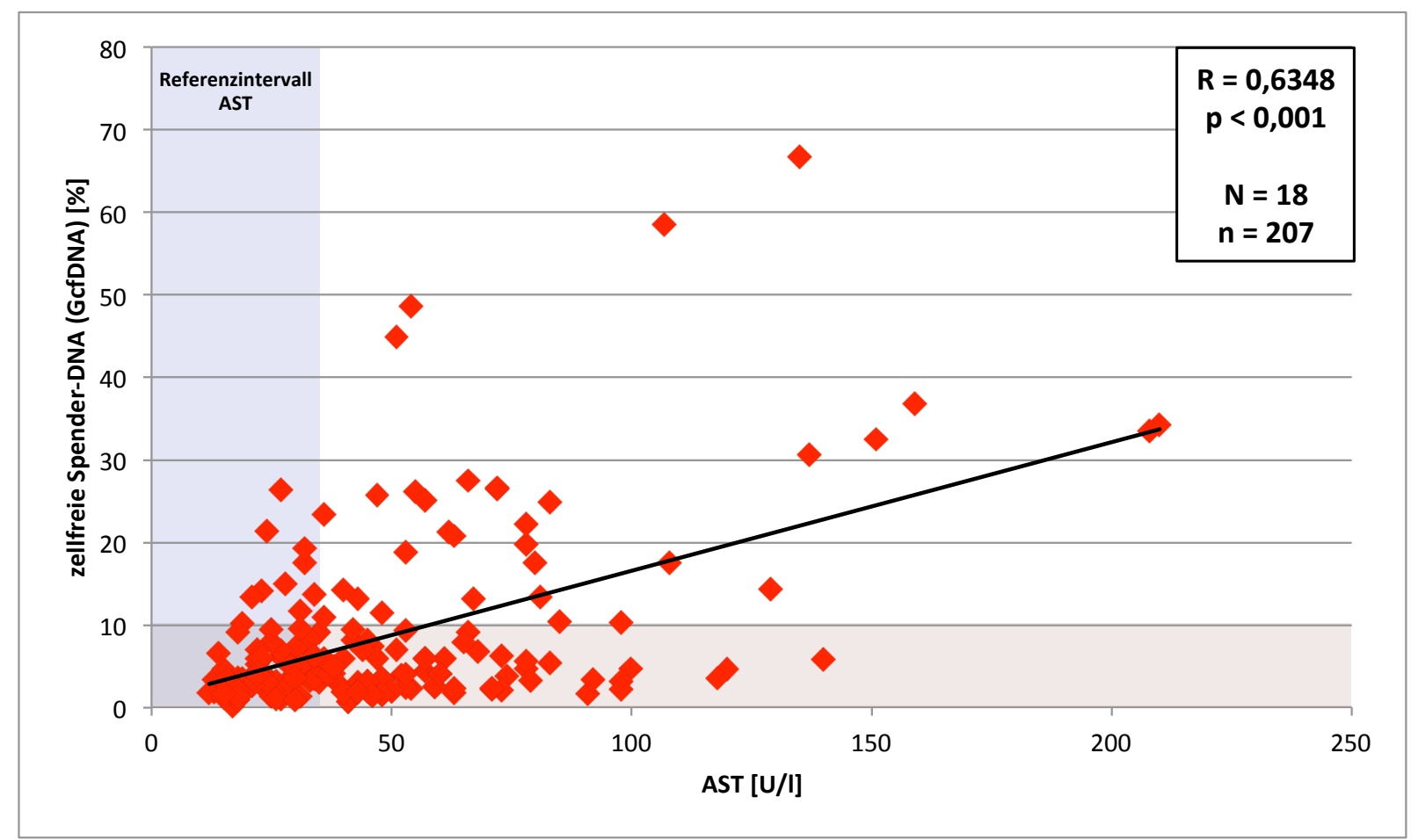

Abbildung 4.13: Signifikante Korrelation von GcfDNA- und Aspartat-Aminotransferase(AST)-Aktivität im Plasma zwischen den Tagen 8 und 30, $\mathrm{N}=18$ Patienten, Subgruppe $(\mathrm{n}=207)$

Bei der Bewertung der GGT ergeben sich ähnliche Resultate wie für die AST (Abbildung 4.14). Bei Unter-Immunsuppression lässt sich auch hier kein signifikanter Anstieg der GGT beobachten $(\mathrm{p}=0,131)$. Hepatitis-C-Infektionen führen zu einer größeren Streuung der GGT-Aktivität. Akute Abstoßungen und Cholestasen gehen mit signifikant erhöhten GGT-Werten einher. Allerdings liegen fast alle Messwerte innerhalb der beobachteten Frühphase nach Transplantation deutlich über dem für die GGT definierten Referenzbereich von 9-36 U/1 bei gesunden Frauen bzw. 12-64 U/1 bei gesunden Männern (Abbott 2012). Bei Tacrolimus-Spiegeln von $\geq 8 \mu \mathrm{g} / 1$ liegen beispielsweise nur 7,1\% der gemessenen GGT-Werte von Transplantatempfängern ohne Hepatitis-C-Infektion innerhalb dieses Referenzbereichs. Bei unzureichender Immunsuppression (Tacrolimus-Spiegel $<8 \mu \mathrm{g} / \mathrm{l}$ ) sind es nur noch 1,5\%. 


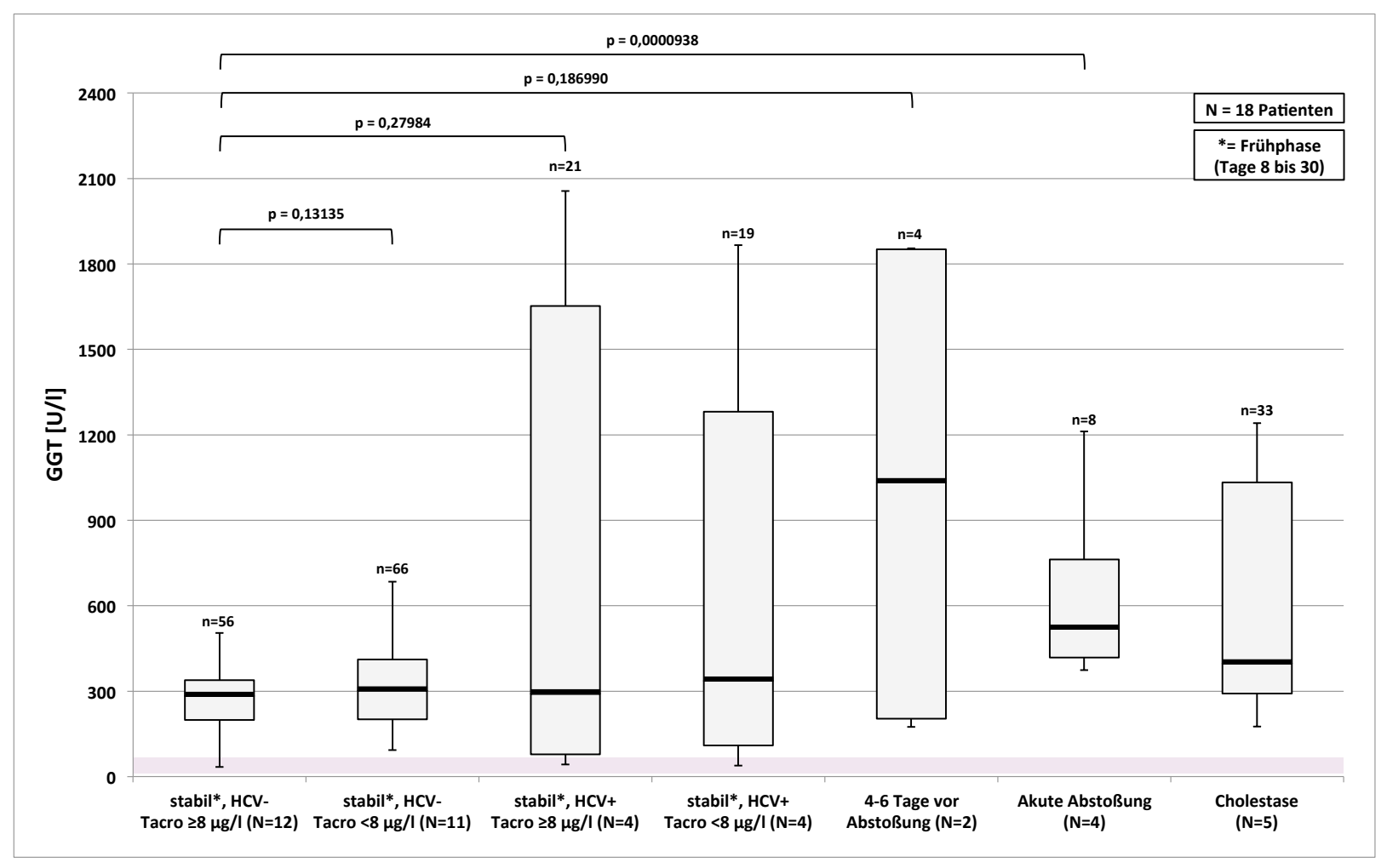

Abbildung 4.14: $\gamma$-Glutamyl-Transferase-(GGT)-Aktivität im Plasma in Abhängigkeit von Tacrolimus-Spiegeln und Hepatitis-C-Status sowie bei Events (Abstoßungen und Cholestasen), $\mathrm{N}=18$ Patienten, Subgruppe $(\mathrm{n}=207)$

Bilirubin ist ein weiterer konventioneller Marker für Erkrankungen der Leber. Der Gesamtbilirubin-Wert im Plasma sollte maximal 1,2 mg/dl betragen (Abbott 2010b). Bei Betrachtung der Gruppeneinteilung aus den vorherigen Vergleichen fällt auf, dass hier eine Unter-Immunsuppression zu signifikant erhöhten Werten führt $(\mathrm{p}=0,035)$. Bei TacrolimusSpiegeln von $\geq 8 \mu \mathrm{g} / \mathrm{l}$ liegen nur 44,6\% der gemessenen Bilirubin-Konzentrationen innerhalb des Referenzbereiches. Bei unzureichender Immunsuppression (Tacrolimus-Spiegel $<8$ g/l) sind es nur noch 21,2\%. Im Vergleich mit der Hepatitis-C-Gruppe fällt kein signifikanter Unterschied auf $(\mathrm{p}=0,482)$. Bei Cholestasen sind ebenfalls angestiegene Bilirubin-Konzentrationen messbar. Dafür ist kein signifikanter Anstieg bei akuten Abstoßungen zu beobachten. Dies ist in Abbildung 4.15 dargestellt. 


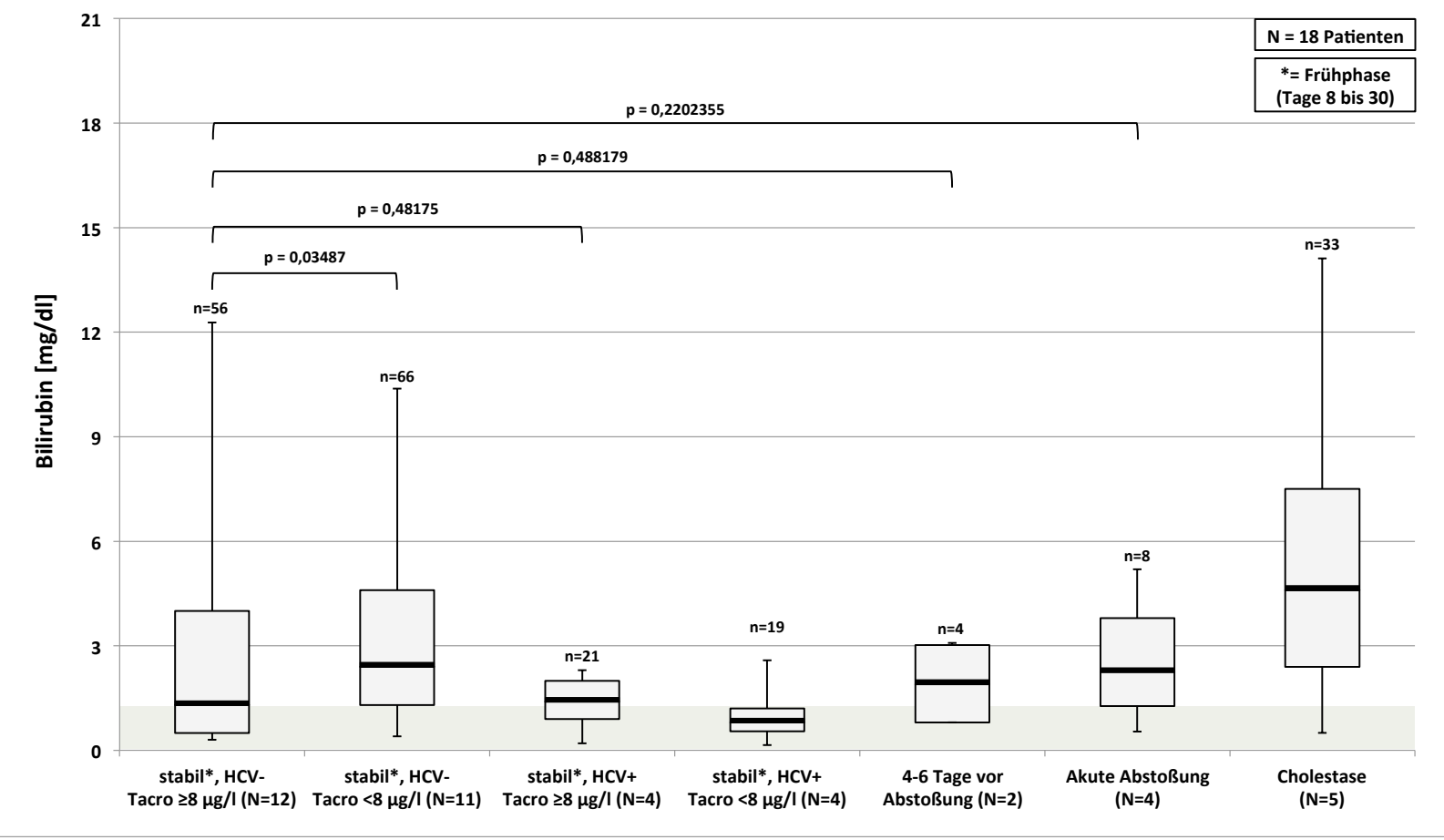

Abbildung 4.15: Bilirubin-Konzentration im Plasma in Abhängigkeit von TacrolimusSpiegeln und Hepatitis-C-Status sowie bei Events (Abstoßungen und Cholestasen), $\mathrm{N}=18$ Patienten, Subgruppe $(\mathrm{n}=207)$

\subsection{Vorstellung der Einzelverläufe}

Zur Komplettierung der statistischen Auswertung sind in diesem Kapitel die einzelnen Patientenfälle mit klinischen Verläufen sowie die Verläufe der GcfDNA und der Routinelaborparameter vorgestellt. Der Beobachtungszeitraum betrug in Anlehnung an die BMBF-Studie (siehe Kapitel 3.1.2) bis zu 365 Tage. Für eine einheitliche Darstellung ist eine Zeitskalierung von 12 bzw. 6 Monaten verwendet worden. Eine Auflistung der Patienten mit ihren demographischen Daten ist der Tabelle $4.1 \mathrm{zu}$ entnehmen.

\subsubsection{Verläufe ohne erkennbare Schädigung des Transplantates}

Ein Beispiel für einen komplikationslosen Verlauf ist LTx4 (Abbildung 4.16). Bei LTx4 handelt es sich um eine 52-jährige weibliche Patientin mit einer zystischen Lebererkrankung (PCLD). Das Spenderorgan stammte von einem 22-jährigen männlichen Spender mit positivem IgG-Antikörpernachweis des Zytomegalievirus (CMV). 


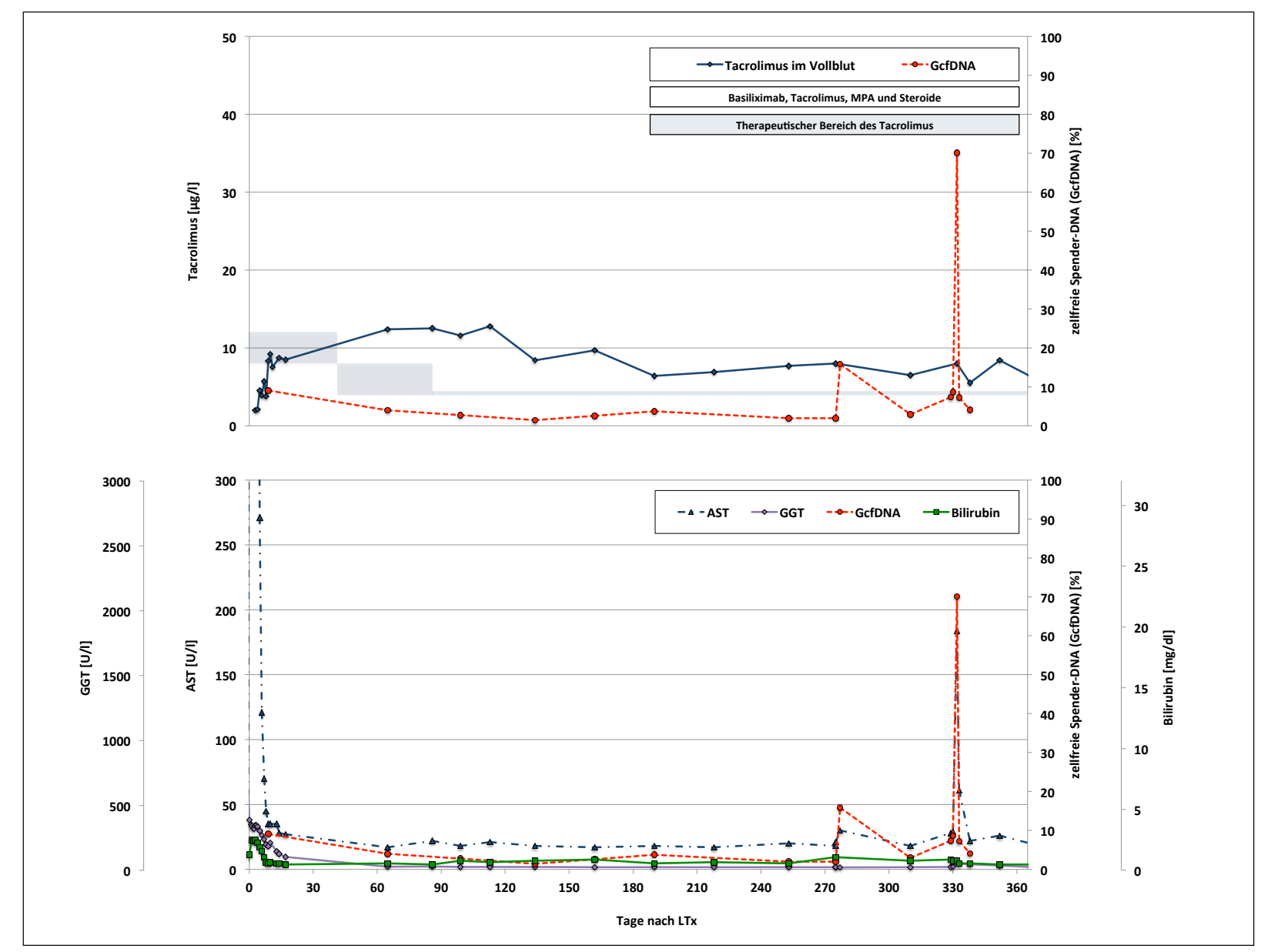

Abbildung 4.16: GcfDNA, Aspartat-Aminotransferase-(AST)-, $\quad \gamma$-Glutamyl-Transferase(GGT)-Aktivität sowie Bilirubin-Konzentration bei Verlauf ohne erkennbare Schädigung des Transplantates (LTx4)

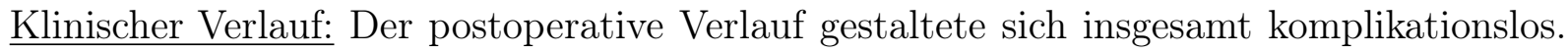
Während des gesamten stationären Aufenthaltes ließen sich in den serologischen Untersuchungen keine Anhalte für eine CMV-Aktivierung/-Reaktivierung finden. Im Spätverlauf entwickelte sich allerdings eine kleine Narbenhernie. Am Tag 331 erfolgte eine Narbenherniotomie. Postoperativ wurde die Medikation mit MMF pausiert, so dass die Immunsuppression ausschließlich mit Tacrolimus fortgeführt wurde. Verlauf der GcfDNA und der Routinelaborparameter: Bereits kurze Zeit nach der Organtransplantation ( $<14$ Tage) waren die GcfDNAWerte unter den Grenzwert von 10\% abgefallen. Im weiteren Verlauf blieben diese auch stabil. Die Konzentration der Immunsuppressiva im Vollblut war zu allen Zeiten suffizient, d. h. im Bereich oder oberhalb der angestrebten Zielspiegel. Die Narbenherniotomie am Tag 331 war mit einem kurzzeitigen Anstieg der GcfDNA verbunden, der aber sofort wieder auf Werte unter $10 \%$ abgefallen ist (siehe Abbildung 4.16). 
Der männliche Patient LTx13 (Abbildung 4.17) war zum Zeitpunkt der Transplantation 62 Jahre alt. Er hatte 7,5 Jahre zuvor bereits eine Lebertransplantation in Form einer Leberlebendspende erhalten. Die Leberzirrhose hatte sich damals bedingt durch eine Hepatitis B und D entwickelt. Nach anfänglich unauffälligem Verlauf entwickelte der Patient zunehmend ein chronisches Leberversagen. Es wurde eine chronische Abstoßung im Sinne eines Vanishing Bile Duct Syndroms (VBDS) mit histologischer Bestätigung diagnostiziert. Daraufhin folgte die Listung zur Re-Transplantation. In der Zeit vor der Re-Transplantation kam es zu einer zunehmenden Verschlechterung des Allgemeinzustandes sowie Multiorganversagen mit der Notwendigkeit zur intermitierenden Dialyse. Nach Restabilisierung des Patienten und letztendlich fortbestehendem Leberversagen erfolgte die Re-Transplantation. Die Spenderleber stammte von einer 77-jährigen weiblichen Spenderin mit unauffälliger Virologie.

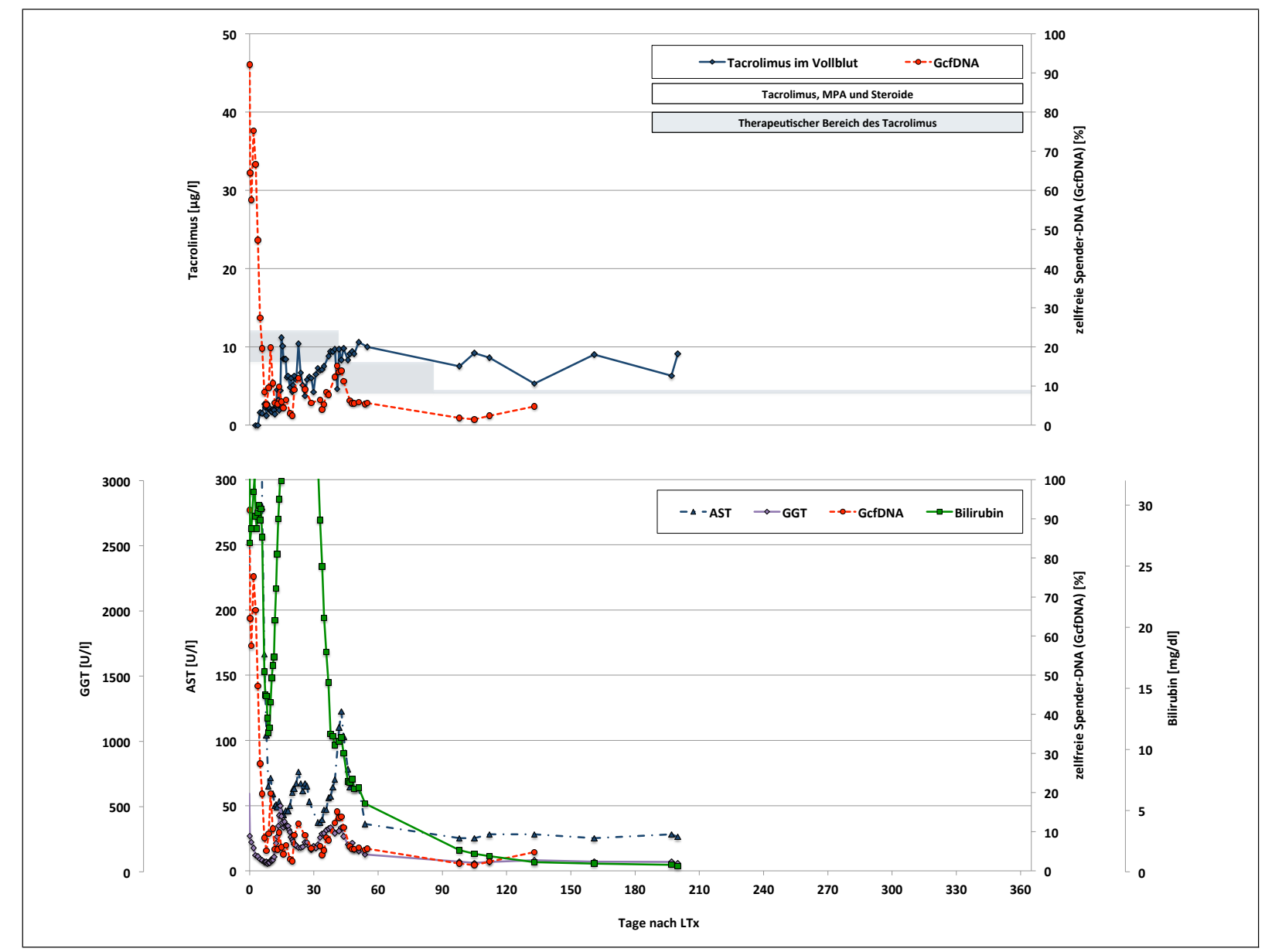

Abbildung 4.17: GcfDNA, Aspartat-Aminotransferase-(AST)-, $\quad \gamma$-Glutamyl-Transferase(GGT)-Aktivität sowie Bilirubin-Konzentration bei Verlauf ohne erkennbare Schädigung des Transplantates (LTx13) 
Klinischer Verlauf: Abweichend vom in Göttingen üblichen Schema der immunsuppressiven Therapie (siehe Kapitel 3.1.3) erhielt der Patient intraoperativ kein Basiliximab. Der postoperative Verlauf gestaltete sich in der Anfangsphase kompliziert: Die Intervalldialysen mussten auch nach Transplantation zunächst fortgesetzt werden. Vom Tag 6 bis Tag 9 war der Patient an ein extrakorporales Leberersatzverfahren, MARS-Therapie, angeschlossen. Nach Beendigung der Therapie stieg der Gesamtbilirubin-Spiegel erneut stark an. Auch in den nächsten Tagen besserten sich die Lebersynthesewerte zunächst nicht wesentlich. Eine Transplantatleberbiopsie erbrachte den Befund einer degenerativen Cholangiopathie mit beginnendem Gangschwund und Anzeichen für eine frühe chronische, zur Duktopenie führende Abstoßungsreaktion. Die anfängliche Hyperbilirubinämie blieb letztendlich weiterhin unklar, ab Tag 31 fielen die Billirubinwerte aber ab. Bei CMV-Reaktivierung erfolgte ab Tag 8 eine Therapie mit Valganciclovir. Aufgrund einer progredienten Panzytopenie wurde die Therapie mit MMF ab dem 4. postoperativen Tag zunächst unterbrochen. Unter der auch klinisch manifesten CMV-lnfektion wurde die Tacrolimus-Therapie ebenfalls zwischen Tag 8 und 12 unterbrochen. Der weitere postoperative Verlauf blieb dann komplikationslos. Verlauf der GcfDNA und der Routinelaborparameter: Die GcfDNA-Werte fielen zunächst auf unter $10 \%$ ab (innerhalb von 7 Tagen). Innerhalb der ersten 50 Tage nach Transplantation waren allerdings auch Werte von bis zu 20\% zu beobachten. Zu diesen Zeitpunkten war die Immunsuppression im subtherapeutischen Bereich (siehe Abbildung 4.17). Parallel war auch ein Anstieg der AST zu beobachten. Mit Erreichen stabiler Tacrolimus-Spiegel zeigte sich fortan auch ein stabiler Verlauf der GcfDNA und der anderen Laborparameter.

Bei LTx15 (Abbildung 4.18) handelt es sich um den ehemaligen Patienten LTx2. 10 Monate nach der letzten Lebertransplantation erfolgte nun eine Re-Re-Transplantation. In der Zwischenzeit war es erneut zur sekundärsklerosierenden Cholangiopathie und chronischen Funktionsverschlechterung des Lebertransplantates gekommen. Die Ätiologie der sekundärsklerosierenden Cholangiopathie blieb letztendlich unklar. Differenzialdiagnostisch muss eine chronische, bereits vor der 1. Transplantation bestehende Stenose im Truncus coeliacus berücksichtigt werden. Diese wurde jedoch in der 2. Transplantation eröffnet und gestentet. Gleichzeitig besteht in der Angiographie ein retrograder Fluss der Arteria hepatica in den Truncus coeliacus. Als Differenzialdiagnose ist jedoch auch eine Ischemic Type Biliary Lesion (ITBL) nach Lebertransplantation denkbar, da der Fluss in der Leberarterie über die 
Arteria gastroduodenalis sehr gut war, wie in einer Mesentericographie gezeigt wurde. Das Organ der Re-Re-Transplantation stammte von einer 58-jährigen weiblichen Spenderin mit unauffälliger Virologie.

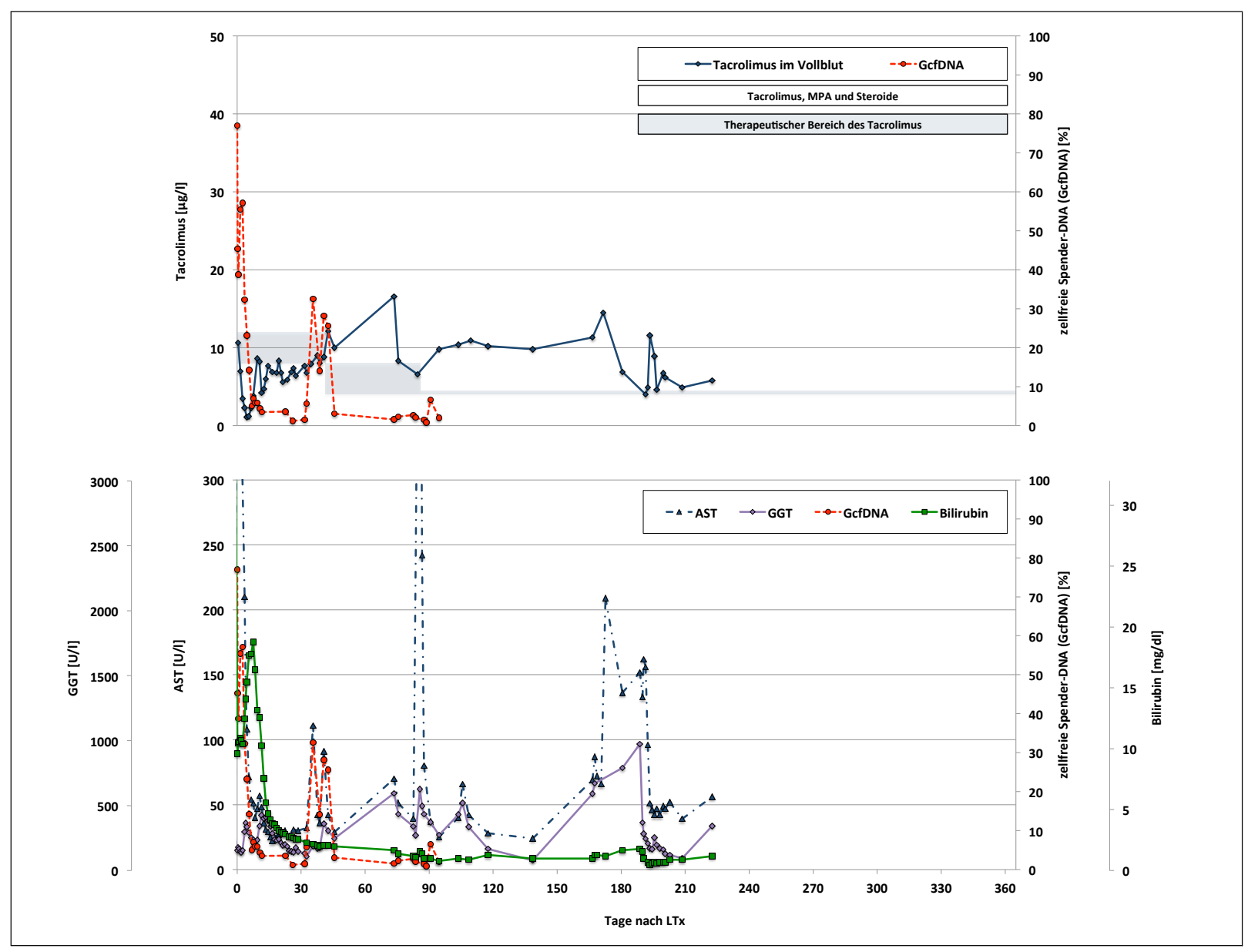

Abbildung 4.18: GcfDNA, Aspartat-Aminotransferase-(AST)-, $\quad \gamma$-Glutamyl-Transferase(GGT)-Aktivität sowie Bilirubin-Konzentration bei Verlauf ohne erkennbare Schädigung des Transplantates (LTx15)

Klinischer Verlauf: Abweichend vom üblichen Schema der immunsuppressiven Therapie (siehe Kapitel 3.1.3) erhielt der Patient intraoperativ kein Basiliximab. Der postoperative Verlauf gestaltete sich trotz stabiler Transplantatfunktion zunächst kompliziert. Es kam zu einer Pankreatitis, die antibiotisch behandelt wurde. Am Tag 14 wurde operativ ein gekammertes Serom/Biliom ausgeräumt. Ebenfalls zeigten sich positive CMV-Titer, weshalb eine Behandlung mit Valganciclovir begonnen wurde. Hinzu kam eine Knochenmarksdepression, die am ehesten medikamentös-toxisch (Valganciclovir, MMF) bedingt war. Die Immunsuppression des Patienten erfolgte unmittelbar postoperativ mit Prednisolon. Bei rekompensierter Nierenfunktion wurde die Medikation um Tacrolimus erweitert. Im weiteren Verlauf konn- 
te das Prednisolon deutlich reduziert werden. Ein Auslassversuch des Prednisolons musste aufgrund konsekutiv ansteigender Transaminasen und Cholestaseparameter zunächst abgebrochen werden. Später wurde MMF aufgrund einer Leukopenie pausiert. Eine Biopsie des Lebertransplantates am Tag 15 zeigte chronische sowie teilweise auch akute Entzündungen im Bereich der Portalfelder und deutete auf eine aufsteigende Cholangitis hin. Am Tag 84 zeigte sich durch endoskopische retrograde Cholangiopankreatikographie (ERCP) eine Anastomosenstenose im Ductus hepaticus communis (DHC). Eine Dilatation der Stenose wurde vorgenommen und der während der OP eingebrachte Stent entfernt. Am Tag 105 erfolgte abermals eine ERCP, bei der sich wieder eine DHC-Anastomosenstenose zeigte. Außerdem bot sich das Bild einer ischämischen Cholangiopathie. Casts wurde entfernt und erneut ein Stent eingelegt. Der nächste Stentwechsel erfolgte zusammen mit der Entfernung von geringgradigem Sludge am Tag 168 im Rahmen einer ERCP. Am 190. Tag erfolgte eine elektive Anlage einer biliodigestiven Anastomose. Dadurch sollten die rezidivierenden Cholangitiden und rezidivierend erforderlichen ERCPs mit Stenteinlagen aufgrund der bekannten Anastomosenstenose im Bereich der Gallengangsanastomose zukünftig verhindert werden. Der Eingriff musste jedoch ohne die geplante Anlage der biliodigestiven Anastomose abgebrochen werden. Eine beginnende Cholangitis wurde durch Antibiose mit Ciprofloxacin und Meropenem therapiert. Die Immunsuppression wurde im weiteren Verlauf von Prograf ${ }^{\circledR}$ auf Advagraf ${ }^{\circledR}$ umgestellt. Verlauf der GcfDNA und der Routinelaborparameter: Die initialen GcfDNA-Messwerte lagen innerhalb der ersten Woche unter der 10\%-Grenze, stiegen aber zwischen den Tagen 30 und 50, parallel zu einem Anstieg der AST, nochmals an (siehe Abbildung 4.18). Die AST und GGT stiegen bis zur ERCP am Tag 84 deutlich an, während die GcfDNA unter 10\% blieb. In Folge der ERCP besserten sich die Laborparameter im Verlauf zunehmend, insbesondere nach erneuter ERCP am Tag 105 waren die Transaminasen und Cholestaseparameter weiter rückläufig. In den folgenden Wochen stiegen AST, GGT und Bilirubin wieder an.

Der männliche Patient LTx16 (Abbildung 4.19) war zum Zeitpunkt der Transplantation 69 Jahre alt. Eine Leberzirrhose mit Leberzellkarzinom (HCC, engl. hepatocellular carcinoma) nach mehrfachen TACE-Sitzungen (Transarterielle Chemoembolisation) und bekannter Hepatitis-B-Infektion stellten die Indikation für die Transplantation. Die Spenderleber 
stammte von einer 60-jährigen weiblichen Spenderin mit positivem CMV-IgG-Titer.

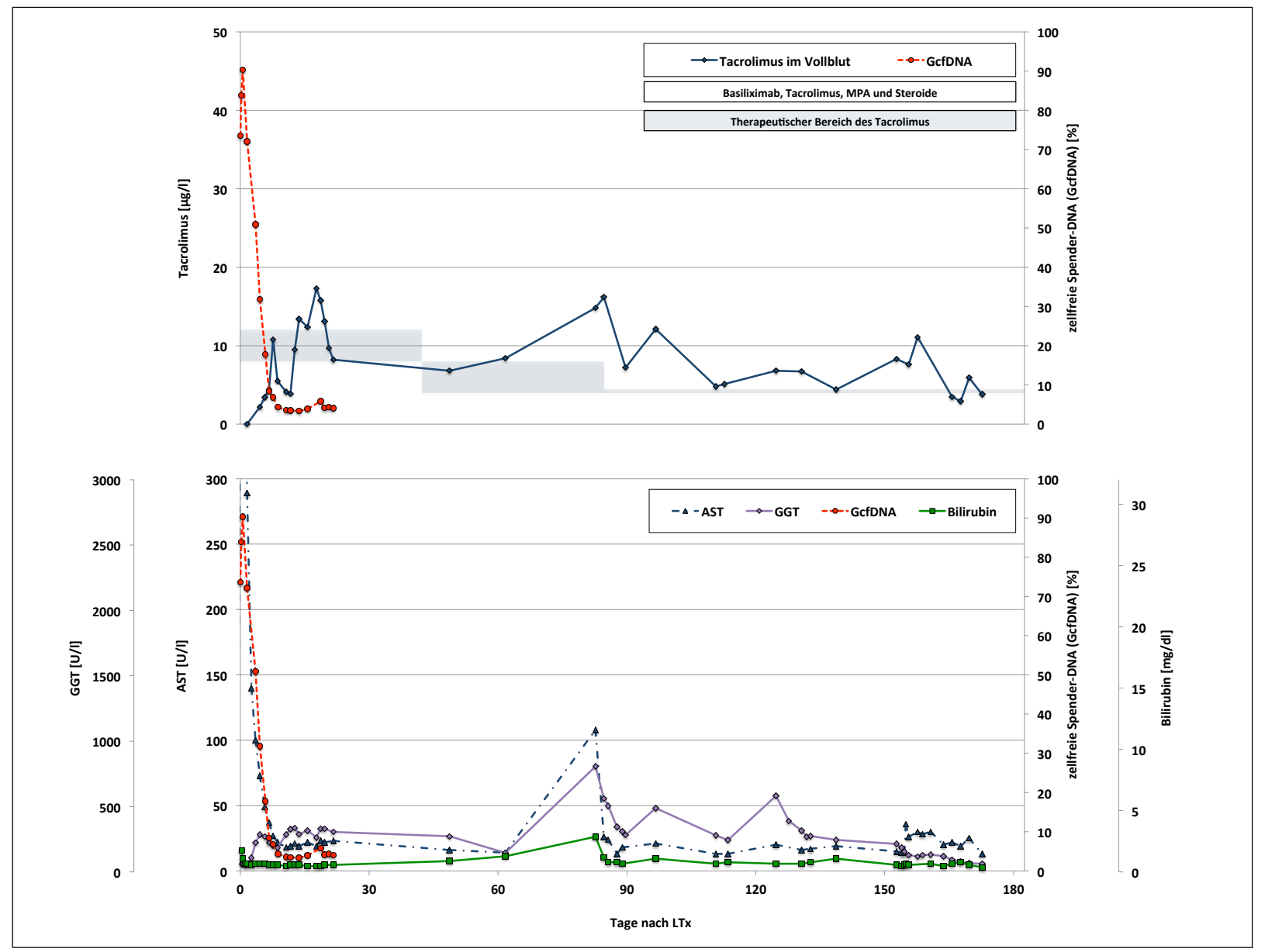

Abbildung 4.19: GcfDNA, Aspartat-Aminotransferase-(AST)-, $\quad \gamma$-Glutamyl-Transferase(GGT)-Aktivität sowie Bilirubin-Konzentration bei Verlauf ohne erkennbare Schädigung des Transplantates (LTx16)

Klinischer Verlauf: Der postoperative Verlauf gestaltete sich aus chirurgischer Sicht problemlos. Zwischenzeitlich zeigte sich laborchemisch eine Infektkonstellation, die unter Antibiose mit Tazobac rückläufig war. Am Tag 84 wurde aufgrund des Verdachts auf eine Anastomosenleckage eine ERCP durchgeführt und wegen erhöhtem C-reaktiven Protein (CRP) und subfebrilen Temperaturen eine antibiotische Therpie mit Meropenem begonnen. Der Patient wurde dabei mit einem Stent versorgt, durch den spontan Galle abfloss. Mikrobiologisch ließen sich im Punktat der Galle pathogene Keime nachweisen, die laut Antibiogramm jedoch sensibel auf die bereits begonnene Antibiose waren. Im weiteren Verlauf kam es zu einer CMV-Reaktivierung und daraus resultierender Valganciclovir-Therapie. Unter erneuter antibiotischer Therapie mit Meropenem besserte sich der Zustand des Patienten mit fallenden Entzündungswerten. Verlauf der GcfDNA und der Routinelaborparameter: Bei dem Patien- 
ten war die GcfDNA innerhalb von 7 Tagen auf Werte unter $10 \%$ abgefallen. Im weiteren Verlauf stiegen AST, GGT und Bilirubin deutlich an und waren in Folge der ERCP am Tag 84 wieder rückläufig Insbesondere die GGT blieb auf einem deutlich erhöhten Niveau (siehe Abbildung 4.19).

Auch LTx21 (Abbildung 4.20) zeigte eine stabile Organfunktion nach der Transplantation. Bei der Patientin handelt es sich um eine 54-jährige weibliche Patientin mit ausgeprägter äthyltoxischer Leberzirrhose und therapieresistenter Aszites. Das Organ stammte von einer 49-jährigen Spenderin mit positiven HbsAg-, HbcAb- und CMV-IgG-Titern.

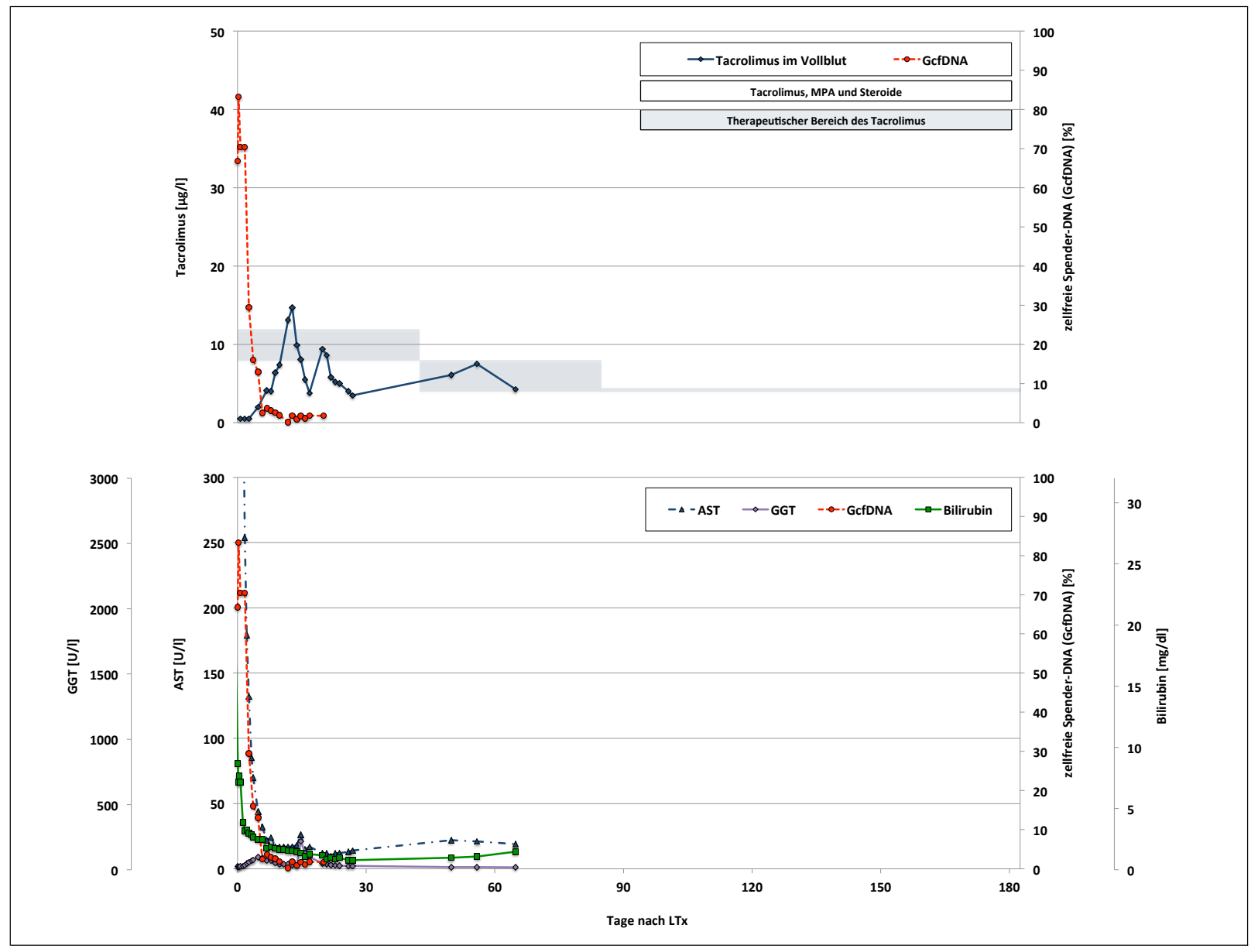

Abbildung 4.20: GcfDNA, Aspartat-Aminotransferase-(AST)-, $\quad \gamma$-Glutamyl-Transferase(GGT)-Aktivität sowie Bilirubin-Konzentration bei Verlauf ohne erkennbare Schädigung des Transplantates (LTx21)

Klinischer Verlauf: Abweichend vom üblichen Schema der immunsuppressiven Therapie (siehe Kapitel 3.1.3) erhielt die Patientin intraoperativ kein Basiliximab. Der postoperative Verlauf war bis zum aktuellen Zeitpunkt komplikationslos. Verlauf der GcfDNA und der Rou- 
tinelaborparameter: Die Werte der GcfDNA lagen innerhalb einer Woche unter 10\%. Auch die anderen Parameter (AST, GGT und Bilirubin) normalisierten sich nach der Transplantation schnell (siehe Abbildung 4.20).

\subsubsection{Patienten mit Cholestasen}

Beim Patienten LTx1 (Abbildung 4.21) trat mehrere Monate nach Transplantation eine intrahepatische Cholestase auf. Bei LTx1 handelt es sich um einen zum Zeitpunkt der Transplantation 49-jährigen männlichen Patienten mit ausgeprägter Leberzirrhose bei Hepatitis C (Genotyp 3a). Die Spenderleber stammte von einem 61-jährigen männlichen Spender mit unauffälligem virologischen Befund.

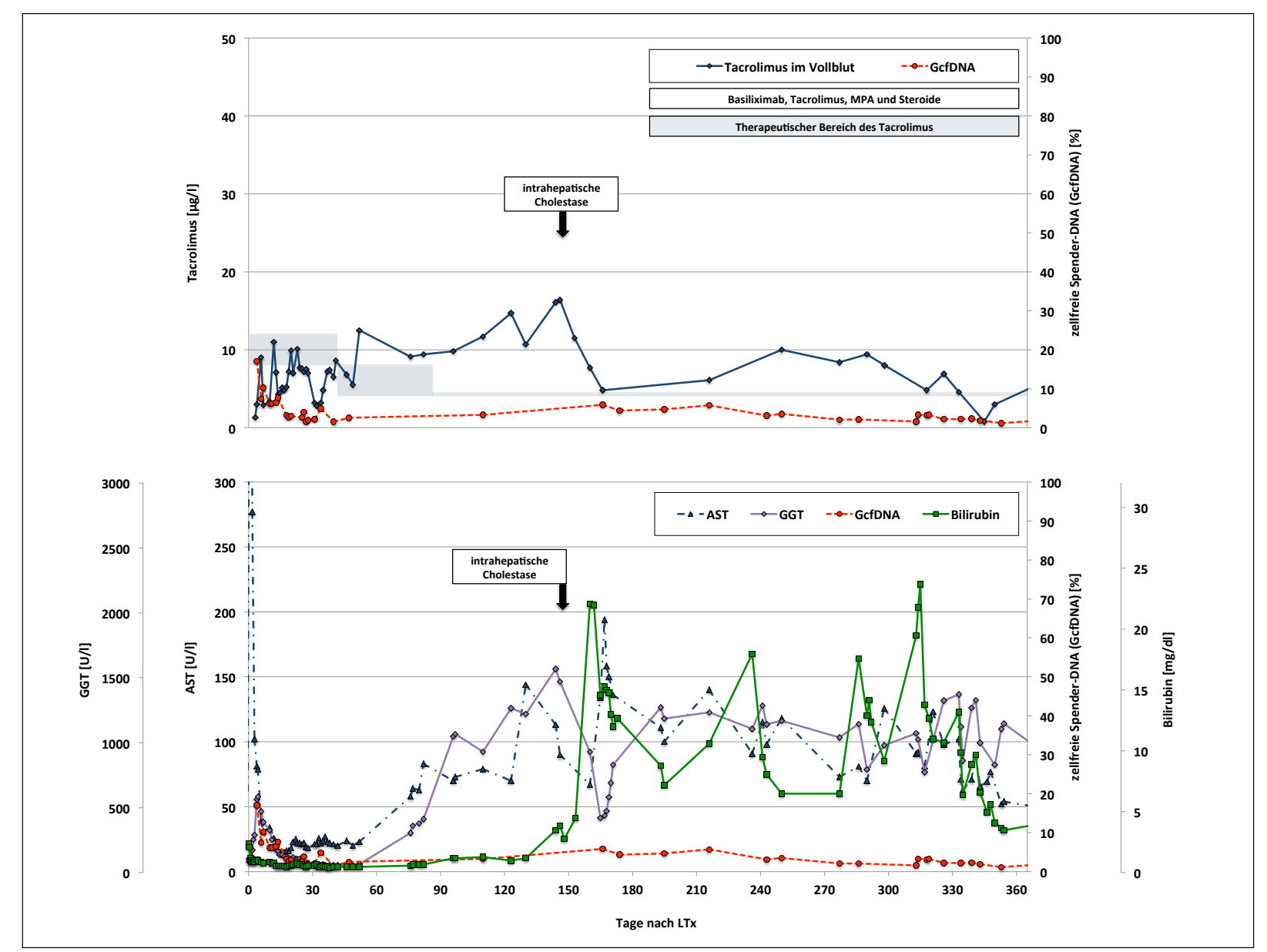

Abbildung 4.21: GcfDNA, Aspartat-Aminotransferase-(AST)-, $\quad \gamma$-Glutamyl-Transferase(GGT)-Aktivität sowie Bilirubin-Konzentration bei Verlauf mit Cholestase (LTx1) 
Klinischer Verlauf: Aus chirurgischer Sicht war der postoperative Verlauf unproblematisch. In den wiederholt durchgeführten laborchemischen und serologischen Untersuchungen zeigte sich zu keinem Zeitpunkt der Verdacht eines akuten Abstoßungsgeschehens bzw. einer Virusinfektion mit Viren der Herpesgruppe. Insbesondere konnte kein Nachweis einer CMVAktivierung gefunden werden. Wegen einer Leukopenie wurde die Therapie mit MPA zwischen den Tagen 20 und 25 pausiert. Aufgrund mäßig erhöhter Bilirubin-Werte mit erhöhter Alkalischer Phosphatase (AP) und GGT wurde am Tag 147 eine ERCP durchgeführt. Dabei zeigte sich ein deutlicher Kaliberunterschied der Arteria hepatica communis zwischen Spender und Empfänger. Nach der Durchführung einer endoskopischen Papillotomie (EPT) war das Bilirubin rückläufig. Eine CT-Untersuchung vom Abdomen/Becken zeigte eine fehlende arterielle Perfusion der Transplantatleber bei Kontrastmittelabbruch in der Arteria hepatica propria. Aufgrund der fehlenden arteriellen Perfusion der Transplantleber wäre prinzipiell eine Re-Transplantation erforderlich gewesen, angesichts des guten Allgemeinzustands des Patienten wurde davon aber abgesehen. Am Tag 164 erfolgte eine ERCP und Einlage einer nasobiliären Sonde. An Tag 196 zeigte sich abdomensonographisch eine Hepatomegalie, Splenomegalie, intrahepatische Cholestase in beiden Leberlappen sowie eine Pankreasgangerweiterung. Im Rahmen einer ERCP erfolgte an Tag 238 ein Stentwechsel. In der ERCP am Tag 287 zeigte sich erneut die bekannte Anastomosenenge im DHC, die jedoch mit Katheter passierbar war. Es erfolgte ein komplikationsloser Stentwechsel. Im CT-Abdomen zeigte sich am Tag 291 eine im Vergleich zur Voraufnahme fortschreitende intrahepatische Cholestase. Aufgrund der niedrigen Leukozytenzahlen wurde Tacrolimus kurzzeitig pausiert. Zum Beheben der Cholestase wurde zunächst eine nasobiliäre Sonde (Tag 341) eingelegt, die erfolgreich Galle förderte. Im Verlauf wurde die nasobiliäre Sonde durch Einlage eines Pigtail-Katheters (Tag 347) ersetzt. Eine Re-Evaluation des Patienten zur erneuten Transplantationslistung wurde durchgeführt. Zum Ende des Beobachtungszeitraums ist der Patient aufgrund der eingeschränkten arteriellen Perfusion der Transplantatleber erneut für eine Transplantation gelistet. Verlauf der GcfDNA und der Routinelaborparameter: Während des gesamten Beobachtungszeitraum blieb die GcfDNA, nach initialem Abfall, stabil unter der 10\%-Grenze, die sie bereits innerhalb einer Woche erreicht und während des gesamten Beobachtungszeitraums nicht mehr überschritten hat (siehe Abbildung 4.21). Bei der ERCP am Tag 164 zeigten die Laborwerte eine ausgeprägte Cholestase: Es war ein deutlicher Anstieg der AST, gefolgt von der GGT und schließlich des Bilirubin, zu beobachten. In Folge der ERCP fielen 
die Werte wieder ab, blieben aber nach wie vor auf erhöhtem Niveau. Auch der Stentwechsel am Tag 238 zeigte nur eine kurzzeitige Auswirkung auf die Laborwerte. Erst unter der nasobiliären Sonde (eingelegt am Tag 341) sowie des Pigtail-Katheters (Tag 347) besserten sich die AST-, GGT- und Bilirubin-Werte deutlich.

Patient LTx14 (Abbildung 4.22) war ein 58-jähriger männlicher Patient mit äthyltoxischer Leberzirrhose und mehrfacher hepatischer Enzephalopathie mit der Notwendigkeit der stationären Behandlung. Das Organangebot stammte von einem 54-jährigen männlichen Spender mit positivem CMV-IgG-Titer.

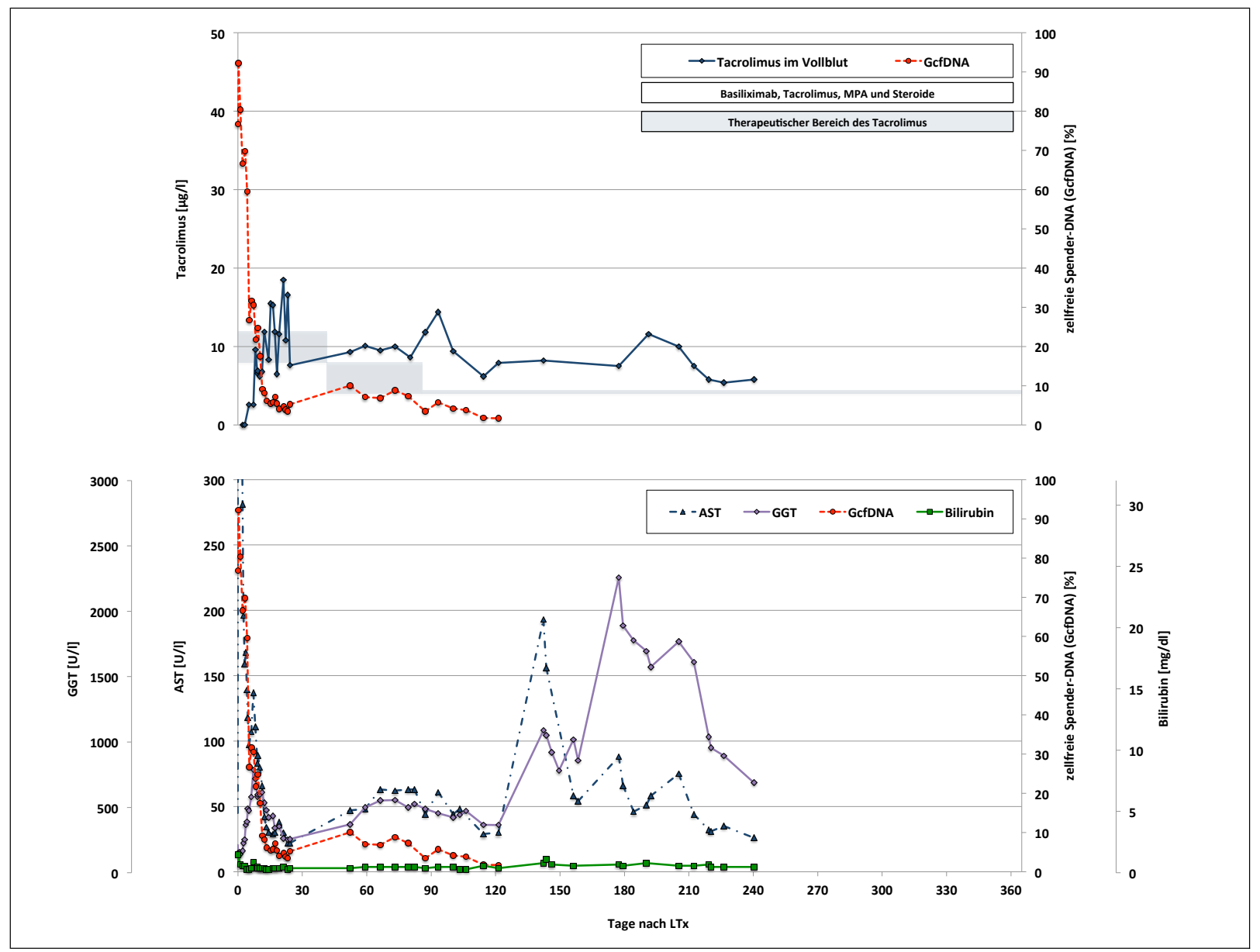

Abbildung 4.22: GcfDNA, Aspartat-Aminotransferase-(AST)-, $\quad \gamma$-Glutamyl-Transferase(GGT)-Aktivität sowie Bilirubin-Konzentration bei Verlauf mit Cholestase (LTx14)

Klinischer Verlauf: Postoperativ wurden wiederholt serologische Untersuchungen auf Reaktivierungen von möglichen Herpesviren, EBV, CMV, Varizella-Zoster-Virus (VZV), Herpessimplex-Viren (HSV), durchgeführt. Diese waren jedoch allzeit negativ. An Tag 81 erfolgte 
eine ERCP. Hier wurde eine EPT sowie die komplikationslose Stententfernung durchgeführt. Bei erneuter ERCP am Tag 103 zeigte sich eine deutliche Kaliberschwankung im Bereich der DHC-Anastomose. Aus diesem Grunde wurde eine Ballondilatation durchgeführt. Am Tag 149 erfolgte eine Stenteinlage bei erneuter ERCP. In einer Biopsie vom Tag 185 zeigte sich der pathologische Befund einer geringen späten akuten Abstoßung. Bei erneuter ERCP am Tag 192 zeigte sich die bekannte Anastomosenstenose bei regelrechter Stentlage, ein Stentwechsel erfolgte nicht. Verlauf der GcfDNA und der Routinelaborparameter: Die GcfDNA erreichte nach 12 Tagen Werte unter 10\% und hat diese Grenze seither nicht mehr überschritten. Allerdings wurde die GcfDNA nur bis zum Tag 122 bestimmt. Im weiteren Verlauf zeigten sich erhöhte Transaminasen und Cholestaseparameter. Später kam es zu stark erhöhten AST-Werten und Anstieg der GGT auf Konzentrationen von über 2200 U/1 (siehe Abbildung 4.22).

\subsubsection{Patienten mit Transplantatabstoßungen}

Im postoperativen Verlauf von LTx2 (Abbildung 4.23) kam es zu mehreren Abstoßungsreaktionen. Bei diesem Fall handelt es sich um eine Re-Transplantation. Aufgrund des chronischen Versagens des vorherigen Lebertransplantates bei sekundär sklerosierender Cholangiopathie war bei diesem 41-jährigen männlichen Patienten die Indikation zur erneuten Transplantation gegeben. Die erste Transplantation erfolgte 20 Monate zuvor aufgrund einer äthyltoxischen Leberzirrhose. Der Patient wird nach multiplen ERCPs bei chronischem Transplantatversagen zur Re-Transplantation gelistet. Es folgte die Transplantation der Spenderleber eines 57-jährigen männlichen Spenders mit positivem CMV-IgG- und Toxoplasmose-Titer. 


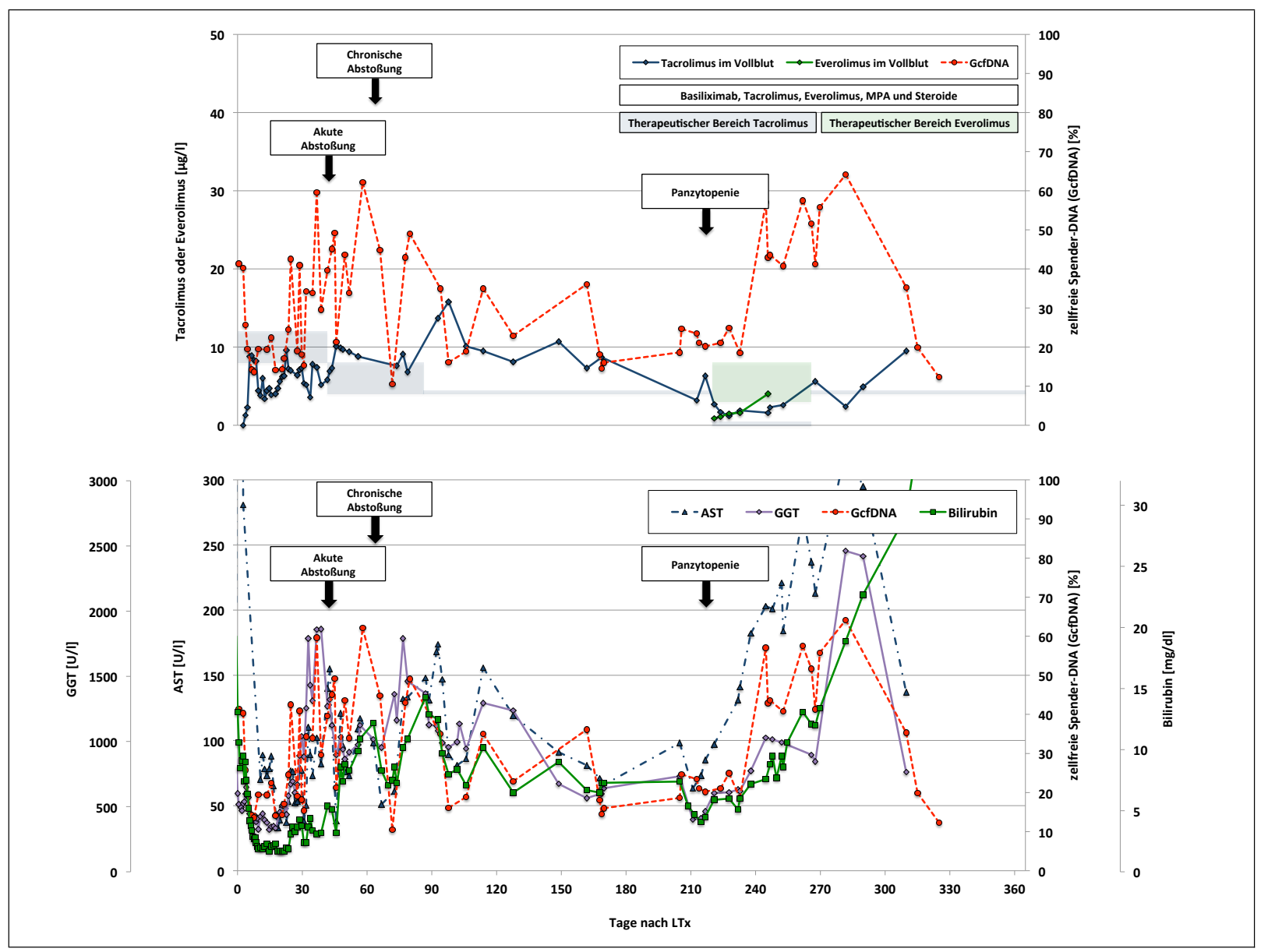

Abbildung 4.23: GcfDNA, Aspartat-Aminotransferase-(AST)-, $\quad \gamma$-Glutamyl-Transferase(GGT)-Aktivität sowie Bilirubin-Konzentration bei Verlauf mit Abstoßung (LTx2)

Klinischer Verlauf: Postoperativ kam es zu einer sekundären Rissverletzung der Spenderleber mit konsekutivem Biliom. Daher erfolgte ein erneuter operativer Eingriff am Tag 17 nach Transplantation. Im weiteren Verlauf war dann ein massiver Transaminasenanstieg sowie Anstieg der Cholestase-Parameter zu beobachten. Eine durchgeführte Leberbiopsie erbrachte zunächst keinen wegweisenden Befund. Aufgrund des Verdachts einer akuten Abstoßung wurde dennoch eine Steroid-Stoßtherapie bei optimierter immunsuppressiver Therapie mit Tacrolimus und MMF durchgeführt. Später zeigte sich ein partieller Abfall der Transaminasen. Unter dem Verdacht einer persistierenden akuten Abstoßung der Spenderleber wurde eine erneute Biopsie durchgeführt, hierbei konnte im Präparat eine akute Abstoßung belegt werden. Es erfolgte eine weitere Steriod-Stoßtherapie. Aufgrund der akuten Abstoßung wurde auf ein Absetzen des Methylprednisolons nach zweimaligen Steroid-Stoßtherapien zunächst verzichtet. Wegen steigender Cholestaseparameter erfolgte am Tag 59 eine ERCP. Hierbei zeigte sich eine DHC-Stenose. Wegen des Verdachts einer Obstruktion erfolgte der Stentwechsel so- 
wie Sludge-Entfernung. Es bestand der Verdacht auf eine ischämische Cholangiopathie. Zur Klärung der Genese der erneuten Leberwerterhöhung erfolgte eine erneute Leberpunktion. In der Gallenflüssigkeit wurde Enterococcus faecium nachgewiesen. Von Tag 65 bis 67 erfolgte abermals eine Prednisolon-Stoßtherapie. Am Tag 75 erfolgte die Entfernung der nasobiliären Sonde. Angiographisch zeigte sich ein chronischer Verschluss des Truncus coeliacus mit sehr guter Kollateralausbildung über Bühlersche und pankreatikoduodenale Arterien. Außerdem zeigte sich eine milde, unter 40\%ige Stenose der Arteria hepatica, ca. 2cm distal der Anastomose. Klinisch wurde vermutet, dass durch die wahrscheinlich schon länger bestehende Truncus-Stenose der Patient eine wiederholte, relative Ischämie der Gallengänge hatte, die dann zu einer entsprechenden Veränderung des Gallengangsystems mit daraus resultierender chronischer Abstoßungsreaktion führte. Es folgten mehrere ERCPs, Stententfernungen und -reimplantationen. Im weiteren Verlauf kam es zur Panzytopenie. Darunter wurden die Immunsuppressiva, abgesehen von Cortison, kurzzeitig pausiert. Die Cortisondosis wurde dafür erhöht. Die immunsuppressive Therapie wurde kurze Zeit später auf Everolimus umgestellt. Eine ERCP erbrachte am Tag 267 den Befund einer chronischen intrahepatischen Cholestase mit ab dem Hilus in beiden Leberlappen verändertem Gallengangssystem und multiplen unregelmäßigen Einengungen, bedingt durch die chronische Entzündung. Der Patient wurde erneut zur Transplantation gelistet und die Everolimusmedikation wieder zurück auf Tacrolimus umgestellt. Nach erneuter Transplantation am Tag 325 nimmt der Patient nunmehr unter dem Pseudonym LTx15 in dieser Studie teil. Verlauf der GcfDNA und der Routinelaborparameter: Während des gesamten Verlaufes waren erhöhte Werte der GcfDNA messbar. Unmittelbar nach der Transplantation fielen die Werte auf $14 \%$ ab und stiegen abermals an (siehe Abbildung 4.23). In der Folgezeit war ein stark schwankender Verlauf mit Spitzen von max. 64\% (Tag 282) zu beobachten (siehe Abbildung 4.23). Steroid-Stoßstherapien sorgten für einen sofortigen und kurzzeitigen Abfall der GcfDNA, die im Anschluss aber sofort wieder anstieg. Bereits kurze Zeit nach der Transplantation war ebenfalls ein massiver Transaminasenanstieg sowie Anstieg der Cholestase-Parameter zu beobachten. Während der Steroid-Stoßtherapie kam es ebenfalls zu einem Abfall der Transaminasen, die anschließend wieder anstiegen. Eine weitere Stoßtherapie führte wieder zu einem Abfall der Leberparameter, wobei nach der Entfernung der nasobiliären Sonde am Tag 75 erneut ein Anstieg der Cholestaseparameter auftrat. 
Auch bei Patient LTx3 (Abbildung 4.24) kam es im postoperativen Verlauf zu einer akuten Abstoßung. Ursprünglich wurde der Patient aufgrund einer äthyltoxischen Leberzirrhose für die Lebertransplantation gelistet. Es handelt sich um einen 68-jährigen männlichen Patienten. Als Zufallsbefund wurde in der Explantatleber der Neubefund eines HCC im Segment I nachgewiesen. Das Organ stammte von einer 71-jährigen weiblichen Spenderin mit positivem CMV-IgG- und Toxoplasmose-Titer.

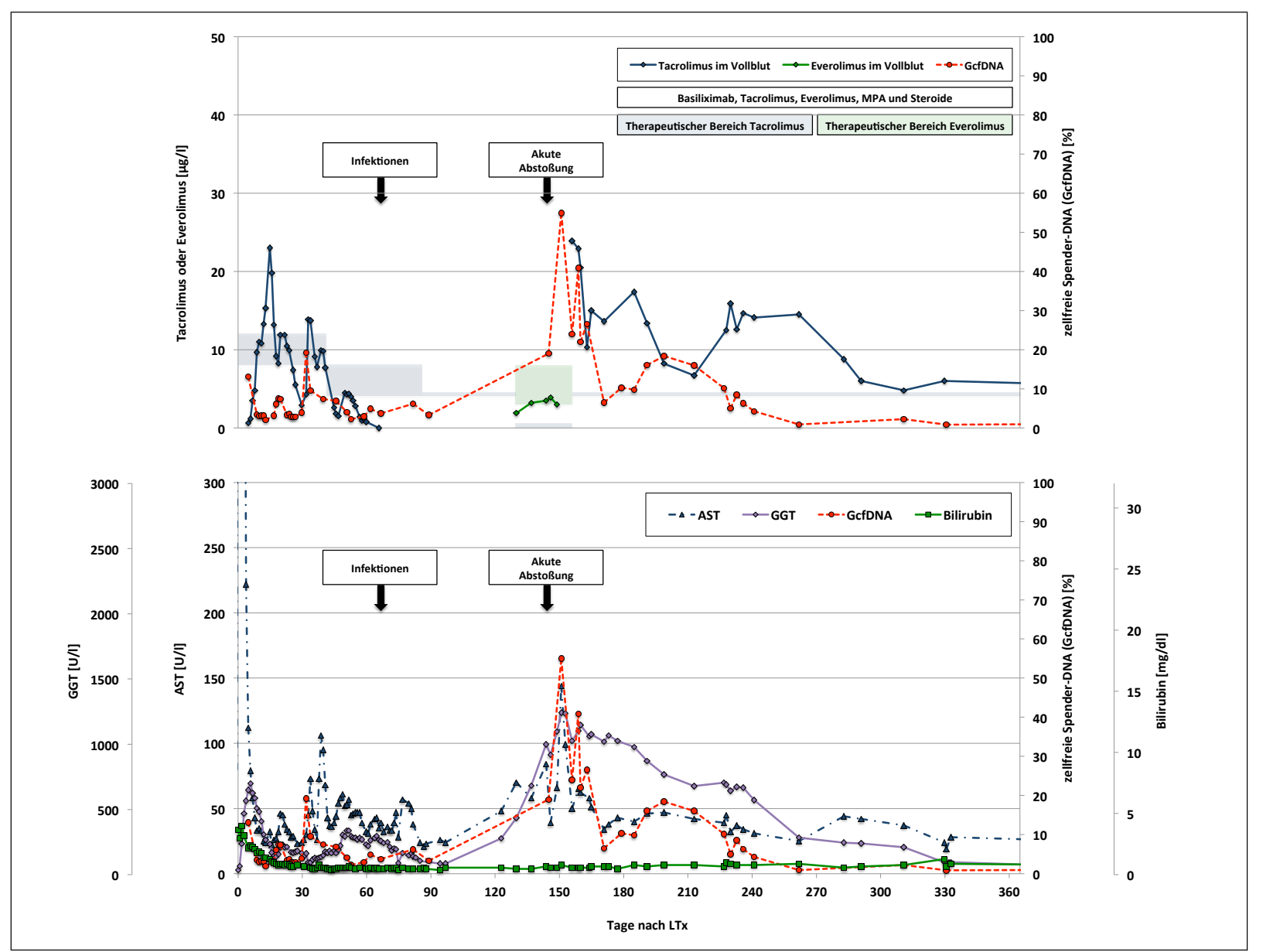

Abbildung 4.24: GcfDNA, Aspartat-Aminotransferase-(AST)-, $\quad \gamma$-Glutamyl-Transferase(GGT)-Aktivität sowie Bilirubin-Konzentration bei Verlauf mit Abstoßung (LTx3)

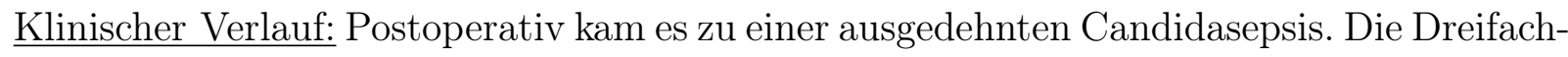
Immunsuppression mit Prednisolon, MMF und Tacrolimus wurde im postoperativen Verlauf mehrfach modifiziert. Tacrolimus wurde aufgrund rezidivierender Infekte und der Candidapneumonie gänzlich abgesetzt. Aufgrund eines massiven Anstiegs der GGT und AP erfolgte am Tag 144, nach Ausschluss einer medikamentös-toxischen Ursache und nach Ausschluss einer arteriellen Durchblutungsstörung, unter dem Verdacht einer Abstoßungsreaktion ei- 
ne Leberbiopsie. Die Leberbiopsie bestätigte diese Verdachtsdiagnose, so dass eine SteroidStoßtherapie über drei Tage durchgeführt wurde. Eine ERCP am Tag 150 ergab keinen Hinweis auf eine Anastomosenstenose bzw. Cholangitis, allerdings wurde eine EPT durchgeführt. Am Tag 174 wurde eine erneute Leberpunktion durchgeführt. Hier erbrachte die histologische Aufarbeitung den Befund einer geringen chronischen Entzündung im Bereich der Portalfelder und Gallengänge, die auf eine milde späte akute Abstoßungsreaktion hindeutete. Verlauf der GcfDNA und der Routinelaborparameter: Initial fielen die GcfDNA-Werte schnell unter die 10\%-Grenze. Ein Messwert von 19\% am Tag 32 ist auf die - zu diesem Zeitpunkt - unzureichende Immunsuppression mit Tacrolimus-Talspiegeln unterhalb des therapeutischen Bereiches zurückzuführen (siehe Abbildung 4.24). Nach der Reha-Behandlung zeigten sich steigende Cholestaseparameter. Der Zeitpunkt der Umstellung der immunsuppressiven Therapie ging ebenfalls mit erhöhten GcfDNA-Werten einher (siehe Abbildung 4.24). Während des Abstoßungsgeschehens stieg die GcfDNA auf bis zu 55\% an (Tag 151) und fiel dann unter der Steroid-Stoßtherapie schnell ab. Auch die AST und GGT stiegen an und waren im weiteren Verlauf nur langsam rückläufig. Mit dem Erreichen suffizienter Talspiegel der Immunsuppressiva fiel die GcfDNA wieder unter die 10\%-Grenze.

LTx8 (Abbildung 4.25) zeigte einen ausgesprochen komplikationsreichen postoperativen Verlauf. Bei dem 60-jährigen männlichen Patienten bestand eine äthyltoxische Leberzirrhose. Zum Zeitpunkt der Aufnahme zeigte sich ein beginnendes Leberversagen und eine Dekompensation der Leberzirrhose. Daraufhin wurde das Organ einer 49-jährigen weiblichen Spenderin mit positivem CMV-IgG-Titer akzeptiert. 


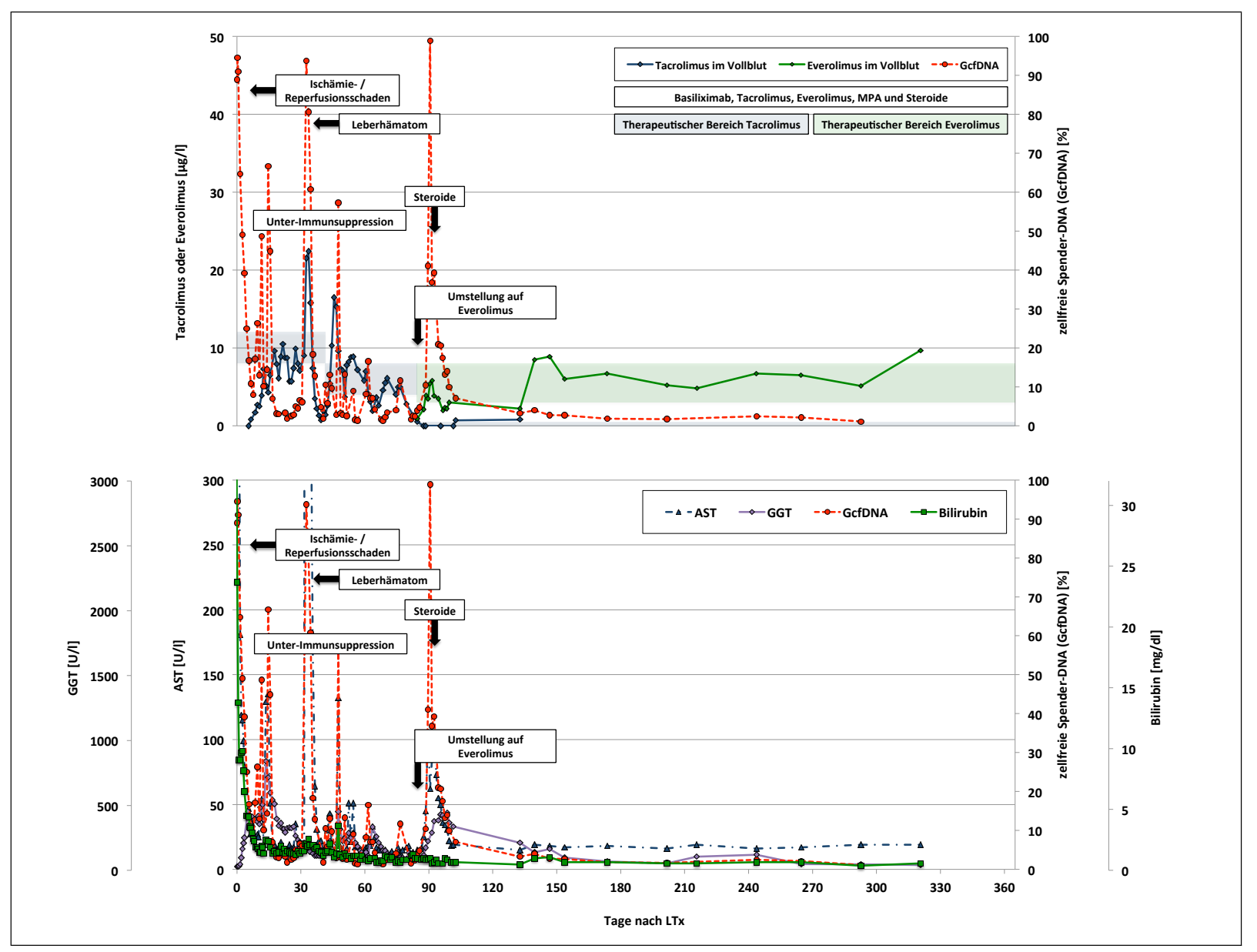

Abbildung 4.25: GcfDNA, Aspartat-Aminotransferase-(AST)-, $\quad \gamma$-Glutamyl-Transferase(GGT)-Aktivität sowie Bilirubin-Konzentration bei Verlauf mit Abstoßung (LTx8, verändert nach Kanzow et al. 2014) - Abdruck mit Genehmigung, Bildnachweis auf Seite 123)

Klinischer Verlauf: Die Transplantation verlief aus chirurgischer Sicht problemlos. Auch postoperativ war die Nierenfunktion zunächst insuffizient und machte weitere Dialysebehandlungen ab dem 6. postoperativen Tag nötig. Wegen anhaltender Niereninsuffizienz wurden die Tacrolimus-Spiegel während der ersten 15 Tage im subtherapeutischen Bereich gehalten. Am 6. postoperativen Tag wurde eine Infektion mit CMV entdeckt und eine antivirale Therapie mit Valganciclovir begonnen. Außerdem wurden Vancomycin-resistenter Enterococcus faecium (VREF) sowie multidrug-resistenter gramnegativer (MDRGN) Staphylococcus haemolyticus in der Drainageflüssigkeit und Pseudomonas aeruginosa im Urin nachgewiesen. Linezolid and Ciprofloxacin wurden zwischen den Tagen 7 und 12 mit in den Therapieplan aufgenommen. Am 19. postoperativen Tag stürzte der Patient und brach sich dabei mehrere Rippen. Computertomographisch zeigte sich ein Subduralhämatom auf der linken Hirnseite sowie ein Bruch der Schädelbasis. Außerdem wurde ein großes subkapsuläres Leber- 
hämatom diagnostiziert. Im weiteren Verlauf entwickelte der Patient eine symptomatische Epilepsie und ein schweres hirnorganisches Psychosyndrom. MMF wurde am 26. Tag wegen Leukopenie abgesetzt. Am 36. Tag wurde eine Panzytopenie, bedingt durch eine toxische Knochenmarksschädigung, nachgewiesen. Aufgrund fiebriger Temperaturen wurde am Tag 32 die antibiotische Therapie mit Linezolid and Ciprofloxacin wieder aufgenommen und bis zum 46. Tag nach Transplantation aufrechterhalten. An Tag 43 wurde, nach Erholung von der Panzytopenie, das Leberhämatom chirurgisch ausgeräumt. Pseudomonas aeruginosa und Vancomycin-resistente Enterococci wurden am Tag 63 erneut nachgewiesen und abermals antibiotisch therapiert. Im weiteren Verlauf erfolgte ab Tag 81 eine Umstellung auf Everolimus als Haupt-Immunsuppressivum, um die Nierenfunktion weiter zu verbessern. Tacrolimus wurde auf eine sehr niedrige Dosierung von $1 \mathrm{mg} / \mathrm{d}$ reduziert. Aufgrund der während dieses Zeitraums zu niedrigen Immunsuppression wurde klinisch die Diagnose einer Abstoßung gestellt und über zwei Tage (Tag 94 und 95) eine Steroid-Stoßstherapie durchgeführt. Verlauf der GcfDNA und der Routinelaborparameter: Während der Anfangszeit mit subtherapeutischen Tacrolimus-Spiegeln war ein deutlicher Anstieg der GcfDNA zu beobachten (siehe Abbildung 4.25). Die Werte waren nach Erhöhung der Tacrolimus-Dosierung wieder rückläufig. In Folge des Sturzes am Tag 19 zeigte sich ein steiler Anstieg der GcfDNA auf Werte über 90\%, der auf eine Ischämieschädigung des Transplantates zurückzuführen war. Zu Beginn der Umstellungsphase auf Everolimus war die Immunsuppression erneut zu niedrig, was sich in abermals angestiegenen GcfDNA-Werten zeigte. Unter der Stoßtherapie war die GcfDNA rückläufig und der Patient zeigte fortan eine stabile Transplantatfunktion mit GcfDNA-Werten unter 10\%. Die Anstiege der GcfDNA gingen ebenfalls mit erhöhten AST- und GGT-Werten einher.

Patient LTx12 (Abbildung 4.26) war ein 64-jähriger männlicher Patient mit äthyltoxischer Leberzirrhose. In der Vergangenheit kam es bereits zur mehrfachen Dekompensation der Leberzirrhose (spontane bakterielle Peritonitis und hepatische Enzephalopathie) und Anlage eines transjugulären intrahepatischen portosystemischen Shunts (TIPS). Der männliche Spender war 58 Jahre alt und zeigte einen positiven Toxoplasmose-Titer-Nachweis. Als Zufallsbefund wurde in der Explantatleber ein HCC festgestellt. 


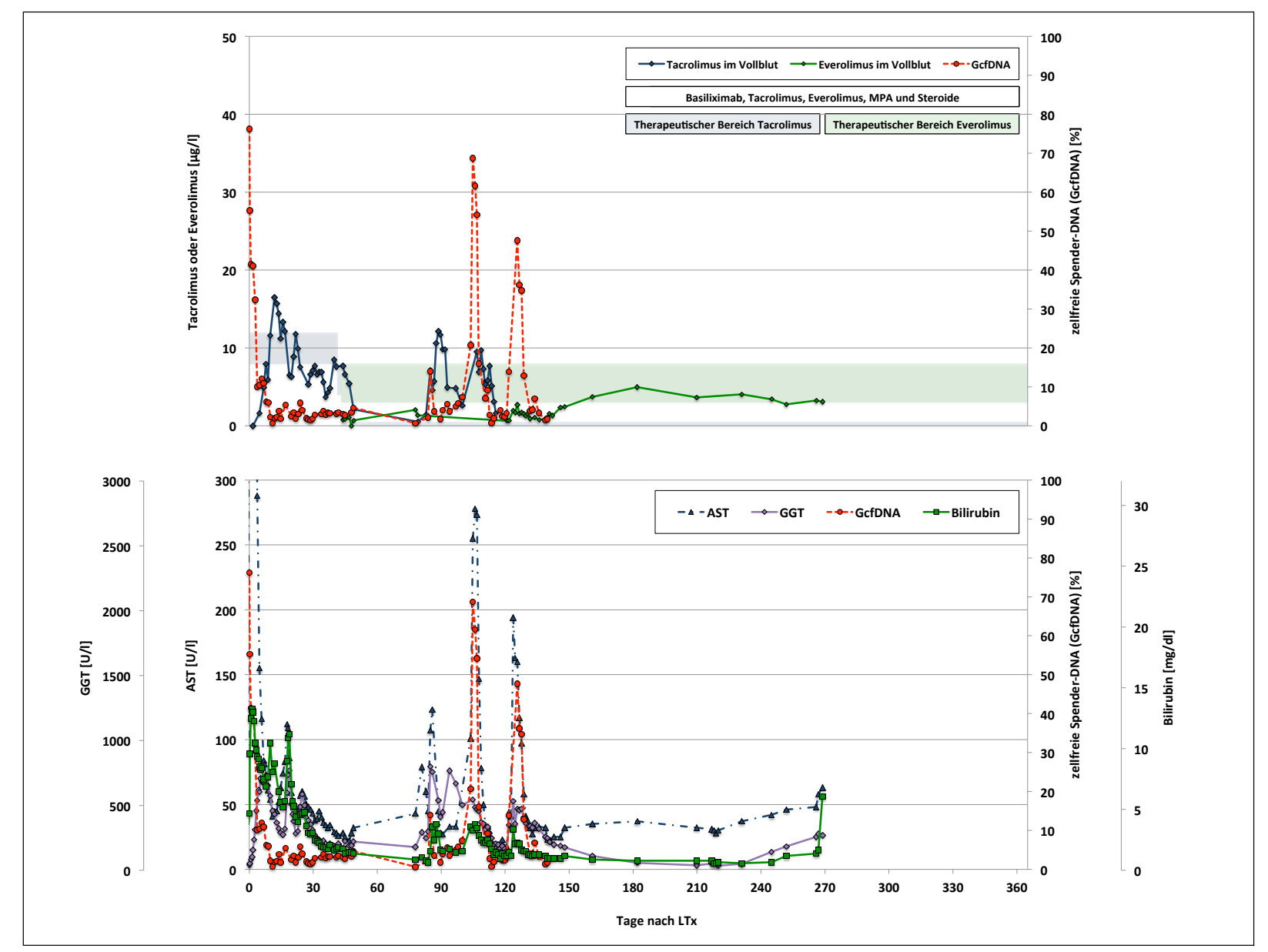

Abbildung 4.26: GcfDNA, Aspartat-Aminotransferase-(AST)-, $\quad \gamma$-Glutamyl-Transferase(GGT)-Aktivität sowie Bilirubin-Konzentration bei Verlauf mit Abstoßung (LTx12)

Klinischer Verlauf: Der postoperative Verlauf gestaltete sich initial unkompliziert. Bei Nachweis von gallehaltigem Sekret über die Drainage im Bereich der Gallengangsanastomose wurde bei Verdacht auf eine Insuffizienz im Bereich der Anastomose am 3. postoperativen Tag eine ERCP durchgeführt. In dieser konnte die Galleleckage bewiesen werden, so dass eine Stenteinlage mit Papillotomie durchgeführt wurde. Hierunter war die Gallesekretion über die einliegende Drainage zunächst rückläufig. Am 19. Tag erfolgte eine Re-ERCP, wobei eine Stentokklusion auffiel. Die einliegende Drainage wurde entfernt, stattdessen wurde eine nasobiliäre Sonde eingebracht. Dadurch konnte die Leckage im Bereich der Gallengangsanastomose komplikationslos abheilen, so dass die nasobiliäre Sonde im weiteren Verlauf entfernt werden konnte. Aufgrund des Nachweises von Candida glabrata im abdominellen Sekret, welches während der Leckage im Bereich des Gallengangs entnommen wurde, wurde eine zielgerichtete antimykotische Therapie begonnen. Die systemischen Candida-Antikörper-Titer waren jedoch zu allen Zeitpunkten negativ. Am Tag 22 wurde eine Infektion mit CMV ent- 
deckt und eine Therapie mit Valganciclovir begonnen. Aufgrund des Zufallsbefundes eines HCCs im Bereich der Explantatleber wurde die Immunsuppression im weiteren Verlauf auf Everolimus sowie MMF umgestellt. Später kam es zu beidseitigen Pleuraergüssen, Aszites sowie Biliombildung durch die bekannte Gallengangsleckage. Am Tag 90 wurde eine ERCP mit Einlage eines Plastikstents durchgeführt. Dabei konnte eine Infektion mit Enterococcus faecium (Nachweis in Aszites und Galle) festgestellt werden, woraufhin eine antibiotische Therapie begonnen wurde. Aufgrund der Immunsuppression wurde zudem eine antimykotische Therapie initiiert. Außerdem konnte wiederholt eine kutane Besiedelung mit einem multiresistenten Pseudomonas nachgewiesen werden. Aufgrund eines akuten Nierenversagens wurde eine Hämodialysetherapie für vier Tage notwendig. Trotz weiterer Eskalation der antiinfektiven Therapie einschließlich der deutlichen Reduktion der Immunsuppression verschlechterte sich der Zustand des Patienten zunehmend. Bei einer weiteren ERCP am Tag 108 wurde der Plastikstent entfernt und in der dabei entnommenen Gallenflüssigkeit multiresistenter Pseudomonas aeruginosa nachgewiesen. Dieser Keim war später auch im Parotisabstrich nachweisbar. Aufgrund der nun nachgewiesenen multiplen Infektionen mit einem multiresistenten Pseudomonas erfolgte eine Umstellung der antibiotischen Therapie auf Colistin und Meropenem sowie Linezolid für den nachgewiesenen E. faecium und Caspofungin wegen des anamnestischen postoperativen Nachweises von Candida glabrata. Aufgrund der Leukopenie sowie deutlich reduzierter Zahl der T-Helferzellen wurde die immunsuppressive Therapie reduziert und Tacrolimus vorübergehend komplett pausiert. Unter dieser antibiotischen Therapie kam es zu einer raschen Verbesserung des Allgemeinzustandes des Patienten und zu einem Abfall der laborchemischen Infektparameter. Auch die Parotitis heilte darunter spontan ab. Bei im Verlauf wieder angestiegenen Leukozytenzahlen wurde die immunsuppressive Therapie mit Everolimus mit einem Zielspiegel von 3-5 $\mu \mathrm{g} / \mathrm{l}$ fortgesetzt. Die Prednisolondosis wurde hingegen reduziert. In der histopathologischen Begutachtung einer Leberbiopsie vom 108. postoperativen Tag ergab sich der Verdacht auf eine Gallenabflussstörung sowie eine milde Abstoßungsreaktion. Ferner zeigten sich Portalfelder mit allenfalls geringgradiger Fibrose und deutlicher Gallengangsproliferation sowie intrahepatischer Cholostase, so dass klinisch eine Gallenabflussstörung ausgeschlossen werden konnte. Bei steigenden Cholestaseparametern wurde am Tag 125 eine erneute ERCP mit Anlage eines Doppelpigtails durchgeführt. Bei einer ERCP am Tag 217 ließ sich kein Stent mehr darstellen, so dass von einem spontanen Abgang des Stents auszugehen ist. Aufgrund der darunter weiterhin normwerti- 
gen Laborparameter wurde kein neuer Stent implantiert. Im Gallepunktat wurden weiterhin Keime nachgewiesen, u. a. ein multiresistenter Pseudomonas aeruginosa. Klinisch zeigten sich jedoch keine Infektzeichen. Verlauf der GcfDNA und der Routinelaborparameter: Der initiale GcfDNA-Abfall führte zu Werten unter der 10\%-Grenze innerhalb von 5 Tagen. Im Anschluss an die ERCP am 3. postoperativen Tag waren systemische Cholestaseparameter auffällig (siehe Abbildung 4.26). Während des Abstoßungsgeschehens kam es zu zwei Peaks der GcfDNA (68\% am Tag 105 und 48\% am Tag 126), die ebenfalls von einem Anstieg der AST begleitet wurden. Die immunsuppressive Therapie, bestehend aus Tacrolimus und Everolimus, war zu diesen Zeitpunkten besonders niedrig eingestellt. Nach der ERCP am Tag 125 waren die Cholestaseparameter und GcfDNA im weiteren Verlauf wieder abfallend und zeigten sich fortan unauffällig. Ab diesem Zeitpunkt waren auch stabile Everolimus-Spiegel im therapeutischen Bereich erreicht.

Bei LTx18 (Abbildung 4.27) handelt es sich um eine 20-jährige weibliche Patientin bei der eine deutlich ausgeprägte sekundär sklerosierende Cholangitis nach extrakorporaler Membranoxygenierung (ECMO-Therapie) bei Lungenversagen im Rahmen einer Sepsis bestand. Die Spenderleber stammte von einer 52-jährigen weiblichen Spenderin mit positivem CMVIgG-Titer. 


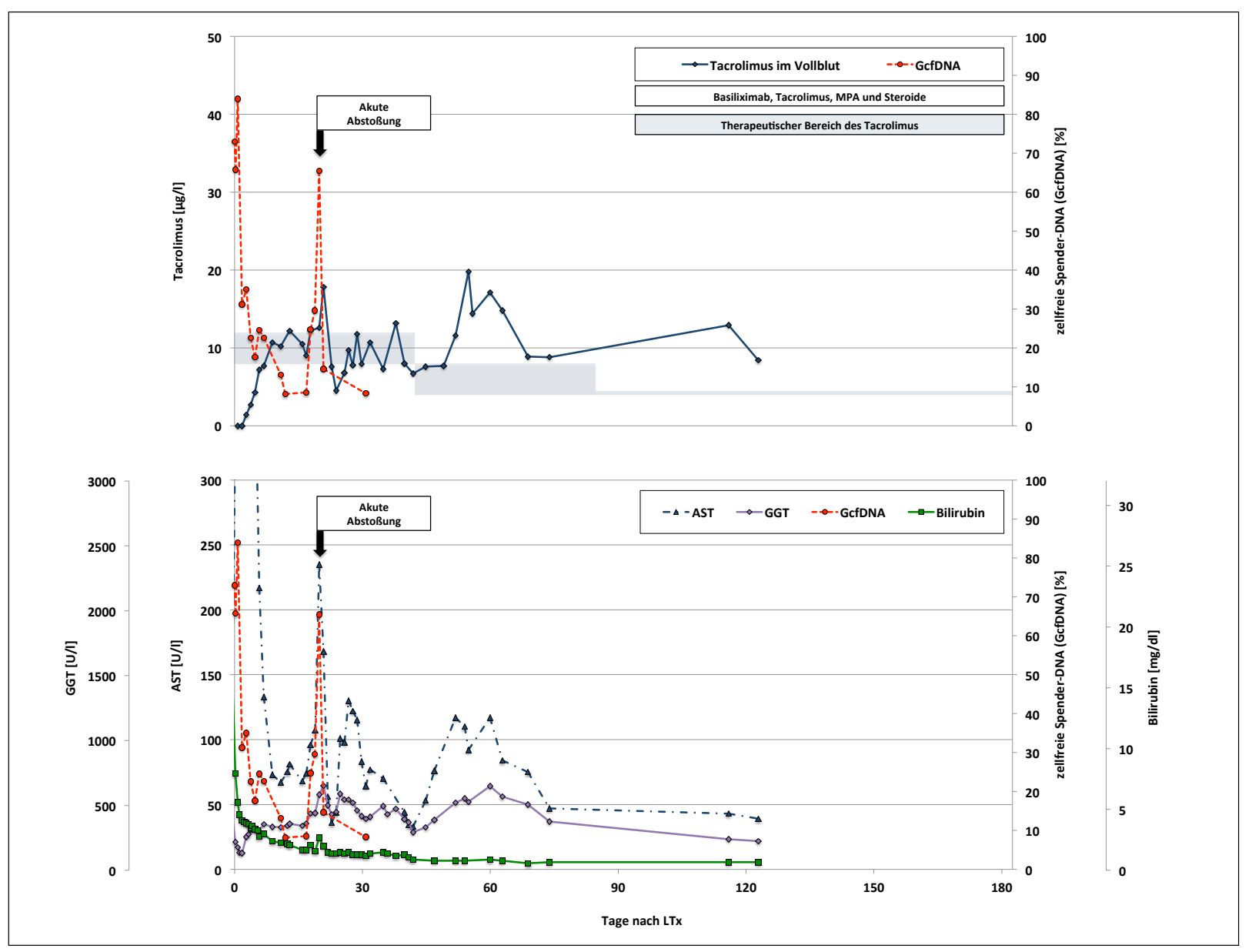

Abbildung 4.27: GcfDNA, Aspartat-Aminotransferase-(AST)-, $\quad \gamma$-Glutamyl-Transferase(GGT)-Aktivität sowie Bilirubin-Konzentration bei Verlauf mit Abstoßung (LTx18)

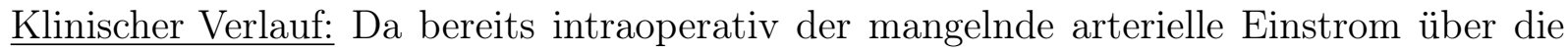
neu angelegte arterielle Anastomose bei ursächlicher ligamentärer Stenose des Abganges des Truncus coeliacus aus der Aorta festgestellt wurde, erfolgte zunächst die Anlage eines arteriellen Bypasses, ausgehend von der Aorta abdominalis auf die A. hepatica. Im postoperativen Verlauf war das klinische Bild eines akuten Kompartmentsyndroms des linken Unterschenkels auffällig. Aus transplantationschirurgischer Sicht gestaltete sich der weitere Verlauf zunächst unkompliziert. An Tag 20 wurde eine ERCP durchgeführt. Diese zeigte jedoch einen regelrechten Zustand nach Lebertransplantation, so dass nach Ausschluss eines arteriellen Durchblutungsproblems mittels Duplexsonographie bei Verdacht auf das Vorliegen einer diskreten Abstoßungsreaktion eine sonographisch gesteuerte Leberbiopsie durchgeführt wurde. Diese bestätigte das Bild einer geringgradigen Abstoßungsreaktion, so dass eine Abstoßungstherapie in Form eines Steroid-Stoßtherapie mit 500mg Methylprednisolon an drei aufeinanderfolgenden Tagen und dem erneuten Einsatz von Methylprednisolon eingeleitet wurde. Am 
Tag 28 wurde Vancomycin-resistenter Enterococcus faecium (VREF) in der Urinbakteriologie entdeckt und eine resistenzgerechte Antibiotikatherapie begonnen. Im weiteren Verlauf wurde aufgrund der deutlichen Infektkonstellation eine antibiotische Therapie mit Meropenem eingeleitet. In einer ERCP am Tag 38 konnte ein Konkrement im Anastomosebereich als Ursache für die angestiegenen Leberwerte ausgeschlossen werden. Daher wurde dann ein Stent angelegt. Unter antibiotischer Therapie waren die Entzündungsparameter rückläufig. Bei erneutem Anstieg der Cholestaseparameter wurde am 54. Tag eine weitere ERCP durchgeführt. Auch hier wurden weder Sludge noch Konkremente nachgewiesen. Es erfolgte ein erneuter Stentwechsel. Bei Nachweis von Hefen im Urin und Stuhl wurde eine Therapie mit Amphotericin B und Fluconazol durchgeführt. Verlauf der GcfDNA und der Routinelaborparameter: Nach 12 Tagen fiel die GcfDNA auf Werte unter der 10\%-Grenze ab und stieg zum Zeitpunkt des Abstoßungsgeschehens auf bis 65\% (Tag 20) an. Initial waren regrediente Cholestaseparameter zu beobachten, die während der Abstoßungsreaktion mit deutlich erhöhten AST-Werten einhergingen (siehe Abbildung 4.27). Unter der Steroid-Stoßtherapie fiel die AST deutlich ab. Die Cholestaseparameter waren im weiteren Verlauf rückläufig aber immer noch erhöht.

\subsubsection{Patienten mit Infektionen}

Patient LTx17 (Abbildung 4.28) war ein 58-jähriger männlicher Patient mit Leberzirrhose, HCC mit mehrfachen TACE-Therapien und bekannter Hepatitis-B-Infektion. Die Spenderleber stammte von einer 74-jährigen weiblichen Spenderin mit positivem HbcAb-, CMV-IgGund Toxoplasmose-Titer. 


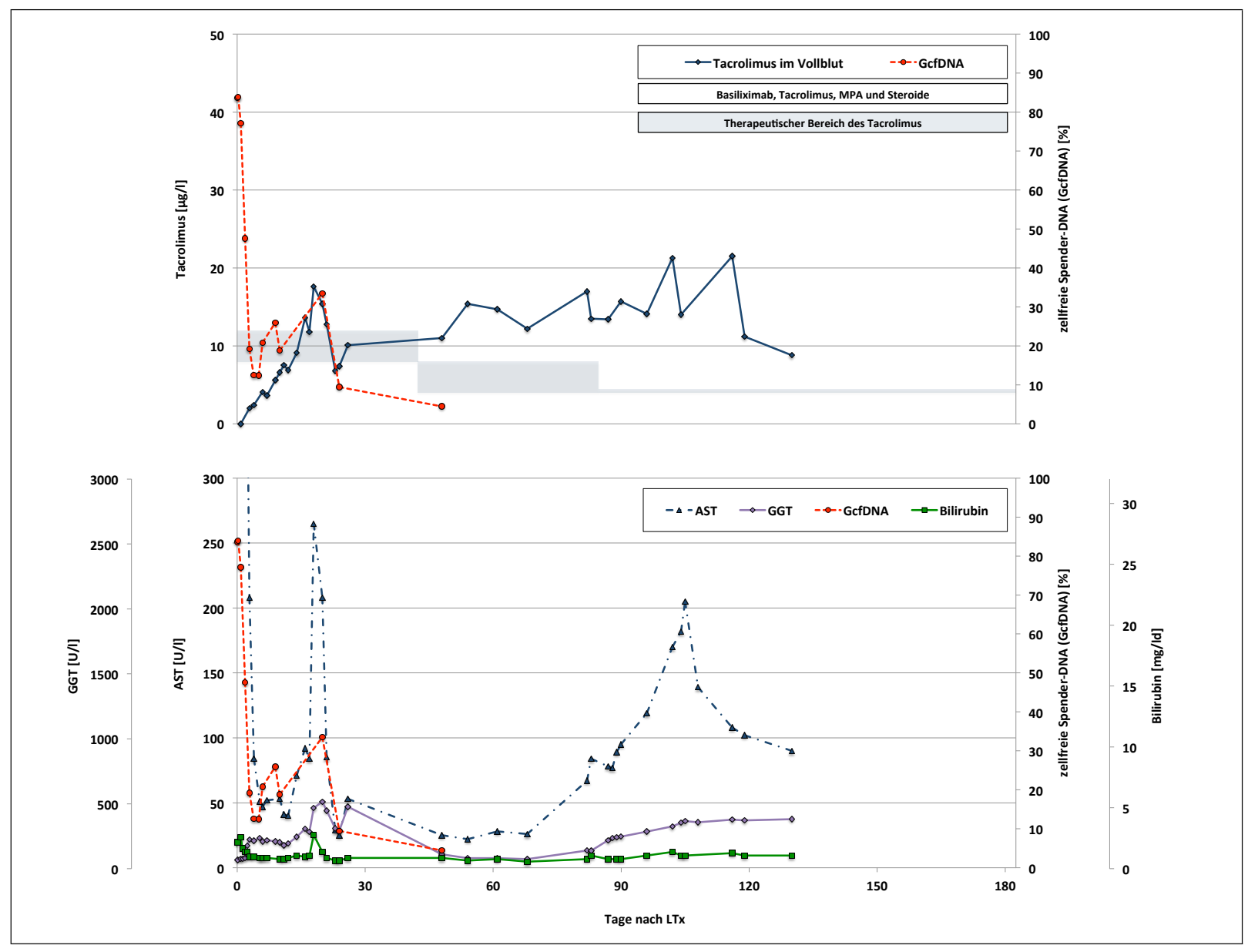

Abbildung 4.28: GcfDNA, Aspartat-Aminotransferase-(AST)-, $\quad \gamma$-Glutamyl-Transferase(GGT)-Aktivität sowie Bilirubin-Konzentration bei Patienten mit Infektionen (LTx17)

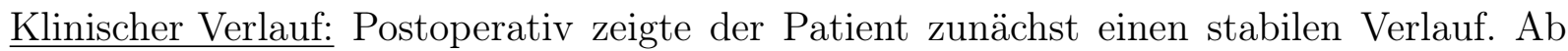
dem 6. postoperativen Tag wies der Patient jedoch diskret ansteigende Entzündungszeichen auf. Nach Ausschluss einer hepatoarteriellen Perfusionsstörung erfolgte am 7. postoperativen Tag eine Leberbiopsie. Diese zeigte keinen Anhalt für das Vorliegen einer Abstoßungsreaktion. In der daraufhin veranlassten ERCP zeigte sich am Tag 19 eine hilusnahe Gallengangsstenose, welche mittels Stenteinlage therapiert wurde. Unter Antibiotikatherapie waren die Infektwerte im weiteren Verlauf ebenfalls deutlich regredient. Aufgrund der im Plasma nachgewiesenen CMV-DNA erfolgte eine Therapie mit Valganciclovir seit dem 69. Tag nach Transplantation. Nach 21 Tagen hoch dosierter Valganciclovir-Therapie wurde die Dosis reduziert. Aufgrund der erneut gestiegenen Cholestaseparameter erfolgte am Tag 84 eine weitere ERCP. Diese gestaltete sich komplikationslos. Der Stent zeigte sich offen. In der entnommenen Galleflüssigkeit konnte Enterococcus faecalis nachgewiesen werden, der auf Meropenem sensibel war und entsprechend therapiert wurde. Aufgrund erneut steigender Cholestasewerte und des 
Verdachts eines Stentverschlusses erfolgte am Tag 104 eine erneute ERCP. Dabei wurde ein Konkrement sowie der Stent entfernt. Verlauf der GcfDNA und der Routinelaborparameter: Die initialen GcfDNA-Werte von über $80 \%$ unmittelbar nach Transplantation fielen bis zum vierten postoperativen Tag auf etwa $12 \%$ ab. Aufgrund einer Unter-Immunsuppression stiegen die Werte wieder auf bis zu 33,5\% am 20. Tag an (siehe Abbildung 4.28). Mit dem Erreichen stabiler Tacrolimus-Spiegel fielen die Werte unter die 10\%-Grenze. Zu Beginn waren ebenfalls ansteigende Cholestaseparameter zu beobachten, die nach der ERCP am Tag 19 rückläufig waren. Im weiteren Verlauf kam es erneut zu einem Anstieg der Transaminasen sowie erhöhtem GGT im Sinne einer Cholestase.

Die weibliche Patientin LTx19 (Abbildung 4.29) war zum Zeitpunkt der Transplantation 56 Jahre alt. Sie erlitt ein akutes Leberversagen nach medikamentös-toxischer Leberschädigung durch Einnahme von Opipramol und Metothreaxat. Infolge des durch die akute Leberinsuffizienz bedingten Multiorganversagens wurde die Patientin zur Lebertransplantation gelistet. Die Spenderleber stammte von einer 53-jährigen weiblichen Spenderin mit unauffälliger Virologie. 


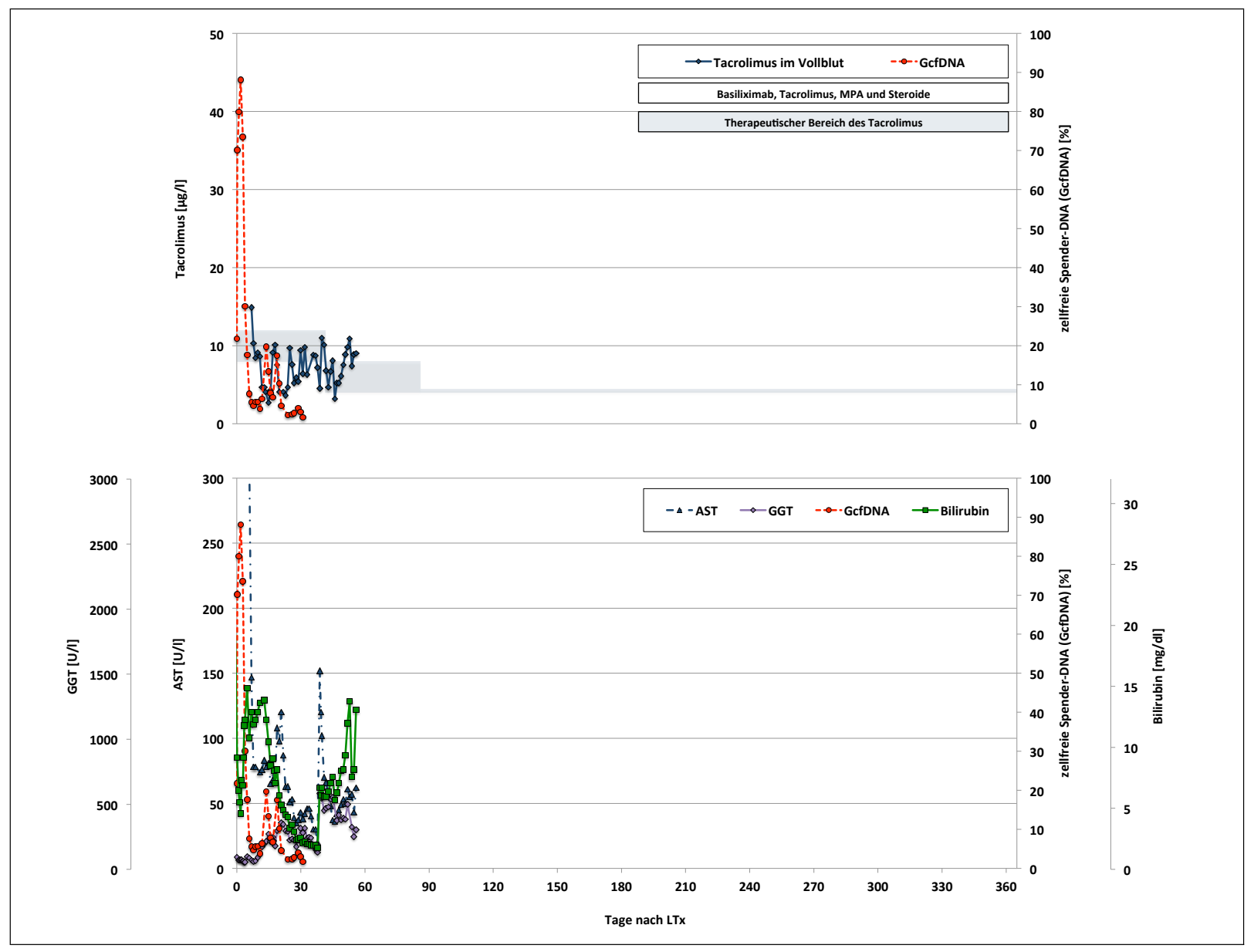

Abbildung 4.29: GcfDNA, Aspartat-Aminotransferase-(AST)-, $\quad \gamma$-Glutamyl-Transferase(GGT)-Aktivität sowie Bilirubin-Konzentration bei Patienten mit Infektionen (LTx19)

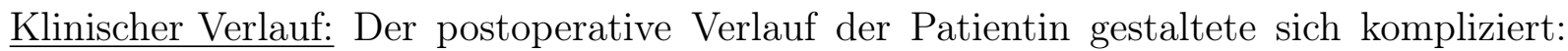
Am 5. postoperativen Tag förderten die intraabdominellen Drainagen Luft, woraufhin eine explorative Laparotomie durchgeführt wurde. Hier konnte eine nekrotisierende/exsudative Pankreatitis diagnostiziert werden. Bei Nachweis von Enterococcus faecium in den Gallenwegen erfolgte eine antibiotische Therapie mit Linezolid und Meropenem, die bei Nachweis von Candida kefyr im Pankreasgewebe um Caspofungin erweitert wurde. Bei einer erneuten explorativen Laparotomie am 17. Tag offenbarte sich eine Dünndarmperforation. Die immunsuppressive Therapie mit MMF und Tacrolimus wurde daraufhin zunächst unterbrochen und drei Tage später mit Tacrolimus und Hydrocortison wieder aufgenommen. Bei positivem DNA-Nachweis von EBV, CMV und Herpes simplex im Rachenspülwasser und HSV und CMV im Serum wurde eine antivirale Therapie mit Ganciclovir begonnen, die am 22. Tag auf Aciclovir umgestellt und bis zur Seronegativität am 52. Tag fortgesetzt wurde. Am 32. postoperativen Tag wurde die Antibiotikatherapie von Linezolid auf Vancomycin 
umgestellt. Bei der Anlage einer intrakraniellen Abszessdrainage wurde am 37. Tag in einem intraoperativ durchgeführtem Abstrich des Hirngewebes Pseudoallescheria boydii, ein Sproßpilz, nachgewiesen. Daraufhin erfolgte ein Wechsel der antimykotischen Therapie von Caspofungin auf Voriconazol. Angesichts der persistierenden lnfektsituation und durchgängigen erheblichen neurologischen Defiziten wurde die Therapie am 56. postoperativen Tag auf ein palliatives Behandlungskonzept umgestellt. Die Patientin verstarb einen Tag später. Verlauf der GcfDNA und der Routinelaborparameter: Die GcfDNA-Werte waren bei der Patientin zunächst bis zum 6. postoperativen Tag unter die 10\%-Grenze gesunken. Im weiteren Verlauf sind sie wieder angestiegen und erreichten am 14. Tag ihr Maximum von 20\%. Zu diesem Zeitpunkt waren die Tacrolimus-Spiegel im subtherapeutischen Bereich. Hiernach waren die Werte wieder rückläufig. Wenige Tage später kam es dann - parallel zu einer verstärkten Immunsuppression - zum Abfall der GcfDNA-Werte unter die 10\%-Grenze (siehe Abbildung 4.29). Unmittelbar nach der Transplantation zeigte die Patientin auch protrahiert niedrige Lebersynthesewerte sowie erhöhte Transaminasen und Cholestaseparameter, die im weiteren Verlauf kurz rückläufig waren, bevor sie erneut anstiegen.

LTx22 (Abbildung 4.30) war zum Zeitpunkt der Transplantation 66 Jahre alt. Bei der Patientin lag eine dekompensierte Leberzirrhose (Child-Pugh-Stadium C) äthyltoxischer Genese vor. Die Spenderleber stammte von einem 53-jährigen männlichen Spender mit positivem CMV-IgG-Titer. 


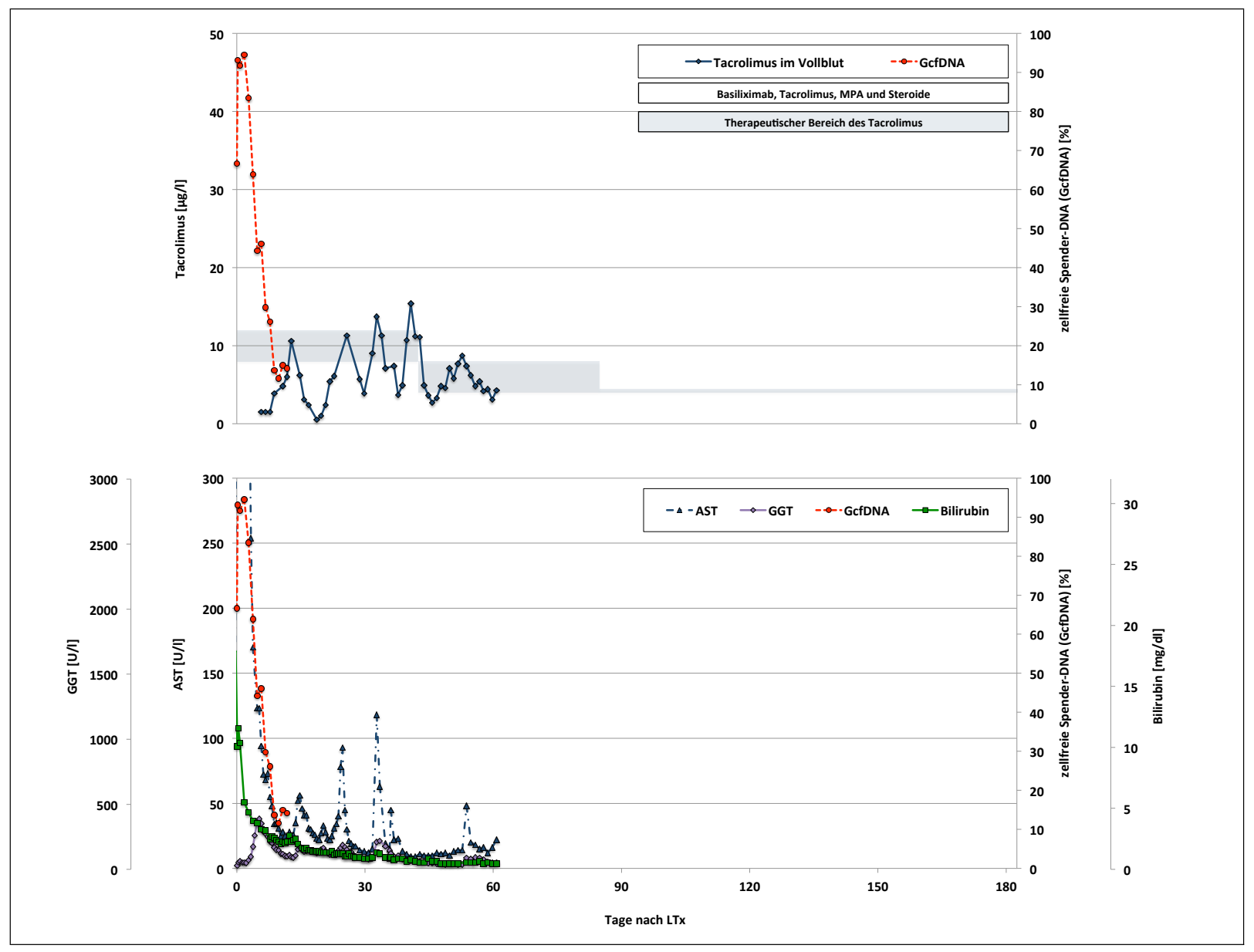

Abbildung 4.30: GcfDNA, Aspartat-Aminotransferase-(AST)-, $\quad \gamma$-Glutamyl-Transferase(GGT)-Aktivität sowie Bilirubin-Konzentration bei Patienten mit Infektionen (LTx22)

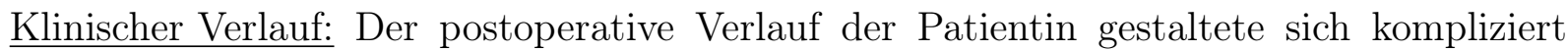
und war vor allem von multiplen Infektionen geprägt: Bereits zum Zeitpunkt der Transplantation war im Urin Enterococcus faecium nachweisbar. Am 12. postoperativen Tag wurde Candida glabrata im Trachealsekret gefunden. In den Drainagen wurde Staphylococcus aureus und Staphylococcus epidermidis am 50. Tag nach Transplantation nachgewiesen. Die antibiotische Therapie bestand bis zur Transplantation aus Ceftriaxon, wurde dann auf Vancomycin sowie Imipenem umgestellt und zur antimykotischen Abdeckung um Anidulafungin erweitert. Im weiteren Verlauf wurde die Therapie auf Linezolid und Meropenem umgestellt. Aktuell erfolgt eine gezielter virustatischer Angriff mit Valganciclovir. Verlauf der GcfDNA und der Routinelaborparameter: Die GcfDNA-Werte fielen bei der Patientin zunächst bis zum 10. postoperativen Tag auf knapp oberhalb der 10\%-Grenze ab. Die Tacrolimus-Spiegel waren während der ersten Wochen nach Transplantation im subtherapeutischen Bereich gehalten worden. Dadurch kam es zum Anstieg der AST mit mehrfachen 
Peaks. Messdaten der GcfDNA für diesen Zeitraum liegen leider nicht vor.

\subsubsection{Patienten mit Hepatitis-C-Infektionen}

LTx7 (Abbildung 4.31) zeigte eine stabile Organfunktion nach der Transplantation. Bei dem Patienten handelt es sich um einen 44-jährigen männlichen Patienten mit Leberzirrhose bei chronischer Hepatitis C-lnfektion (Genotyp 1a) sowie einer äthyltoxischen Komponente. Das Organ stammte von einem 59-jährigen männlichen Spender.

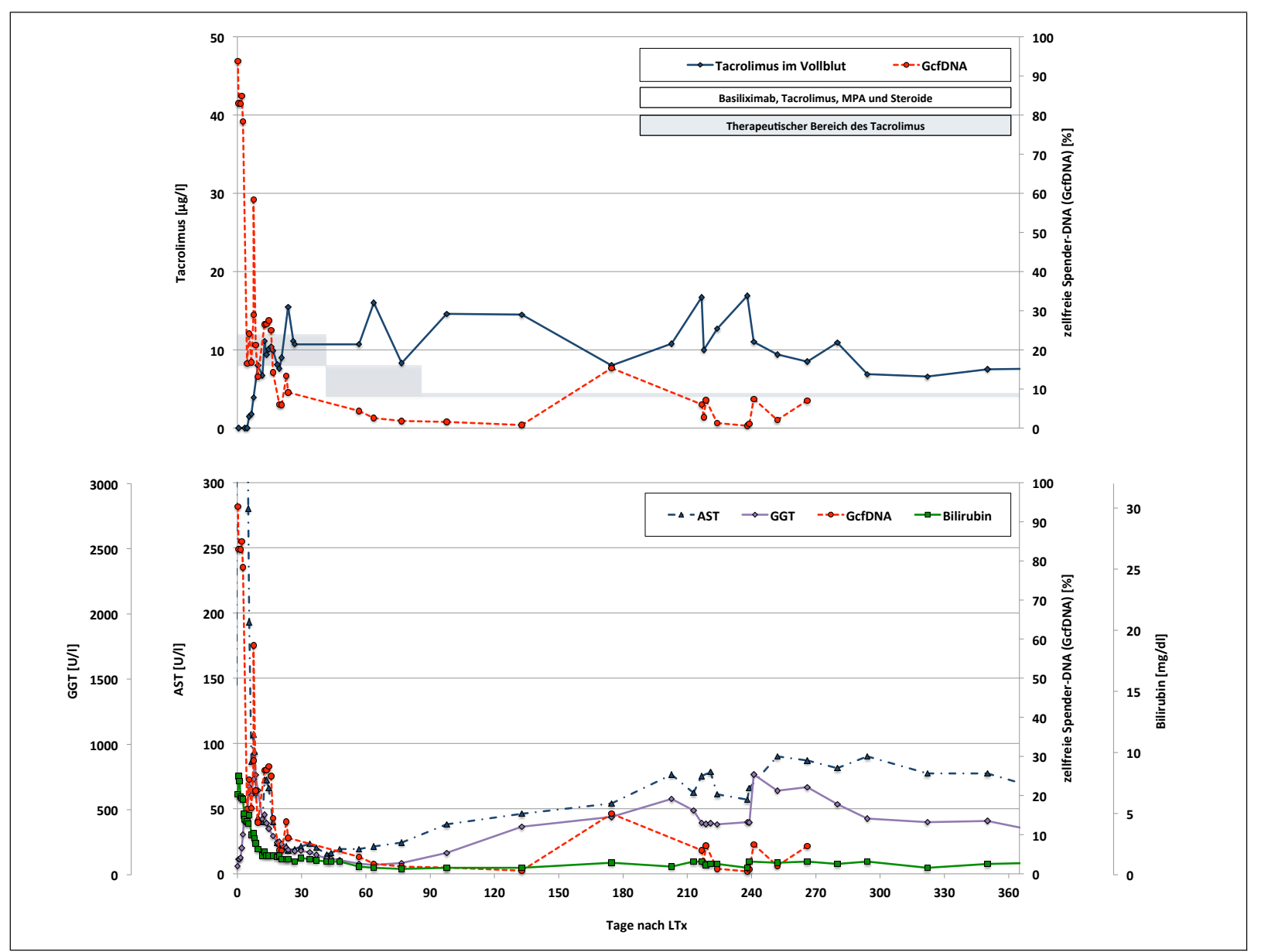

Abbildung 4.31: GcfDNA, Aspartat-Aminotransferase-(AST)-, $\quad \gamma$-Glutamyl-Transferase(GGT)-Aktivität sowie Bilirubin-Konzentration bei Verlauf mit HepatitisC-Infektion (LTx7)

Klinischer Verlauf: Der initiale postoperative Verlauf war im Wesentlichen unproblematisch. Es zeigten sich leicht erhöhte Cholestaseparameter. Außerdem kam es zu einer postoperativen CMV-Aktivierung, woraufhin eine antivirale Therapie mit Valganciclovir begonnen wurde (Tag 21). Am Tag 217 erfolgte eine ERCP. Hier wurde eine hochgradige postoperative 
Gallengangsstenose ohne prästenotische Dilatationen nachgewiesen. Es erfolgte eine erweiterte Papillotomie des Gallengangsphinkters, die Einlage eines nicht selbst expandierenden Stents in den Gallengang sowie eine Ballondilatation der Stenose im Ductus hepatocholedochus. Verlauf der GcfDNA und der Routinelaborparameter: Der initiale Abfall der GcfDNA nach Transplantation war leicht protrahiert, so dass Werte unter 10\% erst nach 20 Tagen erreicht wurden. Die Immunsuppression war suffizient und die GcfDNA lag durchgängig unter 10\%. Lediglich am Tag 175 waren Werte von etwa 15\% messbar, wobei hier die TacrolimusSpiegel vergleichsweise niedrig waren (siehe Abbildung 4.31). Nach der ERCP am Tag 217 blieb die GcfDNA unter der 10\%-Grenze, während andere Marker (AST und GGT) schon deutlich früher angestiegen und auf konstant hohem Niveau geblieben waren. Im Rahmen der ERCP war bei diesen Markern zwar auch ein kurzzeitiger und geringfügiger Abfall zu beobachten, aber die Werte stiegen schon wenige Tage später erneut an.

Bei dem 64-jährigen männlichen Patienten LTx10 (Abbildung 4.32) wurde eine Leberzirrhose bei chronischer Hepatitis-C-Infektion (Genotyp 3a) festgestellt. Differenzialdiagnostisch kam jedoch auch eine äthyltoxische Genese in Frage. Die Spenderleber stammte von einer 83-jährigen weiblichen Spenderin mit positivem CMV-IgG- und Toxoplasmose-Titer. Aufgrund der guten Laborwerte wurde das Organ trotz des hohen Alters der Spenderin akzeptiert. 


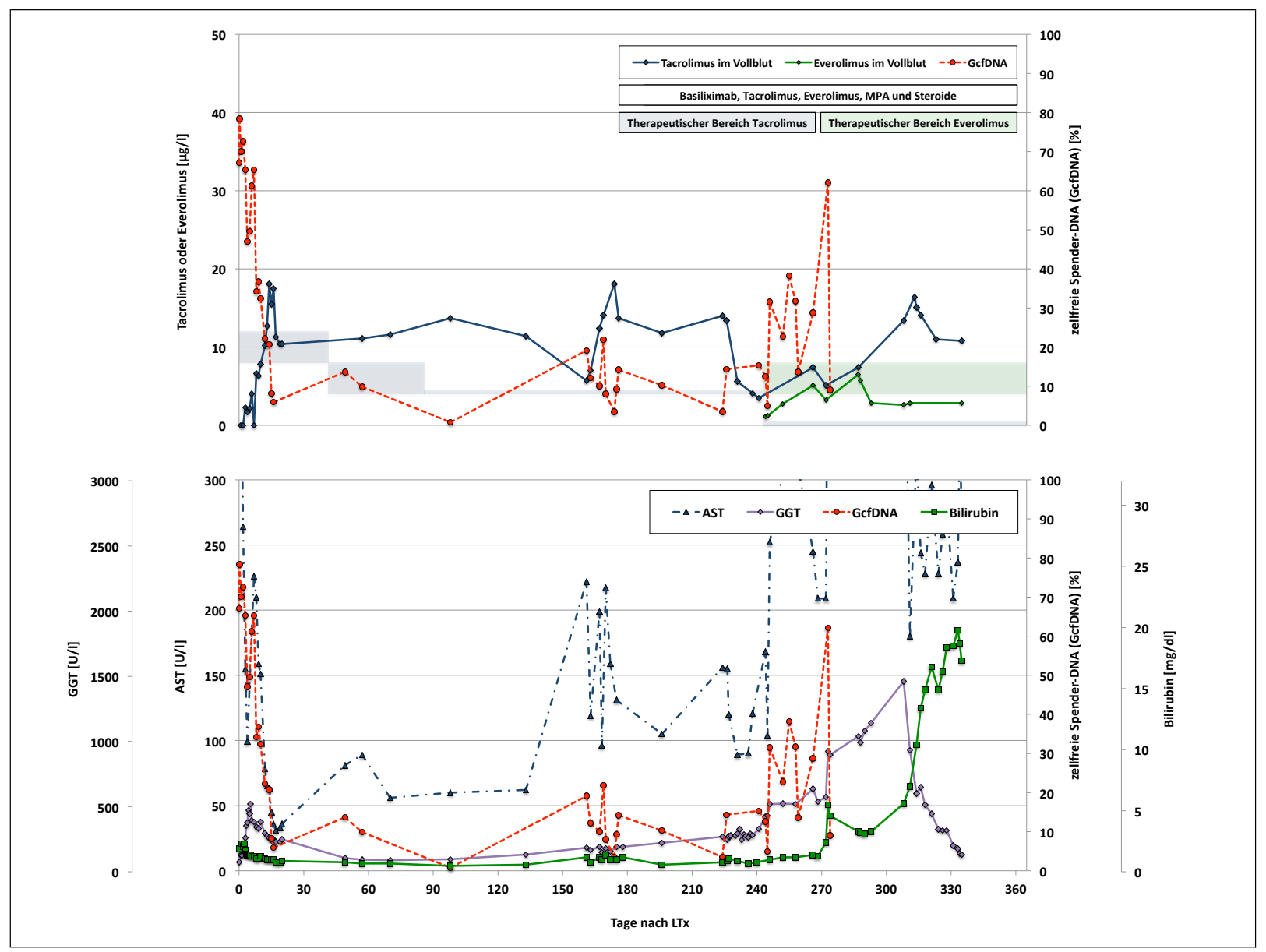

Abbildung 4.32: GcfDNA, Aspartat-Aminotransferase-(AST)-, $\quad \gamma$-Glutamyl-Transferase(GGT)-Aktivität sowie Bilirubin-Konzentration bei Patienten mit Hepatitis-C-Infektion (LTx10)

Klinischer Verlauf: Der postoperative Verlauf gestaltete sich aus chirurgischer Sicht als unproblematisch. In Folge der Transplantation zeigte sich eine erhöhte Hepatitis-Viruslast. Im weiteren Verlauf kam es aufgrund der immunsuppressiven Therapie zu einer Leukozyto- und Thrombozytopenie, weshalb die Dosis von Tacrolimus und MMF reduziert wurde. Schließlich wurde MMF vollständig pausiert (Tag 226) und am Tag 229 eine Therapie mit Prednisolon (20 mg/d) begonnen. Später wurde die Immunsuppression umgestellt und ab Tag 241 eine Therapie mit Everolimus begonnen. Am Tag 254 wurde eine Leberpunktion durchgeführt, die jedoch keine Anzeichen für eine Abstoßungsreaktion aufwies. Die Prednisolon-Dosis wurde auf 7,5mg reduziert, am Tag 262 weiter auf $5 \mathrm{mg}$ reduziert und im Verlauf schließlich ganz abgesetzt. Im Rahmen der ERCP am Tag 269 wurde eine EPT durchgeführt. Der DHC konnte nicht dargestellt werden, so dass eine erneute ERCP am Tag 272 erfolgte. In einer Abdomensonographie vom Tag 308 zeigte sich ein erweiterter DHC sowie eine neu aufgetretene Aszites und eine bekannte, im Vergleich zur Voruntersuchung regrediente, Sple- 
nomegalie. Bei einer Aszites-Punktion ergab sich kein Anhalt für eine spontan bakterielle Peritonitis. In der zytologischen Beurteilung wurden regressiv veränderte Makrophagen und Mesothelzellen beschrieben, Zellen einer Entzündungsreaktion oder einer Neoplasie waren jedoch nicht nachweisbar. Verlauf der GcfDNA und der Routinelaborparameter: Initial war die GcfDNA zunächst innerhalb von 15 Tagen unter die 10\%-Grenze abgefallen. Im weiteren Verlauf zeigten GcfDNA, AST, GGT und Bilirubin schwankende und teils deutlich erhöhte Werte. Die GcfDNA erreichte ihr Maixmum von 62\% am Tag 273 (siehe Abbildung 4.32). Die Hepatitis-C-Virluslast (HCV-RNA-Konzentration) war zu diesem Zeitpunkt mit $8,10^{*} 10^{6} \mathrm{IU} / \mathrm{ml}$ deutlich erhöht.

Der 51-jährige männliche Patienten LTx20 (Abbildung 4.33) litt an einer Hepatitis-Cinduzierten Leberzirrhose (Child-Pugh-Stadium A) mit unifokalem HCC. Das transplantierte Organ stammte von einer 65-jährigen weiblichen Spenderin mit positivem CMV-IgG- und Toxoplasmose-Titer. 


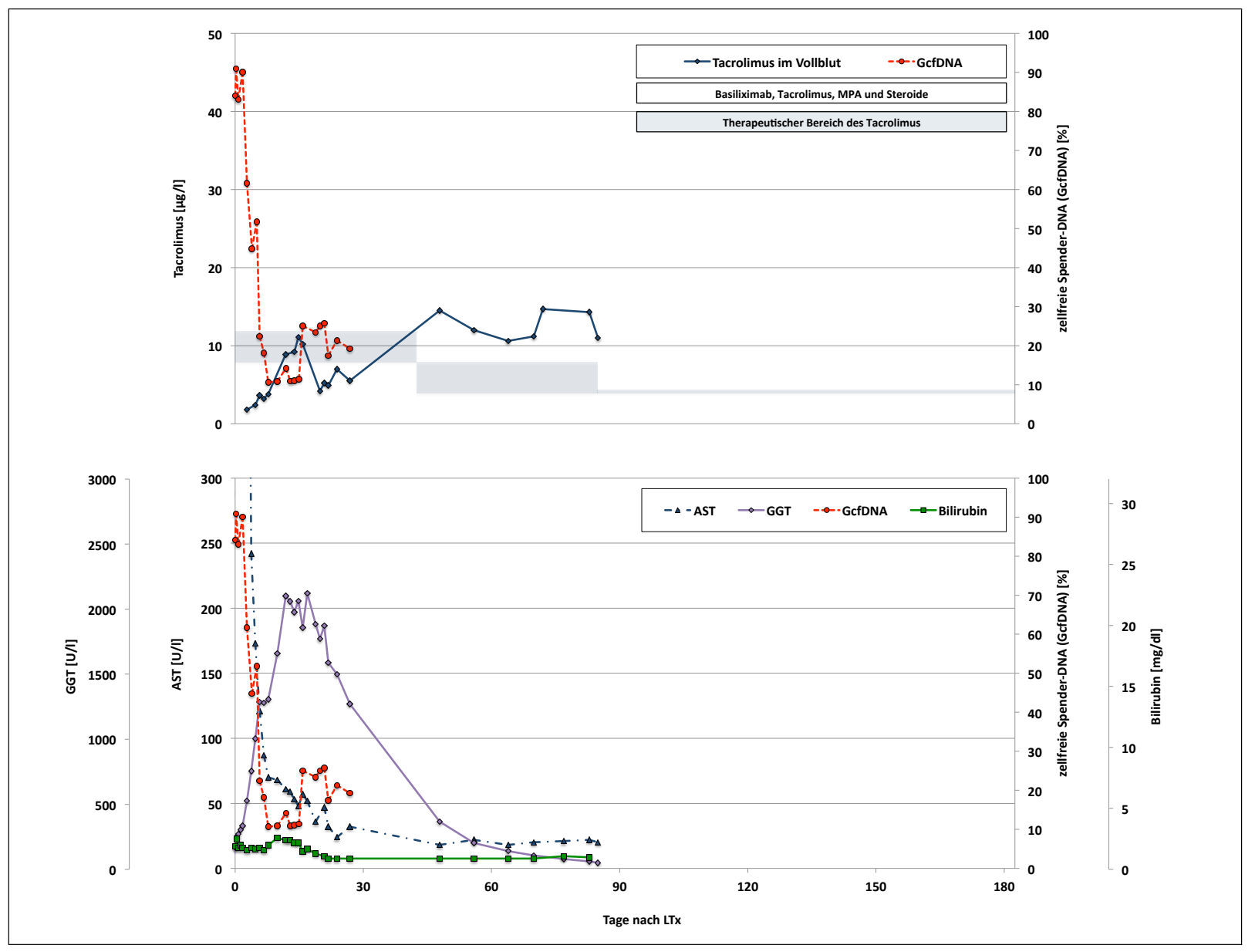

Abbildung 4.33: GcfDNA, Aspartat-Aminotransferase-(AST)-, $\quad \gamma$-Glutamyl-Transferase(GGT)-Aktivität sowie Bilirubin-Konzentration bei Patienten mit Hepatitis-C-Infektion (LTx20)

Klinischer Verlauf: Der postoperative Verlauf gestaltete sich zunächst unkompliziert. Ab der zweiten Woche nach Transplantation manifestierte sich eine virusbedingte Schädigung der Transplantatleber durch Reaktiverung der Hepatitis C. Verlauf der GcfDNA und der Routinelaborparameter: Im Rahmen der routinemäßig bestimmten Leberparameter und der GcfDNA zeigte sich zunächst ein normaler Verlauf der Ischämie- / Reperfusions-Schadensparameter (siehe Abbildung 4.33). Die GcfDNA war nach 7 Tagen auf Werte um $10 \%$ abgefallen. Dann kam es jedoch zu einem erneuten Ansteigen der Cholestaseparameter und Transaminasen. Hier waren vor allem ein deutlicher Anstieg der GGT und der GcfDNA (auf Werte über 20\%) zu erkennen, die auf eine virusbedingte Leberzellschädigung zurückzuführen sind.

Bei den Patienten mit Hepatitis-C-Infektionen (LTx1, LTx7, LTx10 und LTx20) zeigte sich nach Transplantation eine gesteigerte Viruslast (siehe Abbildung 4.34). Die Hemmung des Immunsystems führte hier zu einer Reaktivierung der Hepatitis und zusätzlicher Leber- 
zellschädigung (siehe Kapitel 4.5 und 4.6).

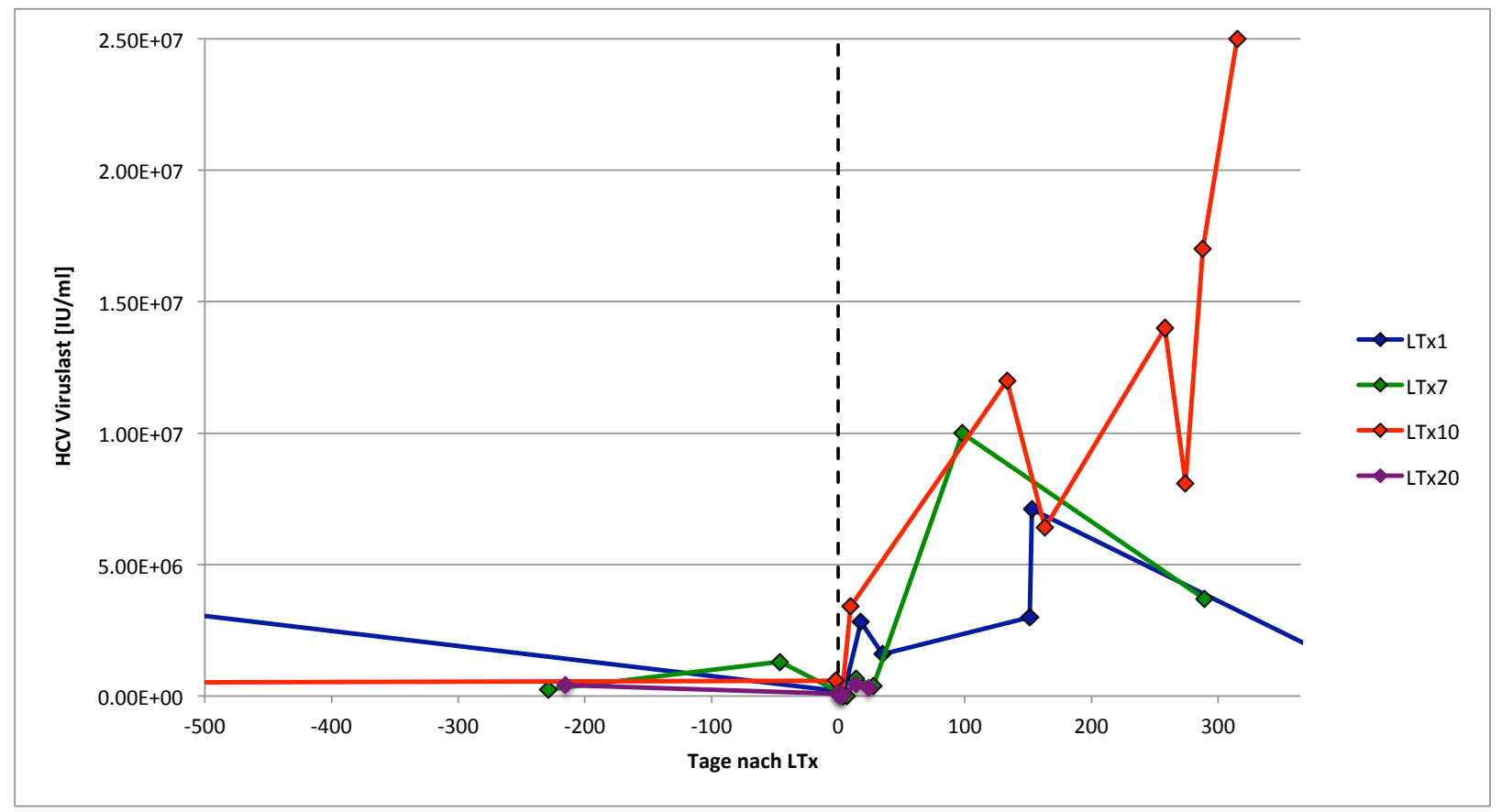

Abbildung 4.34: Verlauf der Hepatits-C-Viruslast vor und nach Transplantation

\subsubsection{Patienten mit Umstellung der Immunsuppression}

Bei Patientin LTx6 (Abbildung 4.35) bestand eine äthyltoxische Leberzirrhose und ein HCC. Dadurch war die Indikation für eine Lebertransplantation gegeben. Als Bridging-Verfahren wurden vor der Transplantation mehrfache TACE-Sitzungen durchgeführt. Die Empfängerin war zum Zeitpunkt der Transplantation 64 Jahre alt. Das Organangebot stammte von einer 41-jährigen weiblichen Spenderin mit positiven EBV- und Toxoplasmose-Titern. 


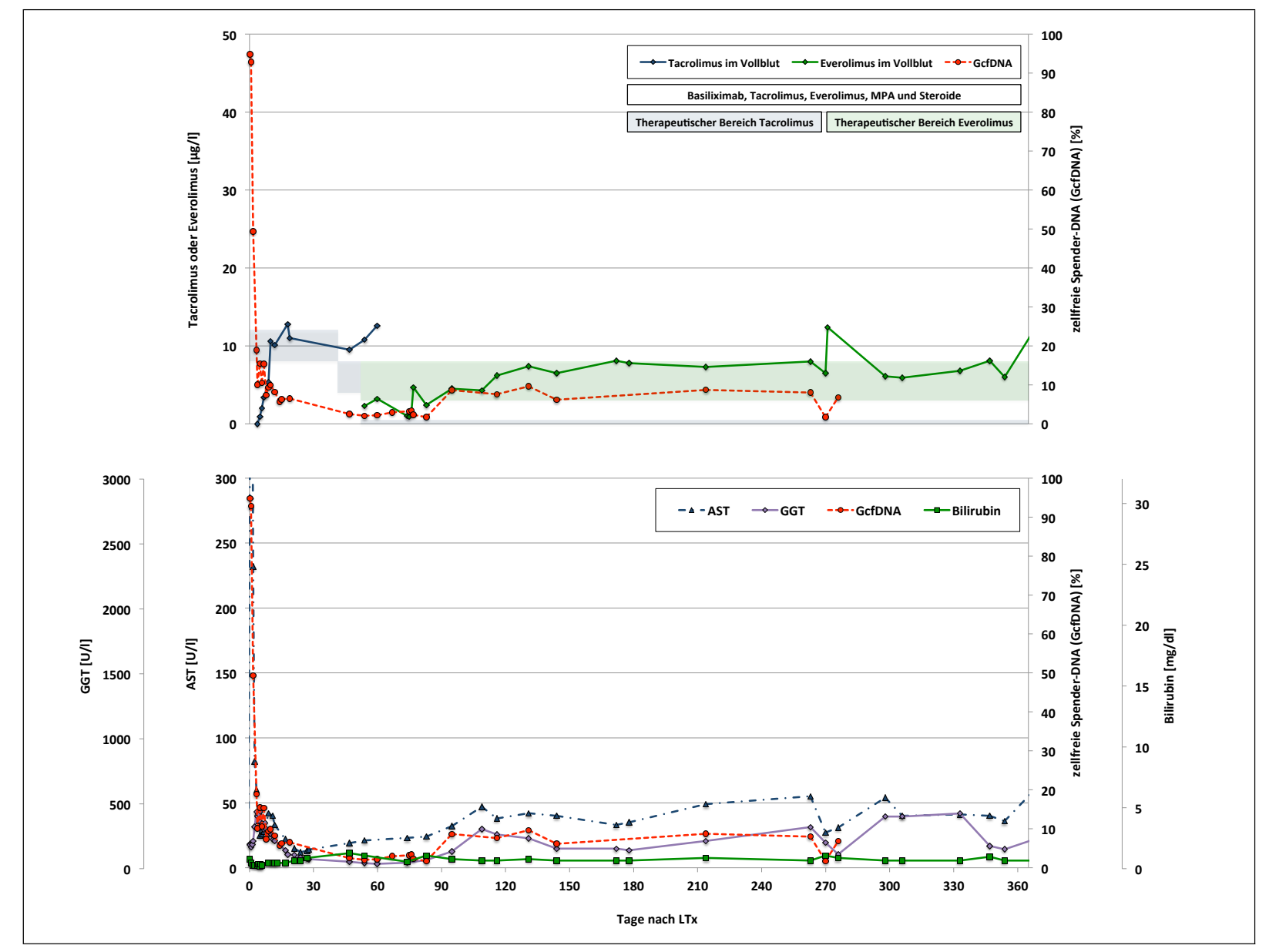

Abbildung 4.35: GcfDNA, Aspartat-Aminotransferase-(AST)-, $\quad \gamma$-Glutamyl-Transferase(GGT)-Aktivität sowie Bilirubin-Konzentration bei Patienten mit Umstellung der Immunsuppression (LTx6)

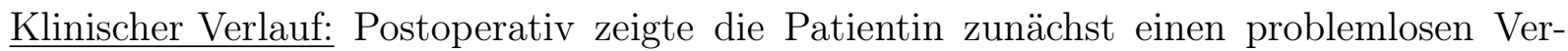
lauf. Später fiel dann eine deutlich eingeschränkte Nierenfunktion auf. Daraufhin wurde die Tacrolimus-Dosierung reduziert und am Tag 48 als Hauptimmunsuppressivum durch Everolimus ersetzt. Am 69. postoperativen Tag wurde Tacrolimus vollständig abgesetzt, die Dosis von Everolimus gesteigert und bis zum Erreichen des Zielspiegels erneut Methylprednisolon zur Vorbeugung einer Transplantatabstoßung verordnet. Darunter waren die Kreatininwerte rückläufig. Verlauf der GcfDNA und der Routinelaborparameter: Innerhalb einer Woche fiel die GcfDNA dauerhaft auf Werte unter 10\%. AST und GGT zeigten im weiteren Verlauf erhöhte Werte (siehe Abbildung 4.35).

Auch bei weiteren Patienten wurde die immunsuppressive Therapie auf Everolimus als Haupt-Immunsuppressivum umgestellt: Bei Patient LTx2 erfolgte die Umstellung am Tag 217, bei LTx4 am Tag 124, bei LTx8 am Tag 81 und bei LTx12 am Tag 43 (siehe Abbil- 
dung 4.36). Hierbei zeigt sich, dass es in vier (LTx2, LTx3, LTx8 und LTx10) von sechs Fällen bei der Umstellung der immunsuppressiven Therapie zu einem Anstieg der GcfDNA auf Werte deutlich oberhalb der kritischen Grenze von 10\% (Beck et al. 2013b) gekommen ist. In zwei dieser Fälle wurde eine Abstoßung per Biopsie nachgewiesen (LTx2 und LTx3).

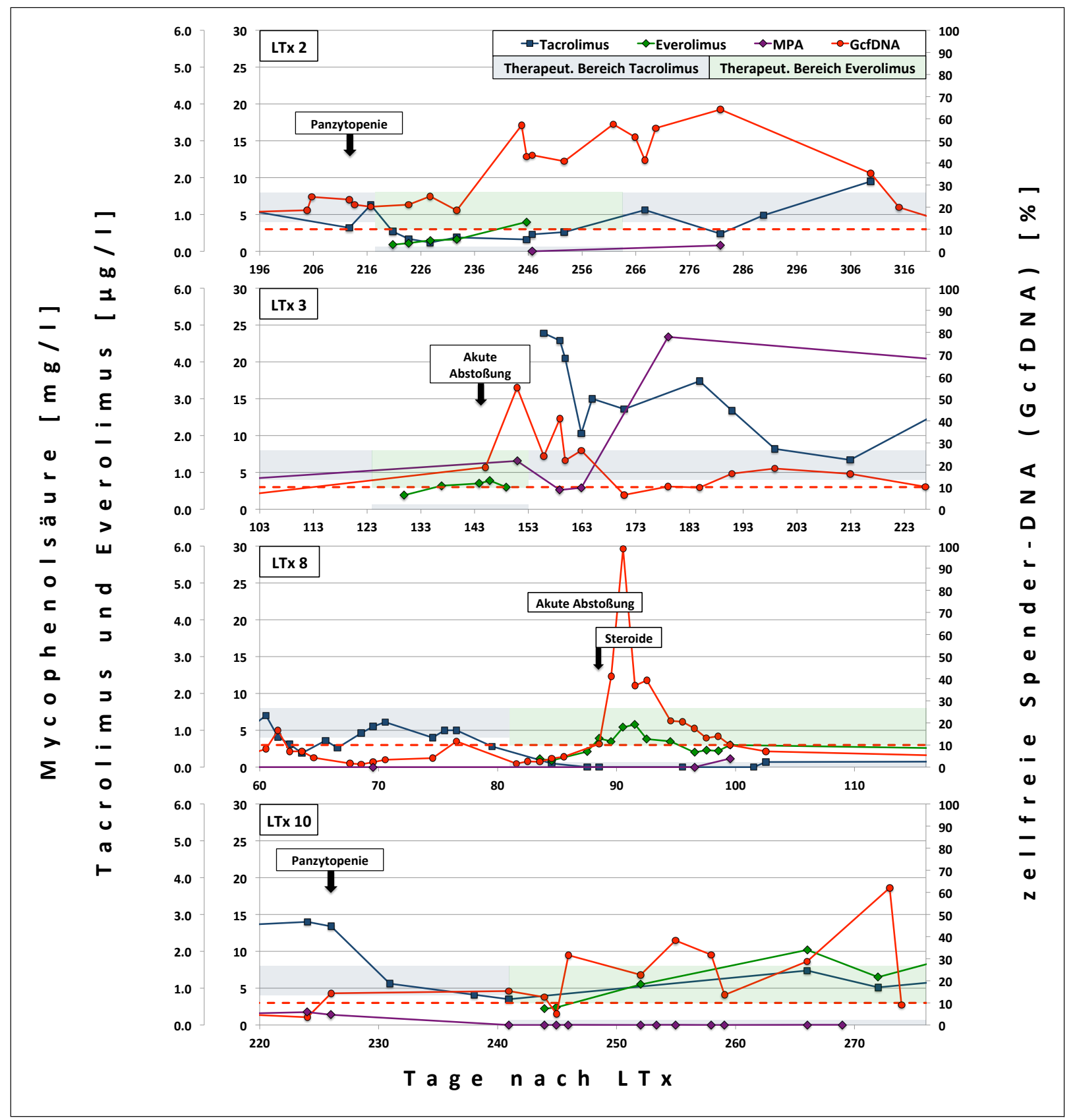

Abbildung 4.36: Verlauf der GcfDNA und Spiegel der Immunsuppressiva im Vollblut während Umstellung der immunsuppressiven Therapie mit erkennbarer Schädigung des Transplantates (der 10\%-Grenzwert für die GcfDNA ist gestrichelt dargestellt) 
Auch die Bedeutung des TDM für MPA lässt sich erkennen, da die gemessenen Konzentrationen in den Fällen mit einer Schädigung des Transplantates unterhalb des therapeutischen Bereiches (1,9 bis 4,0 mg/l) lagen. Dadurch war die Immunsuppression zu diesen Zeitpunkten unzureichend. Erst nach angestiegenen Spiegeln bzw. einer Steroid-Stoßtherapie (LTx8) fielen die Werte der GcfDNA wieder unter 10\% ab. Bei den Umstellungen von LTx6 und LTx12, wo deutlich höhere Spiegel der Immunsuppressiva gemessen wurden, kam es zu keiner erkennbaren Schädigung des Transplantates (siehe Abbildung 4.37). Es zeigt sich, dass sich die GcfDNA umgekehrt proportional zur immunsuppressiven Therapie verhält und ein gutes Monitoring während der kritischen Phase einer Therapieumstellung erlaubt.

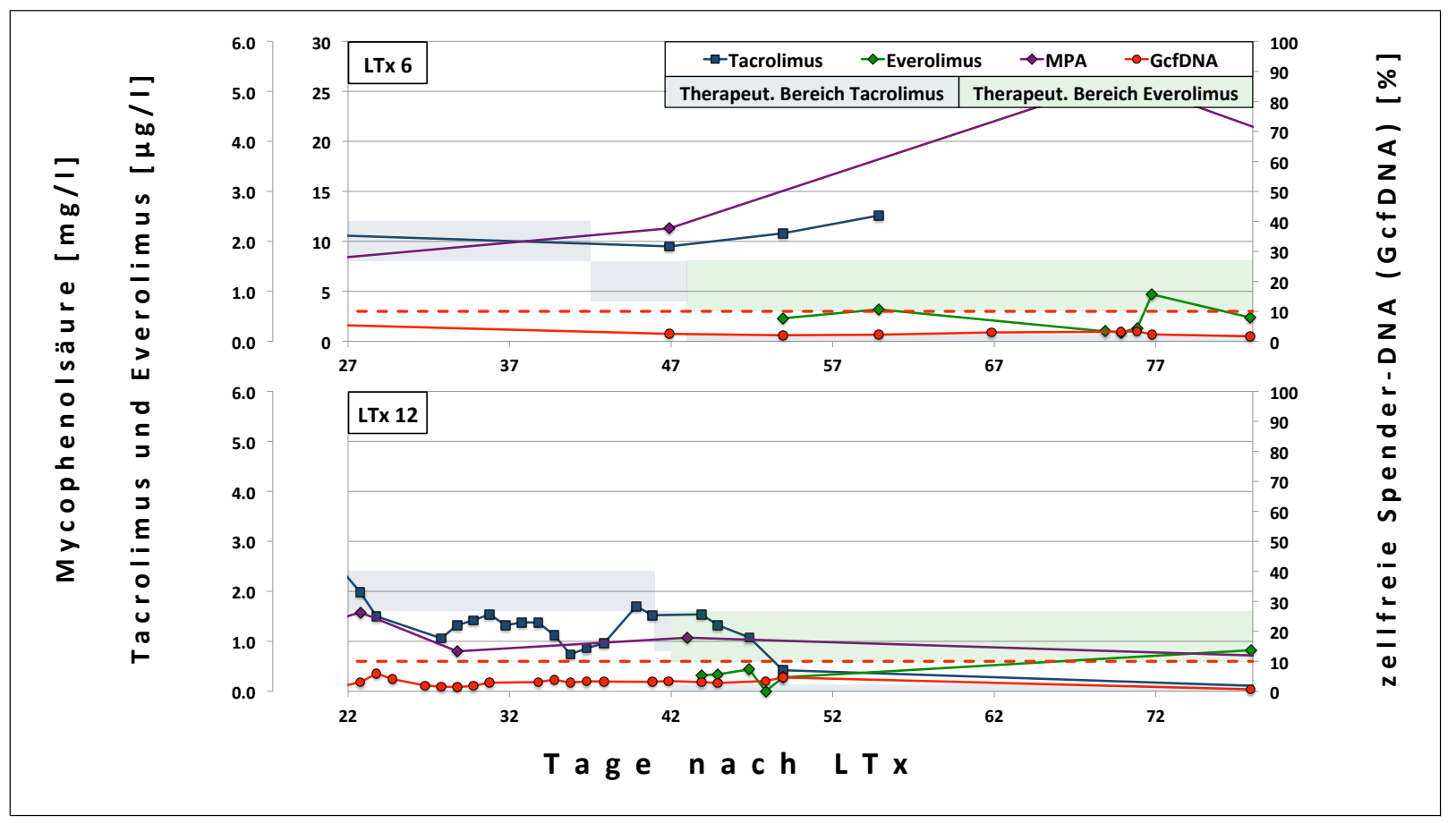

Abbildung 4.37: Verlauf der GcfDNA und Spiegel der Immunsuppressiva im Vollblut während Umstellung der immunsuppressiven Therapie ohne erkennbarer Schädigung des Transplantates (der 10\%-Grenzwert für die GcfDNA ist gestrichelt dargestellt) 


\section{Diskussion}

\subsection{Notwendigkeit für Biomarker}

Die Transplantationsmedizin hat in den letzten Jahren einen immer wichtigeren Stellenwert in unserer modernen Medizin eingenommen. Das Hauptproblem besteht allerdings in einem Mangel an ausreichenden Spenderorganen und überlangen Wartelisten für eine Transplantation (Rahmel 2012). Die eigentliche Schwierigkeit nach einer erfolgten Transplantation stellt die immunsuppressive Therapie dar. Diese gestaltet sich als enge Gratwanderung zwischen Über-Immunsuppression auf der einen und Unter-Immunsuppression auf der anderen Seite. Beides ist mit fatalen Folgen für den Gesamtorganismus und / oder das transplantierte Organ verbunden. Zur besseren Steuerung sind hier neue Biomarker notwendig, die einen Rückschluss auf den Status des Immunsystems bzw. Schädigung des transplantierten Organs zulassen. Dies ist mit TDM alleine nicht möglich. Klassischerweise werden daher in den meisten Transplantationszentren routinemäßig oder zumindest beim klinischen Verdacht einer Abstoßung Biopsien durchgeführt. Die histologische Differenzierung zwischen Leberzellschädigung aufgrund einer akuten Abstoßungsreaktion auf der einen oder durch Virusinfektion (Hepatitis C) auf der anderen Seite ist allerdings schwierig (Petrovic et al. 1997; Burton und Rosen 2006). Histologisch manifestiert sich eine Hepatitis-C-bedingte Schädigung des Transplantates durch Lymphozyten-Infiltration der Portalfelder und des Leberparenchyms, Nekrose der Hepatozyten und Veränderungen der Gallengänge (Lipson et al. 2006). Kennzeichnend für akute Abstoßungen ist eine Entzündung der Portalfelder, Nekrose der Gallengänge mit Entzündung des Endothels der Portalvenen (Demetris et al. 1997). Durch den Versand und die Befundung geht außerdem wertvolle Zeit verloren, in der bereits klinische Interventionen erfolgen könnten. Studien haben gezeigt, dass die Befunde und Einstufungen verschiedener Pathologen divergieren (Crespo-Leiro et al. 2012). Es stellt sich also die Frage, inwieweit Biopsien uneingeschränkt als Goldstandard für die Beurteilung von Organabstoßungen zu betrachten sind. 


\subsection{Nutzen der zirkulierenden zellfreien Spender-DNA als potentieller Biomarker}

Die GcfDNA hat sich in den Untersuchungen als hilfreicher Marker für Organschädigungen gezeigt. Eine solche Schädigung konnte entweder durch unzureichende Immunsuppression, Ischämie der Leber oder durch Infektionen wie z. B. Hepatitis C erfolgen. Diese Unterscheidung ist für die klinische Therapie aber von großer Bedeutung, da sich die Therapiemaßnahmen bei Infektionen (Erniedrigung der Immsuppression) und Abstoßungen (Erhöhung der Immunsuppression) genau konträr verhalten (Petrovic et al. 1997). Der Vorteil der GcfDNA als universeller Marker der Organschädigung gegenüber konventionellen Markern liegt darin, dass sie den Zelluntergang und die damit verbundene DNA-Freisetzung aus dem transplantierten Organ auf direkte Art und Weise widerspiegelt. Beim Einsatz von hoch dosierten Corticosteroiden während Steroid-Stoßtherapien hat sich im Rahmen dieser Arbeit gezeigt, dass die GcfDNA eine kurze Halbwertszeit besitzt und auf Anpassungen der immunsuppressiven Therapie unmittelbar reagiert. Unmittelbar nach deren Gabe ist ein deutlicher Abfall der GcfDNA erkennbar. Aus den analysierten Patientenverläufen ergibt sich eine Halbwertszeit von 23,5 Stunden. Dieser Wert liegt deutlich höher als die Literaturwerte bei fetaler cfDNA, für die eine Halbwertszeit von 16,3 Minuten angegeben wird (Lo et al. 1999c). Dies lässt sich darauf zurückführen, dass im Falle der Organschädigung DNA aus dem Spenderorgan während des betrachteten Zeitraums noch weiter freigesetzt wird. Es handelt sich bei dieser Betrachtung also nicht um terminale Halbwertszeiten.

Durch den Einsatz der GcfDNA bedarf es also nicht mehr der Kombination einer Reihe von konventionellen Markern mit zum Teil langen Halbwertszeiten, geringerer Spezifität und späten Anstiegen, die allgemein nur indirekt eine Aussage über den Organzustand liefern. Für konventionelle Marker wie AST und Alanin-Aminotransferase (ALT) wird in der Literatur eine Halbwertszeit von $17 \pm 5$ bzw. $47 \pm 10$ Stunden angegeben. Die Halbwertszeit der GGT liegt sogar bei 3 bis 4 Tagen (Schmidt und Schmidt 1976). 


\subsection{Diagnostischer Aussagewert der zirkulierenden zellfreien Spender-DNA im Vergleich zu konventionellen Leberfunktionswerten}

Bei Betrachtung der AST fällt auf, dass auch eine große Zahl an stabilen Patienten in der Frühphase nach Transplantation über erhöhte Werte verfügt (siehe Abbildung 4.12). Auch bei therapeutischen Tacrolimus-Spiegeln liegen nur 57,1\% der gemessenen AST-Werte innerhalb des Referenzbereichs. Bei subtherapeutischen Spiegeln sind es nur noch 45,5\%. Dieser Unterschied ist jedoch nicht signifikant. Allerdings zeigen Patienten mit akuten Abstoßungen, ebenso wie im Falle von Cholestasen, deutlich erhöhte AST-Werte. Die GGT zeigt sich noch unspezifischer: Nahezu alle Messwerte der Patienten in der Frühphase befinden sich oberhalb des Referenzbereiches. Auch hier sind, relativ gesehen, höhere Werte bei Cholestasen und akuten Abstoßungen zu beobachten. Es ist kein Einfluss der Immunsuppressiva-Spiegel erkennbar. Bei Betrachtung des Bilirubins als potentiellem Indikator für Abstoßungen fällt auf, dass selbst im Falle einer akuten Abstoßung keine signifikant erhöhten Konzentrationen gegenüber stabilen Patienten vorliegen. Erwartungsgemäß zeigen auch hier Patienten mit Cholestasen einen höheren Bilirubin-Wert. Zusammengefasst lässt sich also sagen, dass die konventionellen Parameter viel unspezifischer für die Beurteilung des Organzustandes sind und keine sichere Aussage über das Auftreten von akuten Abstoßungen sowie Abgrenzung zu anderen Krankheitsbildern (z. B. Cholestasen) erlauben.

Diese Beobachtungen lassen sich auf die pathobiochemischen Prozesse der Enzym- bzw. GcfDNA-Freisetzung zurückführen: Bei der AST handelt es sich um ein im Zytosol und in den Mitochondrien vorkommendes Enzym (Röhm 2007). Eine AST-Freisetzung ist also nicht zwingend mit einem Zelluntergang der Hepatozyten verbunden. Hier reicht schon eine - im Anfangsstadium durchaus reversible - Verletzung der Leberzellmembran-Integrität. Alleine ein ATP-Mangel, Trauma oder verringerte Energieproduktion z. B. durch Sauerstoffmangel aufgrund von Ischämie führt zu einer Verletzung der Barrierefunktion der Zellmembran. Dadurch kommt es zum Ausstrom zytosolischer Inhalte. Ein direkter Angriff auf die Zellmembran kann aber auch durch andere Faktoren wie z. B. Viren erfolgen (Panteghini und Bais 2012). Eine Erhöhung der GGT-Aktivität im Plasma ist nicht mit Zellschädigung oder -untergang verbunden. Das aktive Zentrum der GGT befindet sich auf der Zellaußenseite und kann von hier auch ohne Zellschädigung induziert freigesetzt werden (Panteghini und 
Bais 2012). Auch die Erhöhung der Bilirubin-Konzentration im Plasma ist nicht nur direkt auf eine Zellschädigung, sondern auch auf Cholestasen zurückzuführen. Dabei handelt es sich um eine Störung der hepatobiliären Transportsysteme oder einen gestörten Abfluss der Galle. Durch diesen Rückstau akkumulieren die Gallensäuren zunächst in den Hepatozyten und können dann bei hohen Konzentrationen zum Zelluntergang durch Apoptose führen (Häussinger und Löffler 2007). Bis es jedoch zur Freisetzung der DNA aus dem Zellkern in Form von cfDNA kommt, ist ein ganz anderer Schweregrad der Leberzellschädigung nötig. $\mathrm{Zu}$ diesem Zeitpunkt sind die Zelle und ihre intrazellulären Strukturen bereits irreversibel geschädigt.

Bei der AST handelt es sich also um einen Marker der Zellläsion. Weder eine Erhöhung der GGT noch der Bilirubin-Konzentration steht in jedem Fall in einem direkten Zusammenhang mit nekrotisierender Zellschädigung. Im Gegensatz dazu ist die GcfDNA ein Marker für eine durch Nekrose bzw. Apoptose ausgelöste Organschädigung (Arnalich et al. 2011; Quake 2012). Auch die Betrachtung der weitgehend leberspezifischen Enzyme ALT, im Zytosol lokalisiert, und Glutamat-Dehydrogenase (GLDH), die ausschließlich in den Mitochondrien zu finden ist, wäre für die Diagnose einer Leberzellschädigung möglich (Röhm 2007). Allerdings ist bei der ALT die Halbwertszeit deutlich länger als bei der AST. Die GLDH verfügt zwar mit $18 \pm 1$ Stunden über eine vergleichsweise kurze Halbwertszeit (Schmidt und Schmidt 1976), wird aber im Göttinger Transplantationszentrum nicht immer routinemäßig bestimmt.

\subsection{Diagnostische Aussagekraft der zirkulierenden zellfreien Spender-DNA bei den Verlaufsuntersuchungen}

Unmittelbar nach Transplantation sind bei allen Patienten sehr hohe Konzentrationen der cfDNA aus dem Spenderorgan (GcfDNA) messbar. Innerhalb von wenigen Tagen fallen die Werte schnell ab und liegen im Mittel bereits nach etwa 12,5 Tagen im Bereich von $\leq 10 \%$. Dieser Wert hat sich in einer Gruppe stabiler LTx-Transplantatempfänger als kritische Grenze für eine stabile Transplantatfunktion herausgestellt (Beck et al. 2013b). Allerdings besteht keine signifikante Korrelation der initialen GcfDNA-Freisetzung und der Reperfusions- / Ischämieschädigung des Spenderorgans. Hierbei haben jedoch mehrere Faktoren einen potentiellen Einfluss: Zum einen die KIZ, also die Zeit während des Organtransportes und der Präparation. Diese sollte bei der Leber 14,5 Stunden nicht überschreiten (Padbury et al. 
1994). Zum anderen die WIZ, die Zeit in der sich das Organ bereits im Empfänger befindet und die Anastomosen genäht werden. Damit ist also die kalte Lagerung des Organs beendet, aber es erfolgt auch noch keine Durchblutung. Außerdem kommt das Spenderalter als weitere potenzielle Einflussgröße in Betracht.

Durch die hohe Sensitivität der GcfDNA lassen sich bereits subklinische Abstoßungen erkennen und entsprechende Anpassungen der immunsuppressiven Therapie vornehmen. Dadurch könnte eine zeitnahe Intervention erfolgen. Der Nutzen hierfür zeigt sich dadurch, dass eine nicht erkannte chronische Schädigung des Spenderorgans unbehandelt in den Zustand einer chronischen Transplantatdysfunktion übergehen kann (American Society of Nephrology 2005). Auch eine Unterscheidung zwischen beginnenden Abstoßungen und Cholestasen ist mit diesem neuen Marker möglich (Beck et al. 2013b). Bei mehreren Patienten hat sich bestätigt, dass Cholestasen nicht mit einem Anstieg der GcfDNA einhergehen (LTx1, LTx14). Die Untersuchungen haben sogar gezeigt, dass der verwendete therapeutische Bereich für Tacrolimus zu hoch definiert ist und es im Einzelfall auch bei niedrigerer Immunsuppression mit folglich auch geringeren Nebenwirkungen nicht zur Transplantatschädigung kommt (Oellerich et al. 2014b). Bei den Patienten der vorliegenden Arbeit hat sich gezeigt, dass TacrolimusTalspiegel von mindestens $6,8 \mathrm{\mu g} / \mathrm{l}$ eine suffiziente Immunsuppression sicherstellen. Zu hohe Tacrolimus-Spiegel wirken sich nachteilig auf das Langzeitüberleben von Organtransplantaten aus (Rodríguez-Perálvarez et al. 2013). Auch im Therapieverlauf, insbesondere nach Abstoßungen liefert die GcfDNA einen Hinweis auf den Therapieerfolg (Beck et al. 2013b).

Besonders Patienten mit hohem immunologischem Risiko, Patienten in der Frühphase nach Organtransplantation und der damit verbundenen Initialphase der Immunsuppression sowie Patienten mit Infektionen und chronischen Erkrankungen (z. B. Hepatitis C) könnten nach Organtransplantation von diesem neuen Marker profitieren. Eine Über-Immunsuppression wirkt sich hier besonders kritisch aus. Dies zeigt sich in den angestiegenen Hepatitis-CViruslasten nach Organtransplantation. Die virusassoziierte Transplantatschädigung, die sich in den vergleichsweise höheren GcfDNA-Werten der Patienten mit Hepatitis-C-Infektionen manifestiert, sollte so gering wie möglich gehalten werden. Auch bei kritischen Phasen der immunsuppressiven Therapie wie beispielsweise Monotherapien oder Umstellungen von einem Immunsuppressivum auf ein anderes könnte die GcfDNA wertvolle Hilfestellung leisten und dabei helfen, eine Organschädigung zu vermeiden bzw. sie frühzeitig zu erkennen und ihr entgegenzuwirken. Bei den untersuchten Patienten ist es während dieser kritischen Pha- 
se in vier Fällen (LTx2, LTx3, LTx8 und LTx10) zu deutlich erhöhten GcfDNA-Werten gekommen, was als Zeichen einer Schädigung des transplantierten Organs zu werten ist. Mithilfe der GcfDNA lässt sich also der gemeinsame Effekt der Immunsuppression, zu diesem Zeitpunkt oftmals aus Tacrolimus, Everolimus, MPA und Cortison bestehend, ermitteln. Die GcfDNA verhält sich dabei umgekehrt proportional zur immunsuppressiven Therapie und erlaubt somit ein gutes und - mit einem einzigen Labortest - einfaches Monitoring während der Therapieumstellung. Auch bei der Beurteilung der initialen Organfunktion nach Transplantation hat sich die GcfDNA als hilfreich erwiesen. Bei LTx13, einer Re-Transplantation, zeigte sich anfangs eine Funktionsstörung und stark erhöhte Bilirubin-Werte (maximale Konzentration von 39,4 mg/dl am Tag 22). Die Immunsuppression war während dieser Zeit nur niedrig dosiert. Dennoch war die GcfDNA nur geringfügung erhöht. Eine Organschädigung konnte somit rückblickend ausgeschlossen werden. Sechs Wochen nach Transplantation besserte sich die Symptomatik deutlich, Bilirubin und AST fielen ab.

Mit der Weiterentwicklung der Diagnostik haben wir die Limitationen bisheriger Methoden auf der Basis von cfDNA überwunden. Die ddPCR erlaubt im Zusammenhang mit einem Panel ausgewählter SNPs die exakte Bestimmung der GcfDNA, unabhängig von der Spender-Empfänger-Konstellation (Beck et al. 2013b). Geschlechtsspezifische Einschränkungen aufgrund der Nutzung des Y-Chromosomens als Marker für die GcfDNA, die Notwendigkeit der Bestimmung von Spender-DNA, lange Laufzeiten und hohe Kosten durch DNASequenzierung gehören damit der Vergangenheit an.

Die Untersuchungen haben gezeigt, dass stabile Transplantatempfänger nach Lebertransplantation GcfDNA-Werte unter 10\% aufweisen. Bei unzureichender Immunsuppression (Tacrolimus-Spiegeln unter $8 \mu \mathrm{g} / \mathrm{l}$ ) setzen eine überwiegende Anzahl der Patienten größere Mengen an GcfDNA frei und zeigen somit auf direkte Weise eine Organschädigung durch UnterImmunsuppression auf. Patienten mit Hepatitis-C-Infektionen weisen generell höhere Werte der GcfDNA auf. Bei der Patientengruppe, deren Tacrolimus-Spiegel gleichzeitig im subtherapeutischen Bereich lagen, addieren sich beide Effekte und resultierten somit in noch höheren GcfDNA-Werten. Patienten mit akuten Abstoßungen haben GcfDNA-Werte oberhalb von 50\% (LTx2, LTx3, LTx8, LTx12 und LTx18). In drei dieser Fälle wurde eine Abstoßung per Biopsie nachgewiesen (LTx2, LTx3 und LTx18). Interessanterweise war die GcfDNA schon 4 bis 6 Tage vor einer klinisch manifestierten akuten Abstoßung signifikant erhöht. Diese Ergebnisse decken sich mit denen anderer Arbeitsgruppen (Snyder et al. 2011). Bei 
Patienten mit Cholestasen waren, im Gegensatz zu den konventionellen Abstoßungsmarkern in der Lebertransplantation (AST und GGT), keine erhöhten GcfDNA-Werte feststellbar. Dies bedeutet die Überlegenheit der GcfDNA gegenüber den konventionellen Enzymmarkern beim frühzeitigen und eindeutigen Erkennen von Abstoßungen. Eine Unterscheidung zwischen Abstoßungsreaktionen und Cholestasen ist mit den Laborparametern AST und GGT nicht ohne Weiteres möglich.

Mit der GcfDNA lässt sich bereits frühzeitig eine Organschädigung diagnostizieren. In der Nierentransplantation lässt sich eine Organabstoßung mit konventionellen Markern (anhand des Kreatininanstiegs) z. B. erst erkennen, wenn bereits ein erheblicher Teil der transplantierten Niere zerstört ist (American Society of Nephrology 2005). Auch das frühzeitige Erkennen von chronischer Organschädigung durch DSAs und daraus resultierende chronische Dysfunktion und Organverlust ist mit diesem Marker möglich (Pascual et al. 2002). Besonders interessant ist das Potential der GcfDNA für die Minimierung der immunsuppressiven Therapie. Mithilfe der GcfDNA lässt sich voraussichtlich für jeden Patienten die immunsuppressive Therapie im Sinne einer personalisierten Medizin auf ein absolut notwendiges Maß reduzieren (Oellerich et al. 2014b). Patienten mit einem höheren Grad an Toleranz gegenüber dem Spenderorgan könnten so identifiziert werden und von den Nebenwirkungen der Immunsuppressiva weitestgehend verschont bleiben.

\subsection{Offene Fragen}

Zu klären bleibt die Frage, welche weiteren Faktoren ebenfalls einen Einfluss auf die Freisetzung der GcfDNA und ihren Abbau haben könnten. An erster Stelle ist hier beispielsweise an die Organgröße zu denken. Insbesondere bei der im Bereich der Lebertransplantation möglichen Transplantation einzelner Organhälften (Split-LTx) ist eine geringere GcfDNAFreisetzung zu erwarten. Aber auch die Therapie und der postoperative Verlauf dürften von entscheidender Bedeutung sein. Im Rahmen der postoperativen Intensivtherapie sind häufig auch Dialysebehandlungen notwendig. In der Literatur ist der Einfluss von Dialysebehandlungen bei Patienten mit terminalem Nierenversagen auf die Freisetzung körpereigener zirkulierender Nukleinsäuren beschrieben. Hier steigt die Konzentration der cfDNA unmittelbar nach Dialyse, im Vergleich zur Referenzgruppe gesunder Patienten mit 0,43 ng/ $\mathrm{l}$, auf durchschnittlich 0,98 ng/ $\mathrm{l}$ Plasma an (Atamaniuk et al. 2012). Inwieweit es bei den transplantierten Patienten durch Dialyse auch zu einer Beeinflussung der GcfDNA kommt, 
ist hingegen noch offen. Hier könnte der Quotient aus GcfDNA und gesamter cfDNA im Sinne eines niedrigeren Quotienten verfälscht sein, wodurch unter Umständen sogar ein Anstieg der GcfDNA verschleiert werden könnte. Aufgrund der kurzen Halbwertszeit der cfDNA ist jedoch nur während oder unmittelbar nach Dialyse mit einer relevanten Beeinflussung der relativen GcfDNA-Messwerte zu rechnen. Auch die MARS-Therapie ist ein Verfahren, bei dem mit einer Beeinflussung der GcfDNA-Werte zu rechnen ist. Ebenfalls beeinflusst werden die Messungen der GcfDNA im Verhältnis zur gesamten cfDNA, also der Summe von genomischer cfDNA des Empfängers und der cfDNA des transplantierten Organs (GcfDNA), durch invasive Eingriffe, die zu einer Schädigung der Körperzellen und Muskulatur führen. Dies erfolgt z. B. durch zusätzliche Laparotomien, die nach der eigentlichen Transplantation durchgeführt werden. Auch ein potentieller Einfluss von eventuell in Blutprodukten und Transfusionen enthaltenen Nukleinsäuren ist möglich. Ein weiterer Nachteil der relativen gegenüber einer absoluten Quantifizierung besteht darin, dass aufgrund transplantatunabhängiger Faktoren GcfDNA und genomische cfDNA disproportional ansteigen könnten. Dadurch ist eine Verfälschung des Messresultates bei alleiniger Betrachtung des prozentualen Anteils der GcfDNA an der gesamten cfDNA möglich. Auf der anderen Seite entstehen durch Variablen im Messprozess, wie z. B. Schwankungen der Extraktionseffizienz, auch bei einer absoluten Quantifizierung der GcfDNA Ungenauigkeiten (Lo 2011).

Aber nicht nur die Therapie im Anschluss an die Transplantation und die Variablen der Methodik, sondern auch die Spender-Empfänger-Konstellation beinhaltet Limitationen der verwendeten Methode: So variert die MAF einzelner SNPs innerhalb verschiedener Bevölkerungsgruppen (Garat et al. 2011). Dadurch könnte die Anzahl der benötigten Assays, deren Auswahl auf die Bestimmung der GcfDNA bei europäischen Patienten optimiert ist, beeinflusst und die Analysen ggf. erschwert werden. Insbesondere bei Verwandtenspenden dürfte eine Bestimmung der GcfDNA erschwert bis - im Fall von eineiigen Zwillingen - unmöglich sein. Aber auch mehrfach transplantierte Patienten weisen in der Anfangsphase unmittelbar nach Transplantation das Problem auf, dass differierende cfDNA unterschiedlicher Individuen vorhanden ist: Einerseits aus dem Organ der vorhergegangenen Transplantation und andererseits aus dem neuen Transplantat. In der Praxis dürfte dieses Problem allerdings marginal sein, da die Halbwertszeit der cfDNA sehr gering ist und in der Literatur für fetale cfDNA mit 16,3 Minuten angegeben wird (Lo et al. 1999c). 
Ein großer Schritt bei der Eliminierung derartiger Einflussfaktoren ist kürzlich durch Beck et al. erfolgt. Dabei wird eine Kombination von relativer und absoluter Quantifizierung der GcfDNA genutzt. Auch diese Methode basiert auf ddPCR: Eine DNA-Sequenz aus nichthumanem Ursprung wird dabei in einem definierten Volumen jeder Plasmaprobe zugesetzt. Durch diesen externen Standard ist zunächst die absolute Bestimmung der gesamten cfDNA, die in der Probe enthalten ist, möglich. Multipliziert mit den relativen Konzentrationen [\%] der Spender-DNA ist eine Angabe der GcfDNA in Kopien je Milliliter Plasma möglich. Dadurch wird sowohl unterschiedlichen Gesamtmengen an cfDNA als auch einer variablen Effizienz des Extraktionsprozesses Rechnung getragen und die Vorteile der relativen Quantifizierung mit denen der absoluten verbunden.

Bei der Übertragung der Methodik zur Bestimmung der GcfDNA auf andere Organe ergeben sich weitere Probleme: Es ist anzunehmen, dass jeder Organtyp eine individuelle Entscheidungsgrenze für Organintegrität besitzt. Es hat sich gezeigt, dass stabile NTx$(\mathrm{n}=9)$ und HTx-Patienten $(\mathrm{n}=8)$ mit $1,2 \%$ bzw. $0,9 \%$ deutlich niedrigere GcfDNAKonzentrationen aufweisen (Beck et al. 2013b). Dies ist u. a. möglicherweise auf das größere Organvolumen der Leber im Vergleich zu Herzen und Nieren zurückzuführen. Bei kombinierten Transplantationen mehrerer Organe ist davon auszugehen, dass wiederum andere Grenzwerte für die Definition der Organintegritäten notwendig sind. Leberspezifische Einflüsse, wie z. B. die Möglichkeit einer virusbedingten Leberzellschädigung durch eine Hepatitis-CInfektion oder breite Schwankungen der Organgröße durch die Möglichkeit einer Split-LTx, sind bei Anwendung der GcfDNA bei Transplantatempfängern anderer Organe irrelevant. Dafür kommen dann aber beispielsweise durch den Einsatz einer Herz-Lungen-Maschine und dem eventuellen Nutzen von Fremd-Blut neue potentielle Einfluss- und Störfaktoren auf die GcfDNA hinzu. Snyder et al. haben dieses Problem umgangen, indem sie in den ersten zwei Wochen nach HTx noch keine Messungen durchgeführt haben (Snyder et al. 2011). Bei der Lunge dürfte die GcfDNA aufgrund der sich - durch ihre große Oberfläche und den Kontakt zur Außenwelt - besonders schwierig gestaltenden immunsuppressiven Therapie von großer Bedeutung sein. Auch das Problem der Unterscheidung zwischen Abstoßung und Infektion als Ursache für erhöhte Werte dürfte - ähnlich wie bei der Leber - eine Herausforderung sein.

In weiteren multizentrischen Studien gilt es nun, die Ergebnisse dieser explorativen Studie zu bestätigen und größere Fallzahlen zu generieren. Ebenfalls ist eine Ausweitung der Unter- 
suchungen auf das Gebiet der Nieren- und Herztransplantation sinnvoll. Dabei wird sich auch zeigen, ob eine absolute Quantifizierung der GcfDNA mit ihren zusätzlichen Arbeitsschritten der relativen Quantifizierung für den klinischen Einsatz überlegen ist. 


\section{Zusammenfassung}

Meine Untersuchungen zeigen, dass es sich bei der zellfreien DNA (cfDNA, engl. cell-free $D N A$ ) des Spenderorgans (GcfDNA, engl. graft-derived cell-free DNA) um einen klinisch vielversprechenden Biomarker zur direkten Ermittlung der Organschädigung im Sinne einer „flüssigen Biopsie“ (Beck et al. 2013b) handelt. Alles was dafür notwendig ist, ist eine Blutprobe des Empfängerpatienten. Im Gegensatz zu konventionellen Markern wird die Organschädigung unmittelbar, direkt und hochspezifisch angezeigt. Durch neue Entwicklungen in der Labordiagnostik lässt sich dieser Marker im routinemäßigen Einsatz mittels digital droplet PCR (ddPCR) bestimmen. Die Analyseergebnisse können bei verhältnismäßig niedrigen Kosten innerhalb eines Arbeitstages erstellt werden (Beck et al. 2013b).

Unmittelbar nach Transplantation ist bei allen Patienten eine sehr hohe Konzentration der GcfDNA messbar. Innerhalb von wenigen Tagen fallen die Werte schnell ab und erreichen die Größenordnung stabiler Transplantatempfänger, die in der Lebertransplantation unter 10\% liegen. Dabei besteht keine signifikante Korrelation der initialen GcfDNA-Freisetzung mit der Ischämieschädigung des Spenderorgans, ermittelt durch die Dauer der kalten Ischämiezeit (WIZ). Bei unzureichender Immunsuppression ist eine erhöhte GcfDNA-Freisetzung zu beobachten. Mithilfe der GcfDNA als Marker der Organintegrität lässt sich auch der gemeinsame Effekt verschiedener Immunsuppressiva ermitteln. Die GcfDNA verhält sich dabei umgekehrt proportional zur immunsuppressiven Therapie. Patienten mit akuten Abstoßungen haben im Mittel GcfDNA-Werte oberhalb von 50\%. Die GcfDNA-Werte sind bereits mehrere Tage vor einer klinisch manifestierten akuten Abstoßung erhöht. Auch eine virusassoziierte Transplantatschädigung durch Hepatitis C manifestiert sich in vergleichsweise höheren GcfDNA-Werten. Cholestasen gehen hingegen nicht mit erhöhten GcfDNA-Werten einher.

Die immunsuppressive Therapie könnte sich durch den routinemäßigen Einsatz der GcfDNA sicherer, einfacher, zuverlässiger und individueller gestalten lassen. Unter-Immunsuppressionen und daraus resultierende Abstoßungen würden sich bereits in der subklinischen Phase erkennen lassen und die Therapie von der bloßen Reaktion auf klinische Ereignisse hin zur 
Prävention verschieben. Um das Ziel einer personalisierten Medizin zu erreichen, könnte die Immunsuppression für jeden Patienten auf das absolut notwendige und damit gegenüber der bisherigen Praxis optimale Maß festgelegt werden (Oellerich et al. 2014b). Geringere Nebenwirkungen und eine Reduktion der Kosten für das Gesundheitswesen wären die Konsequenz. Dieser Marker könnte dazu beitragen, das finale Ziel, nämlich eine Verbesserung des Langzeiterfolges nach Organtransplantationen, zu erreichen. Multizentrische Studien zur Validierung dieses Markers vor dem routinemäßigen Einsatz laufen bereits. 


\section{Abkürzungsverzeichnis}

In der vorliegenden Arbeit finden neben den international gültigen physikalischen Einheiten, chemischen Symbolen und international gebräuchlichen Abkürzungen die folgende Abkürzungen Verwendung:

ALT

Alanin-Aminotransferase

AP

Alkalische Phosphatase

AST

Aspartat-Aminotransferase

AUC engl. area under the curve

BMBF Bundesministerium für Bildung und Forschung

cfDNA zellfreie DNA, engl. cell-free DNA

CMV Zytomegalievirus

CNIs Calcineurin-Inhibitoren

CsA Cyclosporin A

ddPCR engl. digital droplet PCR

DHC Ductus hepaticus communis

DSA spenderspezifische Antikörper, engl. donor-specific antibodies

EBV Epstein-Barr-Virus

EPT endoskopische Papillotomie

ERCP endoskopische retrograde Cholangiopankreatikographie

GcfDNA cfDNA des Spenderorgans, engl. graft-derived cell-free DNA gDNA genomische DNA

GGT $\curlyvee$-Glutamyl-Transferase

HCC Leberzellkarzinom, engl. hepatocellular carcinoma HSV Herpes-simplex-Viren 
HTx

Herztransplantation

iATP intrazelluläres ATP

IL-2 Interleukin-2

IMPDH Inosinmonophosphatasedehydrogenase

JAK Januskinase

$\mathrm{KIZ}$ kalte Ischämiezeit

LTX Lebertransplantation

MAF Minor Allelic Frequency

MARS-Therapie Molecular Adsorbent Recirculation System

miRNA microRNA

MMF Mycophenolat-Mofetil

MPA Mycophenolsäure

mRNA Boten-RNA, engl. messenger RNA

mTOR. mammalian Target of Rapamycin

NK-Zellen natürliche Killerzellen

NTx Nierentransplantation

PCR Polymerase-Kettenreaktion, engl. Polymerase Chain Reaction

PKC Proteinkinase C

RCF relative Zentripetalbeschleunigung, engl. Relative Centrifugal Force

ROC-Kurve Grenzwertoptimierungskurve, engl. Receiver Operator Characteristic Curve

SNP Single-Nukleotid-Polymorphismus

SOP Arbeitsanweisung, engl. Standard Operating Procedure

STAT Signal Transducers and Activators of Transcription

TACE transarterielle Chemoembolisation

TDM Medikamentenspiegelbestimmung, engl. Therapeutic Drug Monitoring

Tregs regulatorische T-Zellen

WIZ warme Ischämiezeit

VZV Varizella-Zoster-Virus 


\section{Abbildungsverzeichnis}

1.1 Modell der T-Zell-Aktivierung (Cooper und Wiseman 2010 - Abdruck mit Genehmigung, Bildnachweis auf Seite 123) . . . . . . . . . . 5

3.1 Schema mit den Abnahmezeitpunkten für die im Rahmen dieser Arbeit durchgeführten Untersuchungen der GcfDNA . . . . . . . . . . . . . . 20

3.2 Prinzip der GcfDNA-Messungen (verändert nach Beck et al. 2013b - Abdruck mit Genehmigung, Bildnachweis auf Seite 123) . . . . . . . . . . .

3.3 Verhältnisse der Kopienanzahl ohne und mit vorhergehender Präamplifikation mit Standardabweichungen (Beck et al. 2013b - Abdruck mit Genehmigung, Bildnachweis auf Seite 123) . . . . . . . . . . . . . . . .

3.4 Streudiagramm mit Signalen der einzelnen Droplets (Beck et al. 2013b - Abdruck mit Genehmigung, Bildnachweis auf Seite 123) . . . . . . . . . . .

3.5 Anzahl der Droplets für beide Kanäle und Gesamtzahl aller gemessenen Droplets (Beck et al. 2013b - Abdruck mit Genehmigung, Bildnachweis auf Seite 123

3.6 GcfDNA-Messwerte bei stabilen nieren-, herz- und lebertransplantierten Patienten. Angegeben sind jeweils Mittelwert, Standardabweichung und die Anzahl der verwendeten SNP-Assays (Beck et al. 2013b - Abdruck mit Genehmigung, Bildnachweis auf Seite 123) . . . . . . . . . . . . .

4.1 Einzelverläufe der GcfDNA über die ersten 30 Tage nach Transplantation . .

4.2 GcfDNA und traditionelle Lebermarker bei chronischer Abstoßung und SteroidStoßtherapien (Beck et al. 2013a - Abdruck mit Genehmigung, Bildnachweis

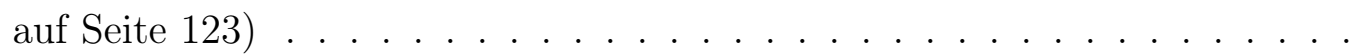

4.3 Abfälle der GcfDNA nach Steroid-Stoßtherapien und näherungsweise Beschreibung der Verläufe durch exponentielle Regression . . . . . . . . . . . . 
4.4 Korrelation der kalten Ischämiezeit (KIZ) mit den Logits der AUCs der GcfDNA über die ersten 8 Tage, 95\%-Konfidenzintervall gepunktet dargestellt . . . . . .

4.5 Boxplots mit den täglichen Tacrolimus-Dosierungen zwischen den Tagen 5 und 30 (verändert nach Oellerich et al. 2014b - Abdruck mit Genehmigung, Bildnachweis auf Seite 123) . . . . . . . . . . . . . . .

4.6 Vergleich der Tacrolimus-Talspiegel im Vollblut mit der GcfDNA-Freisetzung während der Tage 5 bis $30, \mathrm{n}=211$ Wertepaare, $\mathrm{N}=18$ Patienten (verändert nach Oellerich et al. 2014b - Abdruck mit Genehmigung, Bildnachweis auf Seite 123) . . . . . . . . . . . . . . . . . .

4.7 Vergleich der Tacrolimus-Talspiegel im Vollblut mit der Aspartat-Aminotransferase-(AST)-Aktivität im Plasma während der Tage 5 bis 30, $\mathrm{n}=183$ Wertepaare, $\mathrm{N}=18$ Patienten . . . . . . . . . . . . . .

4.8 Vergleich der Tacrolimus-Talspiegel im Vollblut mit der $\gamma$-Glutamyl-Transferase-(GGT)-Aktivität im Plasma während der Tage 5 bis 30, $\mathrm{n}=183$ Wertepaare, $\mathrm{N}=18$ Patienten . . . . . . . . . . . . . . .

4.9 Grenzwertoptimierungskurve (ROC-Kurve), N = 18 Patienten, 95\%-Konfidenzintervall gestrichelt dargestellt (verändert nach Oellerich et al. 2014b Abdruck mit Genehmigung, Bildnachweis auf Seite 123) . . . . . . . . . .

4.10 GcfDNA in Abhängigkeit von Tacrolimus-Spiegeln und Hepatitis-C-Status sowie bei Events (Abstoßungen und Cholestasen), $\mathrm{N}=18$ Patienten, $\mathrm{n}=248$ (verändert nach Oellerich et al. 2014a - Abdruck mit Genehmigung, Bildnachweis auf Seite 123) . . . . . . . . . . . . . . . . . .

4.11 GcfDNA in Abhängigkeit von Tacrolimus-Spiegeln und Hepatitis-C-Status sowie bei Events (Abstoßungen und Cholestasen), N = 18 Patienten, Subgruppe von Abbildung $4.10(\mathrm{n}=207) \ldots \ldots \ldots$

4.12 Aspartat-Aminotransferase-(AST)-Aktivität im Plasma in Abhängigkeit von Tacrolimus-Spiegeln und Hepatitis-C-Status sowie bei Events (Abstoßungen und Cholestasen), $\mathrm{N}=18$ Patienten, Subgruppe $(\mathrm{n}=207) \ldots \ldots$

4.13 Signifikante Korrelation von GcfDNA- und Aspartat-Aminotransferase-(AST)Aktivität im Plasma zwischen den Tagen 8 und 30, N = 18 Patienten, Sub-

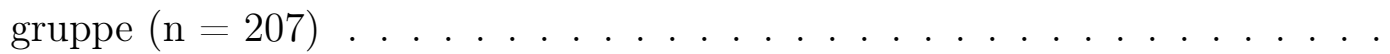


$4.14 \gamma$-Glutamyl-Transferase-(GGT)-Aktivität im Plasma in Abhängigkeit von Tacrolimus-Spiegeln und Hepatitis-C-Status sowie bei Events (Abstoßungen und Cholestasen), $\mathrm{N}=18$ Patienten, Subgruppe $(\mathrm{n}=207) \ldots \ldots \ldots$

4.15 Bilirubin-Konzentration im Plasma in Abhängigkeit von Tacrolimus-Spiegeln und Hepatitis-C-Status sowie bei Events (Abstoßungen und Cholestasen), $\mathrm{N}=18$ Patienten, Subgruppe $(\mathrm{n}=207) \ldots \ldots \ldots$

4.16 GcfDNA, Aspartat-Aminotransferase-(AST)-, $\gamma$-Glutamyl-Transferase-(GGT)Aktivität sowie Bilirubin-Konzentration bei Verlauf ohne erkennbare Schädigung des Transplantates $(\operatorname{LTx} 4) \ldots \ldots \ldots$

4.17 GcfDNA, Aspartat-Aminotransferase-(AST)-, $\gamma$-Glutamyl-Transferase-(GGT)Aktivität sowie Bilirubin-Konzentration bei Verlauf ohne erkennbare Schädigung des Transplantates $(\mathrm{LTx} 13) \ldots \ldots \ldots$

4.18 GcfDNA, Aspartat-Aminotransferase-(AST)-, $\gamma$-Glutamyl-Transferase-(GGT)Aktivität sowie Bilirubin-Konzentration bei Verlauf ohne erkennbare Schädigung des Transplantates $(\operatorname{LTx} 15) \ldots \ldots \ldots$

4.19 GcfDNA, Aspartat-Aminotransferase-(AST)-, $\gamma$-Glutamyl-Transferase-(GGT)Aktivität sowie Bilirubin-Konzentration bei Verlauf ohne erkennbare Schädigung des Transplantates $(\operatorname{LTx} 16) \ldots \ldots \ldots$

4.20 GcfDNA, Aspartat-Aminotransferase-(AST)-, $\gamma$-Glutamyl-Transferase-(GGT)Aktivität sowie Bilirubin-Konzentration bei Verlauf ohne erkennbare Schädigung des Transplantates $(\operatorname{LTx} 21) \ldots \ldots \ldots \ldots$. . . . . . . . . . 5

4.21 GcfDNA, Aspartat-Aminotransferase-(AST)-, $\gamma$-Glutamyl-Transferase-(GGT)Aktivität sowie Bilirubin-Konzentration bei Verlauf mit Cholestase (LTx1) .

4.22 GcfDNA, Aspartat-Aminotransferase-(AST)-, $\gamma$-Glutamyl-Transferase-(GGT)Aktivität sowie Bilirubin-Konzentration bei Verlauf mit Cholestase (LTx14) .

4.23 GcfDNA, Aspartat-Aminotransferase-(AST)-, $\gamma$-Glutamyl-Transferase-(GGT)Aktivität sowie Bilirubin-Konzentration bei Verlauf mit Abstoßung (LTx2) .

4.24 GcfDNA, Aspartat-Aminotransferase-(AST)-, $\gamma$-Glutamyl-Transferase-(GGT)Aktivität sowie Bilirubin-Konzentration bei Verlauf mit Abstoßung (LTx3) . 
4.25 GcfDNA, Aspartat-Aminotransferase-(AST)-, $\gamma$-Glutamyl-Transferase-(GGT)Aktivität sowie Bilirubin-Konzentration bei Verlauf mit Abstoßung (LTx8, verändert nach Kanzow et al. 2014) - Abdruck mit Genehmigung, Bildnachweis auf Seite 123) . . . . . . . . . . . . . . . .

4.26 GcfDNA, Aspartat-Aminotransferase-(AST)-, $\gamma$-Glutamyl-Transferase-(GGT)Aktivität sowie Bilirubin-Konzentration bei Verlauf mit Abstoßung (LTx12) .

4.27 GcfDNA, Aspartat-Aminotransferase-(AST)-, $\gamma$-Glutamyl-Transferase-(GGT)Aktivität sowie Bilirubin-Konzentration bei Verlauf mit Abstoßung (LTx18) .

4.28 GcfDNA, Aspartat-Aminotransferase-(AST)-, $\gamma$-Glutamyl-Transferase-(GGT)Aktivität sowie Bilirubin-Konzentration bei Patienten mit Infektionen (LTx17) 72

4.29 GcfDNA, Aspartat-Aminotransferase-(AST)-, $\gamma$-Glutamyl-Transferase-(GGT)Aktivität sowie Bilirubin-Konzentration bei Patienten mit Infektionen (LTx19) 74

4.30 GcfDNA, Aspartat-Aminotransferase-(AST)-, $\gamma$-Glutamyl-Transferase-(GGT)Aktivität sowie Bilirubin-Konzentration bei Patienten mit Infektionen (LTx22) 76

4.31 GcfDNA, Aspartat-Aminotransferase-(AST)-, $\gamma$-Glutamyl-Transferase-(GGT)Aktivität sowie Bilirubin-Konzentration bei Verlauf mit Hepatitis-C-Infektion $(\mathrm{LTx} 7) \ldots \ldots \ldots \ldots \ldots \ldots \ldots$

4.32 GcfDNA, Aspartat-Aminotransferase-(AST)-, $\gamma$-Glutamyl-Transferase-(GGT)Aktivität sowie Bilirubin-Konzentration bei Patienten mit Hepatitis-C-Infektion (LTx10)

4.33 GcfDNA, Aspartat-Aminotransferase-(AST)-, $\gamma$-Glutamyl-Transferase-(GGT)Aktivität sowie Bilirubin-Konzentration bei Patienten mit Hepatitis-C-Infektion

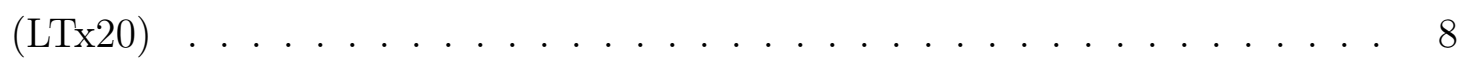

4.34 Verlauf der Hepatits-C-Viruslast vor und nach Transplantation . . . . . . . . 82

4.35 GcfDNA, Aspartat-Aminotransferase-(AST)-, $\gamma$-Glutamyl-Transferase-(GGT)Aktivität sowie Bilirubin-Konzentration bei Patienten mit Umstellung der Immunsuppression $(\mathrm{LTx} 6) \ldots \ldots \ldots \ldots$

4.36 Verlauf der GcfDNA und Spiegel der Immunsuppressiva im Vollblut während Umstellung der immunsuppressiven Therapie mit erkennbarer Schädigung des Transplantates (der 10\%-Grenzwert für die GcfDNA ist gestrichelt dargestellt) 84 
4.37 Verlauf der GcfDNA und Spiegel der Immunsuppressiva im Vollblut während Umstellung der immunsuppressiven Therapie ohne erkennbarer Schädigung des Transplantates (der 10\%-Grenzwert für die GcfDNA ist gestrichelt darge-

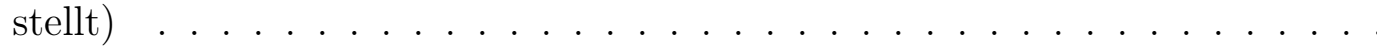




\section{Tabellenverzeichnis}

1.1 Transplantationszahlen im Jahr 2012 in den Vereinigten Staaten von Amerika aus dem SRTR (The Scientific Registry of Transplant Recipients) 2012 Annual Data Report (Matas et al. 2014; Kim et al. 2014; Colvin-Adams et al. 2014; Valapour et al. 2014; Israni et al. 2014; Smith et al. 2014) . . . . . . . . . . . 1

1.2 Häufigkeit des Auftretens akuter Abstoßungsreaktionen in den ersten 3 Jahren nach Transplantation (Rollins 2012) . . . . . . . . . . . . 2

1.3 Anwendung der Medikamentenspiegelbestimmung (TDM, engl. Therapeutic Drug Monitoring) gängiger Immunsuppressiva (Klupp et al. 2002; Streit et al. 2002; Su et al. 2012; Ling et al. 2013) . . . . . . . . . . . . . . 3

3.1 Messwerte der einzelnen Assays für LTx4 am Tag 99 nach Transplantation $(*=$ Ausreißer $) \ldots \ldots \ldots \ldots \ldots \ldots$

3.2 Reaktive Bestandteile des Reagenzienkits für die Bestimmung der AspartatAminotransferase-(AST)-Aktivität (Abbott 2010a) . . . . . . . . . . 28

3.3 Reaktive Bestandteile des Reagenzienkits für die Bestimmung der $\gamma$-GlutamylTransferase-(GGT)-Aktivität (Abbott 2012) . . . . . . . . . . . . . .

3.4 Reaktive Bestandteile des Reagenzienkits für die Bestimmung der BilirubinKonzentration (Abbott 2010b) . . . . . . . . . . . . .

4.1 Demographische Daten und Indikationen zur Transplantation (HCC: Leberzellkarzinom, engl. hepatocellular carcinoma) . . . . . . . . . . . . 3

4.2 Kalte (KIZ) und warme (WIZ) Ischämiezeiten der untersuchten Spenderorgane $(*=$ Drop-outs $) \ldots \ldots \ldots \ldots \ldots \ldots$. . . . . . . . . . . . . . . . . . . . 


\section{Literaturverzeichnis}

Abbott (2010a): Packungsbeilage für den Activated Aspartate Aminotransferase Assay. Abbott Laboratories, Abbott Park, IL, USA, 2010

Abbott (2010b): Packungsbeilage für den Total Bilirubin Assay. Abbott Laboratories, Abbott Park, IL, USA, 2010

Abbott (2012): Packungsbeilage für den Gamma-Glutamyl Transferase Assay. Abbott Laboratories, Abbott Park, IL, USA, 2012

Akhlaghi F, Gohh RY (2010): The level of ATP production in mitogen-stimulated CD4+ lymphocytes is independent of the time of ingestion of immunosuppressive agents. Ther Drug Monit 32, 116-117

American Society of Nephrology (2005): American Society of Nephrology Renal Research Report. J Am Soc Nephrol 16, 1886-1903

Amicucci P, Gennarelli M, Novelli G, Dallapiccola B (2000): Prenatal diagnosis of myotonic dystrophy using fetal DNA obtained from maternal plasma. Clin Chem $\underline{46}$, 301-302

Arnalich F, López-Collazo E, Montiel C (2011): Diagnostic potential of circulating cell-free DNA in patients needing mechanical ventilation: promises and challenges. Critical Care $\underline{15}, 187-188$

Atamaniuk J, Kopecky C, Skoupy S, Säemann MD, Weichhart T (2012): Apoptotic cellfree DNA promotes inflammation in haemodialysis patients. Nephrol Dial Transplant $\underline{27}$, $902-5$

Baron U, Floess S, Wieczorek G, Baumann K, Grützkau A, Dong J, Thiel A, Boeld TJ, Hoffmann P, Edinger M, Türbachova I, Hamann A, Olek S, Huehn J (2007): DNA demethylation in the human FOXP3 locus discriminates regulatory $\mathrm{T}$ cells from activated FOXP3 $(+)$ conventional T cells. Eur J Immunol 37, 2378-2389 
Beck J, Urnovitz HB, Riggert J, Clerici M, Schütz E (2009): Profile of the circulating DNA in apparently healthy individuals. Clin Chem $\underline{55}, 730-8$

Beck J, Bierau S, Balzer S, Andag R, Kanzow P, Hennecke J, Schmitz J, Gaedcke J, Moerer O, Slotta JE, Walson P, Kollmar O, Oellerich M, Schütz E (2013a): Rapid and Cost Effective Measurement of Circulating Cell Free Graft DNA for the Early Detection of Liver Transplant Rejection. Clin Chem $\underline{59}$, Supplement A27

Beck J, Bierau S, Balzer S, Andag R, Kanzow P, Schmitz J, Gaedcke J, Moerer O, Slotta JE, Walson P, Kollmar O, Oellerich M, Schütz E (2013b): Digital droplet PCR for rapid quantification of donor DNA in the circulation of transplant recipients as a potential universal biomarker of graft injury. Clin Chem $\underline{59}, 1732-1741$

Bergmeyer H, Hørder M, Rej R (1986): Approved recommendation (1985) on IFCC methods for the measurement of catalytic concentration of enzymes. J Clin Chem Clin Biochem $\underline{24}, 497-510$

Bhorade SM, Janata K, Vigneswaran WT, Alex CG, Garrity ER (2008): Cylex ImmuKnow assay levels are lower in lung transplant recipients with infection. J Heart Lung Transplant $\underline{27}, 990-4$

Boleslawski E, Conti F, Sanquer S, Podevin P, Chouzenoux S, Batteux F, Houssin D, Weill B, Calmus Y (2004): Defective inhibition of peripheral CD8 T cell IL-2 production by anticalcineurin drugs during acute liver allograft rejection. Transplantation $\underline{77}, 1815-1820$

Boleslawski E, Othman SB, Aoudjehane L, Chouzenoux S, Scatton O, Soubrane O, Calmus Y, Delhem N, Conti F (2011): CD28 expression by peripheral blood lymphocytes as a potential predictor of the development of de novo malignancies in long-term survivors after liver transplantation. Liver Transpl 17, 299-305

Brandhorst G, Streit F, Goetze S, Oellerich M, Armstrong VW (2006): Quantification by Liquid Chromatography Tandem Mass Spectrometry of Mycophenolic Acid and Its Phenol and Acyl Glucuronide Metabolites. Clin Chem 52, 1962-1964

Burton Jr JR, Rosen HR (2006): Acute rejection in HCV-infected liver transplant recipients: The great conundrum. Liver Transpl 12, S38-47 
Cabrera R, Ararat M, Soldevila-Pico C, Dixon L, Pan JJ, Firpi R, Machicao V, Levy C, Nelson D, Morelli G (2009): Using an Immune Functional Assay To Differentiate Acute Cellular Rejection from Recurrent Hepatitis C in Liver Transplant Patients. Liver Transpl $\underline{15}, 216-222$

Cadillo-Chávez R, de Echegaray S, Santiago-Delpín EA, Rodríguez-Trinidad AT, CamachoCarrazo B, Alfaro T, Saavedra-Pozo M, Carrasquillo L, González-Caraballo ZA, MoralesOtero LA (2006): Assessing the risk of infection and rejection in Hispanic renal transplant recipients by means of an adenosine triphosphate release assay. Transplant Proc 38, 918-20

Chandraker A, Strom TB (2013): Transplantation: a new molecular approach to the diagnosis of acute rejection. Nat Rev Nephrol $\underline{9}, 631-2$

Chiu RWK, Poon LLM, Lau TK, Leung TN, Wong EMC, Lo YMD (2001): Effects of BloodProcessing Protocols on Fetal and Total DNA Quantification in Maternal Plasma. Clin Chem 느, 1607-1613

Cobbold SP, Waldmann H (2013): Regulatory cells and transplantation tolerance. Cold Spring Harb Perspect Med $\underline{3}$

Colvin-Adams M, Smithy JM, Heubner BM, Skeans MA, Edwards LB, Waller C, Schnitzler MA, Snyder JJ, Israni AK, Kasiske BL (2014): OPTN/SRTR 2012 Annual Data Report: Heart. Am J Transplant 14, 113-138

Cooper J, Wiseman A (2010): Novel immunosuppressive agents in kidney transplantation. Clinical Nephrology $\underline{73}, 333-343$

Crespo-Leiro MG, Zuckermann A, Bara C, Mohacsi P, Schulz U, Boyle A, Ross HJ, Parameshwar J, Zakliczyński M, Fiocchi R, Stypmann J, Hoefer D, Lehmkuhl H, Deng MC, Leprince P, Berry G, Marboe CC, Stewart S, Tazelaar HD, Baron HM, Coleman IC, Vanhaecke J (2012): Concordance among pathologists in the second Cardiac Allograft Rejection Gene Expression Observational Study (CARGO II). Transplantation $\underline{94}, 1172-7$

Crettola S, Venetzb JP, Fontanab M, Aubertb JD, Ansermotc N, Fathic M, Pascualb M, Eapa CB (2008): Influence of ABCB1 genetic polymorphisms on cyclosporine intracellular concentration in transplant recipients. Pharmacogenet Genom $\underline{18}$, 307-315 
De Serres SA, Sayegh MH, Najafian N (2009): Immunosuppressive Drugs and Tregs: A Critical Evaluation! Clin J Am Soc Nephrol $\underline{4}, 1661-1669$

Demetris AJ, Batts KP, Dhillon AP, Ferrel L, Fung J, Geller SA, Hart J, Hayry P, Hofmann WJ, Hubscher S, Kemnitz J, Koukoulis G, Lee RG, Lewin KJ, Ludwig J, Markin RS, Petrovic LM, Phillips MJ, Portmann B, Rakela J, Randhawa P, Reinholt FP, Reynès M, Robert M, Schlitt H, Solez K, Snover D, Taskinen E, Thung SN, Tillery GW, Wiesner RH, Wight DGD, Williams JW, Yamabe H (1997): Banff schema for grading liver allograft rejection: An international consensus document. Hepatology 25, 658-663

Dong SM, Pai S, Rha SH, Hildesheim A, Kurman RJ, Schwartz PE, Mortel R, McGowan L, Greenberg MD, Barnes WA, Sidransky D (2002): Detection and quantitation of human papillomavirus DNA in the plasma of patients with cervical carcinoma. Cancer Epidemiol Biomarkers Prev 11, 3-6

Falck P, Asberg A, Guldseth H, Bremer S, Akhlaghi F, Reubsaet JLE, Pfeffer P, Hartmann A, Midtvedt K (2008): Declining intracellular T-lymphocyte concentration of cyclosporine a precedes acute rejection in kidney transplant recipients. Transplantation $\underline{85}, 179-184$

Fan HC, Yair JB, Chitkara U, Hudgins L, Quake SR (2008): Noninvasive diagnosis of fetal aneuploidy by shotgun sequencing DNA from maternal blood. PNAS $\underline{105}, 16266-16271$

Franzese O, Mascali A, Capria A, Castagnola V, Paganizza L, Di Daniele N (2013): Regulatory T Cells in the Immunodiagnosis and Outcome of Kidney Allograft Rejection. Clin Dev Immunol $\underline{2013}, 7$ pages

Freissmuth M (2012): Pharmakokinetik, Kapitel 2, 8-39. 1. Auflage; Springer Medizin Verlag, Heidelberg 2012

Fukuda T, Goebel J, Thøgersen H, Maseck D, Cox S, Logan B, Sherbotie J, Seikaly M, Vinks AA (2011): Inosine monophosphate dehydrogenase (IMPDH) activity as a pharmacodynamic biomarker of mycophenolic acid effects in pediatric kidney transplant recipients. $J$ Clin Pharmacol 51, 309-320

Gadi VK, Nelson JL, Boespflug ND, Guthrie KA, Kuhr CS (2006): Soluble Donor DNA Concentrations in Recipient Serum Correlate with Pancreas-Kidney Rejection. Clin Chem $\underline{52}, 379-382$ 
Garat A, Cardenas CLL, Lionet A, Devos A, Glowacki F, Kenani A, Migot-Nabias F, Allorge D, Lo-Guidice JM, Broly F, Cauffiez C (2011): Inter-ethnic variability of three functional polymorphisms affecting the IMPDH2 gene. Mol Biol Rep $\underline{38}, 5185-8$

Glander P, Hambach P, Braun KP, Fritsche L, Giessing M, Mai I, Einecke G, Waiser J, Neumayer HH, Budde K (2004): Pre-transplant inosine monophosphate dehydrogenase activity is associated with clinical outcome after renal transplantation. Am J Transplant $\underline{4}, 2045-2051$

Gupta S, Mitchell JD, Markham DW, Mammen PPA, Patel PC, Kaiser PA, Stastny P, Ring WS, Dimaio JM, Drazner MH (2008): Utility of the Cylex assay in cardiac transplant recipients. J Heart Lung Transplant 27, 817-22

Halloran PF, Pereira AB, Chang J, Matas A, Picton M, De Freitas D, Bromberg J, Serón D, Sellarés J, Einecke G, Reeve J (2013): Microarray diagnosis of antibody-mediated rejection in kidney transplant biopsies: an international prospective study (INTERCOM). Am J Transplant $\underline{13}, 2865-74$

Hartmann B (2012): p70S6 kinase phosphorylation for pharmacodynamic monitoring. Clin Chim Acta $\underline{413}, 1387-1390$

Hashimotoa K, Millera C, Hirosea K, Diagoa T, Aucejoa F, Quintinia C, Eghtesada B, Coreyb R, Yerianc L, Lopezd R, Nizar Z, Fung J (2010): Measurement of CD4+ T-cell function in predicting allograft rejection and recurrent hepatitis $\mathrm{C}$ after liver transplantation. Clin Transplant $\underline{24}, 701-708$

Häussinger D, Löffler G (2007): Leber, Kapitel 33, 1083-1102. 8. Auflage; Springer Medizin Verlag, Heidelberg 2007

Henley KS, Lucey MR, D AH, Baliga P, Brown KA, Burtch GD, Campbell DAJ, Ham JM, Merion RM, Turcotte JG (1992): Biochemical and histopathological correlation in liver transplant: the first 180 days. Hepatology $\underline{16}$, 688-693

Hilgers RA (1991): Distribution-Free Confidence Bounds for ROC Curves. Methods Inf Med $\underline{30}, 96-101$

Hindson BJ, Ness KD, Masquelier DA, Belgrader P, Heredia NJ, Makarewicz AJ, Bright IJ, Lucero MY, Hiddessen AL, Legler TC, Kitano TK, Hodel MR, Petersen JF, Wyatt PW, 
Steenblock ER, Shah PH, Bousse LJ, Troup CB, Mellen JC, Wittmann DK, Erndt NG, Cauley TH, Koehler RT, So AP, Dube S, Rose KA, Montesclaros L, Wang S, Stumbo DP, Hodges SP, Romine S, Milanovich FP, White HE, Regan JF, Karlin-Neumann GA, Hindson CM, Saxonov S, Colston BW (2011): High-Throughput Droplet Digital PCR

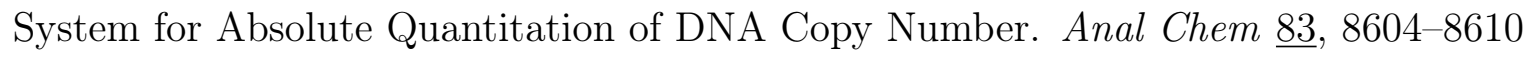

Hollander Z, Chen V, Sidhu K, Lin D, Ng RT, Balshaw R, Cohen-Freue GV, Ignaszewski A, Imai C, Kaan A, Tebbutt SJ, Wilson-McManus JE, McMaster RW, Keown PA, McManus BM (2013): Predicting acutecardiacrejectionfromdonorheart and pre-transplant recipient blood gene expression. J Heart Lung Transplant 32, 259-265

Husain S, Raza K, Pilewski JM, Zaldonis D, Crespo M, Toyoda Y, Shutt K, Spichty K, Bentlejewski C, Pakstis DL, Carey ME, McCurry KR, Zeevi A (2009): Experience with immune monitoring in lung transplant recipients: correlation of low immune function with infection. Transplantation $\underline{87}, 1852-1857$

Huskey J, Gralla J, Wiseman AC (2011): Single time point immune function assay (ImmuKnow) testing does not aid in the prediction of future opportunistic infections or acute rejection. Clin J Am Soc Nephrol $\underline{6}, 423-429$

Israeli M, Ben-Gal T, Yaari V, Valdman A, Matz I, Medalion B, Battler A, Sredni B, Kristt D, Klein T (2010): Individualized immune monitoring of cardiac transplant recipients by

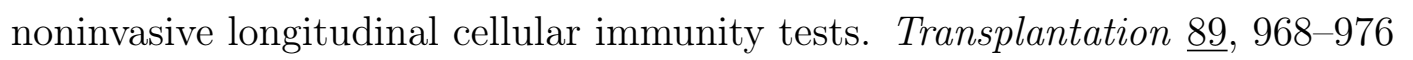

Israeli M, Klein T, Brandhorst G, Oellerich M (2012): Confronting the challenge: Individualized immune monitoring after organ transplantation using the cellular immune function assay. Clin Chim Acta $\underline{413}, 1374-1378$

Israni AK, Skeans MA, Gustafson SK, Schnitzler MA, Wainright JL, Carrico RJ, Tyler KH, Kades LA, Kandaswamy R, Snyder JJ, Kasiske BL (2014): OPTN/SRTR 2012 Annual Data Report: Pancreas. Am J Transplant $\underline{14}, 45-68$

Jamieson A, Taylor SCS (1997): Comparisons of three probability formulae for parentage exclusion. Anim Genet $\underline{28}, 397-400$ 
Jung M, Klotzek S, Lewandowski M, Fleischhacker M, Jung K (2003): Changes in Concentration of DNA in Serum and Plasma during Storage of Blood Samples. Clin Chem $\underline{49}$, $1028-1029$

Jung K, Fleischhacker M, Rabien A (2010): Cell-free DNA in the blood as a solid tumor biomarker-a critical appraisal of the literature. Clin Chim Acta $\underline{411}, 1611-24$

Kamm RC, Smith AG (1972): Nucleic acid concentrations in normal human plasma. Clin Chem $\underline{18}, 519-522$

Kanzow P, Kollmar O, Oellerich M, Schütz E, Schmitz J, Beck J, Slotta JE, Walson PD (2014): Potential of Graft-derived Cell-free DNA Quantification to Improve Outcomes with Marginal Donor Organs - Case Report of Successful Liver Transplantation of a HELLP Syndrome Donor. Abstract accepted for the World Transplant Congress WTC 2014

Kim WR, Smith JM, Skeans MA, Schladt DP, Schnitzler MA, Edwards EB, Harper AM, Wainright JL, Snyder JJ, Israni AK, Kasiske BL (2014): OPTN/SRTR 2012 Annual Data Report: Liver. Am J Transplant 14, 69-96

Klupp J, Holt DW, van Gelder T (2002): How pharmacokinetic and pharmacodynamic drug monitoring can improve outcome in solid organ transplant recipients. Transpl Immunol $\underline{9}$, $211-4$

Kobashigawa JA, Kiyosaki KK, Patel JK, Kittleson MM, Kubak BM, Davis SN, Kawano MA, Ardehali AA (2010): Benefit of immune monitoring in heart transplant patients using ATP production in activated lymphocytes. J Heart Lung Transplant 29, 504-508

Koch-Weser J (1972): Serum Drug Concentrations as Therapeutic Guides. N Engl J Med $\underline{287}, 227-231$

Kovarik JM, Slade A (2010): Overview of sotrastaurin clinical pharmacokinetics. Ther Drug Monit $\underline{32}, 540-543$

Kovarik JM, Stitah S, Slade A, Vitaliti A, Straube F, Grenet O, Winter S, Sfikas N, Seiberling M (2010): Sotrastaurin and tacrolimus coadministration: effects on pharmacokinetics and biomarker responses. J Clin Pharmacol 무, 1260-1266 
Kowalskia R, Posta D, Schneidera MC, Britza J, Thomasb J, Deierhoib M, Lobashevskyb A, Redfieldc R, Schweitzerc E, Herediac A, Reardonc E, Davisc C, Bentlejewskid C, Fungd J, Shapirod R, Zeevid A (2003): Immune cell function testing: an adjunct to therapeutic drug monitoring in transplant patient management. Clin Transplant $\underline{17}, 77-88$

Kowalski RJ, Post DR, Mannon RB, Sebastian A, Wright HI, Sigle G, Burdick J, Elmagd KA, Zeevi A, Lopez-Cepero M, Daller JA, Gritsch HA, Reed EF, Jonsson J, Hawkins D, Britz JA (2006): Assessing Relative Risks of Infection and Rejection: A Meta-analysis using an Immune Function Assay. Transplantation 82, 663-668

Land WG (2006): Immunsuppressive Therapie. 1. Auflage; Georg Thieme Verlag KG, Stuttgart 2006

Lauchart W (1992): Indikation und Ergebnisse der Lebertransplantation. Zent bl Chir 117, 663-669

Lee TC, Goss JA, Rooney CM, Heslop HE, Barshes NR, Caldwell YM, Gee AP, Scott JD, Savoldo B (2006): Quantification of a low cellular immune response to aid in identification of pediatric liver transplant recipients at high-risk for EBV infection. Clin Transplant $\underline{20}$, 689-694

Lemaitre F, Antignac M, Verdier MC, Bellissant E, Fernandez C (2013): Opportunity to monitor immunosuppressive drugs in peripheral blood mononuclear cells: Where are we and where are we going? Pharmacol Res $\underline{14}$, 109-112

Levitsky J, Miller J, Huang X, Chandrasekaran D, Chen L, Mathew JM (2013): Inhibitory effects of belatacept on allospecific regulatory T-cell generation in humans. Transplantation $\underline{96}, 689-96$

Li L, Wozniak LJ, Rodder S, Heish S, Talisetti A, Wang Q, Esquivel C, Cox K, Chen R, McDiarmid SV, Sarwal MM (2012): A common peripheral blood gene set for diagnosis of operational tolerance in pediatric and adult liver transplantation. Am J Transplant $\underline{12}$, $1218-1228$

Ling SY, Huizinga RB, Mayo PR, Larouche R, Frietag DG, Aspeslet LJ, Foster RT (2013): CYP3A and P-glycoprotein Drug-Drug Interactions with Voclosporin. British Journal of Clinical Pharmacology $\mathrm{n} / \mathrm{a}-\mathrm{n} / \mathrm{a}$ 
Lipson K, Lappalainen M, Höckerstedt K, Lautenschlager I (2006): Post-transplant reactivation of hepatitis $\mathrm{C}$ virus: lymphocyte infiltration and the expression of adhesion molecules and their ligands in liver allografts. APMIS $\underline{114}, 247-254$

Litjens NHR, Boer K, Betjes MGH (2012): Identification of circulating human antigenreactive CD4+ FOXP3 + natural regulatory T cells. J Immunol $\underline{188}$, 1083-1090

Lo YM, Corbetta N, Chamberlain PF, Rai V, Sargent IL, Redman CW, Wainscoat JS (1997): Presence of fetal DNA in maternal plasma and serum. Lancet $\underline{350}, 485-7$

Lo YMD, Tein MSC, Pang CCP, Yeung CK, Tong KL, Hjelm NM (1998): Presence of donorspecific DNA in plasma of kidney and liver-transplant recipients. Lancet $\underline{351}, 1329-1330$

Lo KW, Lo YD, Leung SF, Tsang YS, Chan LY, Johnson PJ, Hjelm NM, Lee JC, Huang DP (1999a): Analysis of cell-free Epstein-Barr virus associated RNA in the plasma of patients with nasopharyngeal carcinoma. Clin Chem $\underline{45}, 1292-1294$

Lo YD, Leung TN, Tein MS, Sargent IL, Zhang J, Lau TK, Haines CJ, Redman CW (1999b): Quantitative Abnormalities of Fetal DNA in Maternal Serum in Preeclampsia. Clin Chem $\underline{45}, 184-188$

Lo YMD, Zhang J, Leung TN, Lau TK, Chang AMZ, Hjelm NM (1999c): Rapid Clearance of Fetal DNA from Maternal Plasma. Am J Hum Genet $\underline{64}, 218-224$

Lo YD (2011): Transplantation Monitoring by Plasma DNA Sequencing. Clin Chem 57, $941-942$

Londoño MC, Danger R, Giral M, Soulillou JP, Sánchez-Fueyo A, Brouard S (2012): A need for biomarkers of operational tolerance in liver and kidney transplantation. Am J Transplant $\underline{12}, 1370-1377$

Lui YY, Woo KS, Wang AY, Yeung CK, Li PK, Chau E, Ruygrok P, Lo YD (2003): Origin of Plasma Cell-free DNA after Solid Organ Transplantation. Clin Chem 49, 495-496

Malloy HT, Evelyn KA (1937): The determination of bilirubin with the photoelectric colorimeter malloy. J Biol Chem $\underline{119}, 481-490$

Mandel P, Métais PLandpsclCRSSBF (1948): Les acides nucleiques du plasma sanguin chez l'homme. C R Seances Soc Biol Fil $\underline{142}, 241-243$ 
Mas VR, Dumur CI, Scian MJ, Gehrau RC, Maluf DG (2013): MicroRNAs as biomarkers in solid organ transplantation. Am J Transplant $\underline{13}, 11-9$

Matas AJ, Smith JM, Skeans MA, Thompson B, Gustafson SK, Schnitzler MA, Stewart DE, Cherikh WS, Wainright JL, Snyder JJ, Israni AK, Kasiske BL (2014): OPTN/SRTR 2012 Annual Data Report: Kidney. Am J Transplant 14, 11-44

Mehra MR, Parameshwar J (2010): Gene expression profiling and cardiac allograft rejection monitoring: is IMAGE just a mirage? J Heart Lung Transplant 29, 599-602

Meier-Kriesche HU, Schold JD, Srinivas TR, Kaplan B (2004): Lack of Improvement in Renal Allograft Survival Despite a Marked Decrease in Acute Rejection Rates Over the Most Recent Era. Am J Transplant $\underline{4}, 378-383$

Millán O, Sánchez-Fueyo A, Rimola A, Guillen D, Hidalgo S, Benitez C, Campistol JM, Brunet M (2009): Is the intracellular ATP concentration of CD4+ T-cells a predictive

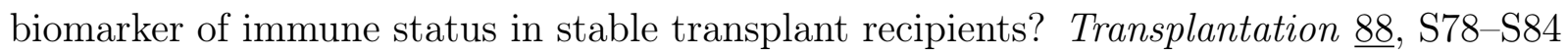

Millán O, Benitez C, Guillén D, López A, Rimola A, Sánchez-Fueyo A, Brunet M (2010): Biomarkers of immunoregulatory status in stable liver transplant recipients undergoing weaning of immunosuppressive therapy. Clin Immunol $\underline{137}$, 337-346

Montenarh M, Löffler G (2007): Nucleotide und Nucleinsäuren, Kapitel 5, 141-172. 8. Auflage; Springer Medizin Verlag, Heidelberg 2007

Newell KA, Asare A, Kirk AD, Gisler TD, Bourcier K, Suthanthiran M, Burlingham WJ, Marks WH, Sanz I, Lechler RI, Hernandez-Fuentes MP, Turka LA, Seyfert-Margolis VL, Immune Tolerance Network ST507 Study Group (2010): Identification of a B cell signature associated with renal transplant tolerance in humans. J Clin Invest $\underline{120}, 1836-1847$

Oellerich M, Kanzow P, Beck J, Schmitz J, Kollmar O, Walson PD, Schütz E (2014a): Graftderived Cell-free DNA (GcfDNA) as a Sensitive Measure of Individual Graft Integrity After Liver Transplantation. Abstract accepted for the World Transplant Congress WTC 2014

Oellerich M, Schütz E, Kanzow P, Schmitz J, Beck J, Kollmar O, Streit F, Walson PD (2014b): Use of Graft-Derived Cell-Free DNA as an Organ Integrity Biomarker to Reexamine Effective Tacrolimus Trough Concentrations After Liver Transplantation. Ther Drug Monit $\underline{36}, 136-140$ 
Padbury RTA, Attard A, Mirza DF, Olliff S, Gunson BK, Mayer AD, Buckels JA, McMaster P (1994): Extended Preservation of the Liver with UW Solution - Is it Justifiable? Transplantation $\underline{57}, 1490-1493$

Panteghini M, Bais R (2012): Tietz Textbook of Clinical Chemistry and Molecular Diagnostics, Kapitel Serum Enzymes, 565-598. 5. Auflage; Elsevier Saunders, St. Louis, MO, USA 2012

Parzen E (1962): On the estimation of a probability density and the mode. Ann Math Stat $\underline{33}, 1065-1076$

Pascual M, Tom Theruvath T, Kawai T, Tolkoff-Rubin N, Cosimi AB (2002): Strategies to Improve Long-Term Outcomes after Renal Transplantation. N Engl J Med $\underline{346}, 580-590$

Petrovic LM, Villamil FG, Vierling JM, Makowka L, Geller SA (1997): Comparison of Histopathology in Acute Allograft Rejection and Recurrent Hepatitis C Infection After Liver Transplantation. Liver Transpl Surg $\underline{3}, 398-406$

Pham MX, Teuteberg JJ, Kfoury AG, Starling RC, Deng MC, Cappola TP, Kao A, Anderson AS, Cotts WG, Ewald GA, Baran DA, Bogaev RC, Elashoff B, Baron H, Yee J, Valantine HA (2010): Gene-Expression Profiling for Rejection Surveillance after Cardiac Transplantation. N Engl J Med $\underline{362}$, 1890-1900

Piedras ALR, Arciniega MDlO, Vázquez JR (2013): Current Issues and Future Direction in Kidney Transplantation, Kapitel Clinical Pharmacology and Therapeutic Drug Monitoring of Immunosuppressive Agents, 309-342. InTech, New York, NY, USA 2013

Pinheiro LB, Coleman VA, Hindson CM, Herrmann J, Hindson BJ, Bhat S, Emslie, $\ddot{A} \dagger$ KR (2012): Evaluation of a Droplet Digital Polymerase Chain Reaction Format for DNA Copy Number Quantification. Anal Chem $\underline{84}$, 1003-1011

Quake S (2012): Sizing up cell-free DNA. Clin Chem $\underline{58,489-90}$

Raggi MC, Siebert SB, Steimer W, Schuster T, Stangl MJ, Abendroth DK (2010): Customized mycophenolate dosing based on measuring inosine-monophosphate dehydrogenase activity significantly improves patients' outcomes after renal transplantation. Transplantation 90, 1536-1541 
Rahmel A (2012): Eurotransplant Annual Report 2012. Eurotransplant International Foundation, Leiden 2012

Rodríguez-Perálvarez M, Germani G, Tsochatzis E, Rolando N, Luong TV, Dhillon AP, Thorburn D, O’Beirne J, Patch D, Burroughs AK (2012): Predicting severity and clinical course of acute rejection after liver transplantation using blood eosinophil count. Transpl Int $\underline{25}, 555-63$

Rodríguez-Perálvarez M, Germani G, Papastergiou V, Tsochatzis E, Thalassinos E, Luong TV, Rolando N, Dhillon AP, Patch D, O'Beirne J, Thorburn D, Burroughs AK (2013): Early tacrolimus exposure after liver transplantation: Relationship with moderate/severe acute rejection and long-term outcome. Journal of Hepatology $\underline{58}$, 262-270

Röhm KH (2007): Stoffwechsel der Aminosäuren, Kapitel 13, 427-476. 8. Auflage; Springer Medizin Verlag, Heidelberg 2007

Rollins G (2012): The Case for Biomarkers in Solid Organ Transplantation. Clin Lab News $\underline{38}, 5-7$

Rosenblatt M (1956): Remarks on some nonparametric estimates of a density function. Ann Math Stat $\underline{37}, 832-837$

Roullet-Renoleaua F, Lemaitrea F, Antignacb M, Zahrc N, Farinotti R, Fernandeza C (2012): Everolimus quantification in peripheral blood mononuclear cells using ultra high performance liquid chromatography tandem mass spectrometry. J Pharm Biomed Anal $\underline{66}, 278-$ 281

Roussey-Kesler G, Giral M, Moreau A, Subra JF, Legendre C, Noël C, Pillebout E, Brouard S, Soulillou JP (2006): Clinical operational tolerance after kidney transplantation. Am J Transplant $\underline{6}, 736-746$

Sagoo P, Perucha E, Sawitzki B, Tomiuk S, Stephens DA, Miqueu P, Chapman S, Craciun L, Sergeant R, Brouard S, Rovis F, Jimenez E, Ballow A, Giral M, Rebollo-Mesa I, Le Moine A, Braudeau C, Hilton R, Gerstmayer B, Bourcier K, Sharif A, Krajewska M, Lord GM, Roberts I, Goldman M, Wood KJ, Newell K, Seyfert-Margolis V, Warrens AN, Janssen U, Volk HD, Soulillou JP, Hernandez-Fuentes MP, Lechler RI (2010): Development of a 
cross-platform biomarker signature to detect renal transplant tolerance in humans. $J$ Clin Invest $\underline{120}, 1848-1861$

Saito H, Sekizawa A, Morimoto T, Suzuki M, Yanaihara T (2000): Prenatal DNA diagnosis of a single-gene disorder from maternal plasma. Lancet $\underline{356}, 1170$

Schiff J, Cole E, Cantarovich M (2007): Therapeutic monitoring of calcineurin inhibitors for the nephrologist. Clin J Am Soc Nephrol $\underline{2}$, 374-84

Schmidt E, Schmidt FW (1976): Kleine Enzym-Fibel. 2. Auflage; Boehringer Mannheim GmbH, Mannheim 1976

Schröppel B, Heeger PS (2010): Gazing into a crystal ball to predict kidney transplant outcome. J Clin Invest $\underline{120}, 1803-1806$

Schulz-Juergensen S, Burdelski MM, Oellerich M, , Brandhorst G (2012): Intracellular ATP production in $\mathrm{CD} 4+\mathrm{T}$ cells as a predictor for infection and allograft rejection in troughlevel guided pediatric liver transplant recipients under calcineurin-inhibitor therapy. Ther Drug Monit 34, 4-10

Schumann G, Bonora R, Ceriotti F, Férard G, Ferrero CA, Franck PFH, Gella FJ, Hoelzel W, Jørgensen PJ, Kanno T, Kessner A, Klauke R, Kristiansen N, Lessinger JM, Linsinger TPJ, Misaki H, Panteghini M, Pauwels J, Schiele F, Schimmel HG (2002): IFCC Primary Reference Procedures for the Measurement of Catalytic Activity Concentrations of Enzymes at 37 degrees C. International Federation of Clinical Chemistry and Laboratory Medicine. Part 5. Reference Procedure for the Measurement of Catalytic Concentration of Aspartate Aminotransferase. Clin Chem Lab Med 느, 725-733

Sellarés J, Reeve J, Loupy A, Mengel M, Sis B, Skene A, de Freitas DG, Kreepala C, Hidalgo LG, Famulski KS, Halloran PF (2013): Molecular diagnosis of antibody-mediated rejection in human kidney transplants. Am J Transplant $\underline{13}, 971-83$

Serban G, Whittaker V, Fan J, Liu Z, Manga K, Khan M, Kontogianni K, Padmanabhan A, Cohen D, Suciu-Foca N, Ratner L, Colovai AI (2009): Significance of immune cell function monitoring in renal transplantation after Thymoglobulin induction therapy. Hum Immunol $\underline{70}, 882-90$ 
Shalev I, Selzner N, Shyu W, Grant D, Levy G (2012): Role of Regulatory T Cells in the Promotion of Transplant Tolerance. Liver Transpl 18, 761-770

Shaw LM, Nicholls A, Hale M, Armstrong VW, Oellerich M, Yatscoff R, Morris RE, Holt DW, Venkataramanan R, Haley J, Halloran P, Ettenger R, Keown P, Morris RG (1998): Therapeutic monitoring of mycophenolic acid. A consensus panel report. Clin Biochem $\underline{31}, 317-22$

Shipkova M, Wieland E (2012): Surface markers of lymphocyte activation and markers of cell proliferation. Clin Chim Acta $\underline{413}, 1338-1349$

Sigdel TK, Vitalone MJ, Tran TQ, Dai H, Hsieh Sc, Salvatierra O, Sarwal MM (2013): A Rapid Noninvasive Assay for the Detection of Renal Transplant Injury. Transplantation $\underline{96}, 97-101$

Smith JM, Skeans MA, Horslen SP, Edwards EB, Harper AM, Snyderf JJ, Israni AK, Kasiske BL (2014): OPTN/SRTR 2012 Annual Data Report: Intestine. Am J Transplant 14, 97111

Snyder TM, Khush KK, Valantine HA, Quake SR (2011): Universal noninvasive detection of solid organ transplant rejection. PNAS $\underline{108}, 6229-6234$

Sommerer C, Zeier M, Czock D, Schnitzler P, Meuer S, Giese T (2011): Pharmacodynamic disparities in tacrolimus-treated patients developing cytomegalus virus viremia. Ther Drug Monit $\underline{33}, 373-379$

Soranzo N, Cavalleri GL, Weale ME, Wood NW, Depondt C, Marguerie R, Sisodiya SM, Goldstein DB (2004): Identifying candidate causal variants responsible for altered activity of the ABCB1 multidrug resistance gene. Genome Res 14, 1333-44

Staatz CE, Tett SE (2004): Clinical Pharmacokinetics and Pharmacodynamics of Tacrolimus in Solid Organ Transplantation. Clin Pharmacokinet 43, 623-653

Starling RC, Hare JM, Hauptman P, McCurry KR, Mayer HW, M KJ, Schmidli H (2004): Therapeutic Drug Monitoring for Everolimus in Heart Transplant Recipients Based on Exposure-Effect Modeling. Am J Transplant 4, 2126-2131 
Starling RC, Pham M, Valantine H, Miller L, Eisen H, Rodriguez ER, Taylor DO, Yamani MH, Kobashigawa J, McCurry K, Marboe C, Mehra MR, Zuckerman A, Deng MC, Working Group on Molecular Testing in Cardiac Transplantation (2006): Molecular testing in the management of cardiac transplant recipients: initial clinical experience. J Heart Lung Transplant 25, 1389-95

Streit F, Armstrong VW, Oellerich M (2002): Rapid Liquid Chromatography-Tandem Mass Spectrometry Routine Method for Simultaneous Determination of Sirolimus, Everolimus, Tacrolimus, and Cyclosporin A in Whole Blood. Clin Chem $\underline{48}$, 955-958

Streit F, Shipkova M, Armstrong VW, Oellerich M (2004): Validation of a Rapid and Sensitive Liquid Chromatography-Tandem Mass Spectrometry Method for Free and Total Mycophenolic Acid. Clin Chem $\underline{50}, 152-159$

Stroun M, Anker P, Lyautey J, Lederrey C, Maurice PA (1987): Isolation and characterization of DNA from the plasma of cancer patients. Eur J Cancer Clin Oncol $\underline{23}, 707-712$

Su VCH, Harrison J, Rogers C, Ensom MHH (2012): Belatacept: a new biologic and its role in kidney transplantation. Ann Pharmacother $\underline{46}, 57-67$

Süsal C, Pelzl S, Döhler B, Opelz G (2002): Identification of Highly Responsive Kidney Transplant Recipients Using Pretransplant Soluble CD30. J Am Soc Nephrol 13, 16501656

Süsal C, Opelz G (2012): Posttransplant sCD30 as a biomarker to predict kidney graft outcome. Clin Chim Acta $\underline{413}$, 1350-1353

Suthanthiran M, Schwartz JE, Ding R, Abecassis M, Dadhania D, Samstein B, Knechtle SJ, Friedewald J, Becker YT, Sharma VK, Williams NM, Chang CS, Hoang C, Muthukumar T, August P, Keslar KS, Fairchild RL, Hricik DE, Heeger PS, Han L, Liu J, Riggs M, Ikle DN, Bridges ND, Shaked A, Clinical Trials in Organ Transplantation 04 (CTOT04) Study Investigators (2013): Urinary-cell mRNA profile and acute cellular rejection in kidney allografts. N Engl J Med $\underline{369}, 20-31$

Suzuki N, Kamataki A, Yamaki J, Homma Y (2008): Characterization of circulating DNA in healthy human plasma. Clin Chim Acta 387, 55-8 
Tan E, Schur P, Carr R, Kunkel H (1966): Deoxyribonucleic acid (DNA) and antibodies to DNA in the serum of patients with systemic lupus erythematosus. J Clin Invest $\underline{45}$, $1732-1740$

Theodorsen L, Strømme JH (1976): gamma-Glutamyl-3-carboxy-4-nitroanilide: the substrate of choice for routine determinations of 7-glutamyltransferase activity in serum? Clin Chim Acta $\underline{72}, 205-210$

Thiene G, Bruneval P, Veinot J, Leone O (2013): Diagnostic use of the endomyocardial biopsy: a consensus statement. Virchows Arch $\underline{463}, 1-5$

Vafadari R, Weimar W, Baan CC (2012): Phosphospecific flow cytometry for pharmacodynamic drug monitoring: Analysis of the JAK-STAT signaling pathway. Clin Chim Acta $\underline{413}, 1398-1405$

Valapour M, Skeans MA, Heubner BM, Smith JM, Schnitzler MA, Hertz MI, Edwards LB, Snyder JJ, Israni AK, Kasiske BL (2014): OPTN/SRTR 2012 Annual Data Report: Lung. Am J Transplant $\underline{14}, 139-165$

van Damme-Lombaerts R, Webb NAY, Hoyer PF, Mahan J, Lemire J, Ettenger R, McMahon L, Cambon N, Boger R, Kovarik JM (2002): Single-dose pharmacokinetics and tolerability of everolimus in stable pediatric renal transplant patients. Pediatr Transplant $\underline{6}, 147-152$

van Hest R, Mathot R, Vulto A, Weimar Willem andand van Gelder T (2005): Predicting the usefulness of therapeutic drug monitoring of mycophenolic acid. Ther Drug Monit $\underline{27}$, $163-167$

Verhelst XPD, Troisi RI, Colle I, Geerts A, van Vlierberghe H (2013): Biomarkers for the diagnosis of acute cellular rejection in liver transplant recipients: A review. Hepatol Res $\underline{43}, 165-78$

Wallemacq P, Armstrong VW, Brunet M, Haufroid V, Holt DW, Atholl Johnston A, Kuypers D, Le Meur Y, Marquet P, Oellerich M, Thervet E, Toenshoff B, Undre N, Weber LT, Westley IS, Mourad M (2009): Opportunities to optimize tacrolimus therapy in solid organ transplantation: report of the european consensus conference. Ther Drug Monit $\underline{31}, 139$ 152 
Walters MI, Gerade HW (1970): An Ultramicromethod for the Determination of Conjugated and Total Bilirubin in Serum or Plasma. Microchemical J 15, 231-243

Wieland E, Olbricht CJ, Süsal C, Gurragchaa P, Böhler T, Israeli M, Sommerer C, Klemens Budde K, Hartmann Bertram andShipkova M, Oellerich M (2010): Biomarkers as a tool for management of immunosuppression in transplant patients. Ther Drug Monit $\underline{32}$, $560-572$

Wieland E, Shipkova M, Oellerich M (2012): Biomarkers in transplantation medicine: Guide to the next level in immunosuppressive therapy. Clin Chim Acta $\underline{413}, 1309$

Wilcoxon F (1945): Individual Comparisons by Ranking Methods. Biometrics Bulletin 1 , $80-83$

Winsten S, Cehelyk B (1969): A rapid micro diazo technique for measuring total bilirubin. Clin Chim Acta 25, 441-446

Wojciechowski D, Vincenti F (2011): Targeting JAK3 in kidney transplantation: current status and future options. Curr Opin Organ Transplant 16, 614-619

Xue F, Zhang J, Han L, Li Q, Xu N, Zhou T, Xi Z, Wu Y, Xia Q (2010): Immune Cell Functional Assay in Monitoring of Adult Liver Transplantation Recipients With Infection. Transplantation $\underline{\text { 89, }}$ 620-626

Zhong XY, Holzgreve W, Hahn S (2000): Detection of fetal Rhesus D and sex using fetal DNA from maternal plasma by multiplex polymerase chain reaction. BJOG $\underline{107}, 766-769$ 


\section{Bildnachweise}

Cooper J, Wiseman A (2010): Novel immunosuppressive agents in kidney transplantation. Clinical Nephrology 73:333-343. Abgedruckt mit Genehmigung des Dustri-Verlags Dr. Karl Feistle GmbH \& Co. KG, Bajuwarenring 4, 82041 Oberhaching.

Beck J, Bierau S, Balzer S, Andag R, Kanzow P, Hennecke J, Schmitz J, Gaedcke J, Moerer O, Slotta JE, Walson P, Kollmar O, Oellerich M, Schütz E (2013a): Rapid and Cost Effective Measurement of Circulating Cell Free Graft DNA for the Early Detection of Liver Transplant Rejection. Clin Chem 59:Supplement A27. Abgedruckt mit Genehmigung der American Association for Clinical Chemistry (AACC), 1850 K Street NW (Suite 625), 20006 Washington, DC, USA.

Beck J, Bierau S, Balzer S, Andag R, Kanzow P, Schmitz J, Gaedcke J, Moerer O, Slotta JE, Walson P, Kollmar O, Oellerich M, Schütz E (2013b): Digital droplet PCR for rapid quantification of donor DNA in the circulation of transplant recipients as a potential universal biomarker of graft injury. Clin Chem 59:1732-1741. Abgedruckt und verändert mit Genehmigung der American Association for Clinical Chemistry (AACC), 1850 K Street NW (Suite 625), 20006 Washington, DC, USA.

Oellerich M, Kanzow P, Beck J, Schmitz J, Kollmar O, Walson PD, Schütz E (2014a): Graftderived Cell-free DNA (GcfDNA) as a Sensitive Measure of Individual Graft Integrity After Liver Transplantation. Abstract accepted for the World Transplant Congress (WTC). Abgedruckt und verändert mit Genehmigung von World Transplant Congress, 15000 Commerce Parkway (Suite C), 08054 Mt Laurel, NJ, USA. 
Oellerich M, Schütz E, Kanzow P, Schmitz J, Beck J, Kollmar O, Streit F, Walson PD (2014b): Use of Graft-Derived Cell-Free DNA as an Organ Integrity Biomarker to Reexamine Effective Tacrolimus Trough Concentrations After Liver Transplantation. Ther Drug Monit 36:136-140. Abgedruckt und verändert mit Genehmigung von Lippincott Williams and Wilkins Journals - Wolters Kluwer Health, 250 Waterloo Road, SE1 8RD London, UK.

Kanzow P, Kollmar O, Oellerich M, Schütz E, Schmitz J, Beck J, Slotta JE, Walson PD (2014): Potential of Graft-derived Cell-free DNA Quantification to Improve Outcomes with Marginal Donor Organs - Case Report of Successful Liver Transplantation of a HELLP Syndrome Donor. Abstract accepted for the World Transplant Congress (WTC). Abgedruckt und verändert mit Genehmigung von World Transplant Congress, 15000 Commerce Parkway (Suite C), 08054 Mt Laurel, NJ, USA. 
12 Anhang 


\title{
12.1 Studienaufklärung und Einwilligungserklärung
}

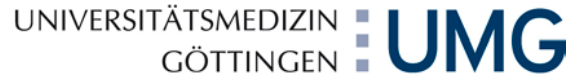

Universitätsmedizin Göttingen, 37099 Göttingen

Zentrum 8 Chirurgie Robert-Koch-Str. 40, 37075 Göttingen

\author{
Klinik für Allgemein- und Viszeralchirurgie \\ Direktor: Univ.-Prof. Dr. med. Michael Ghadimi \\ 37099 Göttingen Briefpost \\ Robert-Koch-Straße 40, 37075 Göttingen Adresse \\ 0551396104 Sekretariat \\ 0551 39-6106 Fax \\ mghadim@chirurgie-goettingen.de E-Mail \\ Ihre Ansprechpartner für die vorliegende Studie:
}

Herr Prof. Dr. med. O. Kollmar Anschrift wie oben, Tel.: 0551/39-6736 Herr Dr. med. J. Gaedcke Anschrift wie oben, Tel.: 0551/39-6944

Göttingen, den 22. April 2013

\section{Information für Patienten ZUR Wissenschaftlichen Studie} MIT DEM TITEL:

PERSONALISIERTE IMMUNSUPPRESSION NACH ORGANTRANSPLANTATION: eine Beobachtungsstudie ZUM NutZen UND ZU Therapeutischen Bereichen INNOVATIVER BIOMARKER

Sehr geehrte Patientin, sehr geehrter Patient,

wenn Sie dieses Schreiben lesen, wurden Sie bereits zuvor angesprochen, an einer wissenschaftlichen Untersuchung zur Immunsuppression (Unterdrückung der Organabstoßung) nach Organtransplantation und zur Früherkennung von Abstoßungsreaktionen mittels der Bestimmung von zirkulierenden Nukleinsäuren teilzunehmen. Wir möchten Sie einladen, an unserer Studie teilzunehmen. Der nachfolgende Text soll ihnen alle wichtigen Informationen zu dieser Studie schriftlich erläutern.

Ihre Teilnahme an dieser Studie ist freiwillig. Dies bedeutet, dass Sie nur dann in diese Studie aufgenommen werden, wenn Sie Ihre schriftliche Einwilligung erklären. Wie immer bei medizinischer Forschung können Sie die Teilnahme an dieser Studie jederzeit widerrufen.

\section{Warum wird die Studie durchgeführt?}

Nach einer Organtransplantation kommt es aufgrund der Immunreaktion des Körpers gegen das neue Organ zu einer Abstoßungsreaktion. Aus diesem Grund müssen Patienten in der Regel mehrere Medikamente einnehmen, sogenannte Immunsuppressiva, welche die Abstoßung des neuen Organs verhindern sollen. Gegen diese Abstoßung möchte man den Patienten so wenig Immunsuppressiva wie möglich verordnen, da diese Medikamente Nebenwirkungen haben können. Die erforderliche Menge (Dosierung) der Medikamente ist bei den Patienten sehr unterschiedlich. Ziel ist es nach Transplantation für 


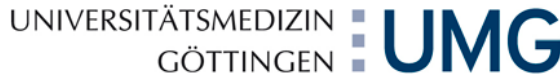

jeden Patienten eine optimierte Behandlung mit immunsuppressiven Medikamenten anzubieten, wie der Titel unserer Studie sagt, eine personalisierte Immunsuppression.

Bei dieser personalisierten Immunsuppression werden bereits seit langem regelmäßig Laborwerte verwendet, um die richtige Dosis zu finden. Hierfür wird die Konzentration der Medikamente im Blut gemessen, um zu sehen, ob die Medikamente gut in den Körper aufgenommen werden und so ausreichend wirken können. In den letzten Jahren haben wir aber viele Hinweise dafür bekommen, dass es eine ganze Reihe weiterer Labortests gibt, die möglicherweise in Zukunft noch besser helfen können, eine individualisierte Immunsuppression durchzuführen. Wir wissen aber noch nicht, wie zuverlässig diese Laborwerte tatsächlich sind und möchten deshalb diese Laborwerte anhand Ihrer Blutproben messen und mit den Informationen zu Ihrer Gesundheit vergleichen.

Genauer gesagt soll die Studie zur Klärung beitragen, ob Messungen der immunsuppressiven Medikamente in Ihren weißen Blutzellen helfen können, die minimal notwendige Dosis immunsuppressiver Medikamente für jeden einzelnen Patienten zu finden. Außerdem sollen weitere Laborwerte zur Aktivität Ihres Immunsystems gemessen werden und molekulargenetische Tests, die wahrscheinlich in Zukunft helfen können, Organabstoßung, Infektionsrisiko sowie Medikamentenwirkungen vorauszusagen, so dass man diese Tests dann zur weiteren Verbesserung der Behandlung verwenden kann. Hierzu zählt insbesondere die Bestimmung von zirkulierenden Nukleinsäuren, die mit der Anzahl der geschädigten Zellen des transplantierten Organs korreliert.

Diese Blutabnahmen und -untersuchungen sollen im Rahmen Ihrer ohnehin nötigen Kontrolluntersuchungen erfolgen. Keine zusätzlichen Untersuchungszeitpunkte sind vorgesehen.

\section{Was geschieht bei der Studie?}

Bei dieser Studie handelt es sich um eine sogenannte Beobachtungsstudie. Dies bedeutet, dass Ihre Behandlung während der Studie genauso sein wird wie es ohnehin der Fall wäre und nach gegenwärtigem Stand der Medizin der Fall sein muss. Sie erhalten also genau die Therapie, wie sie von Ihrem behandelnden Arzt nach gründlicher Überlegung und bestem medizinischen Wissen gewählt wird.

Im Rahmen der Studie möchten wir aber eine Reihe von Daten aus Ihrer Krankenakte aufnehmen sowie Ihr Blut auf die neuen Laborwerte hin untersuchen. Für die Blutuntersuchungen werden wir im Rahmen der ohnehin stattfindenden Blutuntersuchungen zusätzlich die Menge von $25 \mathrm{ml}$ Blut entnehmen. Diese Blutentnahmen werden während der gesamten Studie sieben Mal sowie bei Komplikation stattfinden. In den ersten 14 Tagen Ihres Krankenhausaufenthaltes nach Transplantation (oder weniger, falls Sie früher entlassen werden können) möchten wir zusätzlich zu den genannten $25 \mathrm{ml}$ täglich $5 \mathrm{ml}$ Blut abnehmen. Sollten Sie länger als 14 Tage im Krankenhaus verweilen würden wir ab dem Tag 15 bis zur Entlassung alle drei Tage $5 \mathrm{ml}$ Blut abnehmen. Auch bei Komplikationen in der Zeit nach der Transplantation würden wir 10 $\mathrm{ml}$ extra Blut abnehmen. Die Gesamtmenge pro Abnahme beträgt etwa 0,5\% der Blutmenge des Körpers, so dass diese zusätzliche Entnahme keine medizinischen Folgen und auch keine Folgen für Ihr Wohlbefinden hat.

Sofern es im folgenden Jahr nach der Organtransplantation nicht zu Erkrankungen (Infektionen, Abstoßungsreaktionen oder anderes) kommt, müssen Sie zu regelmäßigen Terminen in die Nachsorge kommen. Genau an diesen Terminen, die alle im Rahmen der normalen Nachsorge nach einer 


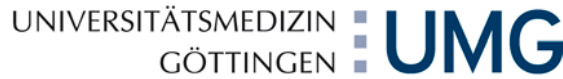

Organtransplantation stattfinden, also unabhängig von Ihrer Studienteilnahme, erfolgen dann die zusätzliche Dokumentationen Ihrer Gesundheit und die Blutuntersuchungen.

Welche Daten werden von Ihnen gespeichert? Hierbei handelt es sich um:

- alle von Ihnen eingenommen Medikamente nach der Transplantation

- alle Hinweise bezüglich einer Infektion oder Abstoßungsreaktion

- Laborwerte, die für die individuelle Behandlung mit immunsuppressiven Medikamenten wichtig sein können (Herzwerte, Leberwerte, Nierenwerte, Blutbild, Cholesterin, Zucker)

- übliche medizinische Messgrößen Ihres Gesundheitszustand (z.B. Blutdruck, Körpertemperatur)

In Ihrem Blut wird im Rahmen der Studie zusätzlich untersucht:

- die Konzentrationen der Medikamente innerhalb der Immunzellen

- Laborwerte, welche die Aktivität Ihrer Immunzellen wiedergeben und die Hinweise zu beginnenden Abstoßungen oder Infektionen geben können

- So genannte zirkulierende DNA (zirkulierende Nukleinsäuren), das ist Erbsubstanz, die ins Blut abgegeben wird, wenn irgendwo im Körper Zellen absterben (z.B. bei einer Organabstoßung). Hierfür sind auch die oben genannten zusätzlichen $10 \mathrm{ml}$ Blut bestimmt.

- Varianten der Gene, die für das Risiko der Organabstoßung, der Infektionserkrankung und der Wirkung und Verträglichkeit immunsuppressiver Medikamente von Bedeutung sein können

Die Blutprobe und die studienrelevanten Daten werden an der Universitätsmedizin Göttingen gespeichert. Dort werden auch die meisten der Laboranalysen durchgeführt und Ihre kodierten (pseudoanonymisierten) Daten gespeichert und gemeinsam mit den Ärzten und Wissenschaftlern aus unserer Klinik ausgewertet.

\section{Welchen persönlichen Nutzen habe ich von der Teilnahme an der Studie?}

Im Rahmen dieser Studie sollen Daten erfasst, welche möglicherweise in Zukunft helfen können, die immunsuppressive Therapie nach einer Transplantation zu verbessern. Kurzfristig können wir Ihnen aus der vorliegenden Studie keinen konkreten persönlichen Nutzen versprechen. Da wir gegenwärtig ja noch nicht wissen, ob die neuen Laborwerte wirklich helfen, die Einstellung der Therapie zu verbessern, werden wir die Ergebnisse auch noch nicht in Ihrer Behandlung einfließen lassen können. Erst nach Abschluss der Untersuchung in etwa 2 Jahren werden wir über die Ergebnisse Bescheid wissen. Über die Ergebnisse der Studie, werden wir Sie dann gerne informieren.

\section{Welche Belastungen und Risiken sind mit der Teilnahme an der Untersuchung verbunden?}

Die Risiken durch die zusätzlich entnommenen Blutmengen sind sehr gering. Es ist aber denkbar, dass Ihnen durch Zuschauen bei der Blutabnahme einmal übel werden könnte und dass es dadurch, dass die Blutabnahme etwa 1 Minuten länger dauert, Blutergüsse (blaue Flecken) an der Entnahmestelle auftreten. Grundsätzlich können bei allen Blutabnahmen in sehr seltenen Fällen einmal ernstere Infektionen oder auch bleibende Schäden von Nerven auftreten, die an der Entnahmestelle verlaufen. Das Risiko derartiger 


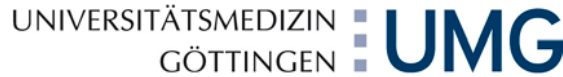

ernsterer Schäden ist aber sehr gering, etwa in der Häufigkeit von einer unter einer Million Blutnahmen und an unserer Klinik sind derartige Schäden noch nie aufgetreten.

\section{Was geschieht mit Ihren Daten?}

Sofern Sie bereit sind, an dieser Beobachtungsstudie teilzunehmen, werden Ihre Daten in der Universitätsmedizin Göttingen gespeichert und von uns ausgewertet, mit dem Ziel eine in Zukunft bessere und individuell angepasste Therapie nach Transplantationen anzubieten.

Für die wissenschaftliche Auswertung werden nur Daten verwendet, aus denen Niemand Rückschlüsse auf Ihre Person ziehen kann. Man spricht hierbei von einer Pseudoanonymisierung, das heißt, Ihre Daten werden für die wissenschaftliche Auswertung unter einer Codenummer auf Papier und in einer elektronischen Datenbank gespeichert, ohne Hinweis auf Ihren Namen, Ihren Wohnort oder andere persönliche Daten.

Ein wichtiges Prinzip heutiger medizinischer Forschung ist die sorgfältige Kontrolle aller Daten. Dafür bitten wir um Ihr Einverständnis, dass eine Person, die nicht unserer Chirurgischen Klinik angehört, ein so genannter Monitor, die Studiendaten mit Ihren Krankenakten vergleicht und alles auf Richtigkeit überprüft. Dieser Monitor unterliegt selbstverständlich der Schweigepflicht.

Alle Ihre persönlichen Daten werden spätestens 15 Jahre nach Ende der Untersuchung gelöscht. Sie können jederzeit Informationen dazu erhalten, welche Daten von Ihnen gespeichert wurden und Sie können jederzeit die Löschung Ihrer persönlichen Daten verlangen. Wenden Sie sich in diesem Falle an das Sekretariat unserer Klinik oder die weiter unten genannte Person.

\section{Was geschieht mit Ihren Blutproben?}

Die Blutproben werden an die Abteilung für Klinische Chemie der Universitätsmedizin Göttingen geschickt. Dort werden die Blutproben codiert, also ohne Hinweise auf Ihre Person, und vor unberechtigtem Zugriff verschlossen gelagert. Es werden aus den Blutproben ausschließlich solche Laboruntersuchungen durchgeführt, die dazu beitragen, die Behandlung von Patienten nach Organtransplantation zu verbessern. Soweit es sich um sehr spezielle Laboruntersuchungen hat, bitten wir Sie um Ihre Zustimmung, dass wir die Blutproben auch an externe Labors weiterleiten dürfen, wenn wir die Analysen nicht hier durchführen können und diese sehr interessante Ergebnisse versprechen. Gegenwärtig sollen die Untersuchungen in den Labors der UMG gemacht werden. Spezielle Untersuchungen zur zirkulierenden DNA werden zudem in den Göttinger Labors der Firma Chronix Biomedical (verantwortlich dort: Herr PD Dr. E. Schütz) durchgeführt. Die Messungen spezifischer Immunproteine (Zytokine) soll in der Abteilung Transplantationsimmunologie der Medizinischen Hochschule Hannover (verantwortlich dort: Frau Prof. Dr. Falk) erfolgen. Die Weitergabe würde wiederum ausschließlich in codierter Weise erfolgen und die Auswertung bleibt in der Verantwortung der Personen, die Ihnen bekannt sind bzw. die Ihnen hier in diesem Dokument genannt werden. $\mathrm{Zu}$ den Laboruntersuchungen gehören auch so genannte pharmakogenomische Untersuchungen. Das bedeutet, dass mit modernen Methoden der Genanalyse untersucht wird, ob es Genvarianten gibt, die in Zukunft helfen können, die Auswahl und Dosierung von 


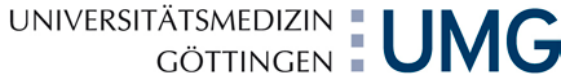

Medikamenten zu verbessern. Auch zu diesen Analysen können Sie Ihre persönlichen Daten einsehen, wenn Sie dies möchten. Allerdings ist vor der Einsicht in Ihre pharmakogenomischen Daten eine Beratung erforderlich, bitte wenden Sie sich in diesem Falle ebenfalls an unser Sekretariat oder die unten genannten Ärzte. Genau wie die medizinischen Daten werden die Blutproben ausschließlich unter Codenummern (pseudonymisiert) gelagert und sofern sie nicht für die zunächst vorgesehenen Untersuchungen komplett verbraucht werden, weiterhin für einen Zeitraum von höchstens 15 Jahren gelagert und ausschließlich für Untersuchungen in der gleichen Zielrichtung wie oben dargestellt (Verbesserung der Behandlung von Patienten nach Organtransplantationen) wissenschaftlich verwendet.

\section{Widerruf der Teilnahme}

Sie können Ihre weitere Teilnahme an unserer Studie jederzeit beenden. Wenn Sie nicht weiter teilnehmen möchten, können Sie entscheiden, ob die bis dahin gespeicherten Daten und Blutproben weiterhin für das Forschungsprojekt verwendet werden dürfen oder nicht. Sie können also jederzeit die Vernichtung der

Daten und Blutproben verlangen. Wenden Sie sich in diesem Falle an das Sekretariat unserer Klinik oder gern auch an den für die Datenspeicherung an der Universität Göttingen verantwortlichen Arzt, Herrn Prof. Dr. med. Brockmöller, Abteilung Klinische Pharmakologie, Telefon 0551 395311, der dann gegebenenfalls zusammen mit den Ärzten unserer Klinik die von Ihnen gewünschten Maßnahmen treffen wird.

\section{An wen wende ich mich bei weiteren Fragen?}

Sofern Sie nach Lesen dieser Information weitere Fragen haben, wenden Sie sich bitte zunächst an die Ärzte, die an unserer Klinik für Ihre Behandlung zuständig sind. Darüber hinaus können Sie sich telefonisch, per Post, oder per e-mail an Herrn Prof. Brockmöller wenden, der für organisatorische Aspekte der Studie verantwortlich ist:

Prof. Dr. med. Jürgen Brockmöller, Universitätsmedizin Göttingen

Robert-Koch-Straße 40, 37075 Göttingen

Tel: 0551395311 (Sekretariat, außerhalb Dienstzeiten Anrufbeantworter); Fax: 05513912767

E-Mail: jbrockm@gwdg.de.

Eine Kopie dieses Informationsschreibens verbleibt bei Ihnen.

Wir danken Ihnen für Ihr Interesse.

Ihr Studienteam 


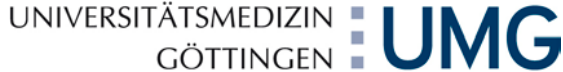

\section{Einwilligungserklärung zur Studie}

\section{„PERSONALISIERTE IMMUNSUPPRESSION NACH ORGANTRANSPLANTATION: EINE BEOBACHTUNGSSTUdie ZUM NUTZEN UND ZU THERAPEUTISCHEN BEREICHEN INNOVATIVER BIOMARKER"}

Ich bin in einem persönlichen Gespräch durch die unten genannte Ärztin oder den unten genannten Arzt ausführlich und verständlich über die Beobachtungsstudie und deren Wesen, Bedeutung, Risiken und Tragweite informiert worden. Ich habe darüber hinaus den Text der Patienteninformation einschließlich der optisch hervorgehobenen Hinweise zur Datenspeicherung gelesen und bin damit einverstanden. Ich hatte die Gelegenheit, mit dem Arzt oder der Ärztin über Beobachtungsstudien zu sprechen. Alle meine Fragen wurden zufrieden stellend beantwortet. Ich hatte ausreichend Zeit, mich zu entscheiden. Mir ist bekannt, dass ich jederzeit und ohne Angabe von Gründen meine Einwilligung zur Teilnahme an der Prüfung zurückziehen kann.

Ich erkläre mich bereit, an der oben genannten Beobachtungsstudie freiwillig teilzunehmen.

Ich erkläre mich auch damit einverstanden, dass die von mir abgenommenen Blutproben Eigentum der Universitätsmedizin Göttingen werden und von den Studienärzten für die Ziele der vorliegenden wissenschaftlichen Studie verwendet werden dürfen.

Ein Exemplar des Informations- und Einwilligungsschreibens habe ich erhalten. Ein Exemplar verbleibt bei der Studienleitung.

Datum Unterschrift des Patienten

Name des Patienten in Druckbuchstaben

Ich habe das Aufklärungsgespräch geführt und die Einwilligung des Patienten eingeholt.

Name des Arztes/der Ärztin in Druckbuchstaben

Datum

Unterschrift des Arztes/der Ärztin 


\subsection{Protokoll der Standard-Immunsuppression nach}

\section{Lebertransplantation}

\begin{tabular}{|c|c|c|c|c|}
\hline & $\begin{array}{l}\text { Tacrolimus } \\
\text { (Prograf }^{\circledR} \text { ) }\end{array}$ & $\begin{array}{c}\text { MMF } \\
\left(\text { Cellcept }^{\circledR}\right)\end{array}$ & $\begin{array}{l}\text { Basiliximab } \\
\left(\text { Simulect }^{\circledR}\right)\end{array}$ & $\begin{array}{c}\text { Methyl- } \\
\text { prednisolon }\end{array}$ \\
\hline AN-Einleitung & $\varnothing$ & $\varnothing$ & $\varnothing$ & $\varnothing$ \\
\hline intraop. & $\varnothing$ & $\varnothing$ & $20 \mathrm{mg}$ i.v. & $\begin{array}{l}10 \mathrm{mg} / \mathrm{kg} \rightarrow \\
500 \mathrm{mg} \text { i.v. }\end{array}$ \\
\hline postop. & $\varnothing$ & $1 * 1 \mathrm{~g}$ über $2 \mathrm{~h}$ i.v. & $\varnothing$ & $\phi$ \\
\hline 1. POD & $\phi$ & $\begin{array}{l}2^{* 1} \mathbf{g} \text { über } 2 \mathrm{~h} \\
\text { i.v. oder p.o. }\end{array}$ & $\varnothing$ & $\begin{array}{l}\text { 100-0-100 mg } \\
\text { i.v. }\end{array}$ \\
\hline 2. POD & 2*0,5-2 mg p.o. & $\begin{array}{l}\text { 2*1 g über } 2 \mathrm{~h} \\
\text { i.v. oder p.o. }\end{array}$ & $\varnothing$ & $80-0-80 \mathrm{mg}$ i.v. \\
\hline 3. POD & 2*0,5-2 mg p.o. & 1-0-1 g p.o. & $\varnothing$ & $\begin{array}{l}40-0-40 \mathrm{mg} \\
\text { p.o. }\end{array}$ \\
\hline 4. POD & $\begin{array}{l}2^{*} 0,5-2 \mathrm{mg} \text { p.o. } \\
\text { Spiegel: } 8-12 \mathrm{ng} / \mathrm{ml}\end{array}$ & 1-0-1 g p.o. & $20 \mathrm{mg}$ i.v. & $\begin{array}{l}20-0-20 \mathrm{mg} \\
\text { p.o. }\end{array}$ \\
\hline 5. POD ff. & $\begin{array}{c}2^{*} 0,5-2 \mathrm{mg} \text { p.o. } \\
\text { Spiegel: } 8-12 \mathrm{ng} / \mathrm{ml}\end{array}$ & 1-0-1 g p.o. & $\varnothing$ & $\begin{array}{c}16-0-16 \mathrm{mg} \\
\text { p.o. }\end{array}$ \\
\hline $\begin{array}{c}\text { drug } \\
\text { monitoring }\end{array}$ & $\begin{array}{c}\text { FK-Spiegel vor } \\
\text { Tabletteneinnahme }\end{array}$ & $\varnothing$ & $\phi$ & $\phi$ \\
\hline Talspiegel & $\begin{array}{l}<6 \text { Wo: } 8-12 \mathrm{ng} / \mathrm{ml} \\
6-12 \text { Wo: 4-8ng/ml }\end{array}$ & $\varnothing$ & $\phi$ & $\phi$ \\
\hline i.v. $\rightarrow$ oral & $\begin{array}{c}1: 1 \\
\text { ohne Überlappen! 1h } \\
\text { vor Mahlzeit }\end{array}$ & $1: 1$ & $\varnothing$ & $1: 1$ \\
\hline $\begin{array}{l}\text { NW / Bemer- } \\
\text { kung }\end{array}$ & $\begin{array}{c}\text { Dosisreduktion bei } \\
\text { gleichzeitiger Gabe } \\
\text { von } \\
\text { Fluconazol/Voriconaz } \\
\text { ol }\end{array}$ & $\begin{array}{c}\text { Dosisreduktion } \\
\text { 2x500mg bei } \\
\text { Leukopenie <3; } \\
\text { Pause bei Leukopenie } \\
<1\end{array}$ & $\begin{array}{c}\text { nicht bei } \\
\text { Pneumonie / } \\
\text { SBP }\end{array}$ & Psychose \\
\hline
\end{tabular}

Tacrolimus (Prograf $\left.{ }^{\circledR}\right)$ : reduzierter Ziel-Spiegel $(\sim 5 \mathrm{ng} / \mathrm{ml})$ erwägen bei: schlechter Leberfunktion, hohem Infektionsrisiko/Sepsis/Massivtransfusion, schwerer Kachexie

\section{Methylprednisolon-Reduktionsschema:}

\begin{tabular}{|c|c|}
\hline Tag nach Leber-TX & Methylprednisolon \\
\hline $\mathbf{6}$ & $16-0-16 \mathrm{mg} \mathrm{p.o.}$ \\
\hline $\mathbf{7 + 8}$ & $16-0-0 \mathrm{mg} \mathrm{p.o.}$ \\
\hline $\mathbf{9 + 1 0}$ & $8-0-0 \mathrm{mg} \mathrm{p.o.}$ \\
\hline $\mathbf{1 1 + 1 2}$ & $4-0-0 \mathrm{mg} \mathrm{p.o.}$ \\
\hline $\mathbf{1 3}$ & absetzen \\
\hline
\end{tabular}

Kepinol $^{\circledR}$ forte alle 2 Tage, bis Methylprednisolon ausgeschlichen ist.

(SOP der Klinik für Allgemein-, Viszeral- und Kinderchirurgie, Universitätsmedizin Göttingen) 


\subsection{Liste der bei der Bestimmung der zellfreien Spender-DNA betrachteten 41 Assays}

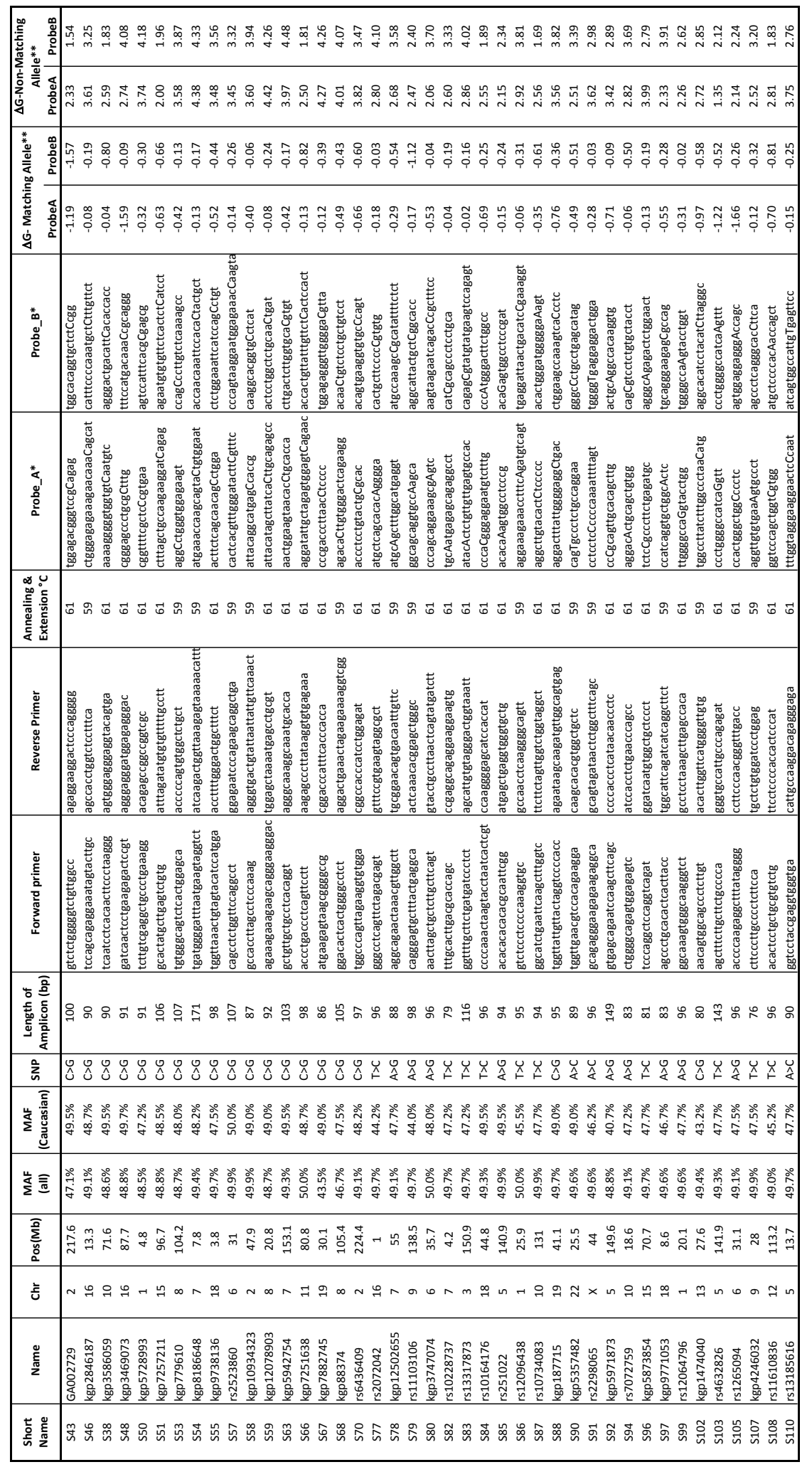

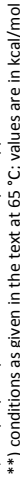

(Tabelle aus Beck et al. 2013b) 


\section{Danksagung}

Ich bedanke mich bei Herrn Professor Dr. Dr. Oellerich für die freundliche Überlassung des überaus interessanten Themas. Er hat mich für die Gebiete der Transplantations- und Labormedizin begeistert und mir, außerhalb meiner eigentlichen Fachrichtung, neue Horizonte eröffnet. Er stand mir für Fragen jederzeit zur Verfügung und begleitete mich durch den Dissertationsprozess. In seinem Sekretariat standen mir Frau Zimara und Frau Kroll stets hilfreich zur Seite. Hier gilt mein besonderer Dank Frau Schmitz, die mir bei Fragen allzeit zur Verfügung stand und bei der Erhebung der klinischen Daten und Proben während meiner Abwesenheiten mehrfach spontan für mich eingesprungen ist.

Bei den Mitarbeitern des Zentrallabors der Klinische Chemie möchte ich mich für die Unterstützung im Rahmen der Logistik der Studienblutabnahmen und der Messung der Routineparameter bedanken. Insbesondere dem Team des Studienlabors um Frau Engelmayer gilt mein besonderer Dank. Sie haben alle Studienblutproben koordiniert und bearbeitet.

Ich danke außerdem Herrn Professor Dr. Schütz, Frau Dr. Beck und Chronix Biomedical, Göttingen, für die Durchführung der GcfDNA-Analysen, die interessanten Einblicke in die Laborarbeit, die ständigen Anregungen ihm Rahmen dieser Studie und Hilfestellungen bei den bereits erfolgten Publikationen. Herr Professor Dr. Schütz hatte stets anregende Ideen bei der statistischen Auswertung.

Ich bedanke mich bei Herrn Professor Dr. Kollmar für die spannenden Einblicke in die Lebertransplantation sowie - zusammen mit Herrn Dr. Slotta und den weiteren Abteilungsärzten - für die Koordination der Studienblutabnahmen. Auch den Pflegekräften und Mitarbeitern auf den Stationen 1016 und 1012 möchte ich für ihre Hilfe bei allen klinischen Fragestellungen danken.

Ebenfalls bedanken möchte ich mich bei Herrn PD Dr. Mörer, der Study Nurse Frau Kernchen und dem Team der chirurgischen Intensivstation 0118 für die gute Kooperation. 


\section{Lebenslauf}

Am 21. Februar 1991 wurde ich, Philipp Kanzow, als einziges Kind der PTA Angela Kanzow, geb. Müller-Reichenbach, und des Zahnarztes und Arztes Joachim Kanzow in Göttingen geboren. Von 1997 bis 2001 verbrachte ich meine Grundschulzeit an der Janusz-Korczak-Schule in Göttingen-Nikolausberg. Anschließend wechselte ich an die Bonifatiusschule Göttingen und besuchte danach das Max-Planck-Gymnasium Göttingen, an dem ich im Jahr 2009 mein Abitur ablegte und die Allgemeine Hochschulreife einschließlich Großem Latinum und Graecum erlangte. Im Jahr 2006/2007 verbrachte ich ein Auslandsjahr an der Trinity Pawling School, NY, USA.

Im Wintersemester 2009/2010 begann ich mein Studium der Zahnmedizin an der GeorgAugust-Universität Göttingen. Im September 2010 legte ich meine naturwissenschaftliche Vorprüfung und im März 2012 meine Zahnärztliche Vorprüfung ab. Durch das Ministerium für Wissenschaft und Kultur wurde ich 2013 im Rahmen eines „Landesstipendium Niedersachsen 2013“ gefördert. Voraussichtlich im Herbst 2014 werde ich mein Studium mit der Zahnärztlichen Prüfung beenden.

Mein Interesse für die Naturwissenschaften entdeckte ich bereits zur Schulzeit und nahm u.a. 2007 am XLAB International Science Camp und 2009 mit dem Thema „Einfluss unterschiedlicher Nutzungsintensitäten auf Kohlenstoffvorräte und -umsätze in Böden am Beispiel der kulturhistorischen Weinberglandschaft Geigersberg, Ochsenbach (BW)“, bei Jugend forscht teil.

Neben meinem Studium bin ich seit dem Wintersemester 2010/11 als Tutor im Auftrag der Fachschaft Medizin, u.a. für die Fächer Biologie, Chemie, Histologie und Physik, tätig. Als studentische Hilfskraft im Bereich IT-Administration bin ich seit dem Wintersemester 2013/14 im ,Studentischen Innovations- und Trainingszentrum“ (SINUZ) des Zentrums Zahn-, Mund- und Kieferheilkunde angestellt. Außerdem engagiere ich mich ehrenamtlich in der Fachgruppe Zahnmedizin und bin studentischer Vertreter in diversen Ausschüssen und Gremien. 
Seit Dezember 2012 bin ich als Doktorand in der Arbeitsgruppe des Niedersachsenprofessors Dr. med. Dr. h.c. Michael Oellerich im Institut für Klinische Chemie mit der Anfertigung meiner Dissertation zum Thema „Zirkulierende Nukleinsäuren im zellfreien Plasma von LTxPatienten als Frühmarker einer Schädigung des Spenderorgans" beschäftigt. 